\title{
Identification of Motivations for Unsafe Driving Actions and Potential Countermeasures
}

M. E. Marks

J. W. McNair

R. K. Jones

K. B. Joscelyn

Transportation Planning and Policy Division

Ph.D. Program in Urban and Regional Planning

The University of Michigan

Ann Arbor, Michigan 48109

Contract No. DOT-HS-9-02276

Contract Amount \$165,345 
This document is disseminated under the sponsorship of the Department of Transportation in the interest of information exchange. The United States Government assumes no liability for its contents or use thereof. 
Techaical Repert Decusentrotion Poge

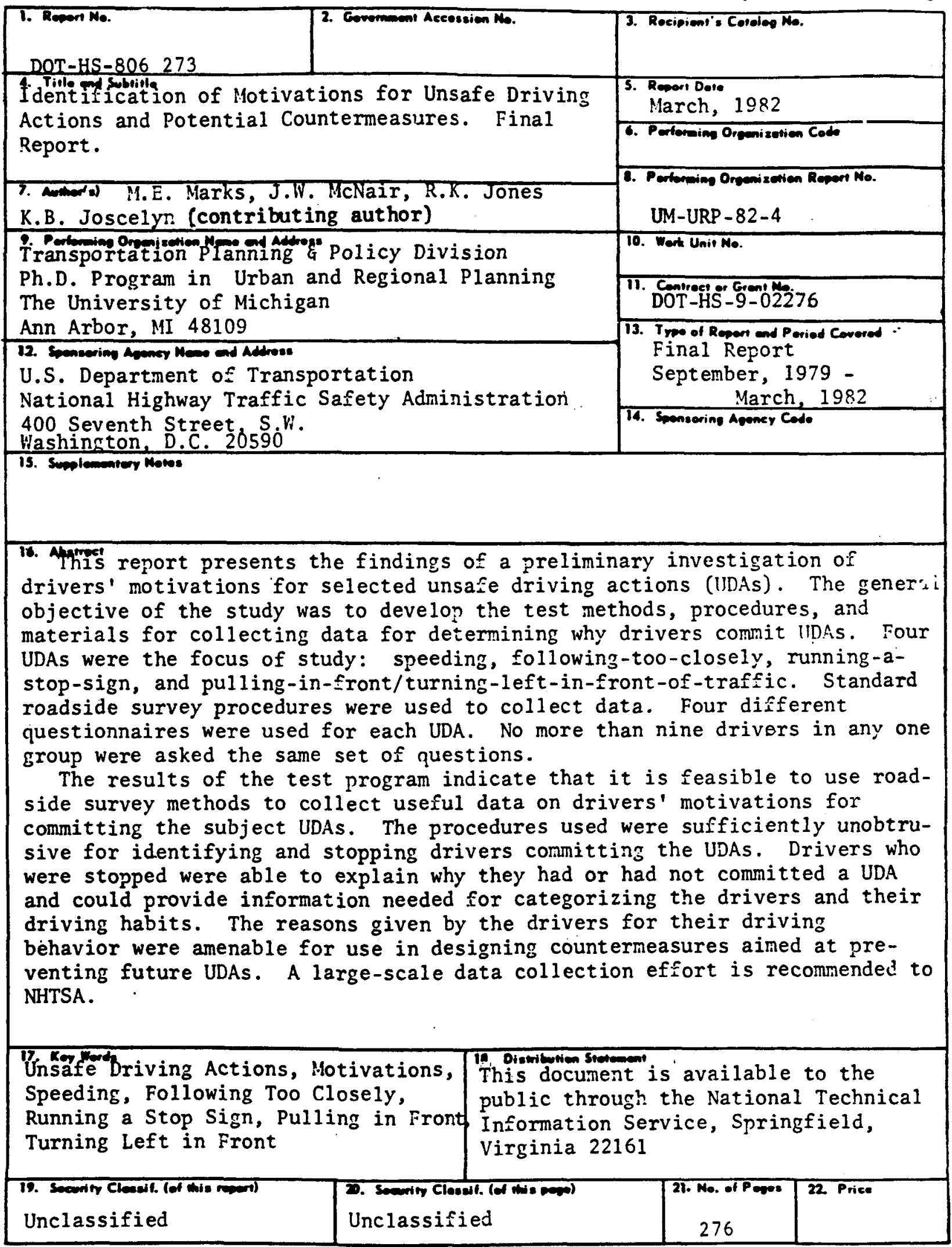




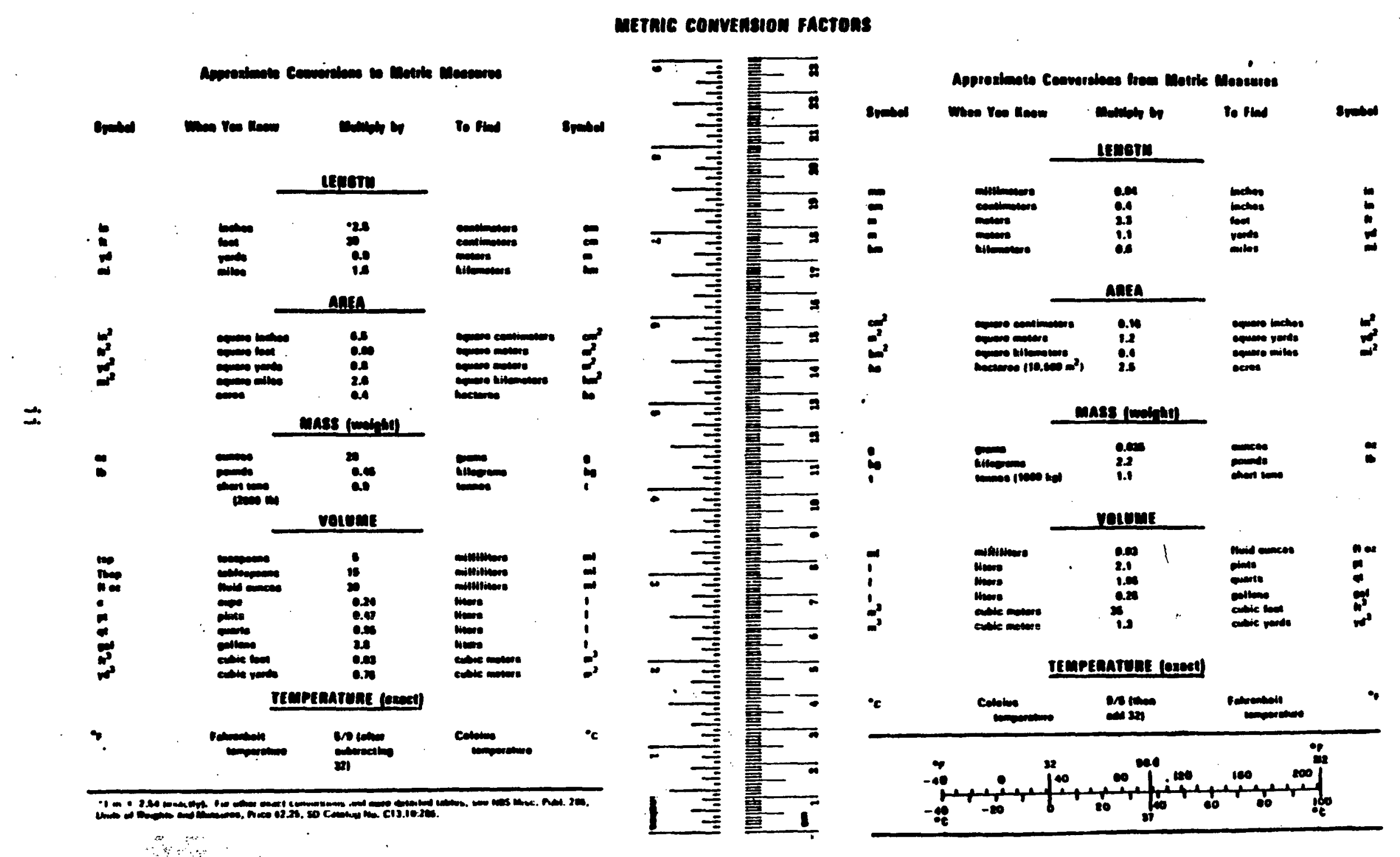




\section{ACKNOWLEDGMENT}

This report is a result of the efforts of many persons. We thank all who assisted in its development, preparation, and production.

Maria E. Vegega, Ph.D., was NHTSA's contract technical manager for the project. Her contributions, both substantive and administrative, are much appreciated.

Special recognition is due to the citizens of Washtenaw County who agreed to participate in the pilot test of the questionnaires and whose responses form the basis for this report. We are also grateful to the owners of the survey sites who allowed us to use their parking lots and driveways for conducting interviews.

We thank Sheriff Thomas R. Minick and Prosecutor William F. Delhey of Washtenaw County for their support of the project. We are especially grateful to Sergeant Carl C. Rinna and the deputies of the Washtenaw County Sheriff's Department who directed traffic at the survey sites. Without the support and cooperation of these people, the project would not have been possible.

We also wish to recognize the contributions of the pilot-test interviewers. Ronald Widmar, Bora Simmons, Catherine Steele, and Nat Bargmann administered the the pilot-test questionnaire. Mr. Widmar and Ms. Simmons also assisted in coding and analyzing the data contained in the driver questionnaires.

Other project personnel and consultants made important contributions. Paul A. Ruschmann participated in the early planning of the survey procedures. Professor Donald C. Pelz of The University of Michigan Institute for Social Research provided assistance in framing the questions in the protocol. The report was edited by Elizabeth Brater. Jane $W$. Kovacs served as production editor. Anne E. VanDerworp and Karen S. Richardson produced the report. We thank all who contributed. 
This report presents the findings of a preliminary investigation of drivers' motivations for selected unsafe driving actions (UDAs). The general objective of the study was to develop and test methods, procedures, and materials for collecting data for determining reasons why drivers commit UDAs. Four UDAs were the focus of study:

- speeding

- following too closely (FTC)

- running a stop sign (RSS)

- pulling in front/turning left in front of traffic (PIF/TLIF)

Standard roadside survey procedures were used to collect data. Four different questionnaires were administered to drivers for each of the four UDAs (i.e., 16 questionnaires). No more than nine drivers in anv one group were asked the same set of questions. The results of the test program indicate that it is feasible to use roadside survev methods to collect useful data on drivers' motivations for committing the subject UDAs. It was found that the procedures used were sufficiently unobtrusive to permit the identification and stopping of drivers committing the UDAs. Drivers who were stopped were able to explain with sufficient specificity why they had or had not committed a UDA and could provide demographic and other information needed for categorizing the drivers and their driving habits. Further, the reasons given by the drivers for their driving behavior were amenable for use in designing countermeasures aimed at preventing future UDAs.

Driver participation in the test survey was high. Seventv-three Dercent of all drivers stopped agreed to be interviewed. Indications were that most of the twenty-seven percent who refuser to particidate in the roadside interview did so because they did not have time and would have participated in a later telephone or personal interview. Thus, overall participation rates in the ninety to ninety-five percent range appear likelv. None of the drivers stopped was obviously impaired by alcohol or drugs.

Only three items of demographic and general driver information presented any significant difficulties for the subjects. Some Arivers did 
not provide information about their income, and some had difficulty in estimating the number of miles they drive each year. A fairlv high percentage (25\%) of the drivers stopped for the running-a-stop-sign UDA did not indicate their educational background.

In general, the subjects had little or no difficulty with the other test items in the survey. There were two exceotions to this finding. First, many drivers had trouble with the wording and scales used in the statements designed to measure their attitudes toward driving. Nevertheless, nearly all of these drivers were able to respond to these statements. Second, the methods used to elicit driver estimates of their following distance (following-too-close UDA) and turning distance (pullingin-front and turning-left-in-front UDAs) were confusing to many of the drivers. The interviewers were able to interact with these subjects to arrive eventually at estimates of these distances, but additional time was required for this.

While this study was concerned primarily with methodologv, the data collected were also of interest. In general, the respondents rated themselves as very good drivers. There was some indication of a greater tendency toward risk taking among drivers wh: had committed UDAs than among drivers who had not. A significant percentage of the Arivers sair that their driving behavior was more "unsafe" on the day of the survey than it usually was. This effect was noted for all of the UDAs studied.

The respondents indicated that driver-related factors affected whether they would commit speeding, FTC, and RSS UDAs, but would have no effect on their committing the PIF/TLIF UDA. Vehicular factors were said to affect driving speed, but were not listed among those factors that affected behaviors associated with the other UDAs studied. The respondents said roadway factors affected their tendency to commit all of the four UDAs studied.

Clearly, information of this type would be useful for countermeasure design, provided that the data had been collected from a representative sample of drivers and driving situations. Variations of different enforcement-countermeasure themes would be appropriate for the speeding and RSS UDAs. Public-information countermeasures are suggested for all 
four of the subject UDAs. Roadway-type countermeasures appear to be indicated for speeding, FTC, and PIF/TLIF UDAs.

In short, the larger-scale data collection effort recommended at the end of the speed pilot test is fully supported by the additional data collected during the pilot testing of the FTC, RSS, and PIF/TLIF UDAs. We recommend that this effort be undertaken by the National Highway Traffic Safety Administration (NHTSA). The procedures and instruments used in the pilot tests are in general satisfactory but should be refined. Such refinements should include:

- measures to improve the logistics and planning of the data collection activity, including selecting sites with minimum traffic through the interview area and with good visibilitv of the road at the "stop-car location, providing good lighting in the interview area, organizing the interview materials into convenient packets, providing emergencv equipment (e.g., jumper cables) for use in the interview area, taking extra care to ensure that all equidment is functioning before the survey, and alternating the roles of interviewer and recorder each time a driver is interviewer

- development of more objective measures for the RSS and PIF/TLIF UDAs

- use of visual aids and models to explain roadwav and traffic geometry to drivers so that their responses will be to the point and more accurate

- changing the wording and scaling of the attitudinal test items to communicate better the nature of the information sought in those items

Adoption of these measures and use of the procedures tested will provide much useful information for designing countermeasures to reduce the incidence of speeding, following-too-closely, running-a-stoo-sign, and pulling-in-front/turning-left-in-front unsafe driving, actions. 


\section{CONTENTS}

1.0 INTRODUCTION 1

1.1 Objectives 1

1.2 Background 2

1.3 Scope and Approach 9

1.4 Organization of Report 11

2.0 GENERAL METHOD 13

2.1 Design $\quad$. 13

2.1.1 Site Selection 13

2.1.2 Selection of Drivers for Survey 15

$\begin{array}{ll}2.1 .3 \text { Equipment } & 16\end{array}$

2.1.4 Interview Methods 17

$\begin{array}{ll}2.1 .5 & \text { Survey Personnel }\end{array}$

2.1.6 Publicity 21

2.1.7 Confidentiality of Responses 22

2.2 Procedures $\quad \cdot \quad 22$

2.2.1 Traffic Observation $\quad 22$

2.2.2 Roadside Survey Procedure 23

2.3 Pilot-Test Analyses $\quad 24$

3.0 SPEEDING 27

3.1 Design 27

3.1.1 Site Selection 27

3.1.2 Schedule of Survey Times 28

3.1.3 Selection of Drivers for Survey 29

$\begin{array}{ll}3.1 .4 \text { Equipment } & 29\end{array}$

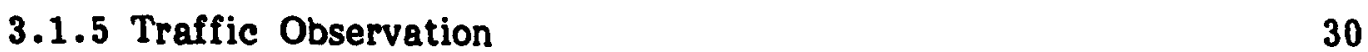

3.2 Results $\quad 30$

3.2.1 Traffic Flow 30

3.2.2 Speeds $\quad 35$

3.2.3 Driver Participation 48

3.2.4 Drivers' Responses to the Interview Questions 50 
3.2.4.1 Interview Length

3.2.4.2 Demographic Information 51

3.2.4.3 General Driver Information 53

3.2.4.4 Drivers' Responses to Speed UDA 56

3.2.4.4.1 Responses Associated with the Driver 57

3.2.4.4.2 Responses Associated with the Vehicle 60

3.2.4.4.3 Responses Associated with the Roadway 61

3.2.5 Utility of Driver Responses for Countermeasure

Development $\quad 62$

3.3 General Survey Procedures $\quad 64$

4.0 FOLLOWING TOO CLOSE (FTC) 67

4.1 Design $\quad 68$

4.1.1 Site Selection $\quad 68$

4.1.2 Schedule of Survey Times $\quad 68$

4.1.3 Selection of Drivers for the Survey 69

4.1.4 Traffic Observations $\quad 69$

4.2 Results $\quad 69$

4.2.1 Driver Participation $\quad 69$

4.2.2 Drivers' Responses to Interview Questions 70

4.2.2.1 Interview Length 72

4.2.2.2 Demographic Information $\cdots$

4.2.2.3 General Driver Information $\quad 74$

4.2.2.4 Drivers' Responses Specific to the FTC UDA 75

4.2.3 Utility of Driver Responses for Countermeasure

$\begin{array}{ll}\text { Development } & 79\end{array}$

4.3 General Survey Procedures $\quad 80$

5.0 RUNNING A STOP SIGN (RSS) 81

5.1 Dẹsign $\quad 81$

$\begin{array}{ll}5.1 .1 \text { Site Selection } & 81\end{array}$

5.1.2 Schedule of Survey Times $\quad 82$

5.1.3 Selection of Drivers for the Survey 83

5.1.4 Traffic Observation $\quad 83$

$\begin{array}{ll}5.2 \text { Results } & 84\end{array}$

5.2.1 Driver Participation $\quad 84$ 
5.2.2 Drivers' Responses to Interview Questions 87

5.2.2.1 Interview Length $\quad 87$

5.2.2.2 Demographic Information 87

5.2.2.3 General Driver Information $\quad 89$

5.2.2.4 Drivers' Responses Specific to the RSS UDA 90

5.2.3 Utility of Driver Responses for Countermeasure

Development $\quad 94$

5.3 General Survey Procedures $\quad 94$

6.0 UNSAFE TURN OR MERGE

6.1 Design $\quad 97$

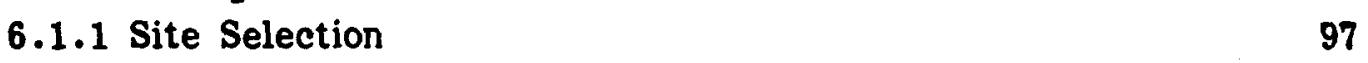

6.1.2 Schedule of Survey Times 98

6.1.3 Schedule of Drivers for Survey 99

6.1.4 Traffic Observation $\quad 99$

6.2 Results 100

$\begin{array}{ll}\text { 6.2.1 Driver Participation } & 100\end{array}$

6.2.2 Drivers' Responses to the Interview Questions 102

6.2.2.1 Interview Length 102

6.2.2.2 Demographic Information 102

6.2.2.3 General Driver Information 104

6.2.2.4 Drivers' Responses to the PIF/TLIF UDA 107

6.3 Utility of Driver Responses for Countermeasure Development 108

6.4 General Survey Procedures 109

7.0 CONCLUSIONS AND RECOMMENDATIONS 111

BIBLIOGRAPHY $\quad 115$

$\begin{array}{ll}\text { THE PRINCIPAL RESEARCHERS } & 117\end{array}$

APPENDIX A - ROADSIDE SURVEY MATERIALS

APPENDIX B - SUPPORTING STATEMENT FOR CLEARANCE REQUEST TO THE OFFICE OF MANAGEMENT

AND BUDGETS

APPENDIX C - REVIEW OF THE LITERATURE 
9 


\subsection{INTRODUCTION}

This document is the final report of a project entitled "Irentification of Motivations for Unsafe Driving Actions and Potential Countermeasures." The project was sponsored by the National Highwav Traffic Safetv Administration (NHTSA) under contract number DOT-HS-9-02.276 and was performed by The University of Michigan and its subcontractor, MidAmerica Research Institute, Inc.

\subsection{Objectives}

The general objective of the study was to develop and test methods, : procedures, and materials for collecting data for determining reasons whv drivers commit unsafe driving actions (UDAs). Specific objectives were:

- to identify possible strategies for collecting valid data on drivers' motivations for committing UDAs

- to select a preferred data-collection strategy and develop methods and materials for applying that strategy for a specific UDA

- to conduct a pilot test of these methods to assess the utility of the information collected for countermeasure development and the overall feasibility of the identified methods

- to refine and augment these data-collection methods as necessary for use in collecting data on three additional UDAs

- to conduct a pilot test of these methods for the three additional UDAs

- to analyze and assess the results of overall test and development programs, and recommend future actions for full-scale data-collection efforts to determine reasons why drivers commit UDAs.

We note that the original project plan called for full-scale data collection after the first pilot test, provided that test results indicated it would be feasible and desirable to do so.

NHTSA decided to modify the project plan after the first pilot test to 
require additional testing and decided not to require full-scale data collection (see Section 1.3).

\subsection{Background}

Unsafe driving actions have been shown to be primary causal factors in motor vehicle accidents. These actions can be defined as acts or omissions by drivers that increase the risk of a traffic crash above a societally acceptable level. These actions can arise from either conscious or unconscious behavior. Central to this notion of UDAs is that there are decisions and reasons underlying a driver's behavior. An identification of these determinants of driver behavior can provide a perspective on the occurrence and persistence of a selected behavior and, subsequently, insight into the design of driver-oriented countermeasures based upon the driver's motivations.

While examples of more broadly defined motivational research in the traffic safety literature are fairly numerous (e.g., correlating psvchometric tests of drivers with accident or violation histories), there has been verv limited investigation to date of the immediate reasons that drivers undertake unsafe actions on the highway. A brief review of such past research provides a background for an examination of the issues confronted by this study.

The concept of motivation has long been used as an explanatorv construct for behavior by psychologists (Atkinson 1964). In the area of highway safety, researchers have drawn upon the utility of this construct to distinguish the dangerous driver from the safe driver. Pelz (1968a) and Pelz and Schuman (1971) have examined the motivational factors in crashes and violations in young drivers. They emphasize male drivers under the age of twenty-five since analyses of traffic accident data indicate that the fatality rates for these young men are twice those for men in their forties. These investigators sampled cross-sections of drivers to see what motivational factors mav account for dangerous driving in these vouth. Their data indicated that the young males who were likelv to have accidents and violations were more involved with cars than those who were not and that dangerous drivers, compared with safe, were more likelv to 
spend time in cars for fun, to work on their cars, ant to race cars. Moreover, a number of emotional factors were found to affect driving in this age group; traffic crashes and violations were often preceded by arguments, fights, or broken engagements. In addition, the new responsibilities and changes in life situation (e.g., marriages, new iobs) that must be met by this age group were also found to have a detrimental effect on ariving behavior.

Distraction was found to be a major factor in traffic crashes hv Greenshields (1959). He surveyed 3,090 drivers involved in mural accirients in Michigan. Of the 990 who responded, twentv percent indicated that they had been distracted at the time of the accident. For some of the respondents (about 1 out of 15 ), the distractions involved events immediately preceding the accident, such as looking for a road, children fussing, or talking. However, for others (approximately 1 out of 1.0 ), these distractions involved stresses or changes in their personal life. Life situation distractions that were cited include worry over exams, marriage, divorce, and illness. Similarly, Selzer and Vinokur (1974) obtained a significant correlation between psychological stress and accidents in their search for higtr-risk drivers. Among the life stresses mentioned in their sample responses were physical illness, marital problems, iob-related problems, worries over school, and financial problems.

Andriessen (1971) used a theoretical model of the motivational determinants of risk-taking behavior to investigate performance on $a$ number of laboratory measures of risk-taking. The model was teveloped by Atkinson (1957) to explain how the motive to achieve and the motive to avoid failure influence behavior in anv situation where performance is evaluated against some standard of excellence. Antriessen found a positive correlation between high need for achievement and riskv behavior. However, skill and perceptual variables were found to explain a greater part of the variance than were the motivational variables.

MeGuire (1976) concludes that, in general, the accident-prone driver is less mature, less responsible, has a lower aspiration level, expresses door attitudes towards the law and driving, and is not as well adjusted as the safe driver, while Naatanen and Summala (1974) conclude that 
aggressiveness is especially influential in traffic behavior and causing accidents.

Thus, past research on driver behavior has attempted to identify and categorize some of the processes underlying unsafe driving; these studies are focused on the emotional, situational, and personality attributes of orivers in relation to their traffic accident or violation historv. However, there are few, if anv, examples of studies aimed at identifying the reasons why drivers have committed (or omitted) an action that increases the risk of a traffic crash.

The roadside survey technique is attractive for this application but carries with it some serious potential difficulties with regard to sample selection and acquisition. In particular, if the roadside measurement and survey methods are not adequatelv unobtrusive, biasing of the samole is likely to occur in at least two different ways. First, given knowledge of the presence of the measurement or the survey process, some drivers mav choose an alternate routing and thus bias the composition of the population being studied; the widespread use of $\mathrm{CB}$ radios contributes greatly to this problem. Second, drivers may adjust their behavior so as to conform to legal norms, social expectations, etc. This would obviously be an extremely important defect in a study aimed at determining the reasons why people commit, or refrain from committing, unsafe driving actions.

Certain procedures were devised to minimize the obtrusiveness of the measurement procedures, drawing on the ingenuity of the research staff, prior research, and modem technology. However, it could not be assumer that all such biasing effects could be eliminated, and in any case it was important to test the extent to which success in this regard could be achieved. It was also important to try to estimate the effect of the observer and survey team's presence on the resulting sample distributions, and the subsequent generalizability from the sample to the normal travel behaviors.

Procedures were devised to minimize these biasing effects, and tests were conducted to determine the extent to which this goal can be achieved. Various approaches had to be examined.

The difficulties of stopping traffic for interviews were recognized in: 
the project. Given the potential for motorists who have committed UDAs to be irritated, intoxicated, etc., it was deemer desirable to have enforcement personnel involved. Careful attention was given to finding ways of minimizing the potential biasing effects of police involvement. A proven method for selecting and acquiring the lesired drivers fid not exist at the beginning of this project and required the utmost care in development and testing.

Another issue facer by the project was determining the extent to which valid and accurate information as to the reasons for committing a UDA, or refraining from doing so, can be acquired. The nature of this concern is indicated by the following excerpt from an article entitled, "Motivation Research as Applied to the Problems of Road Safetv":

The basic tenet of Motivation Research ... is that human beings do not have insight into their motives ... So if we ask people why they behave as they do, they will give us an answer which appears perfectly plausible on the surface but which can often be demonstrated to be at best a half-truth, and at worst a complete rationalization. (Morton-Williams 1961)

While perhaps true on an abstract level, this statement no doubt exaggerates the inability of drivers to identifv the immediate reasons for their conscious driving actions. However, it serves to unierscore the care that had to be taken in the development of a method to determine such "reasons," particularly since drivers who are capable of identifving them may be less willing than able to do so.

Self-report measures such as those called for in the project work statement are subject to distortion by a number of influences. One such influence that has been extensively discussed in the behavioral measurement literature is social desirability. This occurs "when respondents distort their answers to conform to the prevailing norms and values in their own community or the larger society" (Warwick and Lininger 1975). Certain characteristics of self-report measures are especially susceptible to distortion in the responses. These have been noted by Cook and Selltiz (1964):

The purpose of the instrument is obvious to the respondent; the 
implications of his answers are obvious to him; he can consciously control his responses. Thus a person who wishes to give a certain picture of himself whether in order to impress the tester favorably, to preserve his own self-image or for some other reason can rather easilv do so. (1964:40)

As a consequence of social desirability, respondents may be reluctant to admit to behaviors considered immoral or illegal.

Since traffic law violation is an illegal behavior, it is reasonable to suppose that driver discussions of unsafe driving acts will be affected bv the social desirability phenomenon. Cook and Selltiz (1964) discuss a number of techniques that have been devised to make the purpose of a self-report instrument less apparent, to make it easier to give answers that may be undesirable, and to make it harder to give false answers that may be considered desirable. These approaches include:

- assurances of anonymity

- statements emphasizing the importance of honest answers in order to contribute to some desirable outcome

- the building up of rapport between the questioner and respondent

- inclusion of items irrelevant to the behavior in which the investigator is interested

- inclusion of items to which an unfavorable reply is likely to be considered acceptable

- use of forced-choice

Our development of a method for identifying driver motivations paid careful attention to the strategies for minimizing the effects of social desirability and their feasibility for implementation in the studv.

A second factor of concern in self-report measures and interviewing is the problem of memory. In some instances, it mav not be practical or safe to stop drivers after their commission of a UDA. Expressways, for example, are roads where such stopping mav not be feasible; these Arivers may have to be contacted at a later time for interviewing about their driving behavior. Studies of memory have consistently shown that both the time lapse from the occurrence of a behavior and the importance of a 
behavior from the respondent's viewpoint present problems for recall. The relation between the significance of events and memory may be especiallv critical to the assessment of motivations for driving behaviors; Cannell and Kahn (1968) point out: "Events of trivial significance for the respondent may be forgotten almost as quickly as thev occur." For routine matters such as one's breakfast, the content of yesterday's television programs, or (it might reasonably be suggested) one's driving action down the road or around the corner, recollection may dissipate rapidly. The driving task consists of many routinized responses and behaviors; no one particular response may assume enough significance to be stored in the driver's memory for recall.

Somewhat analogous to the assumption that drivers can recall specific driving behaviors is the assumption that drivers also know their motivations for driving as they do. Motivational theorists, however, have not always been in agreement about the basic nature of this behavioral construct. While some have conceptualized motivation in terms of conscious volition, others have emphasized unconscious wants, needs, and drives (Berkowitz 1969). Morton-Williams (1961) explains that a number of complex and irrational factors are involved in sausing people to behave as thev to, including individual, social, cultural, and circumstantial influences. She emphasizes the use of special techniques such as projective tests and attitude scales to probe beneath the superficial answers to arrive at an understanding of individual behavioral choices. An attempt was made, to a limited extent, to incorporate some elements of these and other techniques in the driver questionnaires.

Pelz (1968b) has suggested examination of accident type as an indirect measure of motivation. Factor analysis of six major accident causes demonstrated two general factors, rashness and inattention. He hypothesizes:

In all likelihood, the motivation underlying rash or reckless driving accidents will be found to include aggressive or rebellious motivations. Conditions underlving accidents due to inattention or carelessness may come from rather different sources--pressures, anxieties, depression, or simply the distraction of a change in job, school, marital or social relationships, etc. Violators likewise might be subdivided into 
those indicating recklessness (principally speeding), and those indicating inattention (such as turning from the wrong lane); different motivations may accompany each type. (1968b:8)

No doubt other more specific influences could be structured to augment reliably the information provided by drivers. Another issue of concern was whether any motivational determinants of unsafe driving identified by the project would be useful for countermeasure design. It was possible that the reasons given would be so often vague or suspect, or so diverse, that they would not prove sufficiently useful for countermeasure design to warrant a full-scale data collection.

The editors of Peace Officer, the bimonthlv magazine of the Fratemal Order of Police, solicited entries from officers for a "most creative excuse for speeding" contest. The following are some of the excuses given bv speeding motorists to the police (Detroit Free Press 1979):

- Officer, my wife is going to get pregnant tonight, and I want to be there when she does.

- A woman said she was speeding to keep up with the cars behind her.

- A man and his wife, both wearing crash helmets, said they were speeding home to their basement in order to avoid a hurr icane.

- A man said he had a right to speed to make up for lost time in a construction zone; his average speed in the last hour had been 55 m.p.h., he insisted.

- A man who had just gotten another ticket 10 minutes ago from another trooper cited "double jeopardy" as his constitutional right to refuse a second ticket.

- A person said, "My car is so light that the wind blew it over the speed limit, Officer. Honest."

- A person said, "I was speeding to get awav from my mother-in-law."

The above examples, while obviously selected and reported for their humor, illustrate the possibility that there might be little consistency or generalizability among the reasons people cite for unsafe driving. It is doubtful that such information would prove useful for the development of a 
countermeasure program based upon driver motivation. In any case, this possibility had to be taken into account in the research approach; specifically, results had to be examined carefully to assess their utility for countermeasure design. The initiation of a large-seale data collection effort should be contingent on a positive result.

\subsection{Scope and Approach}

The original project design involved a two-phase technical approach. Phase I was to be devoted to developing and testing orocedures for determining driver motivations for committing unsafe driving actions, as well as to assessing the usefulness of such information for the design of driver-oriented countermeasure programs. Phase I would be of six months' duration and would not require Office of Management and Budget (OMB) approval. Phase II was to be contingent on the results of Phase I, and would involve a full-scale roadside survey and subsequent countermeasure identification.

Phase I was conducted in accordance with this original project design. It involved the development of appropriate observational, measurement, and interview techniques, and, ultimately, their tosting to assess: the degree of bias as a consequence of selection and acquisition, the validity of information obtained as to reasons for commission of unsafe acts, and the utility of information obtained for countermeasure design purooses.

Project staff adapted relevant measurement literature and procedures from the fields of highway safety, social science, and marketing research to the purposes of this studv. Several interview strategies were developed and field-tested for reliability and validitv.

In addition, to simplify the observation task of Phase 1 , only one easily observable UDA, speeding, was examined. Also, this UDA was believed likely to result from conscious behavior in a high proportion of cases.

Observations in Phase I were restricted to only two relatively uncomplicated types of locations, so as to facilitate and emphasize developing and testing of techniques rather than processing data or otherwise diluting resources. Two-lane rural locations rather than an urban freeway were selected as being preferable for developmental purposes, and, 
for this study, it was not necessary to represent numerous types of locations to meet developmental objectives.

Phase I results were carefully evaluated to assess whether the issues of sample selection and acquisition, validity, and utility had been adequately resolved.

The results of the pretests on speeding indicated the following:

- Although vehicular speeds appeared to be affected to some degree by the presence of the traffic observer and the survey equipment, drivers who exceeded the speed limit could still be identified and stopped for participation in the survey.

- Drivers were able, for the most part, to explain with sufficient specificity why they were driving as they were.

- The reasons that drivers gave for committing UDAs were, in many instances, amenable to reasonable countermeasures aimed at preventing future UDAs. It must be emphasized that many of the countermeasures proposed as a result of driver responses have not been implemented before and are only proposals, not actual countermreasure programs.

- A questionnaire was developed to elicit responses from drivers about their reasons for committing (or refraining from committing) UDAs.

- The strategy of using a roadside survey to interview drivers about reasons for committing (or refraining from committing) UDAs was found to be feasible and useful.

Based on these results, Phase II full-scale data collection activities were recommended to NHTSA.

In July 1981, NHTSA opted to pursue continued pilot-test activity rather than the Phase II activity. The project would be used to collect additional preliminary information to be used in future planning activities and would thus represent the pilot and developmental study for a possible large-scale data collection effort in the future.

Three UDAs were selected by NHTSA for these further pilot-test activities:

- following too closely

- running a stop sign or signal 
- pulling in front/turning left in front of traffic

\subsection{Onganization of Report}

This report is presented in eight sections and three appendices. Section 2.0 describes the general approach, design, and procedures used in the data collection effort. Sections 3.0, 4.0, 5.0, and 6.0 present the design and results of tests of the speeding, following-too-close, running-estop-sign, and pulling-in-front/turning-left-in-front UDAs. The overall conclusions and recommendations of the project are set forth in Section 7.0. Section 8.0 is a bibliography of documents cited in the main body of the report.

Roadside survey materials are contained in Appendix A, and Appendix B contains a survey-approval application prepared for the Office of Management and Budget. NHTSA decided not to submit this application to OMB, but to continue testing of the data collection methods. A review of pertinent literature is presented in Appendix C. 


\subsection{GENERAL METHOD}

The development and testing of procedures for determining driver motivations for committing unsafe driving actions were emphasized in the project. The pilot test consister of three to four actual survey sessions for each UDA. The method described below was used for all sessions. Any changes made in the procedures from session to session are noted. Presurvey and postsurvey traffic observations were also made for the speed UDA. This section describes the design and procedures used in the test effort.

\subsection{Design}

2.1.1 Site Selection. The studv roadway was selected on two bases: the commission of the UDA was, indeed, unsafe on the road, and the stopping of drivers for a roadside survey was feasible on that road.

Project staff toured Washtenaw County to select survev locations. Factors considered in the site-selection process included characteristics of the survey site itself, the observer's site, and general characteristics of the survey location.

The following characteristics of the survey site were consifered in the selection process:

- Paved/nonpaved. Presence of pavement or firm gravel at the survey site was considered important, particularlv in light of the fact that survey activity mav take place when unpaved areas are muddy.

- Entrance/exit configuration. It was considered ideal for a survey site to have a separate entrance and exit to minimize the hazards and inconvenience of pulling into and out of the site by survev particioants. Locations with onlv one entrance/exit were considered if the site was large enough to handle incoming and outgoing traffic safelv.

- Size of survey site. A site had to be large enough to accommodate the survey vehicle and a participant's car without interrupting normal activities in the area. 
- Nonsurvey traffic. A site with a low amount of nonsurvey traffic during the survey hours was considered ideal to minimize the potential of the survey to disrupt the normal activities at the site.

- Police location. All sites should have an appropriate area for the police officer to flag drivers to the survey site. The area should be large enough to accommodate the police officer and the patrol vehicle and be located at the entrance to the survey site.

The following characteristics of the observer's site were considered in the selection process:

- Distance from surveg site. It was determined that the observer site should be located about .3 to .5 of a mile from the survey site. This distance provided the observer the necessary time to radio to the police officer and for the proper car to be flagged over. In most instances, it allowed the observer to visually verify that the proper car has been stopped.

- Visibility to traffic. Observer sites that were inconspicuous to traffic were considered ideal. Thus, observer. sites located in parking lots off the roadway were considered preferable to road shoulder sites.

- Other factors associated with the location of the observer site that could affect speed measurement were considered. For example, if there was a stop sign or light a short distance before the observer site, the location was not considered since a car's actual traveling speed on that road would probably not be reached by the time the speed measurement was made.

Several general characteristics of the survey location were also considered:

- Posted speed limit. Only roods having speed limits between forty and fifty-five were considered for the speed UDA.

- Distance from the university. While not determinative, a location convenient to the university was considered attractive, primarily because of the need to transport equipment back and forth to the survey site.

- Traffic volume. Setting a minimum traffic volume was considered necessary to obtain an adequate number of interviews at each survey location. For the Phase I 
activity, this number was set at 5,000 cars per day.

- Presence of intersecting roads. Locations that had intersecting roads between the observer site and the survey site were not considered because of the possibility of a vehicle's turning before it reached the survey site.

Final selection of the survey sites was made after consultation with officials of the Washtenaw County Sheriff's Department. Written permission to use the sites was obtained from the owner or manager of each site. Permission to place traffic measuring equipment on the road was received from the Washtenaw County Road Commission.

2.1.2 Selection of Drivers for Survey. Vehicles were randomly selecter for stopping on a time-interval basis. The interval was determined bv the length of time to complete one interview. This strategy has been used in the past in a number of roadside survevis (Carr et al. 1974; Stroh 1973; Wolfe 1974). A vehicle was not stopped until the Drevious interview har been completed. This ensured that the survey team would have time to complete each interview with drivers who had already been stodped.

During each survey session, the survey team attemoted to interview sixteen drivers; eight exceeding the posted limit and eight complying with the posted limit. (Surveying more than nine drivers in each group would have required clearance and approval from the Office of Management and Budget.)

Although the motivations for unsafe driving for drivers of all tvpes of vehicles were of interest, for practical reasons some types of vehicles were excluded from the pilot test. They were:

- vehicles that because of their size or shape could not pull into and out of the survey area safely (e.g., large trucks, heavy equipment vehicles)

- emergency vehicles (e.g., ambulances, Dolice cars)

- vehicles for hire (e.g., taxis, limousines, buses)

Also, no driver was interviewed more than once. If a triver har been stopped more than once curing any of the survey sessions, the triver would have been thanked for stopping and not reinterviewed. 
2.1.3 Equipment. The driver interviews were conducted inside a recreational vehicle (RV). This type of vehicle has been recommented by highway safety researchers for roadside survey activitv (Carr et al. 1974; Perrine 1971). It can be made more comfortable than outside conditions (e.g., warmer, cooler, drier), and allows the interviewer and rriver to sit facing each other. This latter practice has also been recommended bv survey researchers in general (e.g., Bradburn and Surman 1979). The RV was rented on a daily basis. The $R V$ had a convenient seating arrangement at a table with padded benches on both sides. Arrangements were made to have the university supplement the liabilitv insurance coverage that came with the rental of the RV.

For the speed pilot test, the observer vehicle was rented from The University of Michigan Transportation Services. This vehicle was a late model sedan, usually a Chevrolet Citation. When it became apparent to survey staff that the color of the vehicle may have an effect on traffic speeds, care was taken to obtain a nonwhite observer vehicle. (The apparent effect of color on traffic speeds is discussed in detail in section 3.0.) The observers' personal vehicles were used as the observation vehicles for the remainder of the study; these were: a gray Saab, a beige Chevrolet Impala, and a green pick-up truck.

Portable communications equipment was used to allow conversation between the observer and the survey team. A Dortable citizens' band (CB) radio was used to monitor broadcasts on Channel 19 during most of the speed presurvey and survey activity. Project staff had problems with the rechargeable batteries in the $\mathrm{CB}$ on several occasions. Because of this, two of the speed presurvey observations and one of the speed survey activities were not monitored by the $\mathrm{CB}$. When the $\mathrm{CB}$ was monitored, a tape recorder was used to record all transmissions during the observation or survey period. If the batteries in the $\mathrm{CB}$ were operating properly, the observer tape recorded and monitored the $C B$. If the batteries were not operating, the $\mathrm{CB}$ was run on the electricity produced by the generator in the RV and was tape recorded and monitored by survey team members. The CB was not used for any other UDA pilot-test activitv. 
Other equipment for the survey included a small tape recorder for recording driver interviews (with the triver's consent), a stapler, pencils, lab coats, and name badges for each interviewer. Also, a survev sign was borrowed from the Michigan Department of Highways. This sign was placed several hundred feet upstream from the survey site to inform drivers of the survey activity. Two red flags were attached to the sign to make it as noticeable as possible.

2.1.4 Interview Materials. Interview materials inclured the following:

- observer's records

- interviewer cover sheet

- driver interview questions

- driver consent form for roadside interviews and follow-up interviews

- assurance letter from the Washtenaw County Sheriff and Prosecutor

- "driver excuse" form for drivers late for work or appointments

- thank-you letter from the project director

Examples of these materials are included in Appendix A.

The observer's record was a brief summarv of road, weather, and traffic conditions during each survey session. The observer was also asked to note unusual events (e.g., joggers, school buses) and any CB conversations referring to the survey operations. Included in the observer's record was a listing of the observed driving behavior and the vehicle deseription for each vehicle identified for survey activitv. This record was later compared to that recorded by the survev team to confirm that the correct vehicles had been stopped.

The interviewer cover sheet was completed for each vehicle stopped as a part of the roadside survey. The cover sheet contained information about the driver (e.g., sex, ethnicity, use of occupant restraints, etc.), the vehicle, and subjective judgments made by the survey team about driver's 
willingness to participate and driver's alcohol/drug impairment, if anv. The cover sheet also contained space to record a triver's reason for refusal as well as name and telephone number if the driver was willing to be interviewed later by telephone, in case of refusals to participate.

From the review of the literature, a series of questions was developer to identify drivers' reasons for committing or refraining from committing the specific UDAs. The questions consisted of items addressing general driver characteristics; many of these questions were demographic, such as age or highest level completed in school. Other items relater to driving experience, such as number of years driving or number of traffic tickets for any particular UDA-related violation. Finally, there were items that pertained to the driving behavior at the time of the traffic stop. These included questions about the origin and destination of the trip and frequency of driving on the survey road. These questions were designed to give a set of characteristics to compare to specific driving behavior. The majority of the questions contained items specific to the UDA. These questions were designed to identify the driver's reasons for committing or refraining from committing the UDA at the time of the traffic stod. There were also a series of questions designed to get drivers thinking about their driving behavior with respect to the particular UDA. Drivers were asked to answer these questions not only in terms of their behavior at the time they were stopped, but in terms of their previous Ariving experience on that road. Such probes were viewed as necessarv to aid drivers in verbalizing about changes in driving behavior.

Figure 2-1 depicts the types of items contained in the questionnaire. The questions move from the most general at the base of the pvramid to the most specific at the apex. The driver interview questions were, for the most part, open-ended in nature throughout all four survev sessions. This approach to question design is discussed in Appendix $C$ and has been recommended for studies like the driver motivation studv where little is known a priori about the range of responses that drivers will give. The content of the questions for the first survey session was suggested from the review of relevant risk-taking literature. For speed, UDA proiect staff reviewed the responses given by drivers in the first survey before 
FIGURE 2-1

\begin{abstract}
QUESTION TYPES FOR IDENTIFICATION OF DRIVER MOTIVATIONS FOR UNSAFE DRIVING ACTIONS
\end{abstract}

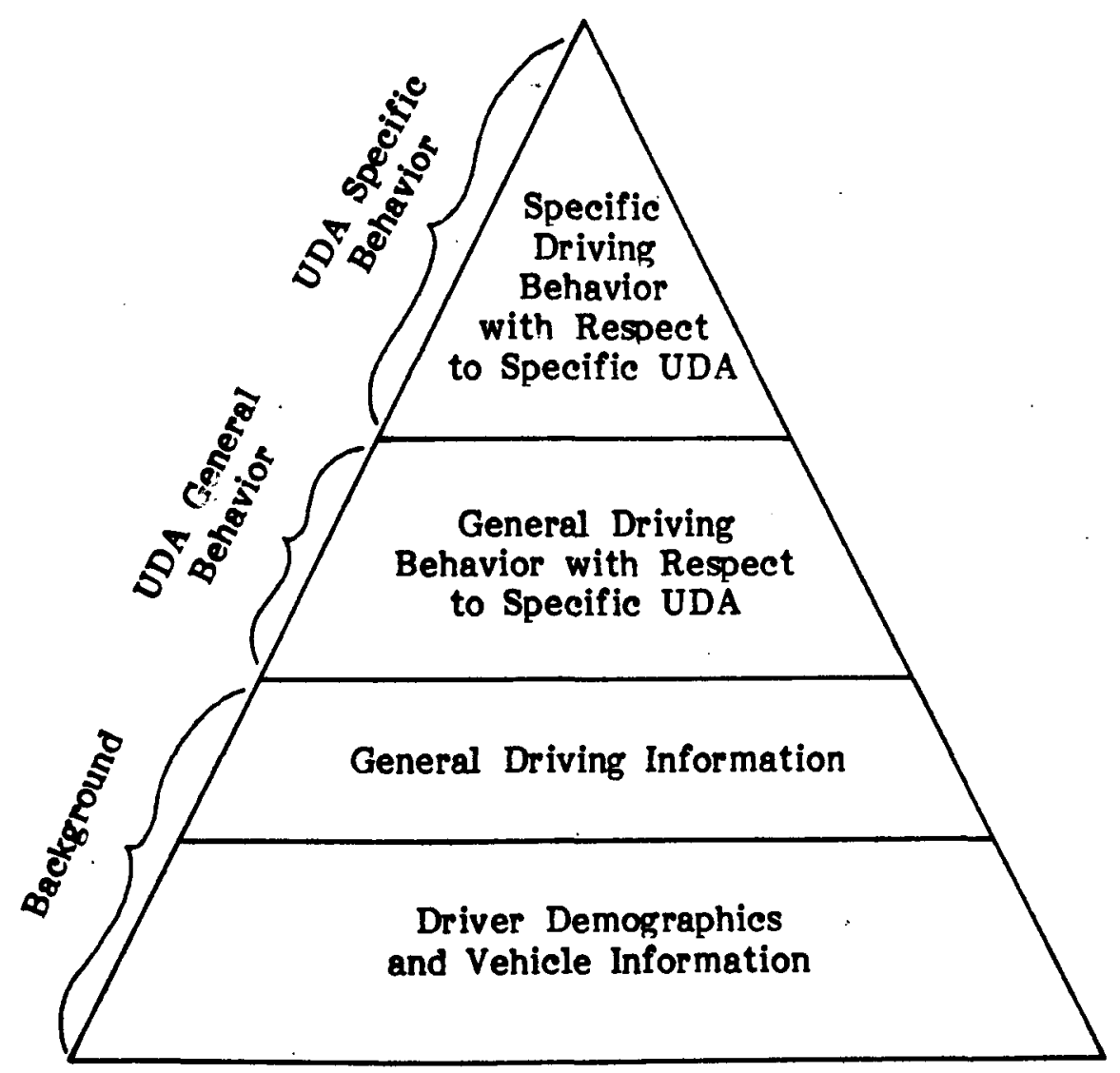


conducting the second survey. Questions were either revised, eliminater, or added as needed based on driver responses. Primary determinants of the selection and revision of questions were whether drivers could give reasons for their behavior and whether those reasons had potential to be reflected in countermeasure development. Some items in the interview materials contained a series of probes. The order of the probes was varied across interviews to control for possible order effects in presentation. The revision of the interview materials continued after each of the four survey sessions. Most questions retained the open-ended format for all four sessions.

Four differeht questionnaires were also used for the following-tooclosely, running-a-stop-sign, and unsafe-turn-or-merge UDAs. These questionnaires were based upon those developed for the speed UDA pilottest.

Other interview materials used turing the four survev sessions included the consent forms for the roadside interview and follow-up interview; a letter signed by the Washtenaw County Sheriff and Prosecutor explaining that drivers would not be subject to anv traffic enforcement activitv arising out of the survey stop; a driver excuse form for trivers late for work or apoointments, and a thank you letter signed by the proiect director. Only minor changes were made in some of these materials during the course of the survey sessions.

2.1.5 Survey Personnel. The personnel necessarv to conduct the roadside survey included: two interviewers, one observer, and one police officer.

The interviewer team consisted of one male and one female interviewer. Interviewers alternated administering the questionnaires and recording the driver responses. The interviewers designated for the speeding pllot-test activity were two senior members of the proiect staff. Because of their experience on this project and in past research efforts, no additional training or briefing was necessary for the interviewers in this phase of the study. Four research assistants were trained as interviewers for the remaining pilot-test activity. 
The observer's primary task was to note the vehicles to be stopped for interview. The observer also made a brief vehicle description of each vehicle to be stopped (e.g., color, make, morlel). These descriptions were compared later with the vehicle descriptions on the interview cover sheet to check that the correct vehicle had been stopped.

The observer also helped to monitor for CB broadcasts about the survev (in the case of the speed UDA) and noted other events that mav have affected traffic speeds (e.g., joghers, bicvclists, emergency vehicles). Members of the Washtenaw County Sheriff's Department server as observers during all speed pilot-test activity. The research assistants alternated roles as observers for the other UDAs. Several observation training sessions were held as well before the actual pilot-test activity was begun.

A sheriff's deputy was present at the survev site to flag down selected drivers and guide them to the interviewer. Past roadside survey experience has shown the necessity of police assistance in this activitv for both safety and legal reasons. The officer's contact with the drivers was minimal. The officer flagged down the designated vehicle, explained that the driver was not stopped for a violation, and directed the driver to the interviewer for further explanation.

Deputies were recruited on a volunteer basis from the Washtenaw County Sheriff's Department. Volunteers were briefed by their commanding officer about the nature of the study before coming; specific survev procedures were explained by project staff immediately before each survey session. All deputies were off duty during the survev sessions. This assured their presence for the duration of each session.

2.1.6 Publicity. Before conducting the field-test activities, the proiect team contacted the university's Information Service regarling publicitv for the study. Feature stories appeared in two local newspapers as well as in two university papers. A picture of the survey team was included in the local papers before the speed pilot test. A Detroit-area radio station also featured $a$ short spot on the survey during its newscasts. 
2.1.7 Confidentiality of Responses. Before personal data were collected from drivers, they were informed what data were being sought, why it was being collected, and how it was to be used as part of the study's procedures. The interviewers described the purpose of the study to the drivers at the initial contact at carside. Drivers were advised that they could leave at once or at any time during the interview and that they were under no obligation to participate. They were also informed that they would not be eited for any traffic violations that led to their being stopped for the survey.

The initial part of the driver interview was anonymous. Thus, written consent was not sought at this point in the interview. The explanation by the interviewer and the subject's response were openly tape recorded with the subject's permission. At the end of each speed interview, drivers were asked if they were willing to participate in a further interview by telephone. An informed consent form was signed by drivers who agreed to participate in the telephone interview.

Confidentiality of responses was maintained at all times. Customary safeguards were instituted to protect the integrity of the data against inadvertent disclosure. These included appropriate instructions to staff, segregation of identifiers, and maintenance of a chain of custody of data.

No traffic enforcement activity took place as a result of the survey stops in agreement with the Washtenaw County Sheriff's Department. Sheriff's deputies were present to stop motorists for survey purposes, not to engage in enforcement activity.

\subsection{Procedures}

2.2.1 Traffic Observation. During the survey activity the observer was in a vehicle parked approximately .3 to .5 mile from the survey site. The observer was notified via communications equipment from the survey site when the interviewers were ready for the next driver interview. Observations alternated between safely driven and unsafely driven vehicles. The observer noted the actions of each appropriate vehicle and radioed a description of the vehicle to the traffic deputy at the survey site. At the same time the observer recorded the vehicle's speed and description (e.g., $\therefore$ : 
yellow Ford) on the observer's sheet. The observer also had the responsibility for monitoring $\mathrm{CB}$ communications activity during the speed pilot test only. Monitoring these communications provided additional information regarding the effects of the survey on traffic flow and gave some indication of the public acceptability of this kind of study.

2.2.2 Roadside Survey Procedure. During this pilot study, drivers were surveyed randomly regarding their reasons for choosing to drive in a particular manner on a selected roadway. The HSRI survey team was stationed in a van at the designated survey site; the police officer's vehicle was parked at the entrance to the survey site. Vehicles were randomly stopped on a time-interval basis determined by the approximate length of time required to complete one interview. Stops were alternated between violators and nonviolators. When the interviewers were ready to interview the next driver, they asked the police officer to radio the observer to look for the next appropriate vehicle; interviewers specified whether a violator or a nonviolator was to be stopped. The observer radiced a brief description of the appropriate vehicle (e.g., blue Chevrolet) to the sheriff's deputy. The deputy flagged down the jesignated vehicle, told the driver that a roadside survey was in progress, and directed the driver to the interviewers for further explanation. If the officer was unable to stop the vehicle, the observer was notified to begin looking for a vehicle traveling in a similar manner.

After the driver was directed into the survey site by the sheriff's deputy, the survey team approached the vehicle. One member of the team served as interviewer; the other member was the recorder. The roles altemated between the two members of the survey team. The interviewer explained to the driver the purpose of the stop and asked if the driver was willing to participate in the study. At the same time, the recorder noted descriptive information about the vehicle and the driver.

Drivers who expressed a willingness to participate were invited by the interviewer to enter the RV for the interview. It was explained to the driver that this was a more comfortable place in which to conduct the interview. If the driver was unwilling to enter the $\mathrm{RV}$, the interview was 
conducted at the side of the driver's car. The interviewer then read the informed consent statement to the driver and asked if the statement was understood. If the driver was willing, the informed consent procedure was tape recorded so that a record of the procedure existed. For drivers who were unwilling to have the tape recorder on, an informed consent form was presented for signing and then placed in a sealed box.

Once the driver had consented, the interview was begun. Drivers were asked if they objected to the tape recorder continuing during the interview. This recording was to serve as an aid in later data analysis. When drivers objected, the tape recorder was turned off. The interviewer administered the set of questions, while the recorder noted driver responses. After the set of questions had been asked, each driver was given a sheet of paper containing either driver background questions (e.g., age, school grade completed) or attitudinal items and was asked to complete the questions. Drivers were again informed that they were not required to answer any of the questions. After finishing these questions in the speed pilot test, the interviewers asked drivers if they would be willing to leave their name and filone number for a follow-up interview by telephone.

At the end of the interview, drivers were given a short letter signed by the project director thanking them for their participation. Also, if drivers desired, an "excuse letter" was available for drivers who were late for work explaining about the survey. Drivers were then thanked for their participation, shown to their vehicle, and directed back into the traffic now.

\subsection{Pilot-Test Analyses}

The analyses of the field-test activity were designed to address the following questions:

- Can unobtrusive methods be developed and implemented to keep the sample as free from bias as possible?

- Will driver participation be sufficient for the purposes of the study? 
- Will community agencies cooperate in conducting a roadside survey?

- Can methods for collecting information about driver motivations be developed and administered to obtain reasons for driving behavior?

- Can drivers give reasons for their behavior?

- Are the reasons drivers cite for their driving actions useful for the development of driver-oriented countermeasure programs?

- Are full-scale data collection and countermeasure identification feasible?

The following four sections describe the design and results of the fieldtest activity undertaken to provide answers to these questions.

The reader should note that this study was basically developmental and methodological in nature. Although the responses of drivers are certainly of interest and can be used in planning future research efforts in the motivational aspects of driving behaviors, readers should be aware that the responses are based on small samples on selected roadways and should not be generalized as representative of drivers engaging in specific unsafe behaviors. However, the responses are of interest for future research. 


\subsection{SPBEDING}

Two types of speed-related UDAs have been defined as being either absolute or relative. The two definitions are as follows:

The absolute speed UDA is the act of driving a vehicle at a speed in excess of a maximum legal limit, or in a normal driving environment, at a speed below a minimum limit.

The relative speed UDA is the act of driving a vehicle at a speed that is so different from the speeds of the vehicles around it that the risk of a crash exceeds that which is societally acceptable. (Jones et al. 1979:36)

Speed-too-fast UDAs are indicated to be causally involved in about sixteen to twenty-three percent of reported accidents, and some thirty to thirtyfive percent of fatal accidents. The accidents involving these UDAs have been, on the average, more serious in terms of both damage and injury. Moreover, in-depth accident reports indicate the speed-too-fast UDA to be a conscious, intentionally undertaken behavior (Treat et al. 1980).

Only the relative-speed-too-fast UDA was addressed in the pilot-test activity. The basis for its selection is its risk to drivers as well as its relatively easy observation and measurement. Observations were further limited to two-lane rural locations; such locations are relatively uncomplicated (in contrast, for example, to an urban freeway). These two restrictions were made for the developmental purposes of testing techniques rather than processing data or otherwise diluting resources.

\subsection{Design}

3.1.1 Site Selection. Two sites were selected for pilot-test activity:

- Site I--Radrick Farm Golf Course maintenance entrance

This location is on Geddes road, a two-lane country road running east and west on the east side of Ann Arbor. There is a speed limit of $40 \mathrm{mph}$ at the survey location. The road at this point is hilly and has a number of sharp curves where the speed limit drops to $30 \mathrm{mph}$. About one mile west of the survey location, Geddes Road straightens 
out and has a speed limit of $50 \mathrm{mph}$.

The survey site was on the north side of the road, allowing westbound traffic to be sampled. The site was paved with gravel and had a convenient entry/exit configuration. The site was large enough to accommodate survey traffic easily.

The observer site was located on the road shoulder between two residential driveways about .3 inile from the survey site.

- Site I-Washtenaw County Farm Bureau parking lot

This location is on Ann Arbor-Saline road, a major north/south country road connecting the cities of Ann Arbor and Saline. Saline is primarily a residential community with a large percentage of its residents commuting to Ann Arbor for work. Ann Arbor-Saline Road has a speed limit of 50 $\mathrm{mph}$ and is a relatively straight two-lane road running through gently rolling hills and farmland.

The survey site was on the east side of the road, allowing northbound traffic to be sampled. The site was paved and had a convenient entrance/exit configuration. It had a large parking area with a low amount of nonsurvey traffic.

The observer site was located about .5 mile south of the survey site on the road shoulder. The road shoulder was not very wide. Thus, the observer vehicle was parked fairly close to the side of the road.

3.1.2 Schedule of Survey Times. Two survey sessions were conducted at each survey location. The times and locations of each survey session were as follows:

- Survey I

- Survey II

- Survey III

- Survey IV
Ann Arbor-Saline Road Tuesday, September 9, 1980 3:30 p.m. to $7: 30$ p.m.

Ann Arbor-Saline Road Monday, September 15, 1980 6:00 a.m. to 10:00 a.m.

Geddes Road

Friday, September 19, 1980 3:30 p.m. to 7:30 p.m.

Geddes Road Thursday, September 25, 1980 6:00 a.m. to 10:00 a.m.

The early morning and late afternoon hours were selected because those 
hours were most likely to tap the commuter traffic on its way to and from work. It was believed that these hours would be among the most difficult hours in which to obtain driver cooperation; adequate cooperation at the most unlikely time would lend greater support to the feasibility of a full-scale study. A minimum of four days was allotted between survey sessions to allow project staff to review the responses to the interview questions and revise the questions accordingly.

3.1.3 Selection of Drivers for Survey. Because this stage of activity focused on the relative-speed-too-fast UDA, speeders were defined as those drivers exceeding the ninety-fifth percentile speed of the vehicles in the traffic stream. A relative-speed UDA was defined above as driving at a speed so different from the speeds of vehicles around it that the risk of a crash exceeds that which is societally acceptable. A societally acceptable risk has been defined as "that associated with the speeds of the fif th through the ninety-fifth percentiles of vehicles in the traffic stream" (Jones et al. 1979:36). Thus, a relative-speed-too-fast UDA occurs when the speed of a vehicle is greater than the speed not being exceeded by ninety-five percent of vehicles in the traffic stream. Traffic speed distributions were gathered in a series of presurvey observations. (These are described below in the section entitled "Traffic Observations.")

3.1.4 Equipment. The TraficOMP ${ }^{B} 141$ RECORDER manufactured by Streeter/Amet was used to measure traffic flow characteristics. The RECORDER unit is a portable system designed to collect and store traffic data at roadside. The unit records traffic volume with capability of classifying vehicles as to velocity in any desired speed ranges. Road tubes were used to input data into the RECORDER. Up to twenty counts per second can be received by the unit, and a maximum of 3,500 counts can be stored. The RECORDER operates on two 6V, 8 Amp/Hour dry cell batteries when used with road tubes. A TraficompO 140 READER translates information from the RECORDER to cassette tape. When connected to the RECORDER, the READER also gives a running display of vehicle speeds as they cross the road tubes. Also, the READER can be 
used with a printer to produce a hard copy printout of accumulated data.

3.1.5 Traffic Observation. Traffic speed and volume were measured before, during, and after the roadside survey activity. This data set was used to determine the distribution of traffic speeds and to assess the effects of the presence of the survey team on traffic behavior.

Traffic volume and vehicle speeds were measured and recorded by the TraficOMP ${ }^{\circledR} 141$ RECORDER located at roadside approximately .3 to .5 mile upstream of the survey site. Two pretest observations were made for the same days and times as the survey activity. For the first set of observations, only the traffic-measuring equipment was on the road; for the second set of observations, the observer's vehicle was parked next to the traffic measuring equipment, as it would be curing the survey activity. No drivers were stopped during either of the pretest observations. The pretest observations were conducted one and two weeks before the survey activity.

Posttest observations were made one week after the survey activity at the site where survey observations took place. Only the traffic-measuring equipment was placed on the road for the posttest observations.

\subsection{Results}

Analysis of the speed pilot test data addressed four issues: (1) the effect of the survey activity on traffic flow; (2) drivers' willingness to participate in the survey; (3) drivers' ability to respond to the interview questions; and (4) the utility of the drivers' responses for use in countermeasure development. These are discussed below.

3.2.1 Traffic Flow. Figures 3-1 through 3-4 present traffic volume information for each survey site during the pretest, testing, and posttest observations. A significant difference in traffic volume was found for only one of the lour testing conditions. This difference occurred for the morning activity at Site $I\left(X^{2}=17.92 ; p<.01\right)$. It is unlikely that this effect is due to the presence of the survey team since the volume of traffic during the roadside activity is greater than during both the presurvey observations (see Figure 3-1). 
FIGURE 3-1

TRAFFIC VOLUME

SITE I (GEDDES ROAD), A.M.

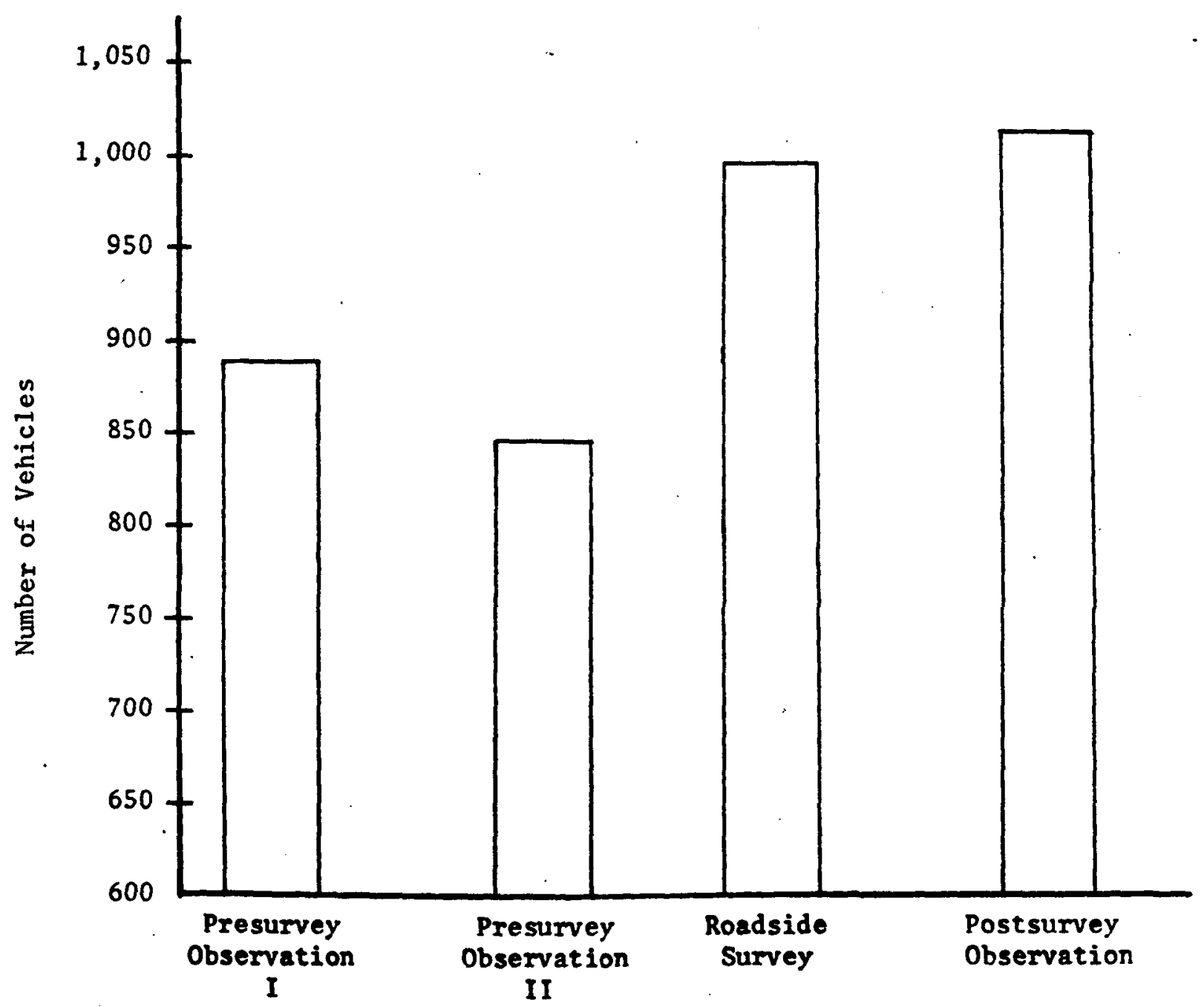


FIGURE 3-2

TRAFFIC VOLUME

SITE I (GEDDES ROAD), P.M.

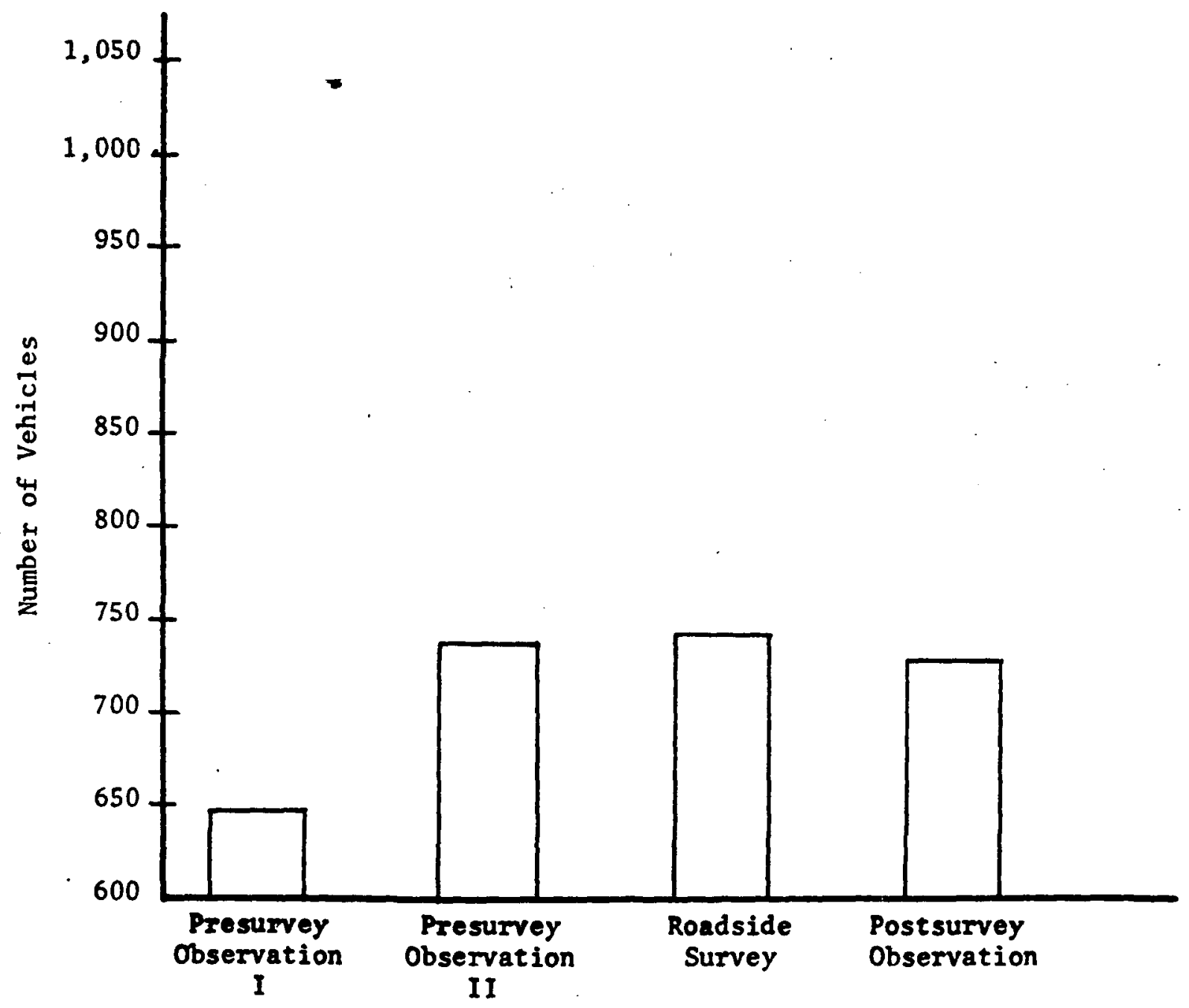


FIGURE 3-3

TRAFFIC VOLUME

SITE II (ANN ARBOR-SALINE ROAD), A.M.

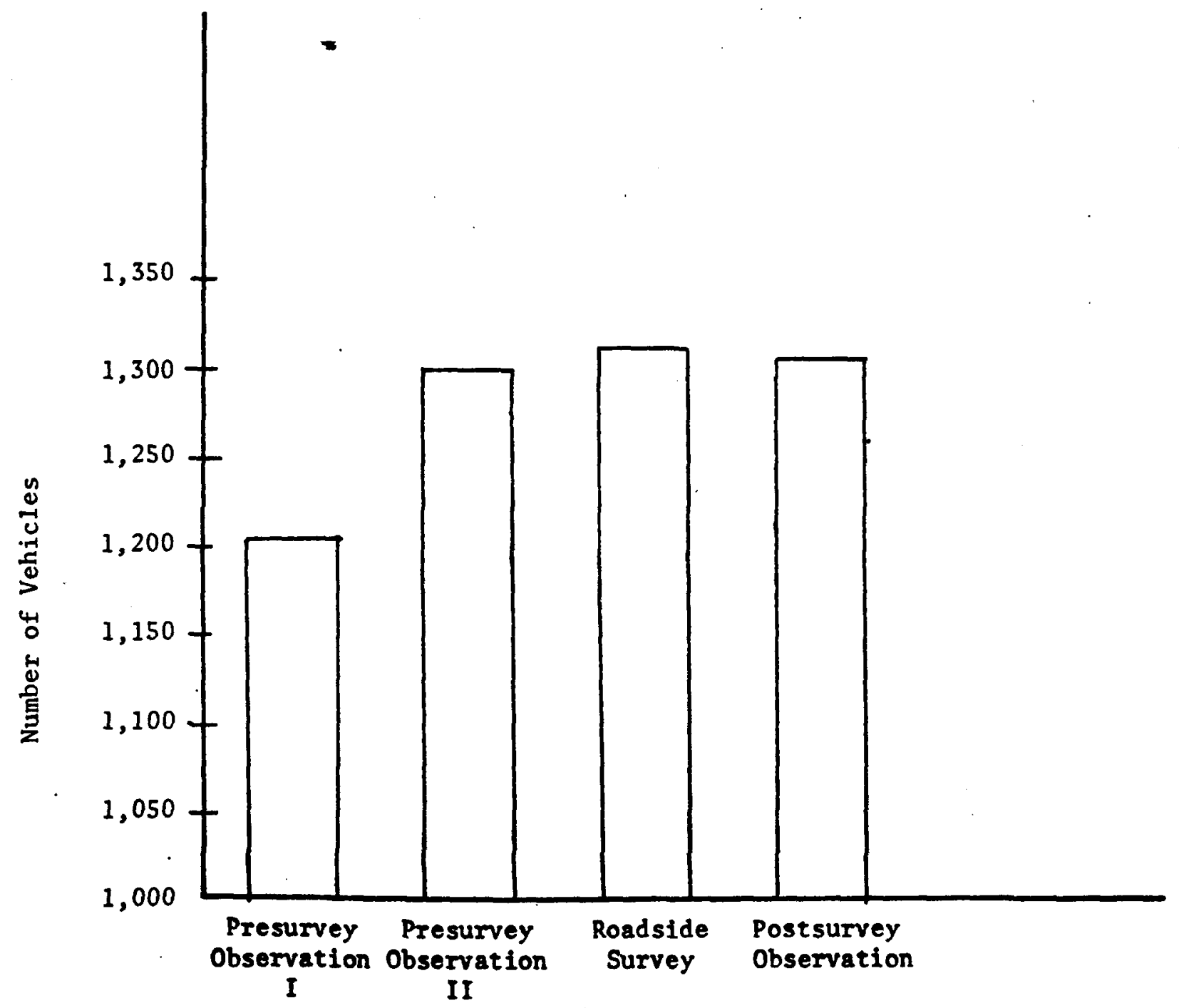


FIGURE $3-4$

TRAFFIC VOLUME

SITE II (ANN ARBOR-SALINE ROAD), P.M.

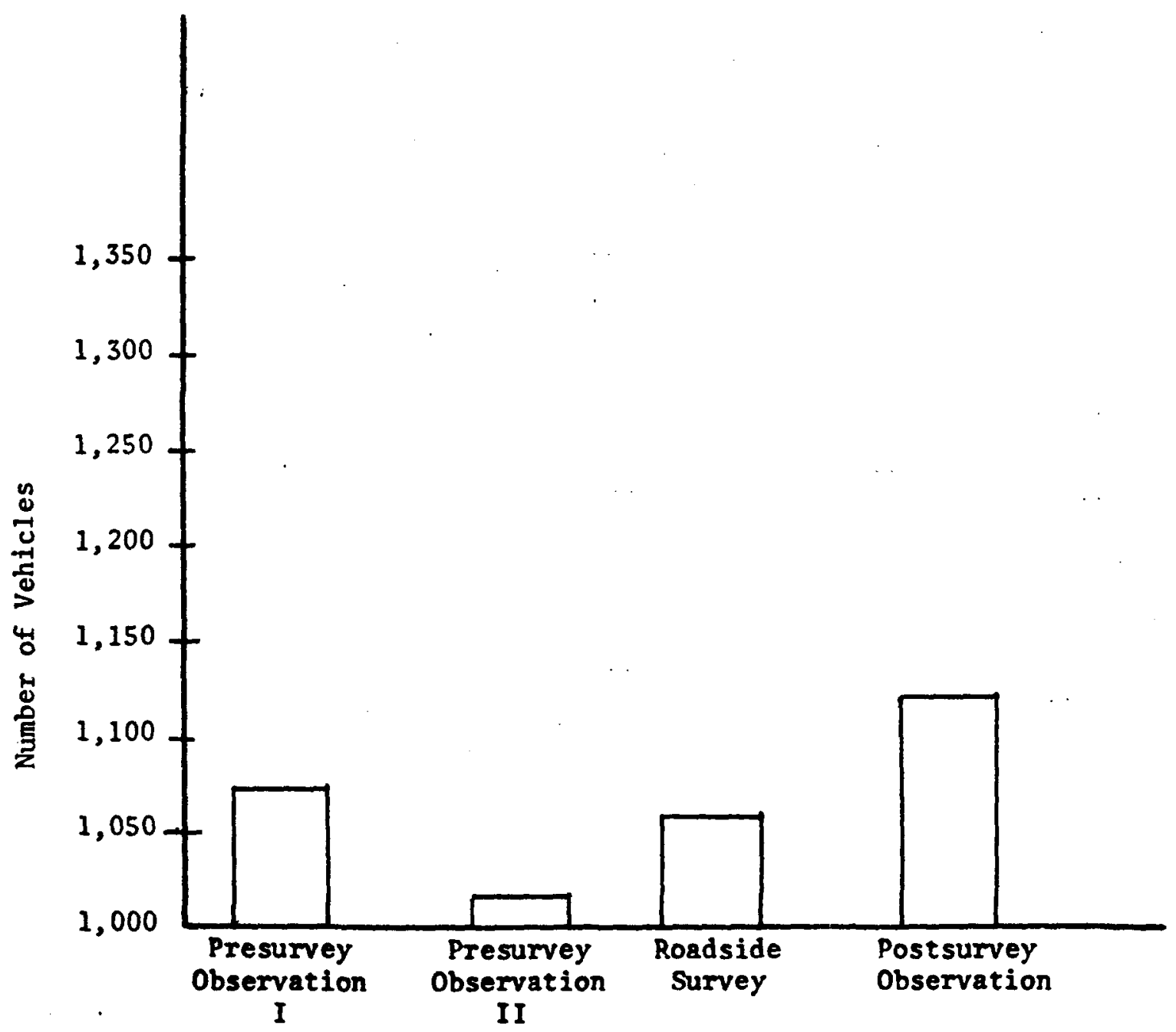


3.2.2 Speeds. Significant differences in traveling speeds were found for both sites during morning and afternoon activity. In most instances, the presence of the observer vehicle and the survey team was accompanied by a decrease in the speed of traffic.

At Site I, the speed limit is $40 \mathrm{mph}$. During the morning hours at Site $I$, the number of vehicles traveling at higher speeds decreased with increasing visibility of survey activity (see Table 3-1). The number of vehicles traveling at 31-35 mph and at 36-40 mph increased from Pretest I; when only the traffic measuring equipment was visible, to Pretest II when the observer was present and parked in a vehicle at roadside. The increase in the number of vehicles traveling within these speed categories was still higher during the pilot-test activity when the observer and the survey team were both present. The number of vehicles in the 31-35 $\mathrm{mph}$ and 36-40 mph categories dropped during post-survey observation when only the traffic measuring equipment was again on the road. Correspondingly, the number of vehicles traveling in the 41-45 $\mathrm{mph}$ and 46-50 $\mathrm{mph}$ categories decreased from Pretest I through the roadside survey; the numbers in these categories rose during the postsurvey. The largest differences were between the roadside survey and postsurvey activities. The modal speed category for Pretests I and II as well as the survey was 36-40 $\mathrm{mph}$; for the postsurvey, it was 41-45 $\mathrm{mph}$.

A chi-square test of significance was used to compare the number of speeders versus nonspeeders across the four observation conditions at Site I (see Table 3-2). The results of this analysis were significant beyond the .01 level $\left(X^{2}=209.77\right)$. There were more nonspeeders under the roadside survey condition than at any other time. This relationship is graphed in Figure 3-5.

A significant difference in speeders versus nonspeeders was also found at Site I for the afternoon activity $\left(X^{2}=261.42, p<.01\right)$. These results are presented in Table 3-2. Here the largest differences between the number of speeders and nonspeeders occurred during the first presurvey observation. These differences diminished through the second presurvey and survey phases. This relationship is plotted in Figure 3-6. 
TABLE 3-1

SITE I (GRDDES ROAD), A.M.

\begin{tabular}{|c|c|c|c|c|c|c|c|c|c|c|c|c|c|}
\hline \multirow{2}{*}{ ACTIVITY } & \multicolumn{12}{|c|}{ SPEED CATEGORIES (mph) } & \multirow{2}{*}{ TOTAL } \\
\hline & $1-30$ & $31-35$ & $36-40$ & $41-45$ & $46-50$ & $51-55$ & $56-60$ & $61-65$ & $66-70$ & $71-75$ & $76-80$ & $81+$ & \\
\hline $\begin{array}{l}\text { Presuryey } \\
\text { Observation I }\end{array}$ & 21 & 67 & 360 & 341 & 82 & 11 & 3 & 0 & $\mathbf{0}$ & $\mathbf{0}$ & 0 & $\mathbf{0}$ & 885 \\
\hline $\begin{array}{c}\text { Presurvey } \\
\text { Observation II }\end{array}$ & 41 & 91 & 379 & 279 & 71 & 6 & $\mathbf{0}$ & 1 & $\mathbf{0}$ & $\mathbf{0}$ & $\mathbf{0}$ & $\mathbf{0}$ & 868 \\
\hline $\begin{array}{l}\text { Roadside } \\
\text { Survey. }\end{array}$ & 44 & 128 & 463 & 296 & 59 & 7 & 0 & 1 & $\mathbf{0}$ & $\mathbf{0}$ & 0 & $\mathbf{0}$ & 998 \\
\hline $\begin{array}{c}\text { Postsurvey } \\
\text { Observation }\end{array}$ & 45 & 47 & 247 & 456 & 199 & 18 & 1 & $\mathbf{0}$ & $\mathbf{0}$ & 0 & $\mathbf{0}$ & $\mathbf{0}$ & 1,013 \\
\hline TOTAL & 151 & 333 & 1,449 & 1,372 & 441 & 42 & 4 & 2 & 0 & D & 0 & 0 & 3,764 \\
\hline
\end{tabular}


TABLE 3-2

SPEEDERS VS. NONSPEEDERS*

\begin{tabular}{|c|c|c|c|c|c|c|c|c|c|}
\hline \multirow{2}{*}{ Site } & \multicolumn{2}{|c|}{$\begin{array}{c}\text { Presurvey } \\
\text { Observation I }\end{array}$} & \multicolumn{2}{|c|}{$\begin{array}{c}\text { Presurvey } \\
\text { Observation II }\end{array}$} & \multicolumn{2}{|c|}{$\begin{array}{l}\text { Roadside } \\
\text { Survey }\end{array}$} & \multicolumn{2}{|c|}{$\begin{array}{l}\text { Postsurvey } \\
\text { Observation }\end{array}$} & \multirow[b]{2}{*}{$x^{2}$} \\
\hline & speed & nonspeed & speed & nonspeed & speed & nonspeed & speed & nonspeed & \\
\hline Site I--AM & 437 & 448 & 357 & 511 & 363 & 635 & 674 & 339 & $209.77^{* *}$ \\
\hline Site I--PM & 445 & 202 & 339 & 399 & 384 & 357 & 417 & 309 & $261.42^{* *}$ \\
\hline Site II - AM & 713 & 495 & 331 & 967 & 97 & 1214 & 439 & 869 & $809.64^{* *}$ \\
\hline Site II--PM & 466 & 604 & 412 & 602 & 227 & $831:$ & 481 & 638 & $151.83^{* *}$ \\
\hline All Sites & 2061 & 1749 & 1439 & 2479 & 1071 & 3037 & 2011 & 2155 & $108.74^{\star \star}$ \\
\hline
\end{tabular}

* numbers shom are number of vehicles

$\star * p<.01$ 
FIGURE 3-5

SPEEDERS VS. NONSPEEDERS

SITE I (GEDDES ROAD), A.M.

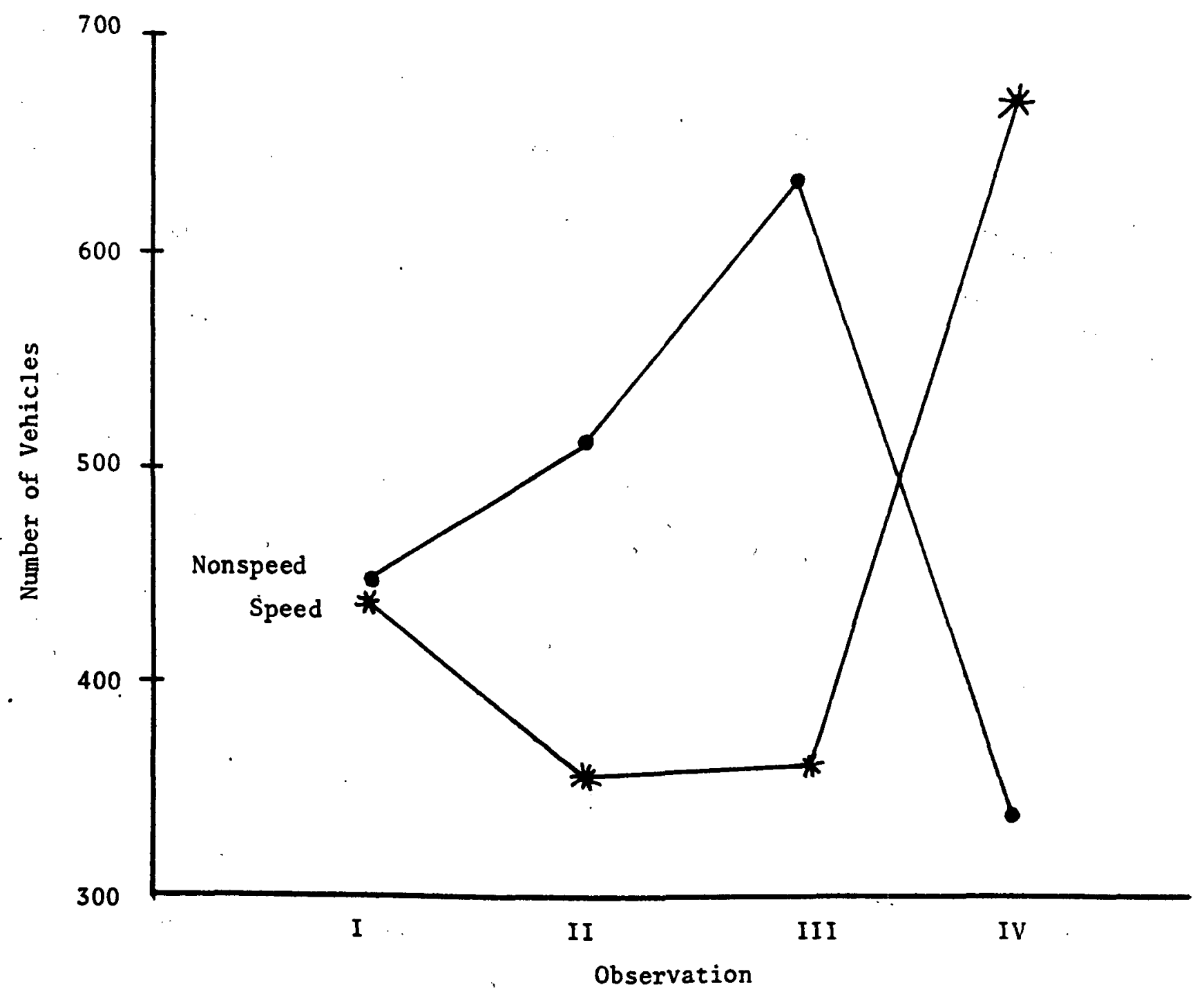


FIGURE 3-6

SPEEDERS VS. NONSPEEDERS

SITE I (GEDDES ROAD), P.M.

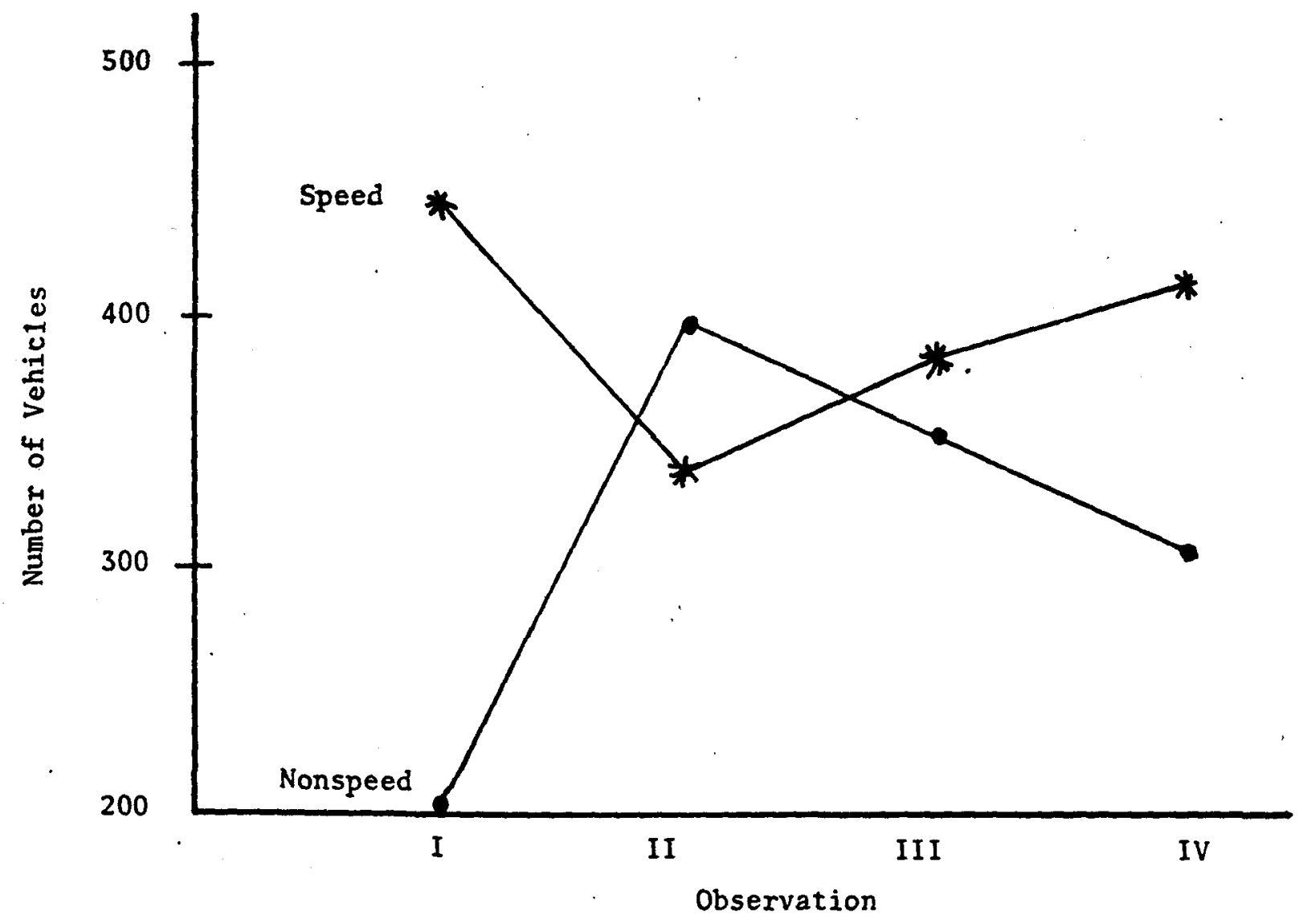


For the afternoon activity at Site I, the number of vehicles in the 41$45 \mathrm{mph}$ and 46-50 $\mathrm{mph}$ categories tended to decrease, while the numbers in the 31-35 $\mathrm{mph}$ and $36-40 \mathrm{mph}$ categories tended to increase during the course of Presurvey I and the roadside survey activity in the afternoon. The largest effects seen here occurred during Presurvey $\Pi$, in which there was a substantial increase in the $30-35 \mathrm{mph}$ category as well as large decreases in the 46-50 $\mathrm{mph}$ and 51-55 mph categories. The modal speed category for all conditions was $41-45 \mathrm{mph}$. These results are shown in Table 3-3.

Significant differences in traffic speeds occurred in a similar manner during the morning hours at site II $\left(X^{2}=809.64 ; p<.01\right)$ (see Table $\left.3-2\right)$. The speed limit on this road is $50 \mathrm{mph}$. Here, the largest differences appeared to occur between Presurvey I and the roadside survey. These differences are illustrated in Figure 3-7. Increases in the number of vehicles in the $31-35,36-40$, and $41-45 \mathrm{mph}$ speed categories were accompanied by decreases in the 51-55 and 56-60 mph speed categories curing the roadside survey. The modal speed category during Presurvey I was 51-55 mph; this dropped to $46-50 \mathrm{mph}$ for the last three activities (see Table 3-4).

Traffic speeds were also found to be significantly different for the afternoon activity at Site II $\left(X^{2}=151.83 ; p<.01\right)$. This information can be found in Table 3-2. More vehicles traveled in the 36-40 mph and the 41-45 mph speed categories during the roadside survey than in the other three activities; this was accompanied by a decline in the number of vehicles. in the 51-55 $\mathrm{mph}$ and the 56-60 mph speed categories. The modal speed category. during all four activities was 46-50 mph. Table 3-5 presents this information in detail. The relationship between speeders and nonspeeders is plotted in Figure 3-8.

The differences between speeders and nonspeeders were significant across all the speed survey sites. The results of the chi-square test yielded differences significant beyond the .01 level $\left(X^{2}=108.74\right)$ (see Table 3-2). The largest differences between the number of speeders and the number of nonspeeders tended to occur during the survey activity. The smallest differences occurred at the posttest. This relationship is plotted 
TABLE 3-3

SITE I (GEDDES ROAD), P.M.

\begin{tabular}{|c|c|c|c|c|c|c|c|c|c|c|c|c|c|}
\hline \multirow{2}{*}{ ACTIVITY } & \multicolumn{12}{|c|}{ SPEED CATEGORY (mph) } & \multirow{2}{*}{ TOTAL } \\
\hline & $1-30$ & $31-35$ & $36-40$ & $41-45$ & 46-50 & $51-55$ & $56-60$ & $61-65$ & $66-70$ & $71-75$ & $75-80$ & $80+$ & \\
\hline $\begin{array}{c}\text { Presurvey } \\
\text { Observation I }\end{array}$ & 16 & 43 & 143 & 272 & 138 & 29 & 6 & $\mathbf{0}$ & $\mathbf{0}$ & $\mathbf{0}$ & $\mathbf{0}$ & $\mathbf{0}$ & 647 \\
\hline $\begin{array}{c}\text { Presurvey } \\
\text { Observation II }\end{array}$ & 43 & 93 & 263 & 283 & 51 & 4 & $\mathbf{0}$ & 1 & $\mathbf{0}$ & 0 & $\mathbf{0}$ & $\mathbf{0}$ & 738 \\
\hline $\begin{array}{l}\text { Roadside } \\
\text { Survey }\end{array}$ & 42 & 74 & 241 & 248 & 114 & 20 & 2 & 0 & 0 & 0 & $\mathbf{0}$ & 0 & 741 \\
\hline $\begin{array}{l}\text { Postsurvey } \\
\text { observation }\end{array}$ & 31 & 37 & 241 & 274 & 120 & 19 & 4 & $\mathbf{0}$ & $\mathbf{0}$ & $\mathbf{0}$ & $\mathbf{0}$ & $\mathbf{0}$ & 726 \\
\hline TOTAL & 132 & 247 & 888 & 1,077 & 423 & 72 & 12 & 1 & 0 & 0 & 0 & 0 & 2,852 \\
\hline
\end{tabular}


FIGURE 3-7

SPEEDERS VS. NONSPEEDERS

SITE II (ANN ARBOR-SALINE ROAD), A.M.

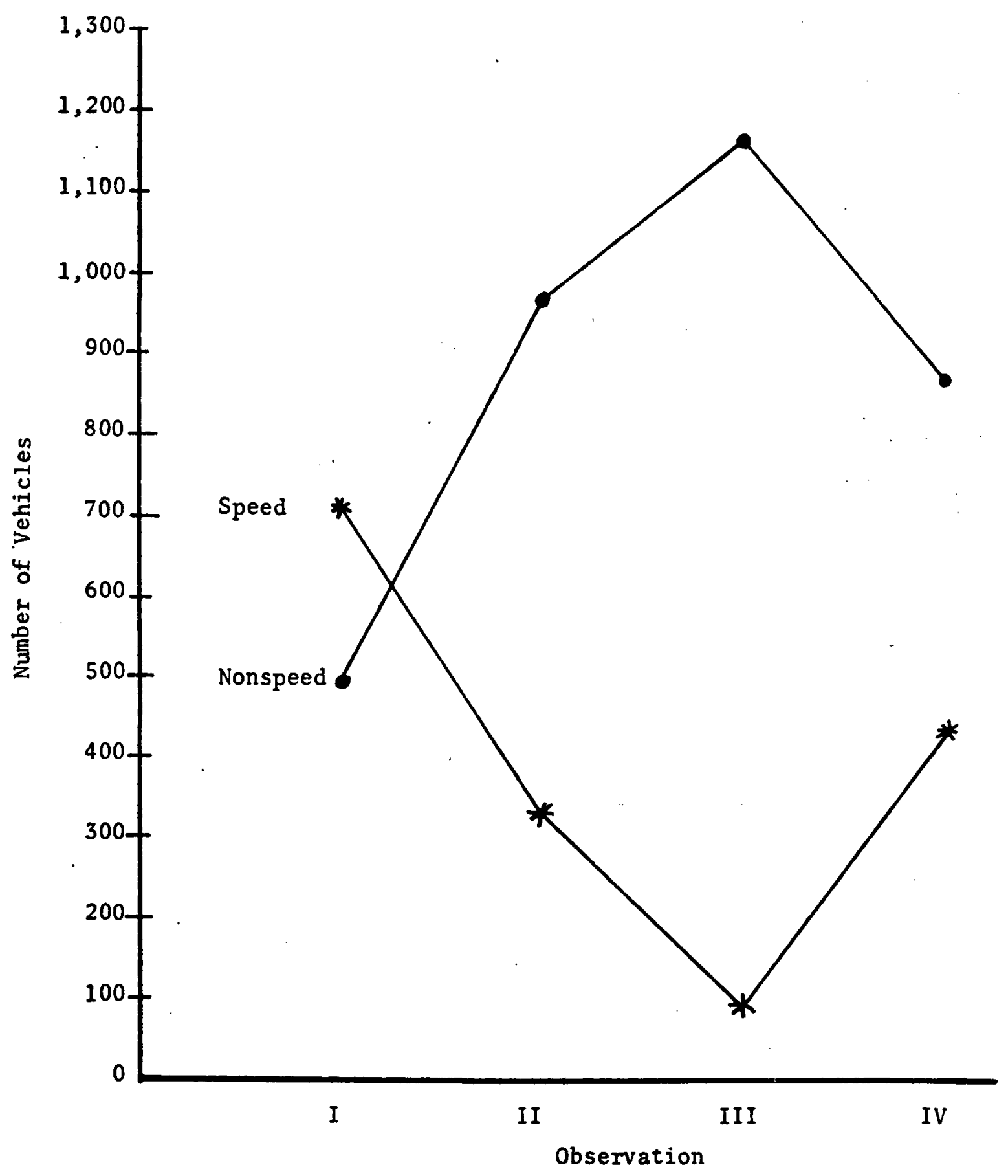


TABLE $5-4$

SITE II (ANN ARBOR-SALINE ROAD), A.M.

\begin{tabular}{|c|c|c|c|c|c|c|c|c|c|c|c|c|c|}
\hline \multirow{2}{*}{ ACTIVITY } & \multicolumn{12}{|c|}{ SPEED CATEGORY (mph) } & \multirow{2}{*}{ TOTAL } \\
\hline & $1-30$ & $31-35$ & $36-40$ & $41-45$ & $46-50$ & $51-55$ & $56-60$ & $61-65$ & $66-70$ & $71-75$ & $76-80$ & $81+$ & \\
\hline $\begin{array}{l}\text { Presurvey } \\
\text { Observation I }\end{array}$ & 19 & 24 & 20 & 112 & $\mathbf{3 2 0}$ & 498 & 170 & 33 & 9 & 1 & 1 & 1 & 1,208 \\
\hline $\begin{array}{l}\text { Presurvey } \\
\text { observation II }\end{array}$ & 31 & 13 & 64 & 308 & 551 & 278 & 43 & 8 & 1 & 1 & $\mathbf{0}$ & $\mathbf{0}$ & 1,298 \\
\hline $\begin{array}{l}\text { Roadside } \\
\text { Survey }\end{array}$ & 48 & 63 & 237 & 488 & 378 & 87 & 6 & 3 & 1 & $\mathbf{0}$ & $\mathbf{0}$ & 0 & 1,311 \\
\hline $\begin{array}{c}\text { Postsurvey } \\
\text { Observation }\end{array}$ & 32 & 13 & 45 & 217 & 562 & 359 & 65 & 10 & 1 & 1 & 1 & 2 & 1,308 \\
\hline TOTAL & 130 & 113 & 366 & 1,125 & 1,811 & 1,222 & 284 & 54 & 12 & 3 & 2 & 3 & 5,125 \\
\hline
\end{tabular}


TABLE 3-5

SITE II (ANN ARBOR-SALINE ROAD), P.M.

\begin{tabular}{|c|c|c|c|c|c|c|c|c|c|c|c|c|c|}
\hline \multirow{2}{*}{ ACTIVITY } & \multicolumn{12}{|c|}{ SPEED CATEGORY (mph) } & \multirow{2}{*}{ TOTAL } \\
\hline & $1-30$ & $31-35$ & $36-40$ & $41-45$ & $46-50$ & $51-55$ & $56-60$ & $61-65$ & $66-70$ & $71-75$ & $76-80$ & $80+$ & \\
\hline $\begin{array}{l}\text { Presurvey } \\
\text { observation I }\end{array}$ & 14 & 6 & 37 & 150 & 397 & 363 & 90 & 10 & 1 & 1 & 1 & $\mathbf{0}$ & 1,070 \\
\hline $\begin{array}{l}\text { Presurvey } \\
\text { observation II }\end{array}$ & 14 & 19 & 39 & 161 & 369 & 305 & 90 & 15 & 1 & $\mathbf{0}$ & 1 & $\mathbf{0}$ & $1,014^{\circ}$ \\
\hline $\begin{array}{l}\text { Roadside } \\
\text { Survey }\end{array}$ & 23 & 25 & 87 & 279 & 417 & 193 & 28 & 4 & 2 & $\mathbf{0}$ & $\mathbf{0}$ & $\mathbf{0}$ & 1,058 \\
\hline $\begin{array}{r}\text { Postsurvey } \\
\text { observation }\end{array}$ & 16 & 22 & 61 & 151 & 388 & 367 & 101 & 10 & 3 & $\mathbf{0}$ & $\mathbf{0}$ & $\mathbf{0}$ & 1,119 \\
\hline 'IO'TAL & 67 & 72 & 224 & 741 & 1,571 & 1,228 & 309 & 39 & 7 & 1 & 2 & 0 & 4,261 \\
\hline
\end{tabular}


FIGURE 3-8

SPEEDERS VS. NONSPEEDERS

SITE II (ANN ARBOR-SALINE ROAD), P.M.

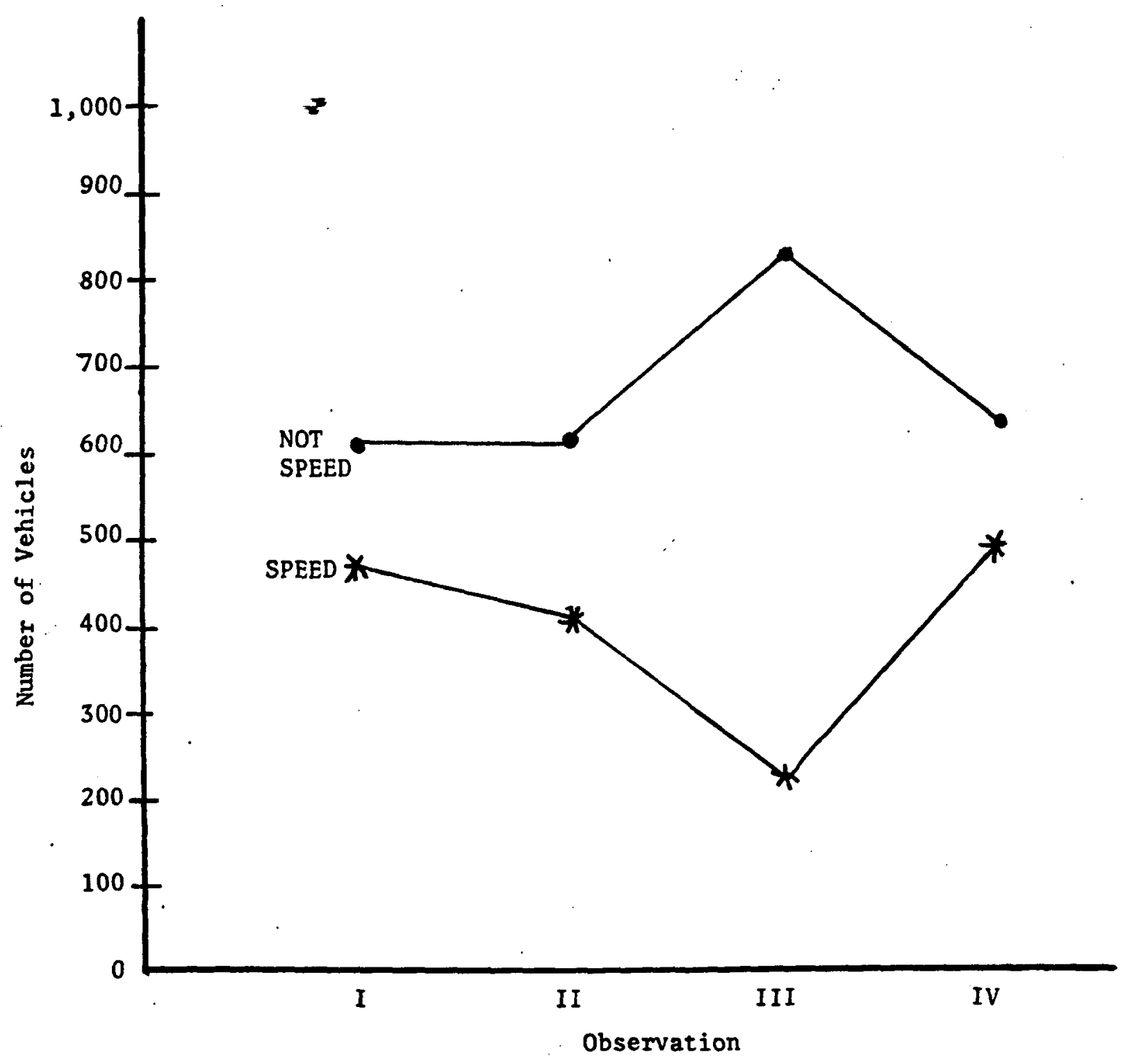


in Figure 3-9.

These results indicate that the obtrusiveness of the roadside activity does appear to affect traveling speeds. Generally, greater activity was accompanied by decrease in the number of vehicles traveling in the higher speed categories; that is, speeds were seen to decline more in the presence of both the survey team and the observer than with the observer alone; traveling speeds also appeared to be lower when the observer was present than when only the traffic measuring equipment was present. Anecdotal accounts by HSRI staff support this conclusion. On one occasion, a staff member driving by a site during a roadside survey noted that drivers were applying their brakes before going over the road tubes. Another staff member reported that drivers in oncoming traffic would flash their lights to motorists approaching the survey site in an apparent attempt to warn them about the survey activity.

Further, there were several reports about the roadside survey activity broadcast over the $\mathrm{CB}$ radio. One driver described the observer vehicle as a "radar car" and the sheriff's vehicle at the survey site as the "catch car." All broadcasts occurred during the roadside surveys. No reports about the observer vehicle or the traffic measuring equipment were heard during Presurvey II. It is possible that drivers' suspicions were not raised to the point of broadcasting a $C B$ report until the sheriff's vehicle and other pretest activity were seen.

One factor that may have contributed to the obtrusiveness of the roadside activities was the color of the observer vehicle. Different vehicles were being used for the Presurvey II and the roadside survey sessions depending upon the vehicles available from The University of Michigan Transportation Services on the day of each activity (Chevrolet Citations were used in all instances with one exception; on that occasion, a Plymouth Volare was used). The possible effects of observer vehicle color were first pointed out by a sheriff's deputy who noted that the white vehicles looked more like a police vehicle from a distance than did the nonwhite vehicles. At least in one instance, the traffic data seemed to support this observation. During the evening hours at site I the percentage of drivers exceeding the speed limit during Presurvey II (when a 
FIGURE 3-9

SPEEDERS VS. NONSPEEDERS

ALL SITES

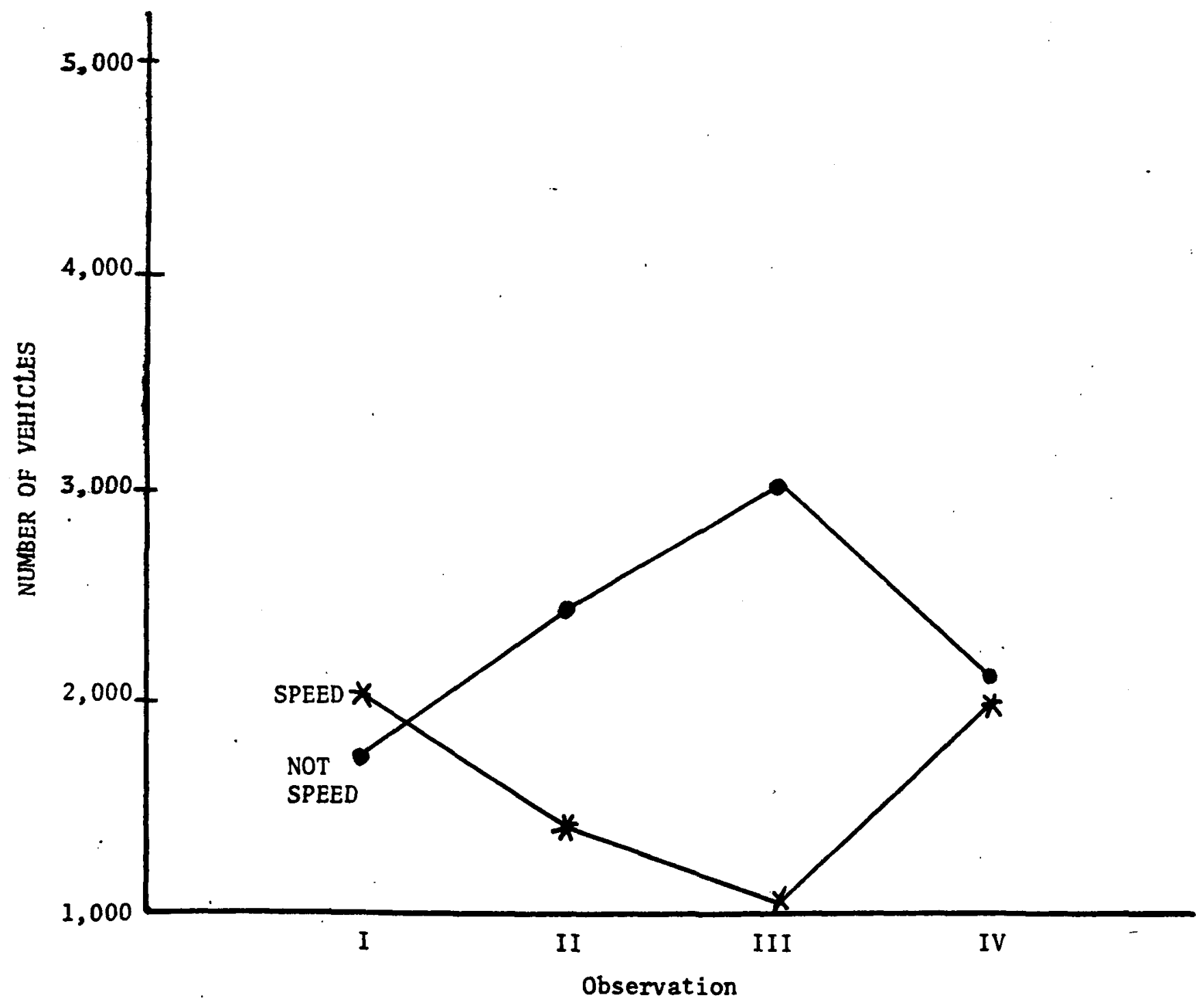


white vehicle was used) was lower than during the roadside survey for the same site and time (see Table 3-3).

Weather and road conditions did not vary greatly throughout the speed pilot-test activity. Most days were clear to cloudy with dry roads. There was one day of patchy fog at Site II. This occurred during the morning hours for Pretest I and did not appear to influence traffic speeds greatly (see Table 3-4). Fog occurred curing all three morning observation sessions at Site I. The fog was heaviest for Pretest II. Rainy conditions occurred once, also at Site $I$ during the first hour of the morning roadside survey. It is possible that such conditions may have contributed to the lower traveling speeds at Site I for these two activities.

3.2.3 Driver Participation. Interviewers made a judgment at the time of the survey stop of the driver's willingness to answer the driver information questions. In addition, the circumstances under which a driver refused to participate were noted. Over all four fields tests, twenty-six percent of the speeders stopped for the survey were judged to have accepted readily. Interviewers indicated that another fifty-five percent of the speeders accepted, but needed some encouragement (such as the offer of the "excuse" letter). Nineteen percent of the speeders refused to participate. Of this nineteen percent, thirteen percent refused the interviewer's request to participate, and six percent refused the police officer at the time they were stopped.

Nonspeeders tended to agree to be interviewed more readily. Over all four field tests, fifty-seven percent of the nonspeeders were judged by the interviewers to have accepted readily. Twenty-five percent of the nonspeeders refused to participate.

The overall acceptance rate was approximately the same for speeders and nonspeeders ( $81 \%$ for speeders versus $75 \%$ for nonspeeders). The difference in the two driver categories lies in the judgments about driver's willingness to accept. Nonspeeders appeared much more willing to agree to be interviewed as opposed to speeders who needed more encouragement to participate. Table 3-6 presents the number and percentage of drivers in each field test who accepted and refused the request to participate in the 
TABLE $\quad 3-6$

DRIVER PARTICIPATION IN THE PILOT TESTS

\begin{tabular}{|c|c|c|c|c|c|c|c|c|c|c|c|c|c|c|c|c|}
\hline \multirow{3}{*}{$\begin{array}{l}\text { ROADSIDE } \\
\text { PILOT } \\
\text { TEST NO. }\end{array}$} & \multicolumn{8}{|c|}{ SPEEDERS } & \multicolumn{8}{|c|}{ NONSPEEDERS } \\
\hline & \multicolumn{2}{|c|}{$\begin{array}{l}\text { Accepted } \\
\text { Readily }\end{array}$} & \multicolumn{2}{|c|}{$\begin{array}{c}\text { Accepted } \\
\text { Reluctant } 1 \text { y }\end{array}$} & \multicolumn{2}{|c|}{$\begin{array}{l}\text { Refused } \\
\text { Officer }\end{array}$} & \multicolumn{2}{|c|}{$\begin{array}{c}\text { Refused } \\
\text { Interviewer }\end{array}$} & \multicolumn{2}{|c|}{$\begin{array}{l}\text { Accepted } \\
\text { Readi iy }\end{array}$} & \multicolumn{2}{|c|}{$\begin{array}{c}\text { Accepted } \\
\text { Reluctantly }\end{array}$} & \multicolumn{2}{|c|}{$\begin{array}{l}\text { Refused } \\
\text { Officer }\end{array}$} & \multicolumn{2}{|c|}{$\begin{array}{c}\text { Refused } \\
\text { Interviewe }\end{array}$} \\
\hline & number & 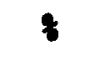 & number & 8 & number & $q$ & number & $q$ & number & 8 & number & 8 & number & 8 & number & $\%$ \\
\hline 1 & 2 & 25 & 4 & 50 & $-0-$ & $-0-$ & 2 & 25 & 5 & 75 & 1 & 14 & 1 & 14 & -0 & -0 \\
\hline 12 & 1 & 14 & 5 & 72 & $-0-$ & -0 & 1 & 14 & 3 & 43 & 2 & 28 & $-0-$ & $-0-$ & 2 & 28 \\
\hline 13 & 1 & 12 & 5 & 63 & 2 & 25 & $-0-$ & $-0-$ & 3 & 50 & 1 & 17 & $-0-$ & $-0-$ & 2 & 33 \\
\hline$\$ 4$ & 4 & 50 & 3 & 73 & $-0-$ & $-0-$ & 1 & $\cdot 13$ & 5 & 63 & 1 & 12 & $-0-$ & $-0-$ & 2 & 25 \\
\hline TOTAL & 8 & 26 & 17 & 55 & 2 & 6 & 4 & 13 & 16 & 57 & 5 & 18 & 1 & 4 & 6 & 21 \\
\hline
\end{tabular}


driver interviews.

Before conducting the field test activity approaches for increasing the likelihood of driver participation had been developed from both the roadside survey literature and practice sessions with the project team. One of these dealt with drivers' reluctance to leave their vehicles. In such instances, interviewers would suggest conducting the interview at carside. This approach was used four times during the speed pilot tests. Although interviews were able to be conducted at carside, the quality of the information obtained does not appear as high as that obtained in the RV. Drivers were less likely to elaborate on their answers during the carside interviews, very often limiting themselves to a simple "yes" or "no" response.

A second approach was to provide drivers with evidence that they had been detained for the purposes of a roadside survey. This took the form of a letter signed by the interviewers that explained the survey and indicated the time of the survey stop. The letter also provided a telephone number to call if anyorie wished to verify the stop (see Appendix A). This letter was found to be useful, particularly in cases where drivers indicated that they might be late for work. No telephone calls were received about the survey.

3.2.4 Drivers' Responses to the Interview Questions. The driver information questions were administered over four field tests. An initial set of questions was developed based on the literature review before any field activity was conducted. After each field test, the questions were modified based on the responses from the previous field test. This section presents the results of the information given by respondents during the field tests. It is divided into four parts:

- interview length

- demographic information

- general driving information

- driver responses about speeding UDA

One purpose of the pilot tests was to determine the feasibility of developing a questionnaire that could elicit driver responses for committing 
a particular UDA. Therefore, the driver data are presented in terms of two questions: (1) Could drivers give responses? and (2) What kinds of responses were given? For the most part, the data are presented as an aggregate of all four field tests. Where individual field test results are of particular interest, the data for each field test is presented separately.

3.2.4.1 Interview Length. For every driver who agreed to answer the driver interview questions, the interviewers recorded the time that the interview began and ended. From this, the length of each interview was determined. During pilot test \#1, the average interview length was 11.4 minutes. This decreased to 10.6 minutes in pilot test $\$ 2$ and decreased further to 9.9 and 10.2 minutes in pilot tests \#3 and \#4. The decrease in time resulted from modifications in the set of questions and increased interviewer familiarity with the survey instrument. Table 3-7 summarizes these results, including the range of interview times as well as the modal interview time length.

\subsubsection{Demographic Information. Demographic information was} obtained during the field tests. Items observable to the interviewers (e.g.; driver sex, ethnicity) were obtained for all drivers stopped for the survey. Demographic information that needed to be obtained by direct question was asked only of drivers who agreed to be interviewed. As mentioned earlier, one purpose of the field tests was to develop a questionnaire for use in a full-scale study. Thus, the actual responses drivers gave to the demographic questions were not as important to pilot test objectives as the determination of whether drivers were willing or able to give responses at all. Therefore, the actual results of the demographic information obtained from drivers in the field tests are not presented here (i.e., $x$ males and $y$ females were surveyed or $z$ was the average income level of survey respondents). Instead, the demographic information is discussed in terms of the ease with which the interviewers were able to obtain responses to the demographic information sought.

With respect to the observer demographic information, there were few problems with obtaining the data. Driver sex could of course be 
TABLE 3-7

INTERVIEW TIME LENGTH

\begin{tabular}{|c|ccc|}
\hline \multirow{2}{*}{$\begin{array}{c}\text { PILOT } \\
\text { TEST NO. }\end{array}$} & $\begin{array}{c}\text { MNTERVIEW TIME LENGTH } \\
\text { (Mins.) }\end{array}$ & $\begin{array}{c}\text { Mode } \\
\text { (Mins.) }\end{array}$ & $\begin{array}{c}\text { Range } \\
\text { (Mins.) }\end{array}$ \\
\cline { 2 - 4 } \#1. & 11.4 & 12 & $8-15$ \\
$\# 2$ & 10.6 & $10,11,12$ & $8-12$ \\
$\# 3$ & 9.9 & 10 & $7-13$ \\
$\# 4$ & 10.2 & 8,10 & $7-19$ \\
\hline
\end{tabular}


determined, even when the drivers refused the police officer rather than the interviewers. The interviewers generally had no problem making a judgment about driver ethnicity.

For the most part, drivers were willing and able to give responses to the demographic information that was obtained by direct questioning. All drivers gave the year they were born, with the exception of one respondent who apparently misunderstood the question and reported birthplace instead of the year. Other questions, such as occupation, marital status, place of residence, and educational level posed no problems to the respondents. The only question that some drivers were hesitant to answer was household income level. A total of seven respondents chose not to answer that question; a few voluntarily indicated that they simply did not know.

3.2.4.3 General Driver Information. General information about drivers was obtained during the four field tests. Information that could be observed (e.g., the use of occupant restraints; number of passengers) was recorded for all drivers stopped for the survey. As with the demographic information, the actual responses drivers gave to the driver information questions were not as important to Phase I objectives as the determination of whether drivers were willing and able to answer such questions. Therefore, just as with the demographic information, the actual responses are not presented here (e.g., drivers drove an average of $x$ miles per year; $y$ percent of drivers wore occupant restraints). Instead, the general driver characteristics are discussed in terms of drivers' ability or willingness to provide the general driver information sought.

Interviewers had few problems obtaining observable information. If drivers came into the survey site and were approached by the interviewers, there was no difficulty in determining the number of passengers in the vehicle or driver's use of occupant restraints. Difficulties did arise when the driver refused the police officer's request to pull into the survey site. Interviewers were usually not able to determine whether these drivers were wearing occupant restraints and occasionally had difficulty determining the number of passengers, if any, in the vehicle. This was particularly true if 
there were any infants or young children as passengers.

There was generally no difficulty in obtaining information on driver characteristics during the interviews. Drivers were able to give information about exposure (that is, vehicle miles traveled). Drivers had no problem giving the number of days driven per week. Some drivers found it difficult to estimate the number of miles they drove per year, although there appeared to be less hesitancy in answering this question when it appeared on the background questions handed to drivers than when it was presented orally by the interviewers. Five drivers indicated that they had no idea and refused to make an estimate.

Drivers also gave information about their experience in driving and their familiarity with the vehicle they were driving as well as the road on which they were stopped for the survey. All drivers were able to relate the number of years they had been driving, although some admitted to making estimates. Similarly, all drivers were able to make estimates of the number of times they had driven on the road on which the field tests were run. Drivers also had no problem relating how long they had been driving the vehicle that they were using at the time they were stopped for the field test.

Drivers had no problem giving information about the origin of their trip on the day of the survey or their destination. Drivers were also willing to give an account of the number of speed violations they had been cited for. No driver indicated that such information was too personal to answer.

Most drivers were able to report a speed limit of the road on which they were stopped for the field tests. Two roads were used during this activity. On the $40 \mathrm{mph}$ road, seventy-four percent of the drivers knew the correct limit; twenty-two percent of the drivers thought the limit was higher, between 40 and $50 \mathrm{mph}$. Only four percent of the drivers were unsure of that limit. On the $50 \mathrm{mph}$ road, sixty-six percent of the drivers knew the correct limit, while twenty-two percent thought they knew the limit but gave incorrect answers. Twelve percent of the drivers were unsure of the correct speed limit. Table 3-8 presents the percentage of drivers' responses to speed limit on each road. 
TABLE 3-8

DRIVERS PERCEPTIONS OF SPEED

LIMITS ON PHASE I ROADS

\begin{tabular}{|l|cc|}
\hline \begin{tabular}{|} 
DRIVER \\
SPEED \\
ESTIMATES
\end{tabular} & $\begin{array}{c}\text { Rite One } \\
\text { (40 mph Limit })\end{array}$ & $\begin{array}{c}\text { Site Two } \\
(50 \text { mph Limit })\end{array}$ \\
\cline { 2 - 3 } $40 \mathrm{mph}$. \\
$45 \mathrm{mph}$ \\
$50 \mathrm{mph}$ \\
$55 \mathrm{mph}$
\end{tabular}


Similarly, almost all drivers responded to questions about their driving speed before being stopped, although few drivers reported a speed that matched their observed speed. Generally, drivers estimated their speed within five $\mathrm{mph}$ of the observed speed. An interesting observation was that speeders tended to underestimate their speed while nonspeeders tended to overestimate their speed. Eighty percent of the speeders estimated their speeds at the time they were stopped for the field test lower than the observed speed; only eight percent estimated higher than their observed speed, and twelve percent gave speeds that matched exactly with the observed speed. Eighty-nine percent of the nonspeeders estimated their speed at greater than the observed speed; eleven percent estimated their speed at less than the observed speed. No nonspeeder's response matched the observed speed exactly.

During the field tests, interviewers obtained general information about the vehicles which drivers were operating, as well as information about the drivers themselves. All drivers were able to give the model year of the vehicle they were driving at the time they were stopped for the survey. Drivers were also able to relate the owner of the vehicle. Most vehicles were owned by the participants.

3.2.4.4 Drivers' Responses to Speed UDA. Most of the information sought during the field tests focused upon drivers' responses to the commission of UDAs. Since the purpose of the field test was to develop an instrument that could elicit driver reasons for committing UDAs, the responses themselves were just as important as whether drivers could give responses at all. Approximately twenty-four percent of the drivers interviewed stated that their driving speeds were different on the day of the pilot test than the last time they drove on that particular road. Of these, eighty-two percent noted their speeds were faster on the day of the test. The majority of these drivers indicated the possibility of being late as underlying the faster driving speed (e.g., "behind schedule," "in a hurry," "slow dresser"). A few drivers indicated that there was less traffic on the road the day of the test than the last time they drove on it; this allowed them to drive at a faster speed. The remaining drivers stated that they 
were driving at a slower speed on the day of the test. Reasons given included driving a different vehicle and looking for the "unusual" on the road (e.g., a friend of a driver had spotted a deer on one road the previous day).

Drivers responses to the probes concerning possible reasons for committing or refraining from committing the relative-speed-too-fast UDA fell into three categories:

- responses associated with the driver

- responses associated with the vehicle

- responses associated with the roadway

These categories provide a convenient framework for presenting the responses below.

3.2.4.4.1 Responses Associated with the Driver. Most responses concerning commission of the speed UDA were associated with characteristics of the drivers themselves. These reponses are presented below.

Fear of Bnforcement. Twenty-two percent of the drivers interviewed cited fear of getting caught as a reason for not driving over or "too much" over the speed limit. Drivers generally allowed 10 to $15 \mathrm{mph}$ above the posted limit as a maximum driving speed. Most drivers had no suggestions on how to keep people from speeding. Those who did mentioned more police officers at "hot spots," more speeding tickets, more radar, more license suspensions, the use of dummy police cars, and higher fines.

state of Mind. Many drivers responded that their driving speed would be affected by emotional or mood characteristics that may be described as "state of mind" responses. Thirty-seven percent responded that being late or in a hurry would affect their driving speed; all indicated that they would go faster under these circumstances. Drivers indicated that the potential negative consequences of being late were the primary reason they would go faster under the circumstances. Some drivers mentioned such consequences as reprimand at work, being fired, embarrassment, or 
missing an appointment or meeting. Drivers who responded that being late had no effect on their driving speed fell into two categories: some said they were never late because they always leave enough time to get where they are going; others noted that the conseguences of being late were not great enough for them to consider changing their driving speed.

Most drivers indicated that their driving speed would change depending upon their mood. Forty-eight percent of the drivers indicated that there were moods that would cause them to go faster than their normal speed. Seven drivers indicated that if they were upset, nervous, or depressed about something they would go faster. Some of these drivers also mentioned the circumstances that might make them upset or nervous, such as a fight with someone or a family problem.

Four drivers noted that if they were angry they would go faster. A common reason given by these drivers for getting angry was "a bad time at work." Three drivers indicated that they might go faster if they were happy or "wound up" about something, such as getting paid. Three drivers also mentioned that if they were preoccupied about something it might cause them to forget about the speed at which they were driving.

Twenty-four percent of the drivers also indicated that their mood could cause them to drive slower. Four drivers indicated that if they were preoccupied with something it would cause them to go slower. Similarly, two drivers indicated that if they were daydreaming they might go slower. Two drivers also mentioned that if they were depressed they would go slower, as did two drivers who indicated that they would go slower if they were relaxed. One driver mentioned that if he had a "didn't care" attitude he was likely to go slower than his normal speed.

Some drivers reported that being tired would affect their oriving speed. Seventeen percent indicated that this would cause them to go slower than usual. They cited impaired vision and slower reflexes as reasons for deciding to go slower. Two percent 
indicated they would go faster if they were tired. One resporitent explained that he would go faster if he was in a hurry to get home and get to bed. A small percentage of drivers (4\%) reported that they do not drive when they think they are "too tired."

Use of Aleohol and Other Drugs. Thirty percent of all drivers interviewed reported that the use of alcohol or drugs affected their driving speed. Most indicated that this would cause them to go slower. Reasons that drivers gave for decreasing their driving speed were fear of getting caught and fear of having an accident. A few drivers indicated they might go faster after drinking, because the alcohol increases their confidence in their ability to drive fast. .

Twenty-eight percent of all drivers interviewed indicated that they did not drink at all, while thirteen percent indicated that they did not drink and drive. The remaining drivers indicated that the use of alcohol or other drugs did not affect their driving speed.

Presence of Passengers. Thirty-two percent of all drivers interviewed indicated that the presence of passengers in the car would have an effect on their driving speed. Twenty-eight percent indicated that the presence of passengers would lead them to go slower. Many of these drivers cited children and spouse (a wife in particular) as being the primary passengers who would affect their speed. Other passengers mentioned included parents, older people, new passengers, and, to some drivers, any passenger at all. The reasons drivers gave for slowing down with passengers in the car dealt primarily with a feeling of care toward the passengers, although some drivers gave reasons that pertained to the dynamies between driver and passenger. One person indicated that she slowed down to impress passengers with her concern for driving safely.

Four percent of all drivers reported that they might increase their speed with passengers in the car. They cited friends, and in one instance a husband, as the passenger who would cause them to increase their speed. The reasons these drivers gave centered around having fun and trying to impress friends. The woman whose husband made her go faster reported that he made her nervous, 
which caused her to increase her speed, an interpersonal dynamic kind of response.

Distractions. Few people indicated that distractions affected their speed. Only four percent of all drivers interviewed indicated that distractions made a difference. All of these responses indicated that conversation often proved to be the distraction. Drivers indicated that it was the lack of attention placed on the driving task due to the conversation that affected their driving speed. Drivers were split as to whether their driving speed increased or decreased with such distraction.

3.2.4.4.2 Responses Associated with the Vehicle. Drivers also reported effects on driving speed associated with the vehicle they were driving.

Vehicle Type. Many drivers reported that the type of vehicle they drive affects their driving speed. Forty-two percent of all drivers interviewed indicated that they would drive slower in a vehicle other than the one they usually drive. The two most commonly mentioned types of vehicles were smaller cars and trucks. Other respondents mentioned bigger cars and campers. Their reasons primarily had to do with the low acceleration, vehicle noise, and vibration associated with some types of vehicles. Similarly, some drivers mentioned that they would go slower if the vehicle was not capable of going as fast as they normally drove. Other drivers indicated they were likely to go slower in different types of vehicles because they were not familiar with the vehicle. In the case of a larger size vehicle, respondents indicated that its size made it difficult for them to know where they were on the road.

Seventeen percent of all drivers interviewed said they were likely to go faster in a different type of vehicle. Sports cars, motorcycles, and bigger cars were the most often mentioned types of vehicles. Common reasons given by drivers included "more fun to go faster"; "easier to go fast"; and "a manual transmission causes me to go faster."

Vehicle Condition. A few drivers cited the condition of the 
vehicle as having an influence on their driving speed. Twenty-two percent of all drivers reported that they were likely to go slower in a vehicle that was not in good condition. They cited the lack of safety with faster speeds in such a vehicle as the primary reason for going slower. Two percent of the drivers reported that they would go faster in a vehicle in bad condition. The reasons for going faster were related to a sense of not caring what happened to the car.

Vehicle Ownership. A number of drivers reported that they would change their driving speed in a car that did not belong to them. Forty-one percent indicated that they would go slower under these circumstances. Vehicles might belong to friends, parents, inlaws, children, or rental firms. The reasons that drivers gave for going slower centered around two areas-responsibility toward other's possessions, and unfamiliarity with a new vehicle. One driver responded that when he drives a rental vehicle he goes slower not so much because he is unfamiliar with the vehicle, but because he is usually unfamiliar with the area in which he is driving the vehicle.

Seven percent of all drivers reported that they would drive faster in a vehicle that did not belong to them. These responses were primarily from drivers who borrowed friends' cars that could go faster than their own. One driver reported that because he is an automotive engineer, he often drives company cars fast to see how they perform.

3.2.4.4.3 Responses Associated with the Roadway. Many drivers reported some influence on their driving speed due to the characteristics of the roadway on which they were driving. All of these reasons centered around concems about safety and the likelihood of having an accident.

Road Locality. Twenty-eight percent of all drivers interviewed cited the location of the roadway on which they were traveling as having an influence on their speed. Those drivers who mentioned road locality indicated locations that would cause them to go slower. Roads that went through residential areas were the most commonly 
mentioned locations, because of the problem of cars pulling out of side streets. Other locations mentioned were school zones and areas having a lot of pedestrian traffic.

Roadway Characteristics. Thirty-nine percent of all drivers indicated that characteristics of the roadway influenced their driving speeds. They indicated that hilly roads or roads with curves were conditions that led to a reduction in their speed. A small proportion of drivers (2\%) mentioned that they would probably go faster on a flat, wide open stretch of road.

Roadway Conditions. Many drivers reported that specific road conditions had an effect on their driving speed. Fifty-nine percent of the drivers indicated that road conditions caused them to go slower. The most commonly mentioned condition was caused by weather, such as ice, snow, or rain. Drivers also mentioned decreased visibility caused by fog or darkness. The presence of slowly moving traffic was also mentioned often by drivers as a road condition that caused them to slow down. The presence of chuckholes or other defects in the roadway were also noted.

A small number of drivers (4\%) reported road conditions that led them to go faster. All of these drivers cited the absence of traffic as the primary reason for increasing their speed.

\subsubsection{Utility of Driver Responses for Countermeasure Development.} The responses drivers gave to each of the questions were analyzed to determine if those responses would be amenable to countermeasure development. It is important to note that the purpose of Phase I was only to determine if feasible countermeasures could be developed from driver responses-not actually to develop those countermeasures. Thus, this section discusses whether feasible countermeasures were suggested by the responses and proposes a few possible countermeasures as illustrations.

Generally, the responses that drivers gave were amenable to the development of feasible countermeasures. Drivers were consistent across a number of topic areas, and several patterns of responses can be identified. These include: fear of enforcement, responsibility, temporary state of 
driver, interpersonal dynamics, safety, and comfort. In several instances, countermeasures were considered not feasible, because of safety, legt, or cost considerations. However, several possible strategies suggested by the driver responses include Public Information and Education (PI\&E) programs, sanctioning schemes, road design, and vehicle equipment or driver aids.

A few examples of feasible countermeasures may be cited. A large percentage of drivers (41\%) reported that they would drive more slowly in somebody else's car. These responses suggest a public information countermeasure program designed to get drivers to drive their own cars as if they were driving someone else's. A similar campaign is suggested by drivers' responses to driving slower with passengers in the car (28\%), particularly children.

Almost one-quarter of the respondents (22\%) cited fear of enforcement as a reason why they would not exceed the speed limit. This response suggests obvious enforcement countermeasures. Some respondents even suggested enforcement tactics that were effective deterrents to them, such as more police in "hot spots" and greater police visibility. A large percentage (39\%) of drivers also reported tliat roadway characteristics have an influence on their driving speed. They indicated that curved or hilly roads caused them to slow down and wide open "straight aways" were roads that they were likely to speed on. A possible countermeasure might be for roads to be built with the effect of these characteristics in mind, allowing of course, for the increased safety risk posed by roadway characteristics.

Finally, a large percentage of drivers reported that their moods affected their driving speed. People who drive faster when they are angry, depressed, or nervous may benefit from an education campaign that would sensitize them to the effect their mood has on their driving speed. Similarly, drivers who are Identified as chronic speeders because of the effect of their moods might benefit from psychological counselling as part of a sanctioning program aimed at resolving the emotional problem. However, court and department of motor vehicles (DMV) sanctioning schemes, such as counseling or education programs, need to be carefully structured to avoid being considered invalid probation conditions or cruel 
and unusual punishment.

\subsection{General Survey Procedures}

During the course of the survey pretests, numerous methods of improving survey procedures were identified. A discussion of how survey procedures could be modified to increase the effectiveness of survey operations is presented here. It begins with suggested improvements in survey site procedures. These are followed by a discussion of methods to increase the effective use of the traffic control deputy and the observer.

An important consideration in the selection of a survey site should be the amount of ingoing and outgoing, nonsurvey traffic. One of the speed sites, at various times, had high levels of nonsurvey traffic going through the site. This created some traffic congestion problems (though relatively minor). Such a site should be avoided in the future if possible. Also, if survey operations are conducted in periods of darkness, a floodlamp should be installed on the outside of the survey vehicle. At one of the survey locations, lighting was poor. During the early morning hours of darkness, the lack of light appeared to intimidate several drivers pulling over for the survey.

The determination of survey team responsibilities (i.e., interviewer versus recorder) was modified to increase efficiency during the survey pretests. The most workable method was developed as follows. Before the survey began, the two members of the survey team decided by a coin toss who would be the interviewer and who would be the recorder for the first interview. From there the roles were alternated throughout the survey. Because both UDA-committing and UDA-noncommitting drivers were interviewed, each team member interviewed two drivers (one of each) before changing roles.

Finally, with respect to survey site procedures, two unusual situations arose that might have been avoided with some advance planning. During the course of one of the survey pretests, a respondent's car would not start after he completed the interview. The respondent was present at the survey site for two hours working on his car while the survey was in progress. At least two subsequent drivers who pulled over for the survey: 
were distracted by the prior respondent's presence at the survey site. The availability of emergency equipment such as jumper cables and simple tools should be considered in future surveys. Of potentially greater significance was an event that occurred after the survey pretests. After the final survey pretest, one of the members of the survey crew developed an illness that was preliminarily diagnosed as German measles. The contagious period of the illness was tracked, and it was determined that the staff member was contagious during the fourth survey pretest. Because of the potential danger to pregnant women who have been exposed to someone with German measles, the Washtenaw County Health Department was contacted for advice. The staff member underwent tests to confirm whether she did, in fact, have German measles, and during that time, names of all survey participants who may have come in contact with her were compiled. The tests failed to confirm that she had contracted German measles, so all further steps to contact the survey participants were dropped. The situation might have been avoided had the survey team members made sure that they were immunized against common communicable diseases before the survey began. Aliirough it is impossible to assure that survey staff will not contract any illness that may be communicated to survey participants, it is reasonable to require that all common immunizations be brought up to date before survey staff come in contact with the public.

The procedures used by the traffic control deputies underwent some important modifications during the survey pretests. During the first three survey pretests, the police vehicle was parked perpendicular to the road and pulled out to block the road to stop traffic. The deputies found great difficulty in doing this, particularly if they were trying to stop a vehicle within a pack of other vehicles. On numerous occasions, deputies were unable to stop. the appropriate vehicle and the observer had to be notified to look for another one. A different procedure was tested during Survey IV. The police vehicle parked parallel to the road at the side. When a vehicle was identified for stopping, the officer turned on his overhead flashers and waved the traffic through until the appropriate vehicle arrived. The officer waved the subject driver into the survey site. This 
procedure worked much more efficiently and is recommended for future activities.

In a related issue, police found it difficult to identify the appropriate vehicles for the survey because of visibility problems caused by overhanging trees at one of the survey sites. Future survey sites should be selected with this consideration in mind, although the new method of stopping vehicles described above minimized the problem. Also, during the course of the survey pretests it became apparent that the police vehicle should be located upstream from the survey vehicle. In some instances, cars stopped for the survey had to make difficult turns into the survey site because they had been stopped at the survey site entrance rather than just before it. 


\subsection{FOLLOWING TOO CLOSE (PTC)}

The following-too-closely (FTC) UDA is defined as follows:

The act of driving a vehicle following another vehicle such that the time separation between the two vehicles is so short as to create a societally unacceptable of crash risk. (Treat et al. 1980:9)

Vehicles are traveling in the same lane of traffic and at about the same speed. With this behavior, separations of from one to two seconds' stopping time create an unacceptably high risk.

The FTC UDA is a member of the family of the following behaviors. In addition to the FTC UDA, the following are other types of following behaviors:

- Following - Delayed Response Induces Conflict is defined as one vehicle following another vehicle at an acceptable time separation, but a delay in response to the lead vehicle braking causes a collision with the lead vehicle or a collision is avoided only through sudden severe avoidance action.

- Closing-Delayed Response Induces Conflict, with Both Vehicles Initially Moving occurs when both vehicles are moving in the same lane and direction but the following vehicle is traveling significantly faster than the lead vehicle. The UDA occurs "when the following driver is so delayed in deceleration and/or steering response that collision with the lead vehicle cannot be avoided or is avoided only through sudden severe avoidance action."

- Closing-Delayed Response Induces Conflict with Lead Vehicle Initially stopped occurs "when one vehicle approaches another which is stopped in its lane and headed in the same general direction and is so delayed in deceleration and/or steering response, that collision with the lead vehicle either cannot be avoided or is avoided only through sudden severe avoidance action" (Treat et al. 1980:10).

Only the following-too-closely UDA was addressed in the pilot-test activity. The basis for its selection was its relatively objective and simple method of observation and measurement.

Research suggests that the FTC UDA tends to occur primarily when traffic volume is high and there is little opportunity to pass. Thus, 
observations were further limited to two-lane rural locations with high traffic volumes; such locations are relatively uncomplicated (in contrast, for example, to an urban freeway) and provide reduced opportunity for following vehicles to pass.

\subsection{Design}

The general survey procedures described in Section 2.0 were used during the test of the FTC UDA. Observation procedures specific to the FTC UDA were also used. These are described below.

4.1.1 Site Selection. Two sites were identified within Washtenaw County which met the survey requirements. After conducting a series of preliminary observations, project staff determined that the same sites used for the speeding UDA could also be used for the FTC UDA. These two sites are described in detail in Section 3.1.1. The same survey and observer configurations were used for both UDAs.

4.1.2 Schedule of Survey Times. Three survey sessions were conducted for the FTC UDA. The times and location of each pilot test were as follows:

- Pilot Test I Ann Arbor-Saline Road

Monday, October 19, 1981

7:30 a.m. to $4: 30$ p.m.

- Pilot Test II Ann Arbor-Saline Road

Wednesday, October 21, 1981

7:30 a.m. to $4: 30$ p.m.

- Pilot Test III Geddes Road

Friday, October 23, 1981

7:30 a.m. to 4:30 p.m.

These times were selected on the basis of traffic volume, site availability, and interviewer availability. 
4.1.3 Selection of Drivers for the Survey. Both drivers committing the FTC UDA and those not committing the UDA were selected for the survey. Identification of each type of driver was made by observation of vehicle gaps. This procedure is discussed more fully below.

4.1.4 Traffic Observations. For the survey, judgments about the occurrence of this UDA were made by measuring drivers' following distance with a stopwatch. A following distance of 1.5 seconds or less was considered unsafe. A distance of greater than 1.5 seconds was considered safe. Observations were made by an observer sitting in a vehicle parked by the side of the road at the observation site. The observer was instructed to identify a reference point directly across the road from the point where he or she was seated. The observer started the stopwatch when the rear bumper of the first vehicle reached the reference point and the stopwatch was stopped when the front bumper of the following vehicle reached the point. The resultant time was used to classify the driver as a violator or nonviolator.

We recognize that the use of stopwatches is not as precise a method ss the use of tapeswitches or other time-distance measuring devices. However, given the preliminary nature of this pilot test, it was determined that the extra expense of more accurate time-distance measurement methods was not warranted.

\subsection{Results}

Analysis of the FTC UDA data addressed three issues: (1) drivers' willingness to participate in the survey; (2) drivers' ability to respond to the interview questions; and (3) the utility of the drivers' responses for use in countermeasure development. These are discussed below.

4.2.1 Driver Participation. In the three PTC pilot tests, seventy-two percent of the drivers stopped agreed to participate in the survey. Of these drivers, fifty-seven percent were judged to have accepted readily, while fifteen percent were determined to have needed encouragement to participate in the study. The remaining twenty-eight percent of the 
drivers declined to participate. All of these drivers refused the request of the interviewer.

There was a variety of weather conditions in these tests. During one session the weather alternated between clear and cloudy, there was rain during another session, and there were periods of snow during the other survey session. A higher percentage of drivers refused to participate in the survey during inclement weather conditions than during good weather conditions. Forty-one percent of the drivers who were stopped while it was raining refused to participate, and forty percent stopped during the periods of snow refused. Conversely, twenty-seven percent of the drivers stopped while the weather was sunny and twenty-two percent of the drivers stopped while it was cloudy refused to participate. The data do not show that drivers who did participate during adverse weather conditions did so any more reluctantly.

Nonviolators tended to agree to be interviewed only slightly more readily. During the tests, forty-eight percent of those drivers accepting readily were violators, while fifty-two percent were nonviolators. Similarly, fifty-four percent of the drivers who needed encouragement were violators, while forty-six percent were nonviolators. Of the drivers that refused, the split between violators and nonviolators was also even. Fiftyfour percent of those drivers refusing to participate were violators, while forty-six percent were nonviolators. Table 4-1 presents the number and percentage of drivers who accepted and refused the request to participate in the tests.

Ninety-seven percent of the drivers agreed to be interviewed inside the interview van. The remaining drivers requested that the interview be conducted at carside.

\subsubsection{Driver's Responses to Interview Questions. The driver} information questions were administered over all three pilot-test sessions. Four different sets of questions were used during these sessions. This section presents the results of the information given by respondents during the tests. It is divided into four parts:

- interview length 
TABLE 4-1

DRIVER PARTICIPATION IN FTC PILOT TESTS

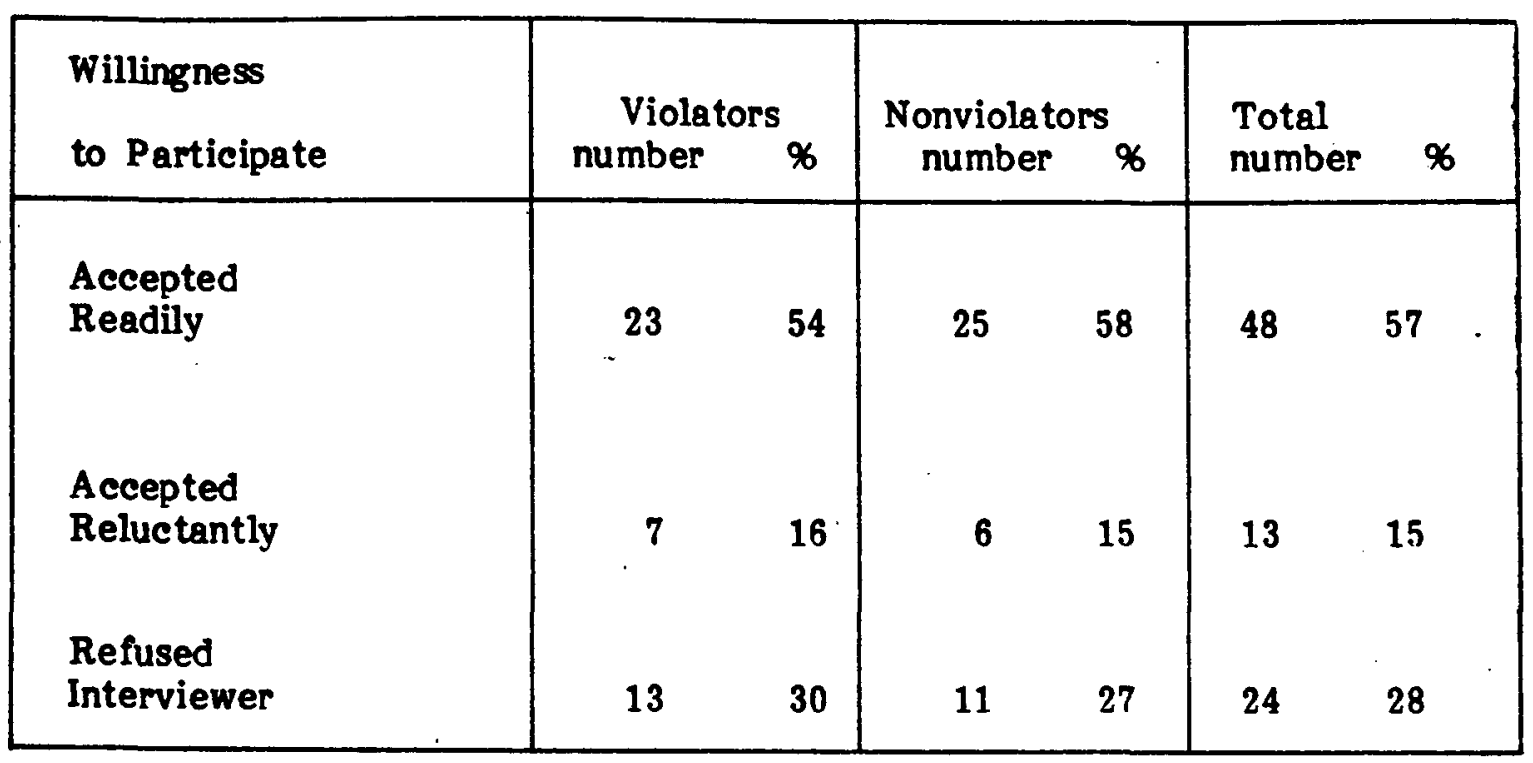

Note: Numbers are summed over all three pilot test conditions. 
- demographic information

- general driving information

- driver responses about the FTC UDA

The drivers responses are presented in terms of two questions: (1) Would drivers respond to the interview questions? and (2) What kinds of responses were given? For the most part, data are presented as an aggregate of all three survey sessions.

4.2.2.1 Interview Length. For all four sets of questions, interview times ranged from 3 to 19 minutes with an average interview time of 9.11 minutes. For the first set of interview questions, the average interview length was 10.7 minutes. This decreased to 10.4 minutes for the second set and then decreased further to 6.9 and 7.3 minutes for question sets three and four. The decrease in time appeared to result primarily from increasing interviewer familiarity over time with the interview procedure. The longest interview lengths (i.e., 18 and 19 minutes) were attributed to drivers' talkativeness or difficulty in understanding the questions. Table 42 presents information about interview length for all four sets of interview questions.

4.2.2.2 Demographic Information. Demographic information was also obtained during the PTC survey sessions. Items of information that could be obtained by observation were obtained for all drivers stopped for the survey. Demographic information that needed to be obtained by direct question was asked of drivers who agreed to be interviewed for three of the question sets. (The fourth question set requested attitudinal information rather than demographic information.)

Interviewers experienced little problem obtaining the observable data, and, for the most part, drivers were willing and able to give responses to the direct questions. All drivers were able to indicate their birth year, occupation, and residence. All but one oriver was able or willing to indicate his or her marital status and educational background. Four drivers were unwilling to give an indication of their income level when asked. 
TABLE 4-2

INTERVIEW TIME LENGTH FTC UDA

\begin{tabular}{|c|ccc|}
\hline \multirow{2}{*}{$\begin{array}{c}\text { Question } \\
\text { Set }\end{array}$} & \multicolumn{3}{|c|}{ INTERVIEW TIME LENGTH } \\
\cline { 2 - 4 } & $\begin{array}{c}\text { Mean } \\
\text { (Mins.) }\end{array}$ & $\begin{array}{c}\text { Mode } \\
\text { (Mins.) }\end{array}$ & $\begin{array}{c}\text { Range } \\
\text { (Mins.) }\end{array}$ \\
\hline$\# 1$ & 10.7 & 10 & $7-19$ \\
$\# 3$ & 10.4 & 10 & $6-18$ \\
$\# 4$ & 6.9 & 6 & $4-18$ \\
& 7.3 & 7 & $3-13$ \\
\hline
\end{tabular}


4.2.2.3 General Driver Information. General information about drivers was also obtained during the FTC survey activities. General driver information included such areas as exposure, driving experience, origin and destination information, and vehicle familiarity.

There was generally little difficulty in obtaining information on driver characteristics during the interviews. Generally, drivers had little trouble giving information about their driving exposure. Nineteen drivers, however, were unable to give the number of miles they drive per year.

Information about driving experience and vehicle and roadway famillarity was also obtained. All drivers were able to estimate the number of years they had been driving. Almost all drivers were able to relate the number of times they had driven on the study road in the last month, although some drivers who drove the road frequently had difficulty making estimates. Drivers had little difficulty indicating the length of time they had been driving the vehicle they were driving on the day of the field test.

All drivers asked were able to indicate both the origin and destination of their trip. Drivers were also geilerally willing to indicate the number of times they had been ticketed for following too closely. Only three percent of the drivers were unable to answer this question, and in both instances it was because they could not remember. Six percent of the drivers indicated that they had been previously ticketed for FTC.

Drivers were asked about their perception of their own driving on one set of questions. These drivers were asked to rate how safe a driver they considered themselves to be on a scale of 1 (very unsafe) to 6 (very 8afe). Drivers were willing to make this judgment about their driving. All drivers rated themselves as safe drivers with sixty-two percent giving themselves a 5 rating. Twenty-five percent gave themselves a 6 rating (the highest rating), and thirteen percent declared themselves as 4's. The reasons that drivers gave for rating themselves as safe drivers included confidence in their ability to drive safely, driving experience, and lack of accidents. 
One set of questions also assessed drivers' attitudes toward driving. Drivers who were asked this set of questions were presented with ten statements on driving and road safety. They were asked to indicate their agreement with each statement on a scale from 1 (strongly disagree) to 5 (strongly agree).

There were some differences between nonviolators and violators suggested by the mean ratings of each category. Violators tended to agree more strongly with risk-taking attitudes. Violators also tended to believe less strongly in traffic regulations and to be more interested in having the driver develop his or her own set of driving rules. Compared with violators, nonviolators tended to be less fatalistic about their chances of having an accident. Nonviolators also regarded other drivers as being more careful than did violators. Table 4-3 presents summary data on the attitude item responses.

4.2.2.4 Drivers' Responses Specific to the FTC UDA. Drivers were asked to identify the type of vehicle that they were following immediately before they were stopped. Seventy-one percent of the drivers quesied identified a kind of vehicle. Twenty-nine percent of the respondents reported that they either could not remember the type of vehicle they were following or did not think that they were following a vehicle at all.

Drivers who indicated they were following a vehicle were also asked to estimate the distance at which they were following. They were shown a scale drawing of the highway they had just traveled and were asked to indicate in inches how far they were behind the vehicle in front of them. The inches on the scale were then translated into feet to represent the drivers' estimated following distance. A majority of the drivers asked were able to use the scale to estimate their following distance. Many drivers, however, had trouble understanding the use of the scale and were unable to give responses in inches. Some drivers simply gave estimates of actual following distance in feet or feet and inches, and several respondents estimated following distance in car lengths. All drivers who perceived that they were following a vehicle, however, were able to give some estimate of their following distance, even though it was in different 
TABLE 4-3

ATTITUDINAL RESPONSES*

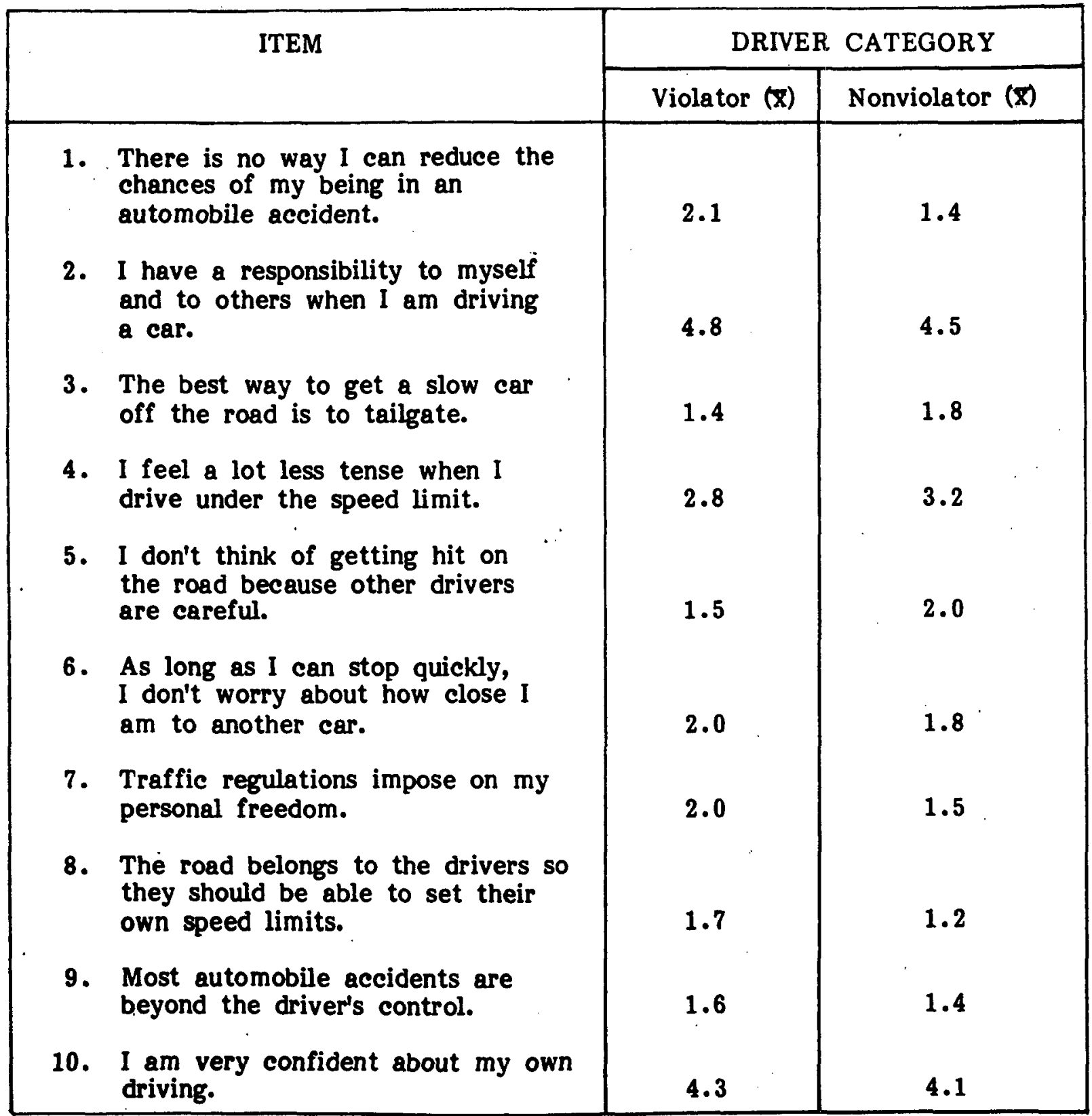

* Respondents were asked to express agreement with each statement on a scale from one (strongly disagree) to five (strongly agree). Numbers are means of responses. 
units than requested by the interviewers.

Drivers were also asked whether their following distances were different on the day they were stopped from other days they traveled the road they were driving when stopped for the field test. Approximately forty-five percent of the drivers indicated that their following distance was different. of these, seventy-three percent of the drivers indicated that their following distance was closer that day than on other days, and twentyseven percent reported that their following distance was greater that day.

of the drivers who followed closer on the day of the field test, fortyseven percent reported that the reason they were following closer was because traffic was heavier, while thirty-two percent indicated that they were late or in a hurry. Sixteen percent of the drivers reported that the driver in front of them was going too slow.

Drivers who were following at a greater distance than usual on the day they were stopped for the field test indicated a variety of reasons for the change in their behavior. Twenty-nine percent of the drivers reported that traffic was lighter, fourteen percent indicated that weather conditions made them more cautious in their following distance, and fourteen percent indicated that road construction caused them to follow cars at a larger distance. Interestingly, a large number of these drivers cited two of the same reasons that drivers who followed more closely cited. Twenty-nine percent reported that a slow driver ahead made them follow at a greater distance, and fourteen percent indicated that heavy traffic made them allow more following distance.

Drivers were also queried in general about a number of other factors that affected their following distance. Forty-five percent of the drivers indicated that they would change their following distance when other people were in the car. Almost all of these drivers indicated that they would allow more distance, although seven percent of the drivers reported that the presence of other people would probably cause them to follow more closely. Of those drivers who reported that they would allow greater following distance with passengers, the most common types of passengers mentioned included children, parents, other relatives, acquaintances, and spouses. The most common reason given for maintaining a larger following 
distance in these circumstances was for safety (63\% of the drivers reported this reason), but other reasons included personal dynamics, wanting to make a good impression, and distractions.

The drivers who reported that they were likely to follow more closely with other people in the car all indicated that this would be the case if they had friends in the car with them. They all reported that the presence of friends would cause them to be distracted and thus follow too closely.

When drivers were queried about the effect that their mood or state of mind would have on their following distance, ninety-four percent of the drivers reported that some type of moods would probably have the effect of inducing them to follow either more or less closely. Seventy-eight percent of the drivers who reported that moods affected their following distance reported that being late or in a hurry had this effect. All of these drivers reported that it would make them follow more closely. Sixty-six percent of drivers indicated that being angry would affect their following distance. Of these, eighty-three percent reported that it would make them follow more clcely, while seventeen percent reported that it would cause them to allow greater distance.

Other moods reported as generally causing drivers to follow more closely included nervousness and being upset. Drivers reported that being happy, relaxed, sad, tired, under the influence of alcohol, or tired generally caused them to follow less closely. Drivers were split as to the effect of preoccupation or daydreaming on their following distance. Approximately half indicated that it would cause them to follow more closely, and half indicated that it would probably cause them to allow more distance.

Drivers were asked about the effect of distractions on their following behavior. Thirty-nine percent of the drivers indicated that talking with others had an effect. Drivers were split as to whether this caused them to follow more or less closely. Sixty percent of these drivers reported that it would cause them to follow less closely, while forty percent indicated that it would cause them to follow more closely. Only twelve percent of drivers indicated that a radio playing had an effect in their following distance. These drivers were split evenly as to whether it could 
cause them to follow more or less closely.

Drivers were also asked about other reasons why they would change their following distances. Drivers gave a number of reasons why their following distance would increase. Thirty-one percent of the drivers reported that weather conditions had that effect. A number of drivers reported that factors associated with the roadway caused them to. follow less closely. Fifteen percent of drivers reported that road conditions such as construction had that effect, and four percent of drivers described the presence of numerous driveways or access roads as making them more careful about their following distance. Four percent of the drivers also reported that their following distance would increase if they knew the road was patrolled heavily by police. Four percent of the drivers also indicated that the physical condition of their car was a consideration in following at a larger distance, and two percent reported that driving a different car had that effect.

A number of drivers cited other reasons why they might follow more closely. Twenty-five percent of the drivers reported that they would follow more closely in heavy traffic, and four percent indicated that their following distance would be closer if there was inadequate opportunity to pass the vehicle in front of them.

\subsubsection{Utility of Driver Responses for Countermeasure Development.} The primary reasons identified for following more closely were the presence of heavy traffic with inadequate opportunity to pass slower traffic and being late or in a hurry while driving.

With respect to heavy traffic and lack of passing opportunities, where leasible, a reasonable countermeasure may be to increase the number of lanes or opportunities to pass so that slow-moving traffic does not impede faster traffic. Countermeasures to address the driver who follows too closely because he or she is late or in a hurry are less feasible, but one such countermeasure might be a public information campaign to try to induce drivers to allow more time in traveling to their destinations.

It was interesting that very few drivers identified the perceived presence of police enforcement as having an effect on their following 
behavior. Thus, it appears that the threat of enforcement would not be a substantial deterrent to the behavior. It is likely that the reason that enforcement does not appear to be a major countermeasure is that drivers do not perceive following too closely as a traffic violation. Very few tickets are written by police for following too closely, and if they are written, they are almost always issued to the following driver in a rearend collision. However, a possible countermeasure that is suggested by drivers' ignorance of following too closely behavior as an unsafe driving action is to make drivers more aware of safe following distances. This could be accomplished through a public information campaign.

The presence of side roads with incoming traffic and residential areas with the perception of children evoke in many drivers the need to allow more distance in following. Where feasible and where they would not run the risk of being counterproductive, these factors may be worthwhile as considerations in placement and design of roadways.

\subsection{General Survey Procedures}

The survey prosedures used in the FTC UDA pilot test generally went smoothly, and there do not appear to be any major changes necessary in a larger scale survey. Drivers had difficulty using the inches scale to determine their following distance. Often they attempted to estimate the actual following distance in feet or car lengths without using the scale. Consideration should be given to developing a more workable scale during a full-scale study. The use of films or videotape of following distance or a scale model of a roadway with the placement of scale vehicles might be useful alternatives. 


\subsection{RUNNING A STOP SIGN (RSS)}

The running-a-stop-sign (RSS) UDA along with its companion UDA, running-a-traffic-light (RTL), are defined as follows:

The RSS or RTL UDA occurs whenever a vehicle enters an intersection on the red phase of an applicable steady red signal alone, except in making a turn on red; or, in the presence of an applicable stop sign or flashing red stop signal, or before making a turn on red, enters the intersection without first substantially stopping within an appropriate range, such that the driver could have adequately checked for oncoming traffic, and could have stopped or yielded as necessary. A vehicle is considered to have "entered" an intersection whenever it penetrates a plane rising vertically from the edge of the intersecting traffic lane nearest the leg controlled by the signal violated. (Treat et al. 1980)

Research suggests that the RSS/RTL UDA is more likely to occur at times and intersections where there is little traffic and the driver is able to see that no traffic is present, thus judging that there is no compelling reason to stop (Treat $\in$ ê al. 1980).

Only the running-a-stop-sign UDA was addressed in the pilot test activity. Observations made by project staff suggested that it occurred more frequently than the RTL UDA. Survey locations appropriate for the field test were also more readily available.

\subsection{Design}

The general survey procedures described in Section 2.0 were used during the RSS UDA. In addition, procedures specific to the RSS UDA were used. These are described below.

5.1.1 Site Selection. Two survey locations were identified within Washtenaw County which met project requirements.

Site I-Climate Equipment supply, Ine. parking lot

This location is at the corner of Maple Road and Winewood Avenue just at the western boundary of the city of Ann Arbor. There is a four-way stop at the corner of Maple and Liberty Roads, approximately 0.2 miles south of the survey site. All vehicles turning north onto Maple Road from Liberty Road or proceeding north on Maple Road through the intersection were candidates for 
the survey.

The survey site was on the east side of Maple Road, allowing the northbound traffic to be surveyed. The site was a dirt parking area at the back of the building. There was very little business-related traffic coming into and out of the site. The site had a convenient entry/exit configuration and was large enough to accommodate survey traffic easily.

The observer site was located in a convenience store parking lot at the comer of Maple and Liberty Roads. The observer had an unobstructed view of all four legs of the intersection.

\section{Site II-Gravel Turnout on Clark Road East of Holmes Road}

This location is on Clark Road in Ypsilanti Township. There is a stop sign on Holmes Road at the intersection of Holmes and Clark Roads, approximately 200 yards west of the survey site. All vehicles turning east from Holmes Road onto Clark Road were candidates for the survey.

The survey site was a gravel area off the road shoulder. The area is bounded by a large vacant lot. The survey site and the vacant lots are owned by Ypsilanti Township. There was no traffic into and out of the gravel area. The site had sufficient room for the survey vehicle, the police vehicle, and survey participants' vehicles.

The observer site was located at the end of a residential street running parallel to Clark Road and dead ending at the corner of Holmes and Clark Roads. The observer had a clear and unobstructed view of traffic approaching the stop sign at Holmes Road.

5.1.2 Schedule of Survey Times. Four pilot-test activities were conducted for the RSS UDA. The times and locations of each activity were as follows:

- Pilot Test I

- Pilot Test II

Pilot Test II
- Pilot Test III
- Pilot Test IV

N. Maple Road

Sunday, October 25, 1981

$8: 30$ Q.m. to $5: 30$ p.m.

Clark Road

Monday, October 26, 1981

7:30 a.m. to $4: 30$ p.m.

Clark Road

Wednesday, October 28, 1981

7:30 a.m. to $4: 30$ p.m.

Clark Road

Friday, October 30, 1981

7:30 a.m. to $4: 30$ p.m. 
These times were selected on the basis of traffic volume, site availability, and interviewer availability.

5.1.3 Selection of Drivers for the Survey. Both drivers committing the RSS UDA and those not committing the UDA were selected for the survey. Identification of each type of driver was made by observation of whether drivers came to a stop at the intersection. This procedure is discussed more fully below.

5.1.4 Traffic Observation. As stated above, the RSS UDA occurs when a driver fails to stop at an intersection controlled in the driver's direction of travel by a stop sign. Determination of whether the RSS UDA is committed is a result of two subjectively measured criteria--whether a vehicle stopped at the stop sign and where the vehicle stopped. Observers in the pilot-test activity made judgments as to whether all candidate vehicles satisfied these two criteria. The methods they used to make these :idgments are described below.

Treat et al. (1980) have tentatively defined stopping as slowing to 2 mph or less. They note the difficulty in an observer making judgments of this kind. Instrumentation, such as radar and tapeswitches, is either of uncertain accuracy or not feasible because of considerations of obtrusiveness, portability, and expense. For these reasons, the pilot study project staff used a technique often used by police officers to determine if vehicles have substantially stopped at a stop sign. This technique involves the observation of the air valve stem. If drivers' tire rotation slows to the point that the observer can see an air valve stem on one of the driver's tires, then the driver was determined to have substantially stopped. Observers used this method during the course of the pilot-test activity to identify drivers for the pilot test.

Observers also differentiated between two types of stop sign violations, although both types were considered candidates for the pilot test. After identifying the violators, the observer would note whether the driver had slowed and made a significant attempt to stop (called a "roll-through") or whether the driver simply drove through the stop sign with little or no 
apparent attempt to stop (called a "run").

With regard to the criteria of where a vehicle stops, Treat and associates point out that if a vehicle stops so far back from the sign that there is not a clear view of cross traffic, the reason for stopping (i.e., to make sure there is no cross traffic) is negated. They suggest two criteria to use to determine whether a vehicle has stopped within an appropriate range of the stop sign. If there is a designated pedestrian crosswalk or vehicle limit line, the vehicle would have to be within twenty feet of the edge of the crosswalk or stop line closest to the vehicle. In the alternative, the vehicle would have to stop within thirty feet upstream of the nearest edge of the intersecting traffic lane closest to the vehicle being observed. Treat et al. also point out that these limits are based on considerations of vision of oncoming traffic and thus apply to typical intersections. If unusual obstructions limit vision at any intersection, these limits would need to be changed. For field test activity, only typical intersections were selected. Observers were instructed to locate a point upstream of each stop sign that satisfied the requirements mentioned above. Observers considered a vehicle to have stopped only if it did so within the specified distance limits.

\subsection{Results}

Analysis of the RSS UDA data addressed three issues: (1) drivers' willingness to participate in the survey; (2) drivers' ability to respond to the interview questions; and (3) the utility of the drivers' responses for use in countermeasure development. These are discussed below.

5.2.1 Driver Participation. Over all of the four field test sessions for the RSS UDA, sixty-seven percent of the drivers stopped agreed to participate. Of these drivers, eighty percent were judged to have accepted readily, while twenty percent were determined to have needed encouragement to participate in the study. The remaining thirtythree percent of the drivers declined to participate. Of these drivers, ninety-two percent refused the interviewers after pulling into the survey; site, and eight percent refused the officer on the roadway without entering 
the survey site.

The weather during the RSS field test sessions did not vary a great deal. All of the field tests were conducted in either clear or cloudy weather. The acceptance and refusal rates varied only slightly. Approximately fifty percent of the drivers who were stopped during clear weather agreed to participate readily, fifteen percent agreed to participate reluctantly, and thirty-five percent refused to participate. Similarly, fiftyseven percent of the drivers stopped on the cloudy days agreed to participate readily, eleven percent agreed to participate with encouragement, and thirty-two percent refused to participate. It does not appear that weather conditions had an effect on participation.

There was a noticeable difference in the willingness to participate between drivers who ran the stop sign (violators) and those who did not (nonviolators). Nonviolators tended ta agree more readily to participate. Sixty-three percent of the nonviolators agreed to participate readily, while only forty-six percent of the violators were judged to have readily agreed. Fifteen percent of the nonviolators agreed to participate after some encouragement, while only twelve percent of the violators agreed after encouragement. Thus, seventy-eight percent of the nonviolators agreed to participate either readily or with encouragement compared to fifty-eight percent of the violators.

A comparison of those who refused yields similar results. Twenty-two percent of the nonviolators refused to participate while forty-two percent of the violators did not agree to participate. Interestingly, three of the drivers who communicated their refusal to participate to the police officer without pulling into the survey site were violators. Table 5-1 presents the number and percentage of drivers who accepted and refused the request to participate in the field test.

Ninety percent of the drivers agreed to be interviewed inside the interview van. The remaining drivers requested that the interview be conducted at their car. 
TABLE 5-1

DRIVER PARTICIPATION *

\begin{tabular}{|l|cc|cc|cc|}
\hline $\begin{array}{l}\text { Willingness } \\
\text { to Participate }\end{array}$ & \multicolumn{2}{|c|}{ Violators } & \multicolumn{2}{|c|}{ Nonviolators } & \multicolumn{2}{|c|}{ Total } \\
number & $\%$ & number & $\%$ & number & $\%$ \\
\hline $\begin{array}{l}\text { Accepted } \\
\text { Readily }\end{array}$ & 27 & 46 & 30 & 63 & 57 & 54 \\
$\begin{array}{l}\text { Accepted } \\
\text { Reluctantly }\end{array}$ & 7 & 12 & 7 & 15 & 14 & 13 \\
$\begin{array}{l}\text { Refused officer } \\
\text { Refused } \\
\text { Interviewer }\end{array}$ & 3 & 5 & 0 & 0 & 3 & 3 \\
\hline
\end{tabular}

- Numbers are summed over all four field test conditions. 
5.2.2 Drivers' Responses to Interview Questions. Driver information questions were administered over all four field test sessions. Four different sets of questions were used during these sessions. This section presents the results of the information given by respondents during the field tests. It is divided into four parts:

- interview length

- demographic information

- general driving information

- driver responses about the RSS UDA

The driver responses are presented in terms of two questions: (1) Could drivers respond to the interview questions? and (2) What kinds of responses were given? For the most part, data are presented as an aggregate of all four survey sessions.

5.2.2.1 Interview Length. For all four sets of questions, interview times ranged from 3 minutes to 20 minutes with an average interview time of 8.23 minutes. For the first set of interview questions the average interview length was $9.2 \mathrm{r}$.nutes. This decreased slightly to 9.1 minutes for the second set and then decreased further to 7.8 and 6.6 minutes for question sets three and four. The decrease in time probably resulted primarily from increasing interviewer familiarity over time with the interview procedure. The longest interview lengths (i.e., over 16 minutes) were primarily a result of drivers being unusually talkative or having difficulty understanding questions without explanation. Table 5-2 presents information about interview length for all four sets of interview questions.

5.2.2.2 Demographic Information. Demographic information was also obtained during the RSS field test sessions. Items of information that could be obtained by observation were obtained for all drivers stopped for the survey. Demographic information that needed to be obtained by direct question was asked of drivers who agreed to be interviewed for three of the question sets. (The fourth question set requested attitudinal information rather than demographic information.)

Interviewers experienced little problem obtaining the observable data 
TABLE 5-2

INTERVIEW TIME LENGTH RSS UDA

\begin{tabular}{|c|ccc|}
\hline \multirow{2}{*}{$\begin{array}{c}\text { Question } \\
\text { Set }\end{array}$} & \multicolumn{3}{|l|}{ INTERVIEW TIME LENGTH } \\
\cline { 2 - 4 } & $\begin{array}{l}\text { Mean } \\
\text { (Mins.) }\end{array}$ & $\begin{array}{l}\text { Mode } \\
\text { (Mins.) }\end{array}$ & $\begin{array}{c}\text { Range } \\
\text { (Mins.) }\end{array}$ \\
\hline 1 & 9.2 & 9 & $6-16$ \\
$\# 2$ & 9.1 & 9 & $5-20$ \\
$\# 3$ & 7.8 & 7 & $4-16$ \\
$\# 4$ & 6.6 & 6 & $3-12$ \\
\hline
\end{tabular}


and, for the most part, drivers were willing and able to give responses to the direct questions. All drivers were able to indicate their birth year and residence. All but one driver were able or willing to indicate marital status. Drivers were either less willing or less able to indicate their educational background and their household income. Twenty-five percent of the drivers did not indicate their educational background, and thirty-five percent did not indicate their household income level when asked.

5.2.2.3 General Driver Information. General information about drivers was also obtained during the RSS field test activities. General driver information included measures of driver exposure (number of miles driven), driving experience, origin and destination information, and vehicle familiarity.

There was generally little difficulty in obtaining the general driver information during the interviews. Drivers had some trouble indicating measures of exposure. Thirty-two percent of the drivers had trouble estimating the number of miles they drive per year.

Information about driving expurience and vehicle and roadway familiarity was also obtained. All but one of the drivers were able to report the number of years they had been driving and all drivers were able to indicate the number of times they had driven the survey roadway in the last month. Those drivers who had driven the road often seemed to experience some difficulty in making estimates, but all were willing to make one. Nine percent of the drivers had difficulty indicating how long they had been driving the vehicle they were using on the day of the field test.

All drivers were able to indicate both the origin and destination of their trip. Drivers were also willing to indicate the number of times they had been ticketed for going through a stop sign. Eight percent of the drivers indicated that they had been ticketed for running a stop sign within the last five years.

Drivers were asked about their perception of their own driving in one set of questions. These drivers were asked to rate how safe a driver they considered themselves to be on a scale of 1 (very unsafe) to 6 (very safe). 
Drivers were willing to make this judgment about their driving. All drivers rated themselves as safe drivers (i.e., ratings of 4 or above) with seventy-two percent giving themselves a 5 rating. Eleven percent gave themselves a 6 rating (the highest rating) and seventeen percent declared themselves to be 4's. The reasons that drivers gave for rating themselves as safe drivers included confidence in their ability to drive defensively, driving experience, and lack of tickets or accidents.

One set of questions also assessed drivers' attitudes toward driving. Drivers who were asked this set of questions were presented with ten statements on driving and road safety. They were then asked to indicate their agreement with each statement on a scale from 1 (strongly disagree) to 5 (strongly agree). Although all drivers responded to the statements, many found the wording difficult and confusing and had trouble using the scale. There did appear to be some differences in the mean ratings given between violators and nonviolators. Nonviolators were unanimous in their strong agreement that they were responsible for their actions while driving. While violators also indicated a strong agreement, it was not unanimous. Nonviolators also tended to believe that there was less they could do to prevent accidents. Nonviolators also indicated that they were slightly more confident about their driving skills and generally felt less tense when they drove. The average item responses of the violators and the nonviolators are presented in Table 5-3.

\subsubsection{Drivers' Responses Specific to the RSS UDA. Drivers were} asked to indicate how they drove through the field test intersection. They were asked to determine whether they had stopped for the stop sign, rolled through, or run the stop sign without stopping. Ninety-seven percent of the drivers were able to describe how they drove through the intersection. Of these drivers eighty-one percent reported that they stopped, and nineteen percent indicated that they rolled through the stop sign. No drivers reported that they went through the stop sign without attempting to stop. Comparing the drivers' perceptions of their stopping activity to the observer's judgment of how the vehicles approached the intersection reveals that drivers who went through the stop sign minimized their failure 
TABLE 5-3

ATTITUDINAL RESPONSES

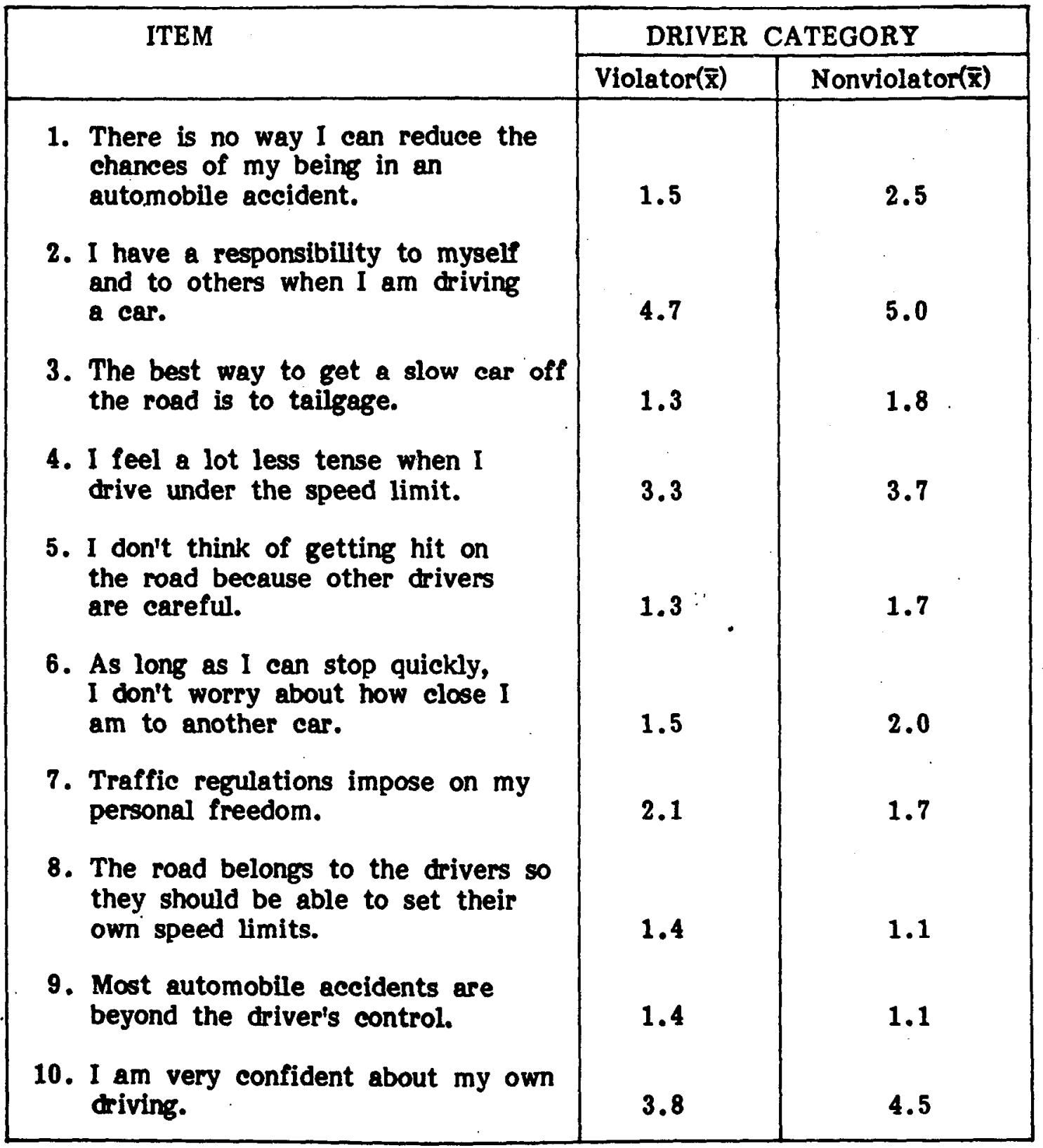

- Respondents were asked to express agreement with each statement on a scale from one (strongly disagree) to five (strongly agree). Numbers are means of responses. 
to stop. The observers reported that fifty-two percent of the vehicles made substantial stops; thirty-four percent of the vehicles rolled through; and fourteen percent of the drivers were judged to have not attempted to stop. Thus, drivers who made no attempt to stop tended either not to admit to it or to perceive their behavior as rolling through the stop sign.

Drivers were also asked whether their stopping behavior was different on the day of the field test than at other times. Only seventeen percent of the drivers indicated that their behavior was different that day. Of these drivers, fifty-eight percent reported that they did not come to as complete a stop as they usually did, and forty-two percent indicated that they stopped more completely on the day of the field test.

Of the drivers who reported that they did not stop as completely as they usually did, seventy-one percent eited the light traffic as a reason. Other reasons cited by drivers were being late or in a hurry, daydreaming, and being able to see that the intersection was clear.

Forty percent of the drivers who stopped more completely reported that they did so because there was more traffic than usual at the intersection. Other reasons cited for making a more complete stop were the presence of children or an older driver in the vehicle in front of them and daydreaming.

Drivers were also queried in general about a number of other factors that might affect their stopping behavior. Sixty percent of the drivers reported that they would make a more complete stop with a particular type of person in the vehicle with them, including children, parents, friends, brothers, sisters, and other relatives. The most common reason for making a more complete stop was concern for safety (91\% of the drivers reported this reason), but other reasons included the desire to avoid criticism and personal dynamics with the person riding in the vehicle with them.

When drivers were queried about the effect that their mood or state of mind would have on their stopping behavior, eighty-five percent of the drivers reported that some type of moods would have an effect of inducing them to stop more or less carefully. Sixty-five percent of the drivers who 
reported that moods affected their stopping behavior indicated that being late or in a hurry had this effect. Eighty-five percent of these drivers reported that such a situation would cause them not to make as complete a stop, while fifteen percent indicated that it would make them more careful. Fifty-eight percent of the drivers reported that being mad or angry affected their stopping behavior, with eighty-two percent indicating that it made them stop less completely, while eighteen percent reported stopping more completely. Fifty percent of the drivers indicated that daydreaming had an effect on their stopping behavior. Eighty percent of these drivers reported that it would make them stop less completely, and twenty percent reported that it would cause them to make a more complete stop.

Other moods or temporary states that at least some of the drivers reported would generally make them stop less completely included being nervous, upset, sick, or under the influence of alcohol. Moods that some drivers cited as inducing them to stop more carefully included being relaxed and being happy.

Drivers were also asked about the effect of distryation on their stopping behavior. Sixty-seven percent of the drivers reported that talking with others would affect how they stoped at a stop sign. Of these, seventy-five percent believed they would make a less complete stop, and twenty-five percent indicated that they would make a more complete stop.

Drivers were also asked about other reasons that would affect how they stopped at a stop sign. Drivers gave a number of reasons why they would stop more completely. Primary among these reasons was the presence of traffic at the intersection, weather conditions, pedestrians and school children, and road conditions. Other reasons cited included a perception of police enforcement or awareness of recent accidents. Only one reason for stopping less completely was clearly communicated by the drivers. A number of drivers reported that, if they were sure that there was no traffic coming from any direction, they would be less likely to come to a complete stop. 


\subsubsection{Utility of Driver Responses for Countermeasure Development.}

As noted above, the primary reason that drivers cited for failing to make a complete stop at a stop sign was the perception that there was no traffic coming and, therefore, no compelling need to stop. An obvious countermeasure that suggests itself for this reason is to decrease the line of sight around intersections with stop signs so that drivers are less sure of the presence (or lack) of other traffic. Unfortunately, this countermeasure would be counterproductive because decreasing the line of sight around an intersection would make the intersection even more hazardous for drivers who continue to try to roll through stop signs. Additionally, the purpose of the stop sign is to force drivers to stop and look for other traffic. It is not intended simply to force drivers to stop for the sake of stopping. If a driver has a clear indication that there is no other traffic around, then rolling or going through a stop sign is not inherently unsafe.

Drivers also indicated that their likelihood of stopping more completely increased with certain types of persons in the vehicle with them. One countermeasure that suggests itself is a public information and education program that attempts to induce drivers to drive as if they were driving with a particular type of person (e.g., grandmother or children). Clearly, drivers indicated that safety for others is a big reason for drivers driving more carefully. Any PI\&E campaign would need to address this theme.

It is interesting that two commonly proposed countermeasures, presence of police enforcement and publicizing accidents, appear not to have a great effect on driver's behavior at stop signs. Although drivers mentioned these reasons during the field test, the number of such responses was very small. It appears from these results that the utility of these countermeasures is not high.

\subsection{General Survey Procedures.}

The survey procedures and the questionnaire for the RSS UDA appear to have functioned well. No major changes in procedures or the questionnaire were suggested. Further work in this area should focus on the development of more effective procedures for determining whether a 
stop, a roll through, or a mn has occurred at a stop sign. Observers noted that it was often a highly subjective judgment whether a driver stopped or rolled through stop sign, even using the air valve stem method. There was generally no difficulty distinguishing between a roll through and a run, however. 


\subsection{UNSAFB TURN OR MBRGB}

Two types of unsafe turn or merge UDAs were considered in this study: pulling in front (PIF) and turning left in front of traffic (TLIF). The PIF UDA occurs at intersections where traffic having a duty to yield pulls out from a road or drive in front of oncoming traffic having the right-of-way. This UDA may occur under the following conditions:

- pulling in front of traffic across an intersection

- turning left into a lane of traffic

- turning right into a lane of traffic

The TLIF UDA involves two vehicles traveling in opposite directions with one going straight and one turning left.

Both the PIF and the TLIF UDAs are gap acceptance maneuvers; the risk posed by the maneuver is dependent upon the speed of the oncoming vehicle as well as its distance from the turning vehicle. The incidence of such UDAs has been found to be higher in high traffic volume areas where gaps between vehicles are small, and the opportunities to enter (or exit) the roadway are few (Lohman et al. 1976).

Only the tuming right PIF and the TLIP UDAs were addressed in the pilot-test activity. Their selection was based upon the types of UDAs occurring at avallable sites. It was necessary to select a site where traffic volume was relatively high and observation and surveying possible.

\subsection{Design}

6.1.1 Site Selection. Two sites were identified within Washtenaw County that met the requirements noted above. (Because of possible conflicts in Jurisdiction with the Ann Arbor Police Department, the Sheriff's Department requested that survey locations be kept outside the central city area.) The two sites selected for pilot-test activity were:

- Site I-Bnvironmental Protection Agency entrance

This location is on Plymouth Road, a major east/west road on the east side of Ann Arbor. There is a speed limit of $40 \mathrm{mph}$ at the survey location. The road at this point has three lanes 
and curves slightly.

The survey site was on the north side of the road, allowing westbound traffic to be sampled. The site was paved and had a reasonable entry/exit configuration. The site was large enough to accommodate survey traffic. However, there was a heavy volume of weekday traffic at this site and there was a need to keep the entrance clear for emergency fire equipment. Therefore, permission to use the site was received for weekend days only.

The observation site was located approximately .3 mile from the survey site at the intersection of Nixon and Plymouth Roads. Nixon Road is a two-lane road with a relatively high volume of traffic due to an adjacent shopping mall as well as a welldeveloped residential area. At this point, Plymouth Road narrows from five lanes to three, and the speed limit drops from $45 \mathrm{mph}$ to $40 \mathrm{mph}$. Only a right turn onto Plymouth Road from Nixon Road is permitted.

The observer was located in a bank parking lot near the Plymouth Road and Nixon Road intersection and observed for vehicles turning right onto Plymouth Road.

- site I-Christian Reformed Church parking lot

This location is on Broadway, an east/west road also on the east side of Ann Arbor. This section of Broadway is located in a residential area and has a speed limit of $25 \mathrm{mph}$.

The survey site was on the north side of the road, allowing west-bound traffic to be sampled. The site was paveci and had a convenient entry/exit configuration. It has a large parking area with a low amount of nonsurvey traffic on weekdays. Because of church activities, however, it was not possible to use the site on weekends.

The observation site was located about .5 mile east of the survey site where Broadway and Plymouth Road meet. At this point, there is a fork in the road with Broadway splitting off to the left and Plymouth Road continuing on the right. The road has three lanes, the center lane being used for turning. The speed limit here on Plymouth Road is $40 \mathrm{mph}$.

The observer was located in the parking lot of a small shopping center. The parking lot is on a slight incline and overlooks the Plymouth-Broadway intersections. Observations were made for vehicles turning left onto Broadway.

6.1.2 Schedule of Survey Times. Three pilot tests were conducted for the PIF and TLIF UDAs. The times and locations of each test were as follows:

- Pilot Test I Plymouth and Nixon Roads

Saturday, October 31, 1981

8:30 a.m. to 5:30 p.m. 
- Pilot Test II Broadway and Plymouth Road Monday, November 2, 1981 7:30 a.m. to $4: 30$ p.m.

- Pilot Test III Broadway and Plymouth Road Wednesday, November 4, 1981 7:30 a.m. to $4: 30$ p.m.

These times were selected on the basis of: (1) traffic volume, (2) site availability, and (3) interviewer availability.

6.1.3 Selection of Drivers for Survey. Both drivers committing the PIF/TLIF UDAs" and those not committing such UDAs were considered for inclusion in the study. Identification of drivers as safe or unsafe were made on the basis of traffic conflict observations. These are discussed more fully below.

6.1.4 Traffic Observation. Both the PIF and TLIF UDAs are gap acceptance maneuvers. Judgments about the occurrence of these DDAs were made on the basis of traffic conflict measures. Specific conflict measures used to observe for the PIF UDA were:

- brake lights (on vehicle having the right-of-way)

- nose diving (by vehicle having the right-of-way)

- lane changes (by vehicle having the right-of-way) to avoid collision within a set period of time

- entry vehicles that start to enter and stop suddenly after their front bumper has crossed into the through lane, or which pull partially or fully off the road to the right, or that accelerate so hard as to spin the drive wheels

- squealing or sliding of tires

- Instability during braking

- notable roll movements during lane change

Similar traffic conflict situations were also used to observe for the TLIF UDA. These included:

- braking actions (by the vehicle going straight, including 
precautionary, controlled, and emergency braking

- lane changing

- rapid deceleration (e.g., nosediving)

- locked wheel braking

- running off the road

- tire skids or squeals

Although more objective measures for these UDAs do exist (such as topeswitches), the installation of such measures represented too great an expense for the purposes of such a feasibility study. All observers were carefully trained on the subjective traffic conflict measures to gain familiarity and expertise in their use.

\subsection{Results}

Analysis of the unsafe turn/merge pilot data addressed three issues: (1) drivers' willingness. to participate in the survey; (2) drivers' ability to respond to the interview questions; and (3) the utility of the drivers' responses for use in countermeasure development. These are discussed below.

6.2.1 Driver Participation. In all three field tests, fifty-eight percent of the violators were judged to have accepted readily. Interviewers indicated that another twelve percent of the violators accepted but needed some encouragement. Approximately thirty-one percent of the violators refused to participate. Of this thirty-one percent, five percent refused the traffic deputy at the time they were stopped, and twenty-six percent refused the interviewers' request to participate.

Nonviolators tended to agree to be interviewed more readily. In all four field tests, seventy-seven percent of the nonviolators accepted readily. Approximately twelve percent of the nonviolators refused.

The overall acceptance rate here was somewhat higher for the nonviolators than for the violators ( $88 \%$ versus $70 \%$, respectively). Table 6-1 presents the number and percentage of drivers who accepted and 
TABLE 6-1

DRIVER PARTICIPATION $(a, b)$

\begin{tabular}{|l|cc|cc|cc|}
\hline \multirow{2}{*}{$\begin{array}{l}\text { Willingness } \\
\text { to Participate }\end{array}$} & \multicolumn{2}{|c|}{ Violators } & \multicolumn{2}{c|}{ Nonviolators } & \multicolumn{2}{c|}{ Total } \\
\cline { 2 - 6 } & number $\%$ & number $\%$ & number & $\%$ \\
\hline $\begin{array}{l}\text { Accepted } \\
\text { Readily }\end{array}$ & 25 & 58 & 27 & 77 & 52 & 67 \\
$\begin{array}{l}\text { Accepted } \\
\text { Reluctantly }\end{array}$ & 5 & 12 & 4 & 11 & 9 & 12 \\
$\begin{array}{l}\text { Refused Officer } \\
\begin{array}{l}\text { Refused } \\
\text { Interviewer }\end{array}\end{array}$ & 2 & 5 & 1 & 3 & 3 & 4 \\
\hline
\end{tabular}

(a) Numbers are summed over all three field test conditions.

(b) Percent may not add up to 100 due to rounding. 
refused the request to participate in the driver interviews. These numbers are summed over all three field-test conditions.

No interviews were conducted at carside during the PIF/TLIF pilot-test activity.

6.2.2 Drivers' Responses to the Interview Questions. The driver information questions were administered over three pilot tests. Four different sets of questions were used during these sessions. This section presents the results of the information given by respondents during the field tests. It is divided into four parts:

- interview length

- demographic information

- general driving information

- driver responses about the PIF/TLIF UDA

The driver responses are presented in terms of two questions: (1) Could drivers respond to the interview questions? and (2) What kinds of responses were given? For the most part, data are presented as an aggregate of all three field tests.

6.2.2.1 Interview Length. For all four sets of questions, interview times ranged from 4 minutes to 26 minutes, with an average interview time of 8.06 minutes. For the first set of interview questions, the average interview length was 10.0 minutes. This decreased to 7.9 minutes for the second set and decreased further to 6.8 and 7.7 minutes for question sets three and four. The decrease in time appeared to result primarily from increasing interview familiarity over time with the PIF/TLIF interview procedures.

Table 6-2 presents information about interview length for all four sets of interview questions.

6.2.2.2 Demographic Information. Demographic information was also obtained during the PIF/TLIF field tests. Observable items continued to be obtained for all drivers stopped for the survey. Demographic information that needed to be obtained by direct questions was asked of drivers who 
TABLE 6-2

INTERVIEW TIME LENGTH FOR PIF/TLIF PILOT TESTS

\begin{tabular}{|c|ccc|}
\hline \multirow{2}{*}{$\begin{array}{c}\text { Question } \\
\text { Set }\end{array}$} & \multicolumn{3}{|c|}{ INTERVIEW TIME LENGTH } \\
\cline { 2 - 4 } & $\begin{array}{l}\text { Mean } \\
\text { (Mins.) }\end{array}$ & $\begin{array}{l}\text { Mode } \\
\text { (Mins.) }\end{array}$ & $\begin{array}{c}\text { Range } \\
\text { (Mins.) }\end{array}$ \\
\hline 1 & 10.0 & 10 & $5-26$ \\
$\# 2$ & 7.9 & 8 & $4-18$ \\
$\# 3$ & 6.8 & 5 & $4-12$ \\
$\# 4$ & 7.7 & $6,8,9$ & $6-9$ \\
\hline
\end{tabular}


agreed to be interviewed for three of the question sets. (A fourth set obtained attitudinal information.)

Interviewers experienced little problem in obtaining the observable data, and for the most part, drivers were willing and able to give responses to the direct questions. All drivers indicated the year in which they were born. Questions about occupation, marital status, residence, and educational level did not appear as problems for the respondents. All but three drivers in the PIF/TLIF pilot test who were asked about income responded.

6.2.2.3 General Driver Information. General information about drivers was also obtained during the PIF/TLIF pilot-test activities. Observable information continued to be recorded for all drivers stopped for the survey. Interviewers had little difficulty in obtaining this information, particularly for those drivers who entered the survey site.

There was generally little difficulty in obtaining information on driver characteristics during the interviews. Drivers in the PIF/TLIF field tests were able to give information cii exposure. Drivers had no problem giving the number of days driven per week. Only two sets of the PIF/TLIF background questions addressed the number of miles driven per year. Five of the drivers who were asked this question did not answer.

Information about driving experience and vehicle as well as road familiarity was also addressed in these pilot tests. Drivers were able to estimate both the number of years they had been driving as well as the number of times they had driven on the study road in the last month. Drivers had little problem indicating how long they had been driving the vehicle in use.

All drivers asked were able to indicate both the origin and destination of their trip. Drivers were also willing to give an account of the number of times they had been cited for an unsafe turn or merge violation. (Only five percent of the drivers asked this question indicated that they had received such a citation.)

Drivers were asked about their perception of their own driving on one set of questions. They were asked to rate how safe a driver they 
considered themselves to be on a scale of 1 (very unsafe) to 6 (very safe). This task was relatively easy for the drivers. All drivers responding to this question rated themselves as safe drivers. The majority of drivers indicated that they gave themselves a high rating because of their good driving record or better than average performance. Others indicated that they did not give themselves a rating higher than 4 or 5 because they sometimes made mistakes or daydreamed.

One set of questions assessed drivers' attitudes toward driving. Drivers were presented with ten statements on driving and road safety. They were then asked to indicate their agreement with each statement on a scale from 1 (strongly disagree) to 5 (strongly agree). Although all drivers responded to each statement, many found the wording difficult and confusing. Some interesting differences in the mean ratings between the PIP/TLIF violators and nonviolators were found. The violators were more likely to view traffic regulations as an imposition on personal freedom; they also seem to worry less about being hit because they view other drivers as careful. Nonviolators, on the other hand, appeared more likely to assume responsibility for their own driving actions, while at the same time being more fatalistic about reducing their chances of an automobile accident. The nonviolators also indicated that they were more relaxed when driving under the speed limit. These differences in item responses are presented in Table 6-3.

Most drivers were able to identify correctly the intersection at which they made their last turn. Only one driver indicated a different intersection. Similarly, most drivers were able to identify the type of oncoming vehicle in front of which they turned. Only seven percent of the drivers were not able to identify the vehicle. Seventeen percent of the drivers indicated no car was approaching when they made the turn. In some cases the approaching vehicle was at such a distance that the drivers did not appear to consider it relevant to their turning maneuver. In a few instances, however, drivers apparently did not perceive that there was an oncoming vehicle; five violators, for example, indicated that there was no oncoming vehicle.

Judgments about driving distance were much more difficult for the 
TABLE 6-3

ATTITUDINAL RESPONSES*

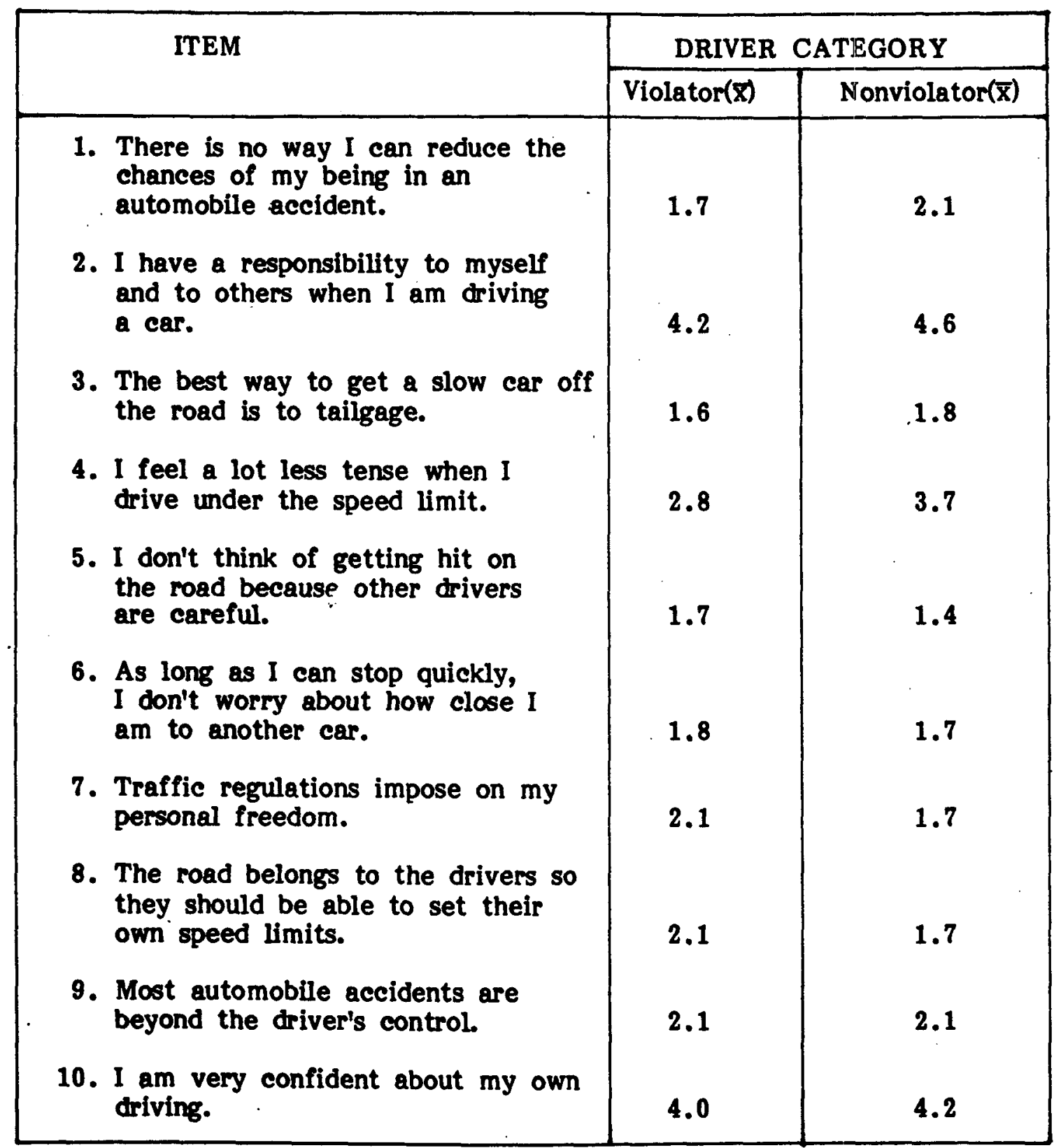

- Respondents were asked to express agreement with each statement on a scale from one (strongly disagree) to five (strongly agree). Numbers are means of responses. 
drivers to make. Drivers were presented with a scale of the road in inches and asked to estimate the distance between them and the oncoming vehicle when they decided to make their turn. Drivers generally seemed to find the scale difficult to use and made their estimates in units independent of the scale, including feet and car lengths. Approximately thirty-five percent of the respondents were unable to make this judgment. Frequently, drivers would volunteer a reference point on the roadway (e.g., a store, a sign) as an indication of the distance of the oncoming vehicle.

6.2.2.4 Drivers' Responses to the PIF/TLIF UDA. Approximately sixtynine percent of the drivers interviewed stated that their turning distances were different on the day of the pllot test than the last time they drove on that particular road. Of these, approximately forty-eight percent indicated that they turned with less distance between them and the oncoming vehicle on the day of the pilot test. An equal number of drivers (41\%) suggested being late and in a hurry or heavy traffic as underlying the change in turning behavior. A few drivers (6\%) stated that they misjudged the speed of the oncoming vehicle. The remaining drivers (12\%) could not explain why their driving had changed.

Approximately forty-six percent of the drivers interviewed stated that there was more room than usual between them and the oncoming vehicle when they turned on the day of the pilot test. Over two-thirds of these drivers (64\%) said the traffic was lighter at the time of their turn on the pilot-test day. Another fourteen percent expressed a concern for safety when turning. The remaining drivers in this category were equally divided (approximately 7\%) among the following responses: the oncoming vehicle's slow speed, the weather, and an opening in the traffic.

Few driver-related responses were associated with the PIF/TLIF UDA. Seven percent of the drivers suggested that their turning behavior would be affected by their state of mind or mood. These responses included being in a hurry, anxious, or generally in a bad mood. No other driver-related responses were indicated as affecting turning behavior.

Eight percent of the drivers reported effects on turning behavior associated with the vehicle they were driving. Three percent of the 
drivers indicated that they leave more distance between themselves and the oncoming vehicle when turning in a larger vehicle. These respondents suggested that larger vehicles are less maneuverable and therefore require more turning distance. Vehicle ownership was cited by five percent of the respondents as influencing their turning behavior. These drivers suggested that they would leave more distance between themselves and an oncoming vehicle when driving a vehicle that did not belong to them.

The most frequently cited influences on turning behavior involved the roadway. Forty-two percent of the respondents reported some effect on their turning distance due to the characteristics of the roadway on which they were driving. Locality was cited by ten percent of the drivers interviewed. A roadway with a history of accidents was one example of a locality where drivers use more distance in turning. Driving patterns (such as cars pulling out of side streets) and pedestrian activity were also cited as instances in which more caution would be used in turning. Twelve percent of the drivers indicated that roadway characteristics influenced their turning distance. These drivers suggested that problem corners, number of traffic lanes, and visibility of oncoming traffic were conditions that influenced the distance they used in initiating a turn. Many drivers reported that specific road conditions had an effect on their turning distance. Twenty percent of the drivers in the PIF/TLIF pilot test indicated that certain road conditions influenced their turning distance. Distractions and heavy traffic were cited by five percent of the drivers as resulting in decreasing turning distances; weather was cited by fifteen percent of the arivers as leading to increased turning distances.

\subsection{Utility of Driver Responses for Countermeasure Development}

The primary influence on turning behavior cited by the drivers in this pilot test was that of the roadway. Forty-two percent of the respondents indicated that roadway location, characteristics, or conditions would influence their turning distances. A number of drivers cited the accident history of an intersection as influencing their turning behavior. Further indication of such influences would be suggestive of a campaign to disseminate accident information about target locations. 
Generally, drivers expressed some difficulty in judging the distance of oncoming vehicles. Regardless of the possible influences on such turning, lurther indication of such difficulty would be indicative of the need for the development of countermeasures focusing upon improvement in driver information processing and decision making.

\subsection{General Survey Procedures}

Two aspects of the PIF/TLIF pilot test were problematic. These were: observation of the UDA and drivers' judgments of turning distance.

Observers for the pilot test indicated that the PIF/TLIF UDA was the most difficult to observe. The two most frequently used cues for the UDA were the breaking or veering of the oncoming vehicle. Even with the use of these cues, however, observers expressed concern about the subjectivity of their observations and highly recommended the use of more objective measures in any future study.

The second problem is related to drivers' abilities to make judgments doout turning distances. Drivers were not able to estimate distance on a numericel scale of the roadway. However, many drivers volunteered information about turning distance in terms of reference points on the roadway. This suggests that better driver information might be obtained with greater use of props in the interview setting. Landscape models of the roadway could be used in discussing various turning circumstances. Similarly, a variety of turning scenarios at selected study intersections could be presented to drivers through the use of film loops as a starting point for discussion. 


\subsection{CONCLUSIONS AND RECOMMENDATIONS}

The results of the test program indicate that it is feasible to use roadside survey methods to collect useful data on drivers' motivations for committing the subject UDAs. It was found that the procedures used were sufficiently unobtrusive to permit the identification and stopping of drivers committing the UDAs. Drivers who were stopped were able to explain with sufficient specificity why they had or had not committed a UDA and could provide demographic and other information needed for categorizing the drivers and their driving habits. Further, the reasons given by the drivers for their driving behavior were amenable for use in designing countermeasures aimed at preventing future UDAs.

Driver participation in the test survey was high. Seventy-three percent of all drivers stopped agreed to be interviewed. Fifty-five percent agreed readily and eighteen percent agreed after discussing the project and the questions with the interviewer. Indications were that most of the twentyseven percent who refused to participate in the roadside interview refused because they did not have the time to do so and would have participated in a later telephone or personal interview. Thus, overall participation rates were probably in the ninety to ninety-five percent range. No difficulties occurred in interacting with the subjects; few were angry at being stopped, none used abusive language, and none was obviously impaired by alcohol or drugs.

Only three items of demographic and general driver information presented any significant difficulties for the subjects. Some drivers did not provide information on their income, and some had difficulty in estimating the number of miles they drive each year. A fairly high percentage $(25 \%)$ of the drivers stopped for the running-a-stop-sign UDA did not indicate their educational background.

In general, the respondents had little or no difficulty with the other test items in the survey. There were two exceptions to this finding. First, many drivers had trouble with the wording and scales used in the 
statements designed to measure their attitures toward driving. Nevertheless, nearly all of these drivers were able to respond to these statements. Second, the methods used to elicit driver estimates of their following distance (following-too-close UDA) and turning distance (pullingin-front and turning-left-in-front UDAs) were confusing to manv of the drivers. The interviewers were able to interact with these subjects to arrive eventually at estimates of these distances, but additional time was required for this.

While this study was concerned primarily with methodology, the data collected were also of interest. In general, the respondents rated themselves as very good drivers. There was some indication of a greater tendency toward risk-taking among drivers who had committed UDAs than among drivers who had not. A significant percentage of the drivers responded that their driving behavior was more "unsafe" on the day of the survey than it usually was. This effect was noted for all of the UDAs of concern in the project.

The respondents indicated that driver-related factors affected whether they would commit.speeding, FTC, and RSS UDAs, but would have no effect on their committing the PIF/TLIF UDA. Factors cited for speeding included fear of enforcement and being late or in a hurry. The negative consequences of both factors were the main concern to the drivers, e.g., fines, being fired, and embarrassment. About half of the drivers interviewed in the speeding test said their mood (e.g., being nervous, depressed, upset, angry) would tend to increase their speed, and about onefourth said their mood (e.g., being preoccupied, debresser, relaxer, not caring) would cause them to drive slower. Most drivers (30\%) in the speeding UDA test said that alcohol would cause them to drive slower, and some (17\%) said that being tired would have a similar effect. About a third of the drivers in the speeding UDA test indicated that the presence of passengers would make them drive slower than usual. A fewi thought that distractions would affect their speed.

By contrast, thirty-nine percent of the drivers interviewed on the FTC UDA said that distractions would affect their following distance. These respondents were about equally divided as to whether distractions would 
increase or decrease their following distance. Some drivers interviewed on the RSS UDA also indicated that distractions would cause them to come to a less complete stop at a stop sign. The FTC interviews stronglv indicated that driver mood affects following distance: sixty-six percent said that anger would cause them to follow too closely. The same effect was observed for RSS; many of these drivers also stated that other moods and emotions (e.g., nervousness, anger) would tend to cause a less complete stop. The drivers interviewed for FTC and RSS also said the presence of passengers would decrease their tendency to commit these UDAs.

Vehicular factors were said to affect driving speed but were not listed among those factors that affected behaviors associated with the other UDAs studied. Sports cars, motorcycles, and larger cars were associated with higher speeds, while trucks, low-performance cars, and smaller cars were associated with slower speeds. Twentv-two percent of the drivers interviewed in the speeding UDA test said thev would Arive slower in a car in poor condition; forty-one percent would drive slower in a car owned by somebody else.

The respondents said roadway factors affected their tendencv to commit all of the four UDAs studied. Certain roar localities (e.g., roads in residential areas, school zones, and areas with heavy pedestrian traffic), road characteristics (e.g., hills, curves), and road conditions (e.g., poor weather, poor visibility, slow traffic) were said to cause slower driving. Many of the same factors would also result in a lower incidence of the other three UDAs, according to the respondents. However, slow, heav traffic, and lack of passing opportunities would increase the incidence of FTC, but light traffic might increase the incidence of RSS. Drivers interviewed in the PIF/TLIF test said that knowledge of past accidents stemming from this UDA would tend to increase the distance thev would allow for the turning maneuver. "Problem" corners, bad weather, and Door visibility of oncoming traffic would have a similar effect.

Clearly, knowledge of the type indicated above would be useful for countermeasure design, provided the data had been collected from a representative sample of drivers and driving situations. Variations of different enforcement-countermeasure themes would be appropriate for the 
speeding and RSS UDAs. Public-information countermeasures are suggested for all four of the subject UDAs. Roadway-type countermeasures appear to be indicated for speeding, FTC, and PIF/TLIF UDAs.

In short, the larger-scale data collection effort we recommender at the end of Phase I of the project is fully supported by the arditional iata collected during the pilot testing of the FTC, RSS, and PIF/TLIF UDAs. We recommend that this effort be undertaken by NHTSA. The procedures and instruments used in the pilot tests are in general satisfactorv but should be refined. Such refinements should include:

- measures to improve the logisties and planning of the data collection activity, incluring selecting sites with minimum traffic through the interview area and with good visibilitv of the road at the stop-car location, providing good lighting in the interview area, organizing the interview materials into convenient packets, providing emergency equipment (e.g., jumper cables) for use in the interview area, taking extra care to ensure all equipment is functioning prior to the survey, and alternating the roles of interviewer and recorder each time a driver is interviewed

- more objective criteria for identifying the RSS and PIF/TLIF UDAs

- use of visual aids and models to explain roadway and traffic geometry to drivers so that their responses will be to the point and more accurate

- changing the wording and scaling of the attitudinal test items to communicate better the nature of the information sought in those items

Adoption of these measures and use of the procedures tested will. provide much useful information for designing countermeasurers to reduce the incidence of the speeding, following-two-closelv, running-a-stop-sign, and pulling-in-front/tuming-left-in-front unsafe driving actions. 


\section{BIBLIOGRAPHY}

Andriessen, J.H. 1971. Motivational determinants of risk-taking behavior. Paper presented to the International Symposium of Psychological Aspects of Driver Behavior, 2-6 August 1971, Noordwijerhout, The Netherlands.

Atkinson, J.w. 1957. Motivational determinants of risk-taking behavior. Psychological Review 64(6):359-372.

Atkinson, J.W. 1964. An introduction to motivation. Princeton, New Jersey: D. VanNostrand Company, Inc.

Berkowitz, L. 1969. Social motivation. In The Handbook of Social Psychology, vol. III, eds. G. Lindzey and E. Aronson, pp. 50-135. Reading, Massachusetts: Addison-Wesley Publishing Company.

Bradburn, N.M. and Sudman, S. 1979. Improving interview methods and questionnaire design. San Francisco, California: Jossey-Bass Publishers.

Cannell, C.F. and Kahn, R.L. 1968. Interviewing. In The Handbook of Social Psychology, vol. ii, pp. 526-595. Reading Massachusetts: AddisonWesley Publishing Company.

Carr, B.; Borkenstein, R.F.; Perrine, M.W.; VanDerkom, L.C.; and Voas, R.B. 1974. International conference on research methodology for roadside surveys of drinking-driving alcohol countermeasures workshop. Final report. National Highway Traffic Safety Administration report no. DOT-HS-801-22!.

Cook and Selltiz. 1964 A multiple-indicative approach to attitude measurement. Psychological Bulletin 62:36-55.

Detroit Free Press. Speeding excuses are real winners. June 12, 1979.

Greenshields, B.D. 1959. Attitudes, emotions, accidents. Traffic Quarterly 13:221-235.

Jones, R.K.; Treat, J.R.; and Joscelyn, K.B. 1979. A definitional study of three unsafe driving actions: Speed, following too closely, and driving left of center. Ann Arbor: The University of Michigan Highway Safety Research Institute report no. UM-HSRI-79-83. Sponsored by the National Highway Traffic Safety Administration contract no. DOT-HS-7-01797.

Lohman, L.S.; Lessett, E.C.; Stewart, J.R.; and Campbell, B.J. 1976. Identification of unsafe driving actions and related countermeasures. Final report. National Highway Traffic Safety Administration report no. DOTHS-803-064.

MeGuire, F.L. 1976. Personality factors in highway accidents. Human Factors 18(5):433-442.

Morton-Williams, J. 1961. Motivation research as applied to the problems 
of road safety. International Road Safety Traffic Review 9(2):31-35.

Naatanen, R. and Summala, H. 1974. A model for the role of motivational factors in driving decision-making. Accident Analysis and Prevention 6:243-261.

Pelz, D.C. 1968a. Driver motivations and attitudes. In Driver behavior: Cause and effect. Proceedings of the second annual traffic safety research symposium of the automobile Insurance Industry, ed. J. O'Day, pp. 101-122. Washington, D.C.: Insurance Institute for Highway Safety.

Pelz, D.C. 1968b. Driver motivations and attitudes. Paper presented at Second Annual Auto Insurance Industry Traffic Safety Research Symposium, 19-21 March 1968, Northbrook, Illinois.

Pelz, D.C. and Shuman, S.H. 1971. Motivational factors in crashes and violations of young drivers. Paper presented to the American Public Health Association Meetings, 13 October 1971, Minneapolis, Minnesota.

Perrine, M.W. 1971. Methodological considerations in conducting and evaluating roadside research surveys. National Highway Traffic Safety Administration report no. DOT-HS-800-471.

Selzer, M.L. and Vinokur, A. 1974. Detecting the high risk driver: The development of a risk questionnaire. National Highway Traffic Safety Administration final report DOT-HS-801-099.

Stroh, C. 1973. Roadside surveys of drinking-driving behavior. In Alcohol and Road Safety Series, vol. IV. Ottawa: Department of Transport.

Treet, J.R.; Thompson, D.S.; Jones, R.K.; and Joscelyn, K.B. 1980. National analysis of unsafe driving actions: Interim report on UDA selection and definition. Preliminary draft. National Highway Traffic Safety Administration contract no. DOT-HS-8-02023.

Warwick, D.P. and Lininger, C.A. 1975. The sample survey: Theory and practice. New York: McGraw-Hill Book Company.

Wolfe, A.C. 1974.1973 U.S. national roadside breathtesting survey: Procedures and results. National Highway Traffic Safety Administration report no. DOT-HS-800-241. 
Mary Beth Marks is an assistant research scientist with the Urban and Regional Planning Program of The Universitv of Michigan. She received a B.A. degree in psychology from John Carroll University in 1974 and received her $\mathrm{Ph} . \mathrm{D}$. degree in social psychology from The Universitv of Colorado in 1978. Her research interests have been in the area of humanoriented highway safety research and have focused on individual choices in transportation.

John W. MeNair is a senior staff attorney with Mid-America Research Institute. He received a B.A. degree in political science and history from The University of Michigan in 1971 and a J.D. degree from The University of Santa Clara in 1976. He is a member of the bar of the State of Michigan. He has been active in highway safety research since 1978, primarily in the areas of traffic law and adjudication of traffic offenses.

Ralph $\mathbf{K}$. Jones is president of Mid-America Research Institute, Inc. He received his B.S. in mathematics from Drury College in 1950 and studied afterward at Wichita State University, The Universitv of Michigan, and Purdue University. He is currently involved in research and research management in the areas of transportation, health, and safety. He has directed and participated substantively in many research and demonstration projects dealing with the human component of the Highwav Transportation System.

Kent B. Joscelyn is Director of Transportation Planning and Policy at The University of Michigan Urban and Regional Planning Program and is a partner in the law firm of Joscelyn \& Treat, P.C. He received a B.S. degree in physics from Union College in 1957 and a J.D. degree from Albany Law School in 1960. He is a member of the bar of the State of Michigan, the State of New York, and the District of Columbia. Mr. Joscelyn is a member of numerous professional societies and advisory committees and is the editor of the international Journal of Criminal Justice. His research interests span a broad spectrum of areas related to the analysis of societal systems, including law, public safety, and systems analysis. 
FOLLOWING-TOO-CLOSELY

-Pilot Test-

OBSERVER INFORMATION SHEET

DATE :

TIME :

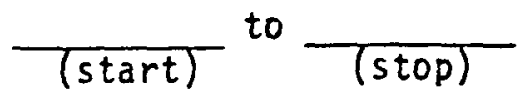

Road Name:

Site:

Traffic Direction:

Roadway class [check one]:

Locality type [check one]:

- 1. City street

- 3. U.S./State main road

- 4. Interstate/Turnpike

- 5. Manufacturing/Industrial

1. Residential

2. Farm/Undeveloped

- 3. Shopping/Business.

- 4. Industrial

Posted Speed:

Weather conditions (Note changes):

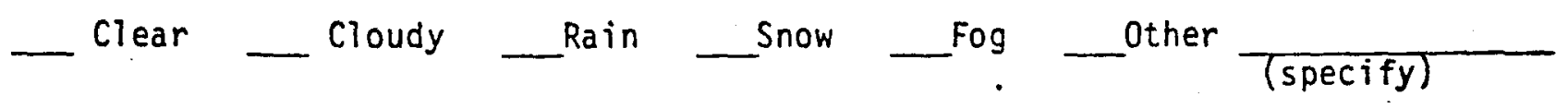

Road conditions (Note changes):

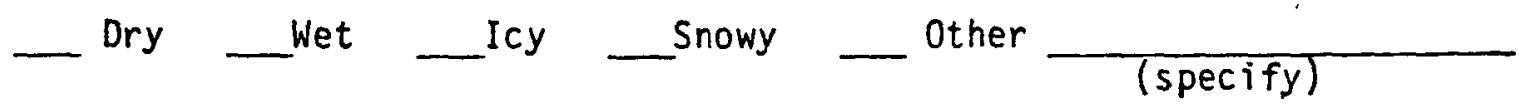

Lighting conditions:

$T_{\text {(time) }}^{\text {Dark }} \frac{\text { (time) }}{}^{\text {Dawn/Dusk }}$ (time) $^{\text {Light }}$




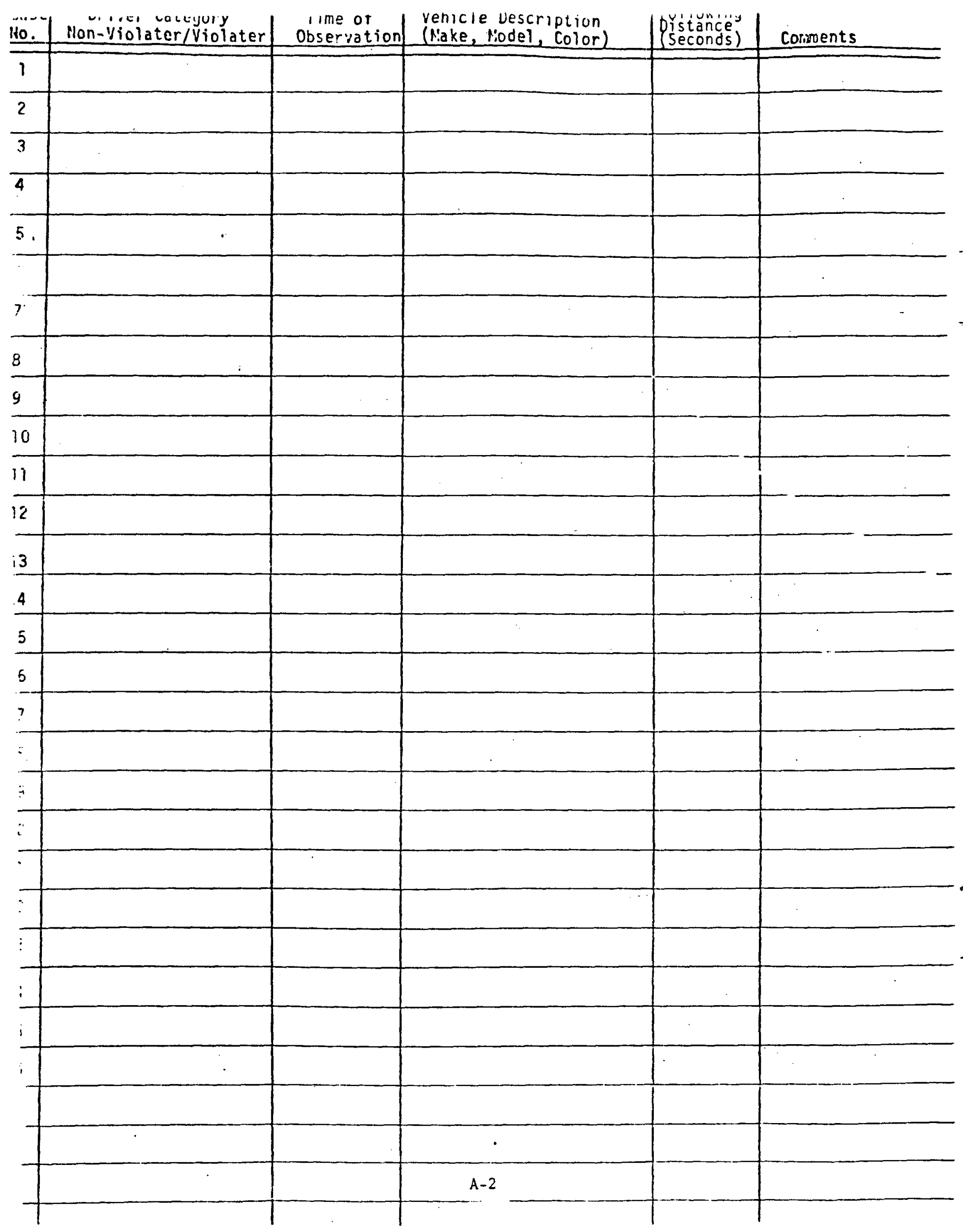




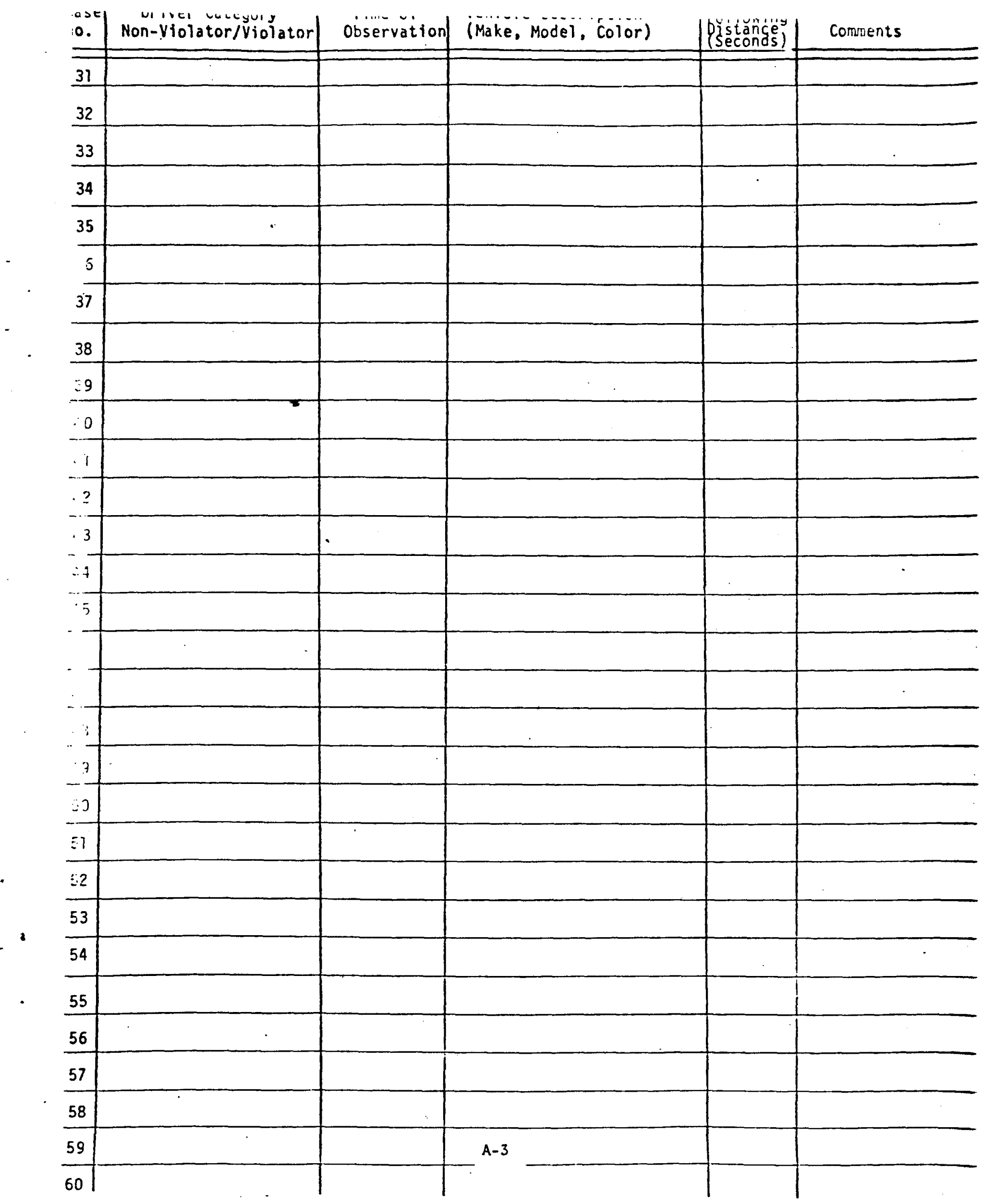


RUNNING-A-STOP-SIGN

-Pilot Test-

OBSERVER INFORMATION SHEET

DATE:

TIME: to (stop)

Road Name:

Site: Traffic Direction:

Roadway class [check one]:

Locality type [check one]:

1. City street

- 2. County road

- 3. U.S./State ma in road

- 4. Interstate/Turnpike

- 5. Manufacturing/Industrial

1. Residential

- 2. Farm/Undeveloped

- 3. Shopping/Business

- 4. Industrial

\section{Posted Speed:}

Weather conditions (Note changes):

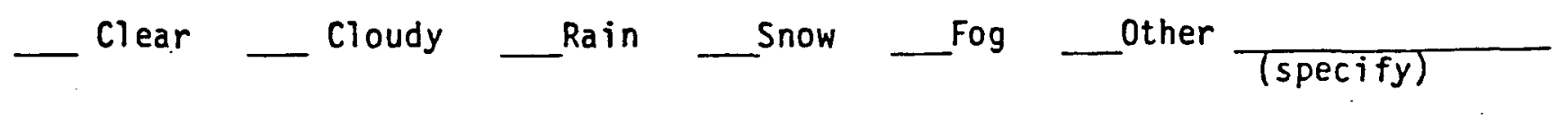

Road conditions (Note changes):

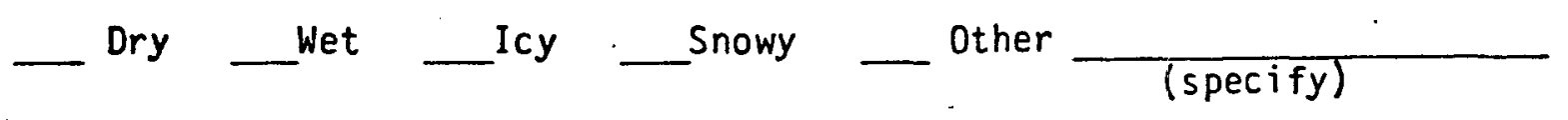

Lighting conditions:

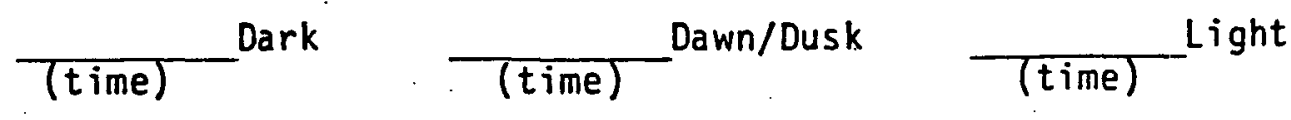




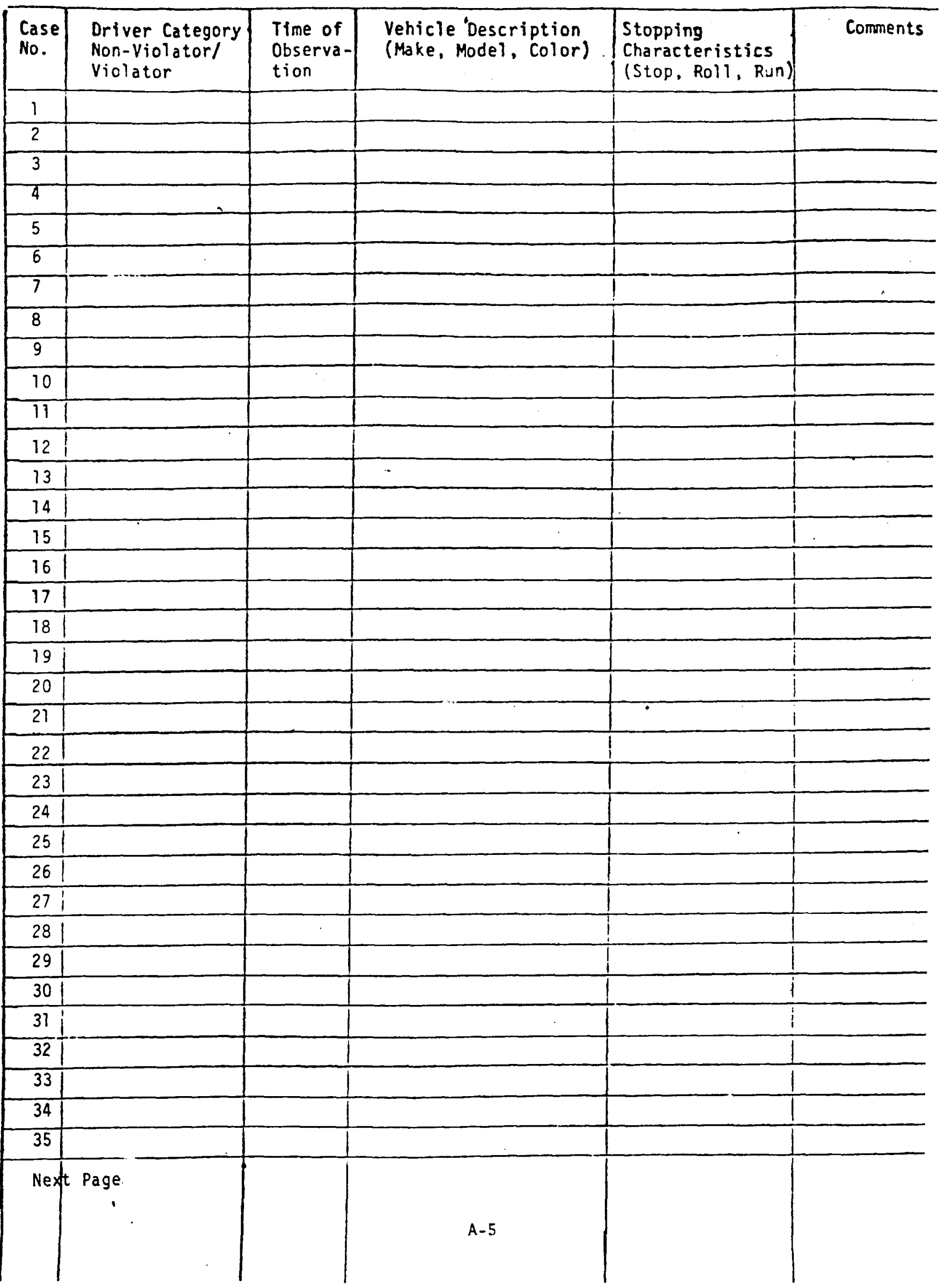




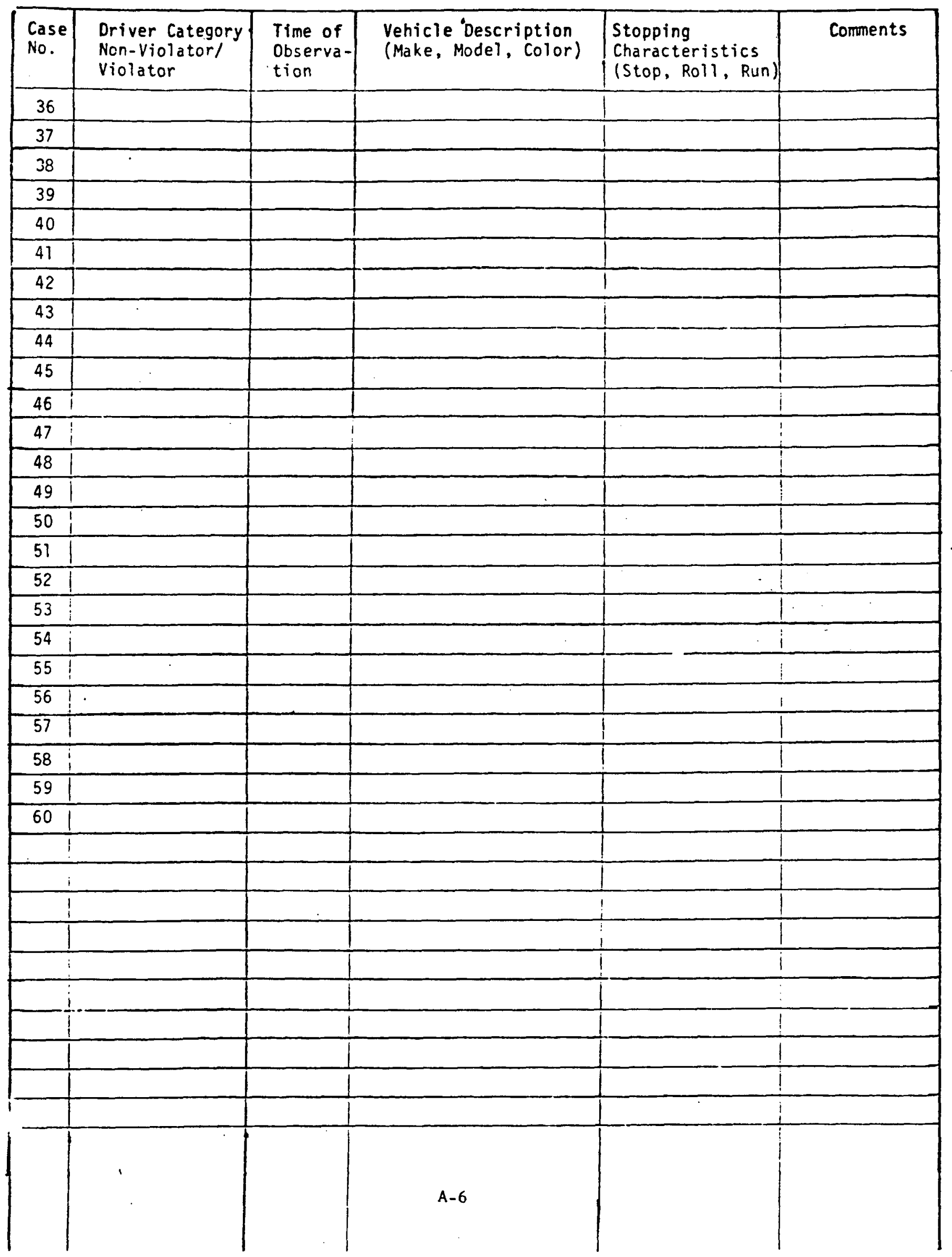


PULLING-IN-FRONT/TURNING

-Pilot Test-

OBSERVER INFORMATION SHEET

DATE :

TIME:

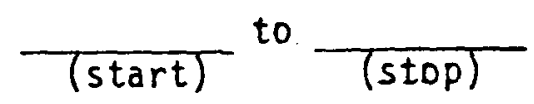

Road Name:

Site:

Traffic Direction:

Roadway class. [check one]:

Locality type [check one]:

- 1. City street

-2. County road

- 3. U.S./State main road

- 4. Interstate/Turnpike

-5. Manufacturing/Industrial

- 1. Residential

- 2. Farm/Undeveloped

- 3. Shopping/Business

4. Industrial

Posted Speed:

Weather conditions (Note changes):

_ Clear _ Cloudy _ Rain Snow Fog _ _ ${ }^{\text {Other }}$ (specify)

Road conditions (Note changes):

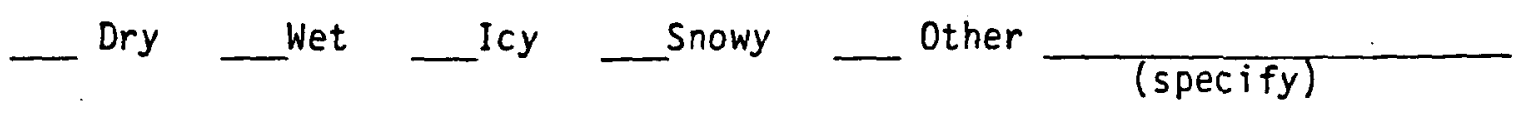

Lighting conditions:

$T_{\text {(time) }}^{\text {Dark }} \frac{\text { (time) }}{}^{\text {Dawn/Dusk }} \frac{\text { (time) }}{}^{\text {Light }}$




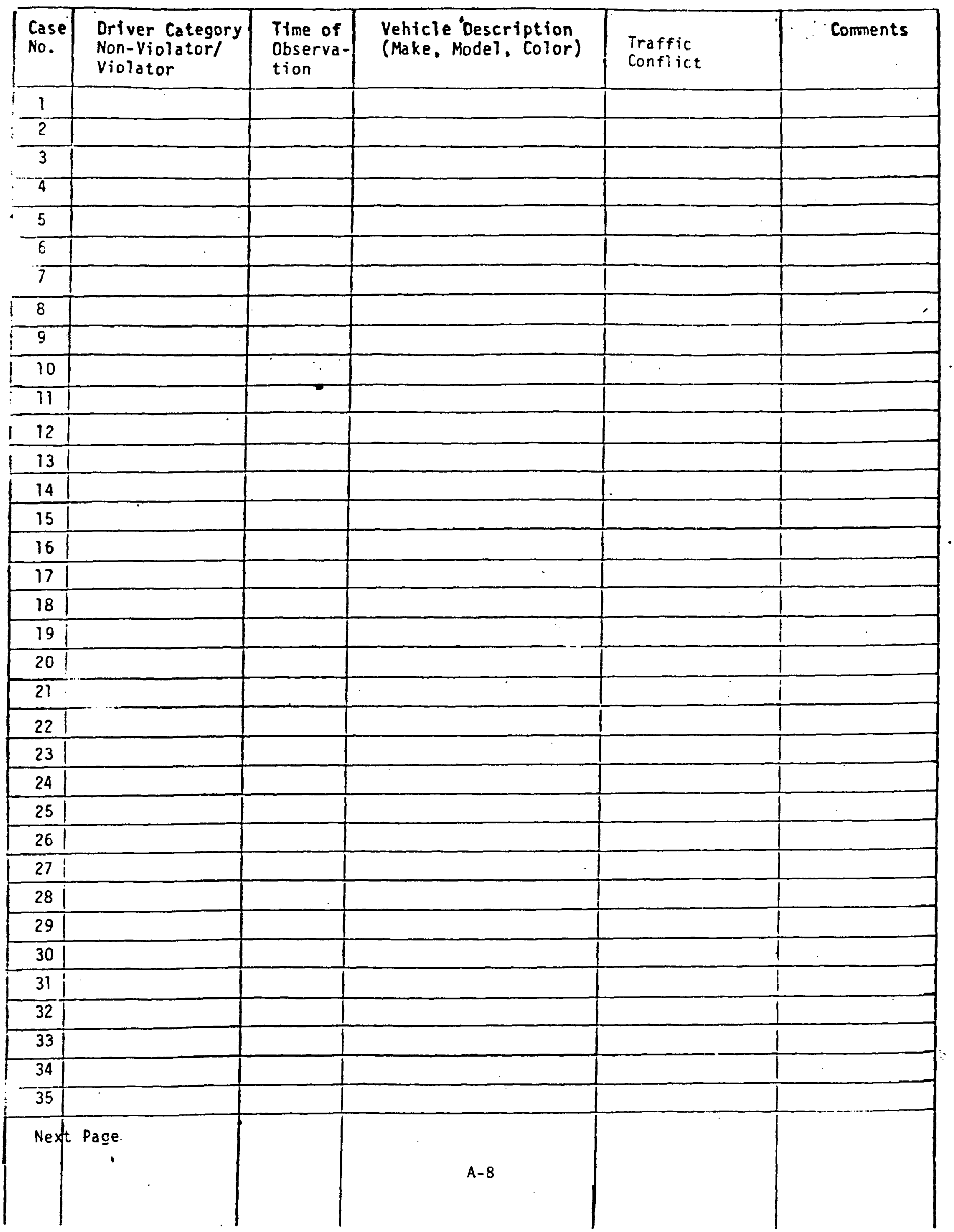




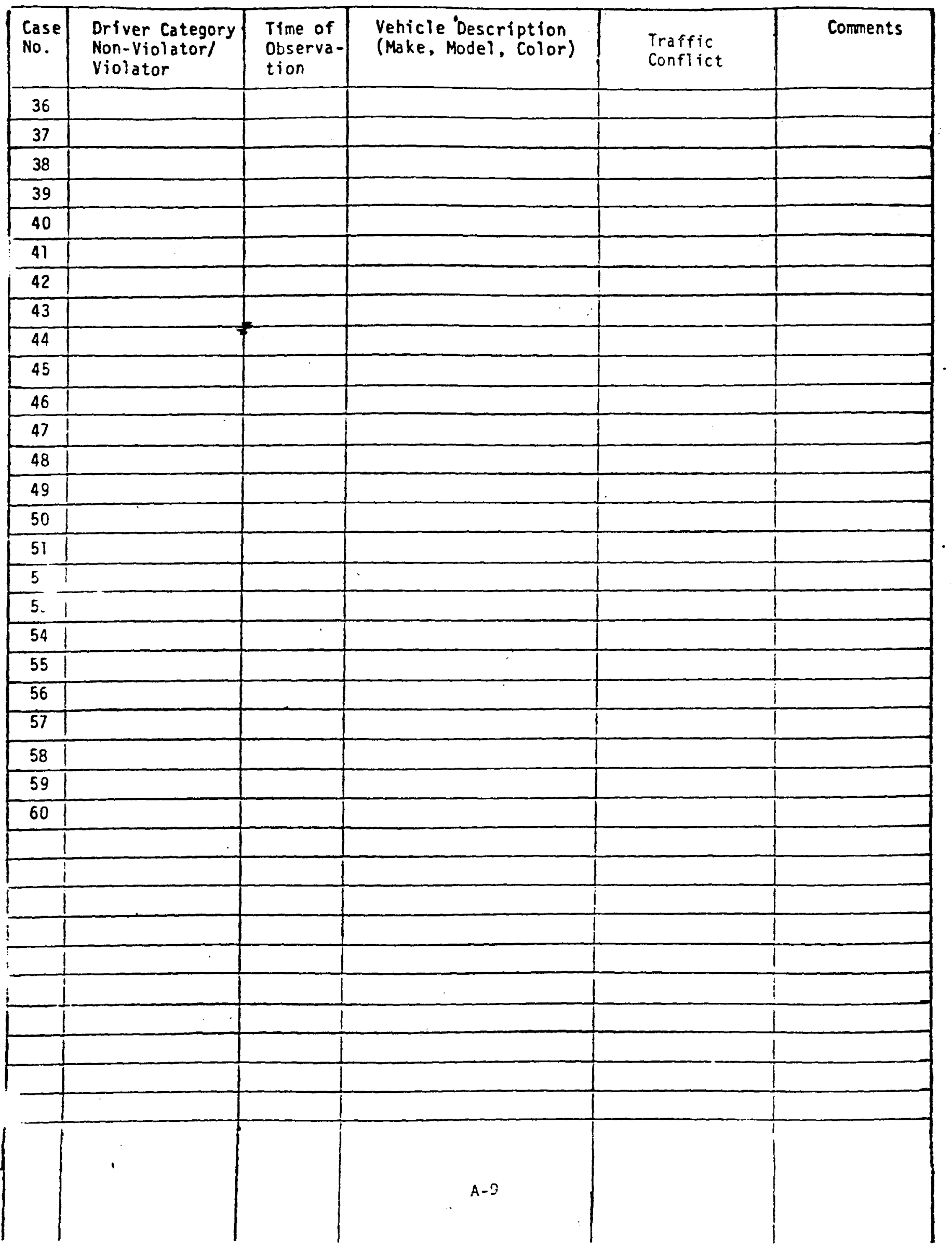


1. Observed behavior:

- 1. Speed, absolute (55)

- 2. Speed too fast for conditions

- 3. Speed too slow

- 4. Pulling in front

- 5. Turning left in front of traffic

- 6. Following

- 7. Running stop sign/traffic signal

- 8. Other

2. Case No.

3. Date (month/day/year)

4. Site

(road name)

5. Officer

6. Interviewer

7. Time of stop

8. Weather at time of stop:

$\begin{array}{ll}\text { 1. } & \text { Clear } \\ -2 . & \text { Cloudy } \\ -3 . & \text { Rain } \\ -4 . & \text { Snow } \\ - \text { 5. } & \text { Fog } \\ -6 . & \text { Other }\end{array}$

(specify)

9. Road conditions at time of stop:

$\begin{array}{ll}\text { 1. } & \text { Dry } \\ -2 . & \text { Wet } \\ - \text { 3. } & \text { Icy } \\ - \text { 4. } & \text { Snowy } \\ - \text { 5. } & \text { Other }\end{array}$

(specify)

10. Lighting at time of stop:

1. Dark
- 2. Dawn/Dusk

- 3. Light

11. Driver category:

1. Violator
-2 . Non-violator

12. Vehicle type:

1. Sub to small car

- 2. Mid to full-size car

- 3. Sports car

- 4. Jeep

- 5. Van

6. Pickup

- 7. Truck

- 8. Motorcycle

- 9. Recreational vehicle

- 10. Other (specify)

13. Vehicle make:

1. AMC

- 2. Buick

- 3. Cadillac

- 4. Chevrolet

- 5. Chrysler

- 6. Dodge

- 7. Ford

- 8. Lincoln

- 9. Mercury

- 10. Oldsmobile

- 11. Plymouth

- 12. Pontiac

- 13. Alfa Romeo

- 14. Aston Martin

- 15. Audi

- 16. BMW

- 17. Datsun

- 18. Ferrari

- 19. Fiat

- 20. Honda

- 21. Jaguar

- 22. Lancia

- 23. MG

- 24. Maserati

- 25. Mazda

- 26. Mercedes-Benz

- 27. Peugeot

- 28. Porsche

- 29. Renault

- 30. Rolls Royce

- 31. Saab

- 32. Subaru

- 33. TVR

- 34. Toyota

- 35. Triumph

- 36. Volvo

- 37. Volkswagen

-38 . 
14. Vehicle color:
1. Black
2. Blue
- 3. Brown
- 4. Gold
- 5. Gray/Silver
- 6. Green
- 7. Maroon
- 8. Red
- 9. Tan
- 10. White
- 11. Yellow

15. Vehicle condition:

- 1. Nothing unusua 1

-2. Excessive rust

- 3. Body damage (e.g., dents)

- 4. Equipment problems (e.g., muffler, speedometer)

5. Owner modifications

6. Other

$$
\text { (specify) }
$$

16. Driver wearing occupant restraints:

o. N/A

- 1. Yes

- 2. No

- 3. Not sure

17. Adult passengers:

$$
\text { Tnumber) }
$$

18. Child passengers:

$$
\text { (number) }
$$

19. Pets in vehicle:

$$
\text { Tnumber }
$$

20. Eating or drinking (non-aicohol) while driving:

1. Yes

- 3. Not sure

21. Loud radio or stereo:

- 1. Yes

- 3. Not sure

22. Other distractions:

- 1. Yes ${ }^{2}$ No (specify)

3. Not sure
23. Oriver sex:

- 1. Male

- 2. Femaie

24. Driver ethnicity:

- 1. White

- 2. Black

- 3. Hispanic

- 4. Oriental

- 5. Other

-

25. Driver impairment:

1. No evidence

- 2. Evidence, but not impaired

- 3. Evidence and impaired

- 4. Evidence and seriously impaired

- 5. Not sure

$$
\text { (explain) }
$$

26. Ride offered:

3. Yes
- 2. No

27. Reason for ride offer:

0. N/A

- 1. Alcohol impairment

- 2. Other drug impairment

-3. Fatigue

- 4. Illness

-5. Other

(specify)

28. Oriver accepted ride:

- $0 . \quad N / A$

- 1. Yes

Z2. No

29. Willingness to participate:

- 2. Readily

- 3. Refuse officer

- 4. Refuse interviewer

- 5. Fail to stop/turn around

- 6. Other 
30. Refusal reason:

0 . N/A

- 1. Late for work

- 2. Work-related trip

- 3. Late for non-work appointment

4. Late for social

(specify) engagement

- 5. Other $\frac{}{\text { (specify) }}$

(specify)

- 6. Unknown

31. Phone interview:

[If yes, give driver back of questionnaire to sign.]

$\begin{array}{ll}0 . & \text { N/A } \\ =1 . & \text { Yes } \\ -2 . & \text { No }\end{array}$

32. Interview place:

- 2. Van Carside

33. Interview start time

34. Interview stop time

35. Total interview time

(Subtract 33 from $3 \overline{4}$ ) 
Hello, I'm - This is

(interviewer name)

(Interviewer name) - We're from the University of Michigan.

$$
\text { We've stopped you to ask you to }
$$

take part in a highway safety study. It's not a traffic stop; you're not going to receive a ticket. The police officer is here only to control traffic.

We would like you to spend about 10 minutes to answer some questions for us about how you drive. We're trying to learn more about driving and your point of view. What we're interested in are your opinions about driving.

Will you help us out by answering some questions?

If driver hesitates, interviewer may counter as follows:

Possible driver excuses

1. Late; no time

2. Continued driver hesitation

3. Dislikes surveys

4. Mistrust of interviewers

5. Does not want to leave car

\section{Possible responses}

1. Washtenaw County has been selected by the federal government as the first test site for a national study. Your cooperation is very important to this study.

2. If it would help, we can provide you with a letter to verify that you took part in the study this morning (afternoon). If driver still hesitates, interviewer asks directly, "Will you participate?"

3. Same argument as \#1

4. Show personal identification and letter from Sheriff if necessary. Note police presence for driver's protection.

5. Can we conduct the interview at carside? 
If driver agrees to interview, explain that we have an interview van where the interview will be more comfortable. If driver does not want to go to interview van, offer to do interview at carside.

If driver refuses to participate, interviewer should note the reason for refusal. If driver does not offer a reason, interviewer should thank the driver and politely ask the reason for refúsal. For example: "Thank you for stopping and would you just tell us the reason for not wanting to participate? (pause) It would help in future study planning."

Also, if driver refuses to participate, interviewey should ask: "Would you be willing to be contacted by telephone at a later date to answer. some questions about your driving here today?" If yes; take driver name and phone number, and continue: "We may be contacting some additional arivers within the next couple of weeks."

Thank driver for stopping. 


\section{INFORMED CONSENT PROCEDURES}

Before we begin the interview, we are required to get your consent. If it's all right with you, we'd like to tape record this so that we will have a record of your agreement to participate.

Wait for driver response. If driver does not object to tape recorder, turn it on and read the informed consent statement.

If driver does not want to be tape recorded, ask to sign bottom of informed consent statement.

[Read Informed Consent Statement]

[If tape recorded:]

[If not tape recorded:]

$\downarrow$

Do you understand what I've just read?

[Pause for response.]

Will you participate?

[Pause for response.]

Now we're ready for the interview. If you don't object, may we keep the tape recorder on?

[Adhere to driver's response.]
Will you sign the bottom of this informed consent statement?

Hand statement to driver for signing.

Now we're ready for the interview. Would you mind if this was tape recorded?

[Adhere to driver's response.] 


\section{INFORMED CONSENT STATEMENT}

Your participation in this survey is completely voluntary.

\section{[Give driver Sheriff's letter.]}

Also, the Washtenaw County Sheriff and Prosecutor have agreed that you will not be ticketed for any traffic violations that may have been the reason you were stopped for this survey.

Any information you give us will be used to help make driving saffer for you and others.

Also, if you participate, you are free to quit at any point. You may also refuse to answer any question you find objectionable. All we ask is that you do answer the questions as accurately and honestly as possible. It is not a test; there are no right or wrong answers. We are really interested in your point of view and driving.

I understand the above and agree to be interviewed for this study. 
Ph.D. Program in Urban \& Regional Planning TRANSPORTATION PLANNING \& POLICY

506 E. Liberty Street

Ann Arbor, Michigan 48109

(313) 763-1276
THE UNIVERSITY OF MICHIGAN

2149 ART \& ARCHITECTURE BUILDING 2000 BONISTEEL BOULEVARD ANN ARBOR, MICHIGAN 48109

(313) $763-4190$

Dear Survey Participant:

You are being asked to participate in a research study conducted by The University of Michigan to find out why people drive . as they do. The results will be used to help make driving safer for you and others.

We have given this study our full support. You will not be ticketed or prosecuted for any driving behavior that resulted in your being stopped for this survey. The polii,e are here only to direct traffic--not to issue traffic tickets.

We hope that you can take the time to contribute to this important area of highway safety research by answering a few questions today.

Sincerely,

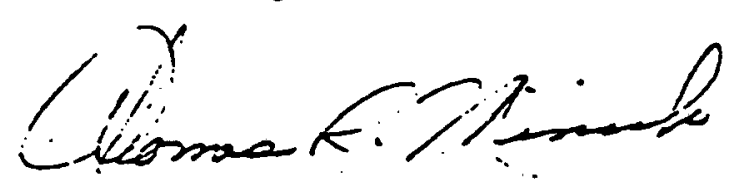

Sheriff Thomas R. Minick Washtenaw County

Kan Chen. Electrical and Computer Engineering, Program Director. Dónald R. Deskins, Rackham Graduate School; Mulan J. DLuhy. Social Work; RAChel Kaplan, Natural Resources; JohN D. Nrstilen. Geography; jack Rothman, Social Wotk; Kenneth H. Shapiro, Natural Resoutces. 
1. Had you heard about this study before being stopped just now?

- l. Yes

2. No $\rightarrow$ [Go to Question 3]

2. [If "Yes" to Question 1] Where did you hear about it?

- 1. Newspaper

- 2. TV/Radio

- 3. "Word of mouth"

- 4. Other

3. How many days did you drive last week? [Get specific number] days

4. Think about the vehicle you were following just before we stopped you. What kind of a vehicle was it?

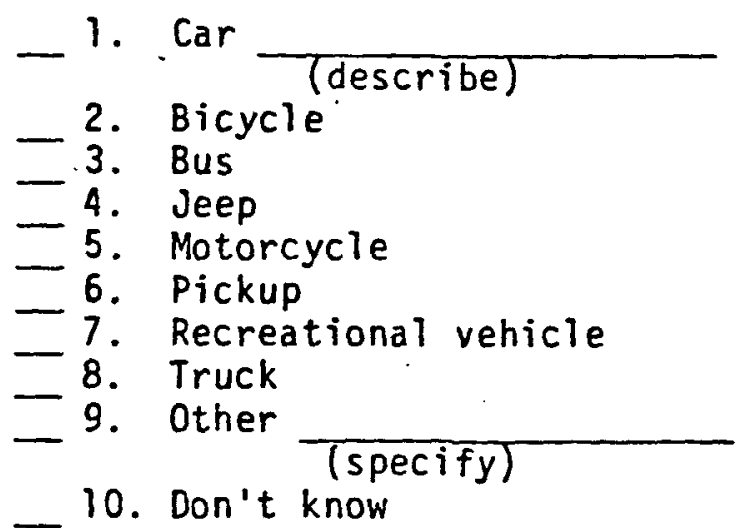

5. [Show driver scale of road.]

Can you show me the distance between you and that vehicle on this picture of the road?

[Note distance in inches (or fraction of an inch) aloud for recorder] inches 
6. $\left[\begin{array}{l}\text { Refer to scale of road; start at a following distance just } \\ \text { under that indicated by driver in Question } 5 \text {. }\end{array}\right]$

Do you think you would ever follow on this road

at this distance? [Show to driver on scale.]

Continue to reduce distance until driver answers "No."
Exclude "passing" or "emergency" responses. Note aloud
for recorder the distance in inches (or fraction of an
inch) at which driver answers "No."

inches

7. How come you wouldn't drive like that on this road?

[Check al] that apply.]

1. Illegal

- 2. Fear of enforcement

- 3. Road specific conditions

- 4. Traffic conditions

(specify)

- 5. Characteristics of locale

6. Vehicle-related

- 6. (specify)

- 7. Driver comfort

8. Unsafe $\rightarrow$ How so?

(specify)

- 9. Other

8. Where were you going just now when stopped? [Trip purpose]

- 1. Bar/Club

- 2. Restaurant

- 3. Own home

- 4. Friends/Relatives home

- 5. Sport/Recreation

- 6. Work/School (specify)

(specify)

(specify) 
10. How many times did you drive on this part of [road name]

in either direction in the last month? [Get specific number.]

[IF FIRST TIME, GO TO QUESTION 13.]

11. The distance between you and the vehicle you were following today--was

it different than your following distance the last time you drove on

this road? How so?

\section{- 1. Closer \\ - 2. More distance \\ - 3. Varied more today \\ - 4. No difference}

[IF NO DIFFERENCE, GO" TO QUESTION 13.]

12. Why were you following (closer/with more distance) today?

- 1. Driving a different car $\rightarrow$
What is it about this car that changed your following distance?
- 2. Late/Hurry

3: Traffic heavier
What is it about the heavier traffic that changed your following distance?

3. emergency

4. overslept

5. other

\section{specify}

1. reprimand

2. discipline

3. fired

4. embarrassed

What happened to make you late?

1. didn't manage time well

-2. unexpected delays; driver had no control over them int appointment

6. nothing

7. other (specify)

4. Traffic lighter

What is it about lighter traffic that changed your following distance? 
12. (Continued)

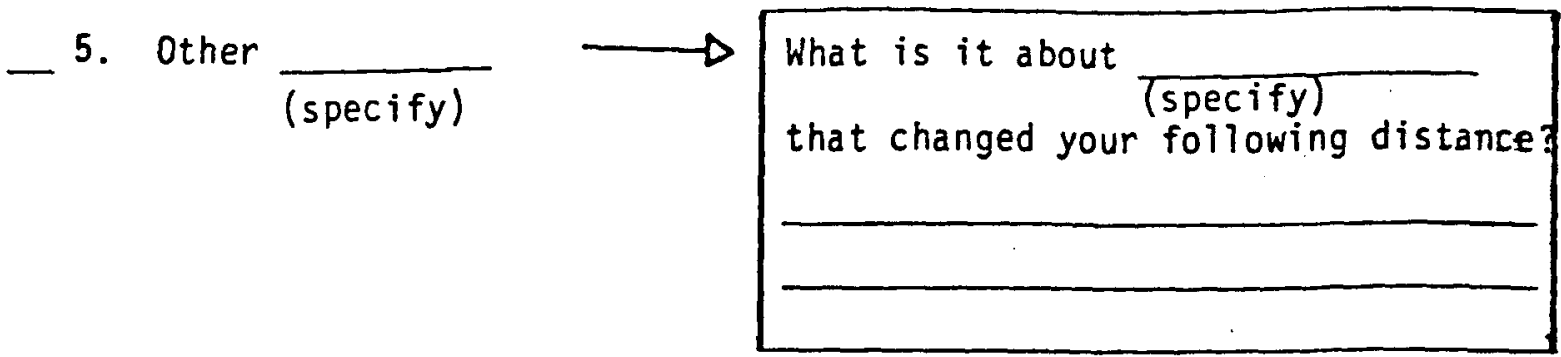

[IF DRIVER ANSWERED QUESTION 12, GO TO QUESTION 20.]

13. How did you feel when you started out on this driving trip?

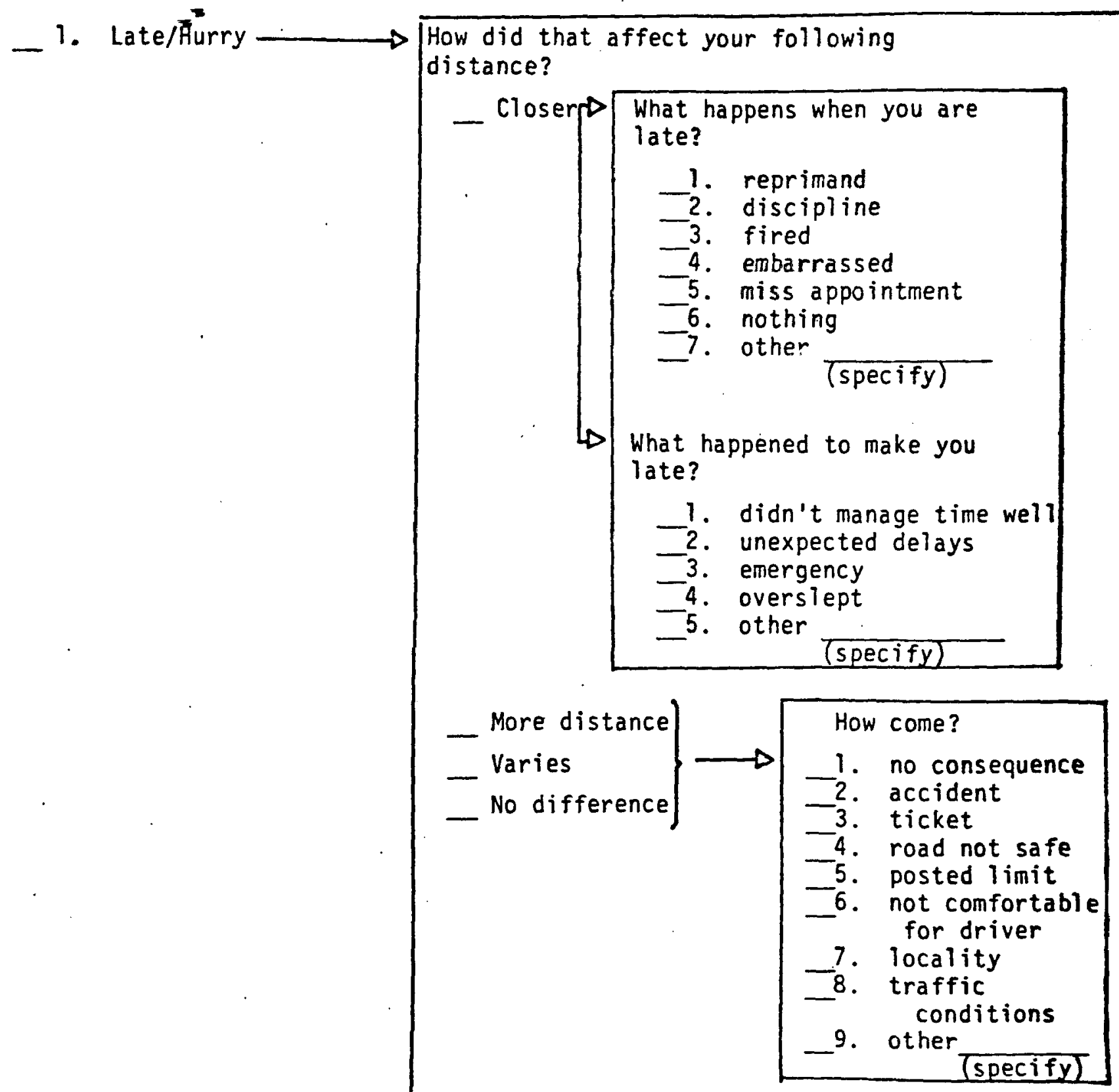


13. (Continued)

2. Tired

-3. Sick/111

-4. Angry

- 5. Nervous/Anxious

-6. Good mood/Happy

二7. Sad/Depressed

- 8. Preoccupied

- 9. Daydreaming

-10. "Under the influence"

- 11. Relaxed

- 12. Upset

- 13. Can't explain

- 14. Other

(specify)

- 15. OK, all right $\longrightarrow[$ Go to Question 14.]

IF DRIVER ANSWERED "OK, ALL RIGHT" TO QUESTION 13, ASK QUESTIONS 14-19; IF
DRIVER ANSWERED IN CATEGORIES $1-14$ IN QUESTION 13, GO TO QUESTION 20.

14. [Show driver diagram of 1-6 scale.]

On a scale of 1 to 6 , with 7 being "extremely unlikely" and 6 being "extremely likely," please say how likely your following distance will change when these people are in the car with you.
children
parents
husband/wife
in-laws
friends
acquaintances
brother/sister
other relatives

[For each "4," "5," or "6" response, ask the following:]

How does your following distance change with

(person)

Do you go closer, with more room, or what? Why is that? 
15. Sometimes drivers are affected by things going on around them. Do you follow other cars closer, with more distance, or what, when:

$\left[\begin{array}{ll}\text { 1. } & \text { Closer } \\ \text { 2. } & \text { More distance } \\ \text { 3. } & \text { Varies } \\ \text { 4. } & \text { No difference }\end{array}\right]$

a. A radio or tape is playing?

b. Talking to others in the car?

c. Do any other distractions affect your following distance? How so?

16. Drivers are often affected by their mood or what is on their mind. Tell me how these affect your following distance. Do you follow closer, with more room, or what?

$\left[\begin{array}{ll}\text { 1. } & \text { Closer } \\ \text { 2. } & \text { More distance } \\ \text { 3. } & \text { Varies } \\ \text { 4. } & \text { No difference }\end{array}\right]$,

_a. Being late, in a hurry

— b. Being angry

- c. Being happy; in a good mood

- d. Being nervous or anxious

- e. Being preoccupied or thinking about things

- f. Being relaxed

- g. Being sad or depressed

- h. Being tired

- i. Being "under the influence of alcohol"

- j. Being upset

- k. Daydreaming

- 1. Feeling sick or ill

- m. Anything els.e

(specify)

17. The last time you drove a vehicle larger than the one you are driving today, did you follow closer, with more room, or what?

- 1. Closer

- 2. More distance

3. Varied

4. No difference $\longrightarrow$ [Go to Question 20.]

5. N/A $\longrightarrow[$ Go to Question 20.] 
18. What kind of vehicle was that?

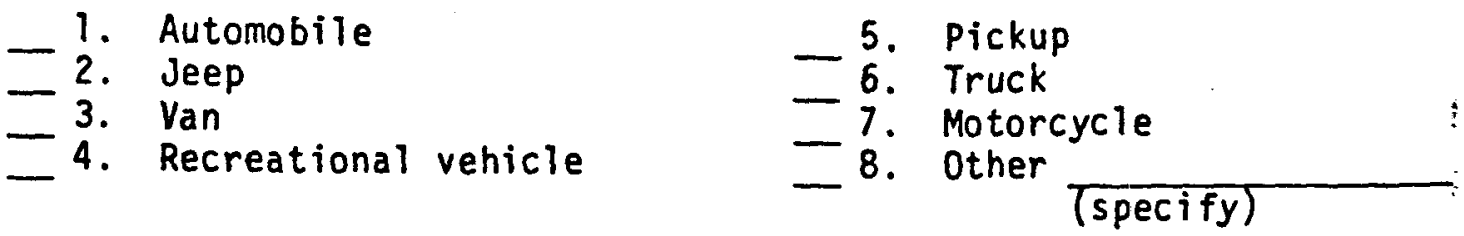

19. What made you follow (Fill in with response from Question 17.)

- 1. Comfort

- 2. Visibility or manueverability of vehicle

- 3. Familiarity of vehicle

- 4. Equipment-specific reason

-5. Other

(specify)

20. Are there any other reasons for changing your following distance on this type of road?

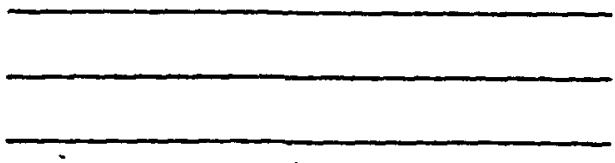

I have just a few more short questions to ask you.

21. How many years have you been driving?

22. How many years have you been driving this vehicle?

23. What is the model year of this vehicle?

24. Is this your vehicle?

$\begin{array}{ll}\text { 1. } & \text { Yes } \longrightarrow[\text { Go to Question 26.] } \\ -2 . & \text { No }\end{array}$

25. [Ask only if "No" to Question 24.]

Whose is it?

1. Friends

- 2. Parents

- 3. Other relatives

4. Job-related vehicle

- 5. Rental vehicle

- 6. Leased vehicle (through employer)

26. Have you ever received a traffic ticket for following-too-closely?.

- 1. Yes $\quad 2$. No $\longrightarrow[$ Go to Question 28.]

27. [If "Yes" to Question 26]

How many in the last 5 years? 
28. What is your occupation?

29. In what year were you born?

30. Where do you live? [Name of city, township, or village]

[Hand driver attitude items with pencil.]

Here are the final questions. Would you please answer them? 
PULLING-IN-FRONT/TURNING INTERVIEW QUESTIONS

-Set One-

1. Had you heard about this study before being stopped just now?

- 1. Yes

- 2. No $\rightarrow[$ Go to Question 3]

2. [1f "Yes" to Question 1] Where did you hear about it?

$\begin{array}{ll}\text { 1. } & \text { Newspaper } \\ \text { 2. TV/Radio } \\ \text { 3. } \\ \text { - } 4 . \text { Other } \frac{\text { Other mouth" }}{\text { (specify) }}\end{array}$

3. How many days did you orive last week? [Get specific number] days

4. Where did you turn onto this road [road name]? [e.g., from a driveway a parking lot, the name of another street.]

IIF DRIVER GIVES CORRECT RESPONSE, ASK QUESTION 5; IF TPIVER GIVES
INCORRECT RESPONSE, GO TO QUESTION 8 .

5. Think about the vehicle you (pulled/turned) in front of. What kind of a vehicle was it?

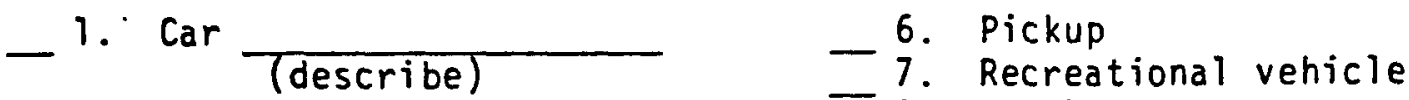

$$
\begin{aligned}
& \text { 2. Bicycle } \quad \text { - 8. Truck } \\
& \text { - 3. Bus - 9. Dther } \\
& \text { - 4. Jeep } \\
& \text { - 5. Motorcycle } \\
& \text { 10. Don't know }
\end{aligned}
$$

6. [Show driver scale of road.]

Can you show me the distance between you and that vehicle on this picture of the road?

[Note distance in inches (or fraction of an inch) aloud for recorder] inches 
7. $\left[\begin{array}{l}\text { Refer to scale of road; start at a pull-out/turn distance just } \\ \text { under that indicated by driver in Question } 5 \text {. }\end{array}\right]$

Do you think you would ever pull-out/turn on this road

at this distance? [Show to driver on scale.]

Continue to reduce distance until driver answers "No."
Exclude "passing" or "emergency" responses. Note aloud
for recorder the distance in inches (or fraction of an
inch) at which driver answers "No."

inches

8. How come you wouldn't drive like that on this road?

[Check all that apply.]

1. Illegal

- 2. Fear of enforcement

- 3. Road specific conditions

- 4. Traffic conditions

(specify)

(specify)

- 5. Characteristics of locale

6. Vehicle-related

(specify)

-

7. Driver comfort

(specify)

8. Unsafe $\rightarrow$ How so? $\frac{}{\text { (specify) }}$

- 9. Other

9. Where were you going just now when stopped? [Trip purpose]

1. Bar/Club

- 2. Restaurant

- 3. Own home

- 4. Friends/Relatives home

- 5. Sport/Recreation

- 6. Work/School
7. Shopping/Errands

- 8. Work-related appointment

- 9. Non-work appointment

- 10. Driving around/Joyriding

- 11. Refused to answer

- 12. Other

(specify)

10. Where did you start out from?

1. Bar/Club

- 2. Restaurant

- 3. Own home

- 4. Friends/Relatives home

- 5. Sport/Recreation

- 6. Work/School

\section{Shopping/Errands}

- 8. Work-related appointment

-9. Non-work appointment

- 10. Driving around/Joyriding

- 11. Refused to answer

— 12. Other 
11. How many times did you drive on this part of [road name]

in either direction in the last month? [Get specific number.]

\section{[IF - FIRST TIME, GO TO QUESTION 14.]}

12. The distance between you and the vehicle you (pulled/turned) in front of today--was it different than the last time you turned

like that? How so?

1. Closer

- 2. More distance

- 3. Varied more today

- 4. No difference

[IF"NO DIFFERENCE", GO TO QUESTION 14.]

13. Why were you turning (closer/with more room) today?

- 1. Driving a different car $\rightarrow$
What is it about this car that changed your turning distance?

What happens if you are late?

1. reprimand

2. discipline

3. fired

4. embarrassed

5. miss appointment

6. nothing

7. other

(specify)

What happened to make you late?

1. didn't manage time well

2. unexpected delays; driver had no control over them

3. emergency

4. overslept

5. other

(specify)

What is it about the heavier traffic that changed your turning distance?

What is it about lighter traffic that changed your turning distance? 
13. (Continued)

- 5. Other $\frac{.}{(\text { specify })}$

What is it about that changed your turning distance?

[IF DRIVER ANSWERED QUESTION 13, GO TO QUESTION 21.$]$

14. How did you feel when you started out on this driving trip?

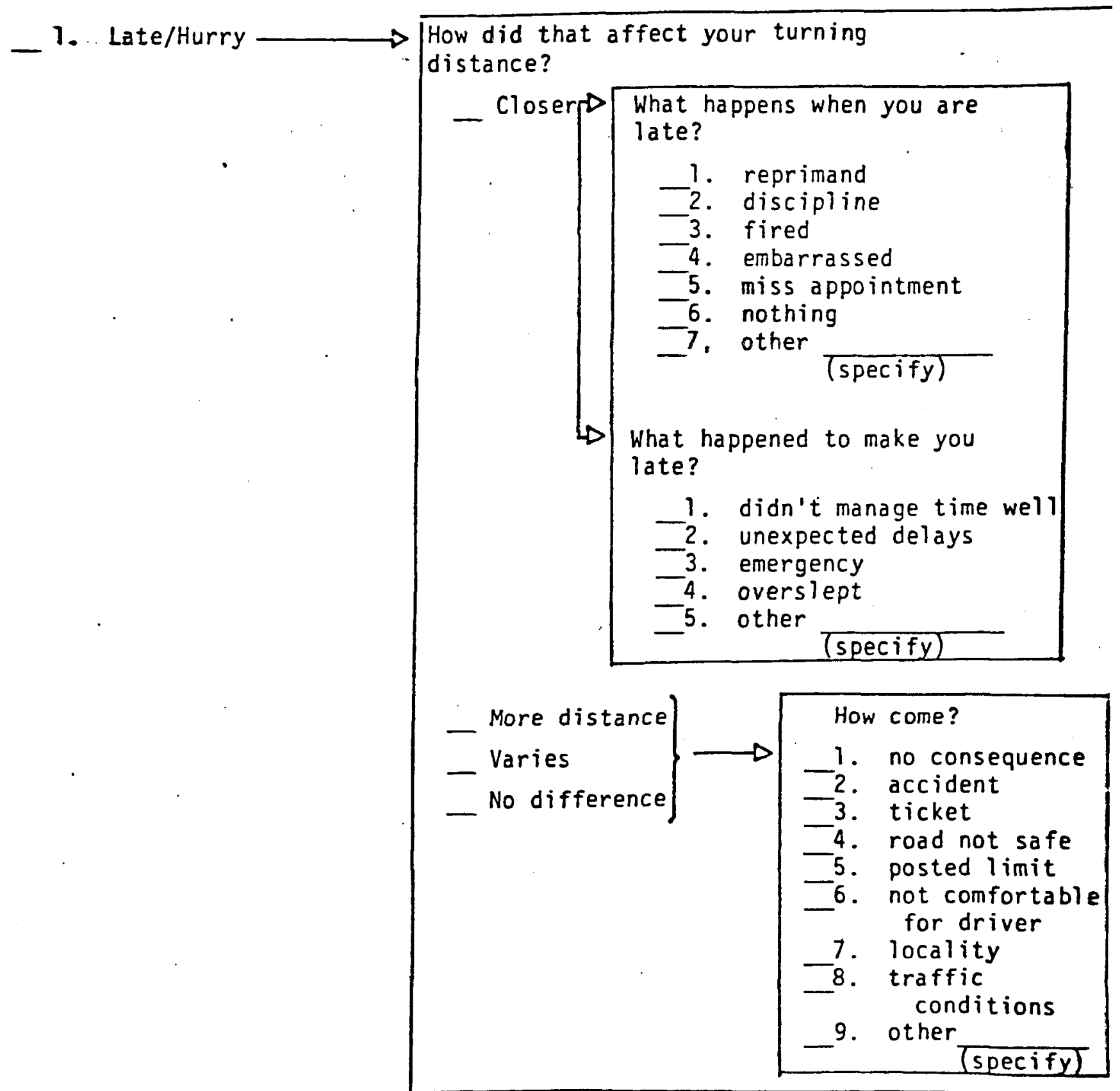


14. (Continued)

- 2. Tired

-3. Sick/111

- 4. Angry

- 5. Nervous/Anxious

-6. Good mood/Happy

-7. Sad/Depressed

- 8. Preoccupied

- 9. Daydreaming

- 10. "Under the influence"

- 11. Relaxed

- 12. Upset

- 13. Can't explain

- 14. Other (specify)

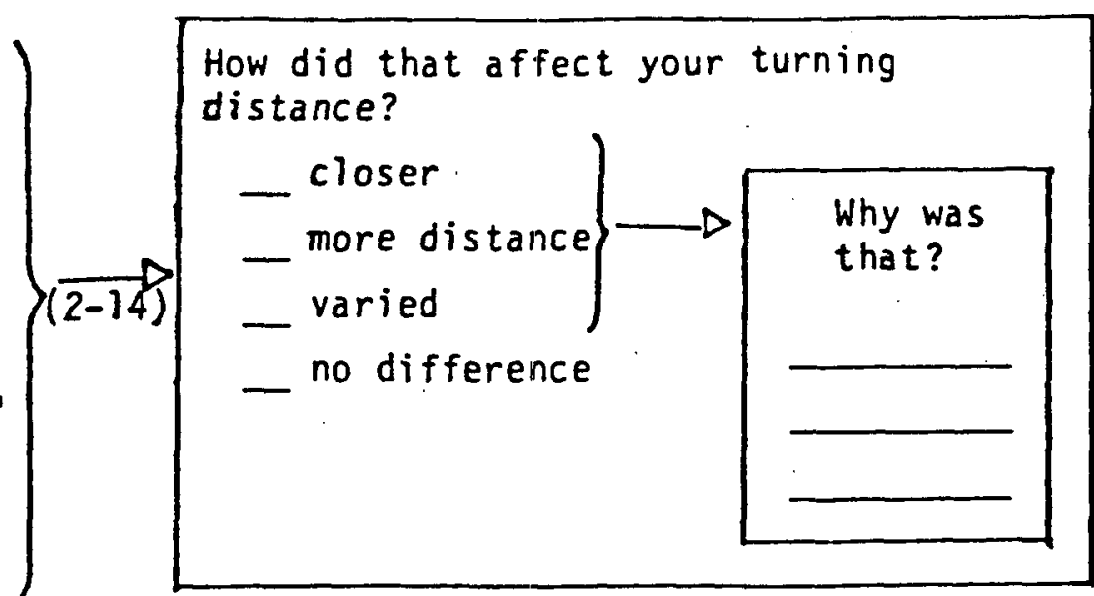

How did that affect your turning distance?

- 15. OK, all right $\longrightarrow[$ Go to Question 15.]

IF DRIVER ANSWERED "OK, ALL RIGHT" TO QUESTION 14, ASK QUESTIONS 15-20; IF
DRIVER ANSWERED IN CATEGORIES $1-14$ IN QUESTION 14, G0 TO QUESTION 21.

15. [Show driver diagram of 1-6 scale.]

On a scale of 1 to 6 , with 1 being "extremely unlikely" and 6 being "extremely likely," please say how likely your (turning/pulling into traffic) will change when these people are in the car with you.

children
parents
husband/wife
in-laws

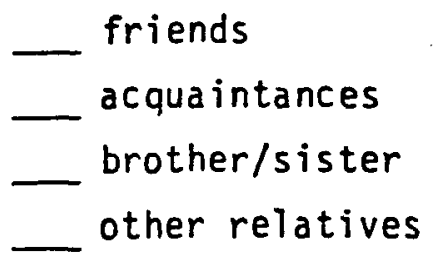

[For each "4," "5," or "6" response, ask the following:]

How does your (turning/pulling into traffic) change with (person)

Do you turn/pull into traffic closer, with more room, or what? Why is that? 
16. Sometimes drivers are affected by things going on around them. Do you (turn/pull into traffic) closer, with more room, or what when:

$\left[\begin{array}{ll}\text { 1. } & \text { Closer } \\ \text { 2. } & \text { More distance } \\ \text { 3. } & \text { Varies } \\ \text { 4. } & \text { No difference }\end{array}\right]$

a. A radio or tape is playing?

b. Talking to others in the car?

c. Do any other distractions affect your turnina? How so?

17. Drivers are often affected by their mood or what is on their mind.

Tell me how these affect your (turning/pulling into traffic). Do you turn closer, with more room, or what?

$\left[\begin{array}{ll}\text { 1. } & \text { Closer } \\ \text { 2. } & \text { More distance } \\ 3 . & \text { Varies } \\ 4 . & \text { No difference }\end{array}\right]$

a. Being late, in a hurry

b. Being angry

c. Being happy; in a good mood

d. Being nervous or anxious

e. Being preoccupied or thinking about things

f. Being relaxed

g. Being sad or depressed

h. Being tired

i. Being "under the influence of alcohol"

j. Being upset

k. Daydreaming

- 1. Feeling sick or ill

- m. Anything else

(specify)

18. The last time you drove a vehicle larger than the one you are driving today, did you (turn/pull into traffic) closer, with more room, or what?

- 1. Closer

2. More distance

3. Varied

4. No difference $\longrightarrow$ [Go to Question 21.]

5. N/A $\longrightarrow[$ Go to Question 21.] 
19. What kind of vehicle was that?

\begin{tabular}{ll} 
1. Automobile & -5. Pickup \\
- 2. Jeep & -6. Truck \\
- 3. Van & -7. Motorcycle \\
- 4. Recreational vehicle & -8. Other \\
\hline
\end{tabular}

20. What made you turn

(Fill in with response from Question 18.)

1. Comfort

- 2. Visibjlity or manueverability of vehicle

- 3. Familiarity of vehicle

- 4. Equipment-specific reason

- 5. Other

(specify)

27. Are there any other reasons for changing the way you (turn/pull into traffic) on this type of road?

I have just a few more short questions to ask you.

22. How many years have you been driving?

23. How many years have you been driving this vehicle?

24. What is the model year of this vehicle?

25. Is this your vehicle?

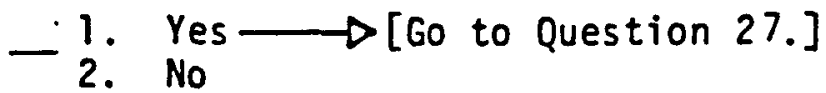

26. . [Ask only if "No" to Question 2 5.]

Whose is it?

1. Friends

- 2. Parents

- 3. Other relatives

- 4. Job-related vehicle

- 5. Rental vehicle

- 6. Leased vehicle (through employer)

27. Have you ever received a traffic ticket for unsafe (turning/pulling) into traffic?

1. Yes $\quad$ 2. No $\longrightarrow[$ Go to Question 29.]

28. [If "Yes" to Question 27.]

How many in the last 5 years? 
29. What is your occupation?

30. In what year were you born?

31. Where do you live? [Name of city, township, or village]

[Hand driver attitude items with pencil.] Here are the final questions. Would you please answer them? 
1. Had you heard about this study before being stopped just now?

1. Yes
-2 . No $\rightarrow[$ Go to Question 3]

2. [If "Yes" to Question 1] Where did you hear about it?

$$
\begin{array}{ll}
\text { 1. Newspaper } \\
\text { - 2. TV/Radio } \\
\text { - 3. "Word of mouth" } \\
\text { - 4. Other }
\end{array}
$$

3. How many days did you drive last week? [Get specific number] days

4. Can you tell me how far back the last stop sign you passed was? [Number of intersections or street name]

$\left[\begin{array}{l}\text { IF DRIVER GIVES CORRECT INTERSECTION ASK QUESTIONS } 5 \text { THROUGH } 8 ; \\ \text { IF DRIVER GIVES WRONG INTERSECTION, GO TO QUESTION } 9 .\end{array}\right.$

5. How would you say you drove through that interestion? Did you stop, roll through, run through?

\section{[IF DRIVER ANSWERED "RUN THROUGH," GO TO QUESTION 7.]}

6. Do you think you would ever run through that stop sign?
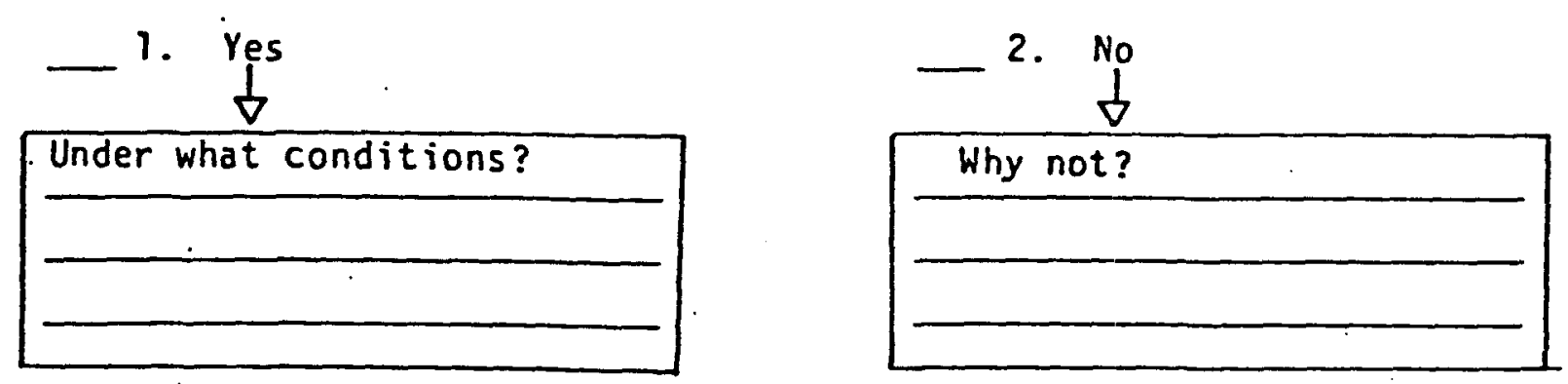

7. Is the way you drove through that intersection today different than the last time you drove through it? [How is that?]

1. Did not stop or sent through faster today.

2. Stopped or went through slower today.

3. No difference $\longrightarrow$ [Go to Question 9]

4. First time on this road today $\longrightarrow$ [Go to question 10] 
8. Why did you stop differently today?

- 1. Driving a different car $\rightarrow$
What is it about this car that changed your stopping?

What happens if you are late?

1. reprimand

2. discipline

3. fired

4. embarrassed

5. miss appointment

6. nothing

7. other

(specify)

What happened to make you late?

1. didn't manage time well.

2. unexpected delays; driver had no control over them

3. emergency

4. overslept

5. other

3. Traffic heavier

What is it about the heavier traffic that changed your stopping?

4. Traffic lighter

What is it about lighter traffic that changed your stopping?

5. Other

$$
\text { (specify) }
$$

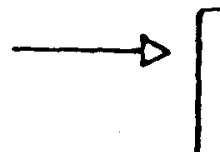

What is it about

$$
\text { (specify) }
$$

that changed your stopping?

9. How rany times did you drive on this part of [road nare] in either direction in the last month? [Get specific number] 
10. Where were you going just now when stopped? [Trip purpose]

$\begin{array}{ll}\text { 1. } & \text { Bar/Club } \\ \text { - 2. Restaurant } \\ \text { - 3. Own home } \\ \text { - } \text {. Friends/Relatives home } \\ \text { - } \text {. } \text { Sport/Recreation } \\ \text { - Work/School }\end{array}$

11. Where did you start out from?

1. Bar/Club

2. Restaurant

- 3. Own home

- 4. Friends/Relatives home

- 5. Sport/Recreation

- 6. Work/School
- 7. Shopping/Errands

- 8. Work-related appointment

- 9. Non-work appointment

- 10. Driving around/Joyriding

- 11. Refused to answer

- 12. Otrer

[IF DRIVER ANSWERED QUESTIION 8, GO TO QUESTION 20]

12. How did you feel when you started out on this driving trip?

1. Late/Hurry

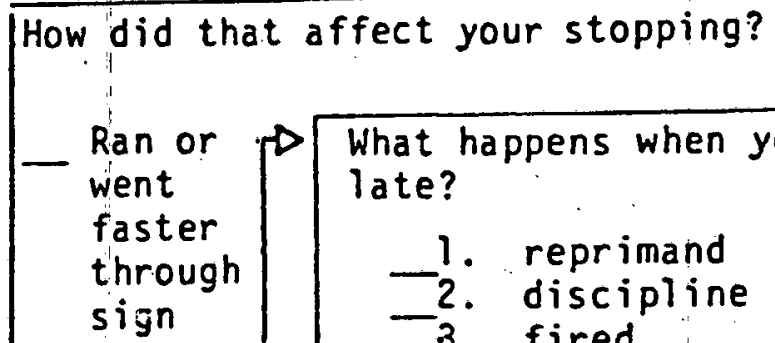

How did that affect your stopping?

Ran or went faster through sign

7. Shopping/Errands

8. Hork-related appointment

9. Non-work appointment

10. Driving around/Joyriding

11. Refused to answer

(specify) 
12. (Continued)

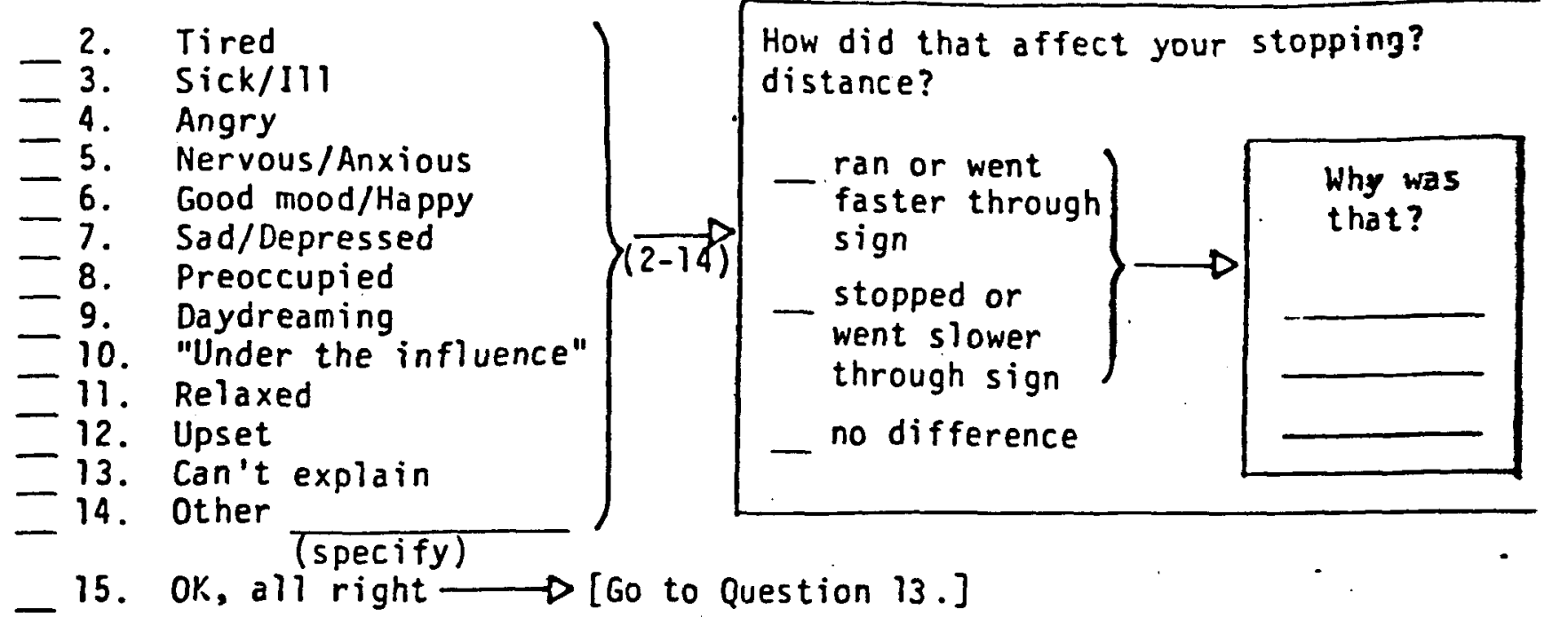

IF DRIVER ANSWERED "OK, ALL RIGHT" TO QUESTION 12, ASK QUESTIONS 13-19; IF
DRIVER ANSWERED IN CATEGORIES 1-14 IN QUESTION 13, GO TO QUESTION 20;"

13. [Show driver diagram of 1-6 scale.]

On a scale of 1 to 6 , with 1 being "extremely unlikely" and

6 being "extremely likely," please say how likely your

stopping will change when these people are in the car with you
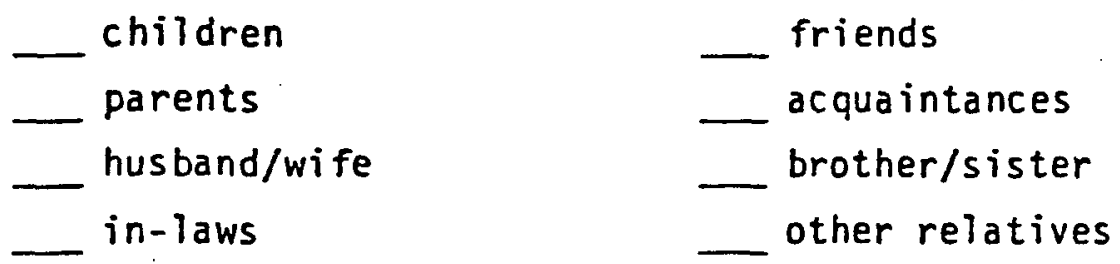

[For each "4," "5," or "6" response, ask the following:]

How does your stopping change with (person)

Do you go through the stop sign faster, slower, or what? Why is that? 
14. Sometimes drivers are affected by things going on around them. Do you stop more or less carefully or what, when:

$\left[\begin{array}{ll}\text { 1. } & \text { Less carefully } \\ \text { 2. } & \text { More carefull.v } \\ \text { 3. } & \text { Varies } \\ \text { 4. } & \text { No difference }\end{array}\right]$

a. A radio or tape is playing?

b. Talking to others in the car?

c. Do any other distractions affect your stoppinq? How so?

15. Drivers are often affected by their mood or what is on their mind. Tell me how the following affect your stopping. Do you stop less or more caretully or what?

$\left[\begin{array}{ll}\text { 1. } & \text { Less carefully } \\ \text { 2. } & \text { More carefully } \\ \text { 3. } & \text { Varies } \\ \text { 4. } & \text { No difference }\end{array}\right]$

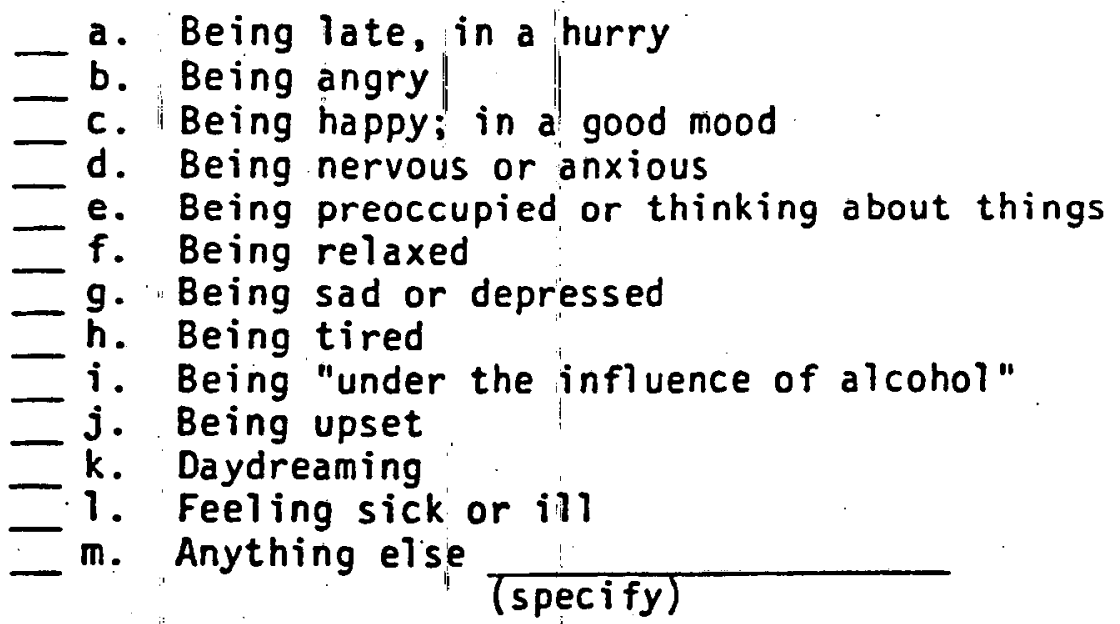

16. The last time you drove a vehicle larger than the one you are driving today, did you stop less or more carefully or what?

- 1. Less carefully

2. More carefully

3. Varied

4. No difference $\longrightarrow$ [Go to Question 19.]

- 5. N/A $\longrightarrow[$ [Go to Question 19.] 
17. What kind of vehicle was that?

1. Automobile

- 2. Jeep

3. Van

- 4. Recreational vehicle

- 5. Pickup

6. Truck

- 7. Motorcycle

- 8. Other

\section{(specify)}

18. What made you stop

(Fill in with response from Question 15.)

1. Comfort

- 2. Visibility or manueverability of vehicle

- 3. Familiarity of vehicle

- 4. Equipment-specific reason

5. Other

- (specify)

19. Are there any other reasons for changing your driving on this type of road?

I have just a few more short questions to ask you.

20. How many years have you been driving?

21. How many years have you been driving this veticle?

22. What is the model year of this vehicle?

23. Is this your vehicle?

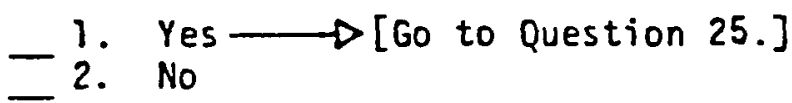

24. [Ask only if "No" to Question 23.]

Whose is it?

1. Friends

- 2. Parents

- 3. Other relatives

4. Job-related vehicle

- 5. Rental vehicle

- 6. Leased vehicle (through employer)

25. Have you ever received a traffic ticket for running a stop sign or traffic signal

-1. Yes $\quad$ 2. No $\longrightarrow[$ Go to Question 27.$]$

26. [If "Yes" to Question 25]

How many in the last 5 years? 
27. What is your occupation?

28. In what year were you born?

29. Where do you live? [Name of city, township, or village]

[Hand driver attitude items with pencil.]

Here are the final questions. Would you please answer them? 
Listed below are 10 statements of how people feel about driving. We are interested in how you agree or disagree with the statement. Please indicate whether you strongly agree, agree, neither, disagree, or strongly disagree that the statement is true for you. . There are no right or wrong answers; the only important answer is how you feel.

1. There is no way I can reduce the chances of my being in an automobile accident.

2. I have a responsibility to myself and to others when I am driving a car.

3. The best way to get a slow car off the road is to tailgate.

4. I feel a rot less tense when I drive under the speed limit.

5. I don't think of getting hit on the road because other drivers are careful.

6. As long as I can stop quickly, I don't worry about how close

I am to another car.

7. Traffic regulations impose on my personal freedom.

8. The road belongs to the drivers so they should be able to set their own speed limits.

9. Most automobile accidents are beyond the driver's control.

10. I am very confident about my own driving.

\begin{tabular}{|c|c|c|c|c|}
\hline $\begin{array}{l}\text { Strongly } \\
\text { Agree }\end{array}$ & Agree & Neither & Disagree & $\begin{array}{l}\text { Strongly } \\
\text { Disagree }\end{array}$ \\
\hline 5 & 4 & ${ }^{3}$ rcie one) & ) & 1 \\
\hline 5 & ${ }^{4}$ (c & $\stackrel{3}{3}^{(1)}$ one) & ) & 1 \\
\hline 5 & ${ }^{4}(c$ & ${ }^{3}$ & ) & 1 \\
\hline 5 & ${ }^{4} / c$ & ${ }^{3}$ ircle one) & ) & 1 \\
\hline 5 & 4 & ${ }^{3}$ ircle one) & 2 & 1 \\
\hline 5 & ${ }^{4}(c$ & ${ }^{3}$ & 2 & 1 \\
\hline 5 & ${ }^{4} \cdot(c$ & ${ }^{3}$ ircle one) & ) & 1 \\
\hline 5 & ${ }^{4}$ (c & $\stackrel{3}{\text { ircle one) }}$ & 2 & 1 \\
\hline 5 & ${ }^{4}$ (c & ${ }^{3}$ ircle one) & 2 & 1 \\
\hline 5 & ${ }^{4}(c$ & $\stackrel{3}{\text { rcle one }}$ & 2 & 1 \\
\hline
\end{tabular}


1.. Are you currently ... (Choose the one that now fits you best.)

- 1. Never married

- 2. Married. How long?

- 3. Separated. How long?

- 4. Divorced. How long?

5. Widowed. How long?

2. What was the last level you completed in school? Please circle the last grade completed.

$\begin{array}{lrrrrrrrr}\text { elementary } & 1 & 2 & 3 & 4 & 5 & 6 & 7 & 8 \\ \text { high school } & 9 & 10 & 11 & 12 & & & & \\ \text { college } & 13 & 14 & 15 & 16 & & & & \\ \text { graduate } & 17 & 18 & 19 & 20 & 21 & 22 & & \end{array}$

3. Please indicate your household income by checking the appropriate line.

- 1. less than $\$ 4,999$ per year

2. $\$ 5,000$ to $\$ 9,999$ per year

3. $\$ 10,000$ to $\$ 14,999$ per year

4. $\$ 15,000$ to $\$ 24,999$ per year

5. $\$ 25,000$ to $\$ 49,999$ per year

6. $\$ 50,000$ or more per year

4. How many thousands of miles do you drive a year? 


\section{BACKGROUND QUESTIONS}

1. Are you currently ... (Choose the one that now fits you best.)

- 1. Never married

- 2. Married. How long?

- 3. Separated. How long?

- 4. Divorced. How long?

- 5. Widowed. How long?

2. What was the last level you completed in school? Please circle the last grade completed.

$\begin{array}{lrrrrrrrr}\text { elementary } & 1 & 2 & 3 & 4 & 5 & 6 & 7 & 8 \\ \text { high school } & 9 & 10 & 11 & 12 & & & & \\ \text { college } & 13 & 14 & 15 & 16 & & & & \\ \text { graduate } & 17 & 18 & 19 & 20 & 21 & 22 & & \end{array}$

3. Please indicate your household income by checking the appropriate line.

1. less than $\$ 4,999$ per year

2. $\$ 5,000$ to $\$ 9,999$ per year

3. $\$ 10,000$ to $\$ 14,999$ per year

4. $\$ 15,000$ to $\$ 24,999$ per year

5. $\$ 25,000$ to $\$ 49,999$ per year

6. $\$ 50,000$ or more per year

4. How many thousands of miles do you drive a year? 


\section{BACKGROUND QUESTIONS}

1. In what year were you born?

2. What is your job or occupation?

3. Are you currently ... (Choose the one that now fits you best.)

- 1. Never married

2. Married. How long?

- 3. Separated. How long?

- 4. Divorced. How long?

5. Widowed. How long?

4. What was the last level you completed in school? Please circle the last grade completed.

$\begin{array}{lrrrrrrrr}\text { elementary } & 1 & 2 & 3 & 4 & 5 & 6 & 7 & 8 \\ \text { high school } & 9 & 10 & 11 & 12 & & & & \\ \text { college } & 13 & 14 & 15 & 16 & & & & \\ \text { graduate } & 17 & 18 & 19 & 20 & 21 & 22 & & \end{array}$

5. Please indicate your household income by checking the appropriate line.

1. less than $\$ 4,999$ per year

2. $\$ 5,000$ to $\$ 9,999$ per year

3. $\$ 10,000$ to $\$ 74,999$ per year

4. $\$ 15,000$ to $\$ 24,999$ per year

5. $\$ 25,000$ to $\$ 49,999$ per year

6. $\$ 50,000$ or more per year

6. How many thousands of miles do you drive a year?

7. Where do you live? (the name of your city, township, or village) 


\section{"Thank You"}

Thank you very much for talking with us today. Your answers will be helpful in making highways safer for all drivers. [Hand driver thank-you letter]. Here is a letter explaining a little more about the study and thanking you for your participation. Also, if you are going to be late for work or an appointment, we can give you a letter explaining where you were this morning. [Wait for driver response].

Once again, thank you very much. 


\section{Ph.D. Program in Urban \& Regional Planning}

TRANSPORTATION PLANNING \& POLICY

506 E. Liberty Street

Ann Arbor, Michigan 48109

(313) $7.63-1276$
THE. UNIVERSITY OF MICHIGAN

2149 ART \& ARCHITECTURE BUILDING 2000 BONISTEEL BOULEVARD ANN ARBOR, MICHIGAN 48109

(313) 763.4190

To Whom It May Concern:

This driver has participated in a roadside survey of drivers today, , at - We regret any inconvenience this may have caused to you.

This study is sponsored by the National Highway Traffic Safety Administration (NHTSA) of the U.S. Department of Transportation. NHTSA is sponsoring the study as a part of an international program of road safety research to obtain data on the underlying reasons for the driver behaviors that result in death, injuries and losses in excess of forty billion dollars each year in the United States.

The responses that this driver has given us today will help in providing us with much needed information to further improve nighway safety.

Again, we apologize for any inconvenience to you and thank you for your consideration.

Sincerely,

Interviewer

Kan Chen, Electrical and Computer Engineering, Program Director. Donald R. Deskins, Rackham Graduale School; Milan J. Dluhy. Social Work; RAChel KAplan. Nalutal Resources; Johx D). NYstuen, Geography: jack Rothman, Social Work; KenNeth H. ShApIRo, Natural Resources. 
Ph.D. Program in Urban \& Regional Planning TRANSPORTATION PLANNING \& POLICY

506 E. Liberty Street

Ann Arbor, Michigan 48109

(313) $763-1276$

\section{THE UNIVERSITY OF MICHIGAN}

2149 ART \& ARCHITECTURE BUILDING 2000 BONISTEEL BOULEVARD ANN ARBOR, MICHIGAN, 48109

(313) $763-4190$

Dear Survey Participant:

Your participation in our roadside survey has been invaluable.

Unsafe driving actions have been shown to be causaliy involved in over eighty-five percent of traffic crashes". These actions are defined as. acts or omissions by drivers that increase the risk of a traffic crash. In this study information is being collected to describe the reasons drivers undertake, or refrain from undertaking, specific unsafe driving behaviors.

This study is being sponsored by the National Highway Traffic Safety Administration (NHTSA) of the U.S. Department of Transportation. NHTSA is sponsoring the study as a part of an international program of roadside safety research to obtain data on the underlying reasons for the driver behaviors that result in death, injuries, and losses in excess of forty billion dollars each year in the United States.

The answers that you have given today will help in providing us with this much needed information to improve highway safety.

Thank you very much for your time, and cooperation.

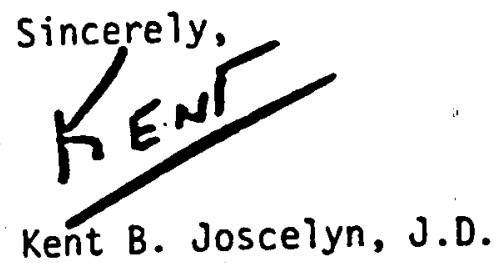

Project Director

Kan Con, Electrical and Computer Engineering, Program Director. Donald R. Desxins, Rachham Graduate School; MiLAN J. DLUhy, Social Work; RACHEL KAPLAN, Natural Resources; JohN D. NYstuen, Geography; JACK Rothman. Social Work; KenNeth H. Shapiro, Natural Resources. 


\section{APPENDIX B}

SUPPORTING STATEMENT FOR CLEARANCE REQUEST TO THE OFFICE OF MANAGEMENT AND BUDGETS 


\section{SUMMARY}

Unsafe driving actions (UDAs), on the part of the driver, have been shown to be causally involved in over eighty-five percent of traffic crashes. These actions are defined as acts or omissions by drivers that increase the risk of a traffic crash to an unacceptable level. A better understanding of the reasons for the occurrence of these UDAs is necessary to develop methods to reduce their incidence.

The study is" sponsored by the National Highwav Traffic Safety Administration (NHTSA) of the U.S. Department of Transportation. Seven UDAs have been proposed as candidates for study: speeding above the limit; speeding too fast for conditions; speed too slow; following too closely; pulling in front of traffic; turning left in front of traffic; and running a stop sign or traffic signal.

A roadside survey will be used to collect data. This approach is a well-established one in transportation and highway safety research. Roadside surveys have been reported since 1938 with literally hundreds of thousands of drivers participating. Preliminary testing of roadside survey procedures was undertaken for this study; results indicated that such procedures were both feasible and useful.

Using standard procedures for roadside surveys, Arivers who have committed UDAs will be identified, stopped, advised of the purposes of the study, and asked to participate. (These procedures are described in Section 2.) A like number of drivers from the same roadway set who have not committed a UDA and whose behavior presents a low risk will also be stopped and asked to participate. No more than fourteen sites will be used. All will be located in Washtenaw County, Michigan.

The drivers will be identified by an observer who is a member of the survey team. A police officer will signal the triver to stop, advise the driver that the stop is part of a roadside survey and direct the driver to a member of the research team who will explain the purposes of the sturtv and obtain the driver's informed consent. The study protocol explicitly provides for minimal contact between the officer and the subjects. If a 
driver consents, an interview will be conducted. Drivers who do not wish to participate will be thanked for stopping and then guided back into the traffic flow.

The information obtained in the study will be used to help NHTSA identify future driver-oriented countermeasure programs. 


\section{SUPPORTING STATBMENT FOR OMB CLEARANCE REQUEST: IDENTIFICATION OF MOTIVATIONS POR UNSAFB DRIVING ACTIONS AND POTENTIAL COUNTERMEASURES}

\section{JUSTIFICATION}

(i) Necessity for the study

Unsafe driving actions (UDAs) have been shown to be causally involved in over eighty-five percent of traffic crashes. These actions are defined as acts or omissions by drivers that increase the risk of a traffic crash to an unacceptable level. This may occur as a result of intentional or unintentional behavior.

The National Highway Traffic Safety Administration (NHTSA) has initiated a number of efforts to identify and define UDAs. The Universitv of North Carolina Highway Safety Research Center has completed a project for NHTSA that provides a preliminary identification of the principal UDAs. Also, The Universitv of Michigan Highwav Safety Research Institute (HSRI) has recently completed work on comprehensive definitions of "high risk" UDAs and the feasibility of their measurement and analysis (Treat et al. 1980).

The proposed research recognizes the importance to countermeasure design of knowing precisely why these UDAs are or are not committed, since different reasons (i.e., motivations) will often imply a need for different countermeasures. Yet while considerable research has been conducted regarding the attitudinal and personality bases for risk-taking behavior, we know of no comparable effort to date to determine the reasons that drivers undertake, or refrain from undertaking, specific unsafe triving behaviors. The proposed research thus is timely and of potential importance.

The roadside survey approach was selected for this studv because it 
addresses the following concerns. First, the need to identify drivers who actually commit UDAs is paramount. Contacting drivers in a setting where their driving behavior is not already known cannot assure that UDAcommitting drivers have been identified.

Second, even if at-risk drivers can be identified in other than a roadside setting, the issue of memory becomes important. Studies of memory have consistently shown that both the time lapse from the occurrence of a behavior and the importance of a behavior from the respondent's viewpoint present problems for recall. The relation between the significance of events and memory mav be especially critical to the assessment of motivations for driving behaviors; Cannell and Kahn (1968) point out: "events of trivial significance for the respondent mav be forgotten almost as quickly as they ocour." The driving task consists of many routinized responses and behaviors; no one particular response mav assume enough significance to be stored in the driver's long-term memorv for recall. The roadside survey method is an attempt to minimize the memory problem.

Finally, a roadside method involving an immediate stop is important to assure that the driver who committed the UDA is correctly identified. Simply noting the driver's license plate number at the time the UDA was committed; determining the owner of the car by the license number; and contacting the owner at a later time does not assure that the proper driver will be contacted. Someone other than the owner may have been driving the car when the UDA was committed. Also, this procedure is potentially embarassing if the owner was unaware that the vehicle was being operated at the time of observation.

(ii) How, By Whom, and For What Purpose the Data Would be Osed

The survey data will be collected and analyzed bv staff from NHTSA's contractor, The University of Michigan Highway Safety Research Institute, (HSRI), who will prepare a final report based upon its analysis. HSRI will be assisted in these activities by its subcontractor, Mid-America Research Institute. 
The final report will be used by NHTSA to identify countermeasures that have the potential for preventing the selected UDAs. It is also anticipated that NHTSA will use the results of the sturv to guide them in planning future countermeasure programs aimed at the selected UDAs.

To this end, the final report will contain an analysis of the responses of drivers to the survey questions. The analysis will address two basic questions about drivers and their reasons for committing UDAs:

1. What are the reasons that drivers give for committing selected UDAs?

2. What are reasonable countermeasure programs that have potential for use in preventing drivers from committing the selected UDAs?

With respect to the first question, driver responses will be grouped in terms of general motivations (reasons) for either committing or refraining from committing the selected UDAs. The analysis of all iriver responses will identify the most comsion reasons given by drivers. Further, the data sought will allow the examination of the relationships between these reasons and situational and demographic variables.

With respect to the second question addressed in the analvsis, countermeasures that address the reasons drivers give for committing the selected UDAs will be identifier. For example, a feasible countermeasure in response to drivers who explain that they were speeding because thev were unaware of the speed limit might be to oost more speed limit signs on those roads.

\section{(iii) Ose of similar Data for Study Purposes}

Past research reveals few, if any, examples of studies aimed at identifying the reasons why drivers have committed (or refrained from committing) an action that increases the risk of a traffic crash, through roadside survey procedures or otherwise. Under Project ABETS, Perrine, Waller, and Harris (1971) used police officers and road block procedures to Interview drivers concerning biographical data, driving historv and drinking 
history (although specific reasons for driving after drinking are not known to have been studied). Many of the Alcohol Safety Action Programs sponsored by the National Highway Traffic Safety Administration in the early 1970s also conducted roadside surveys for information about drinking drivers, but as in Project ABETS, specific reasons for drinking and driving are not known to have been collected.

Roadside observation procedures have also been used in recent vears in studies of restraint usage, although none of these to our knowledge also stopped the observed subjects to probe their reasons for use or nonuse. (Roadside survey procedures are described in detail in Section 2.) Among such observational studies is one recently conducted in Detroit and surrounding urban counties in southeast Michigan (Motorists Information, Inc. 1978) in which observers were stationed at 224 rantomlv sampled intersections to observe restraint usage before and after an educational campaign.

Thus, the data that this study proposes to collect has, to our knowledge, never been collected. No current similar data is available for use in place of the data to be collected bv this studv. No previous research as attempted to approach drivers at the time they were observed committing the UDAs of concern to this study and determine the reasons for their actions. (The UDAs are identified in Section 2.)

\section{(iv) Bfforts to Identify Duplication}

A preliminary task of this project called for a literature review of the relevant material on driver motivations for committing UDAs. This review included roadside observation and survey techniques used bv highwav safety researchers as well as methods of observation and measures of motivation used in the fields of psychology; sociology and in marketing. The literature review yielded no previous research that attempted to approach drivers at the time they were observed committing a UDA and determine the reasons for their actions. 


\section{(v) Reporting Hours Required}

The driver interviews are not expected to exceed fifteen minutes.

$$
=
$$




\section{DBSCRIPTION OF THE INPORMATION COLLECTION}

\section{(i) Potential Respondents}

The sample universe for this study consists of drivers operating vehicles on selected roads in Washtenaw County, Michigan. A sample of no more than 2,000 drivers will be surveved using the roadside survey technique and possible followup telephone contacts as described below. The strategy for selecting the motorists to be interviewed will depend upon the UDAs. Some UDAs may occur relatively infrequently (for example, running a stop sign). For these UDAs, survey teams will be instructed to stop all drivers committing that UDA. Other UDAs occur quite frequently (for example, speeding). A strategv for stopping these UDA drivers is the time-interval approach. The interval will be determined by the length of time it takes to complete one interview. This strategy was used in the pilot test activity and has been used in the past in a number of other roadside surveys (Carr et al. 1974; Stroh 1973; Wolfe 1974). A vehicle will not be stopped until the previous interview has been completed. This ensures that an interviewer will have time to complete each interview with drivers who have already been stopped. Non-UDA drivers will be selected on a basis similar to that used for drivers who commit UDAs. Using this approach, one interviewer can conduct three to four interviews per hour. For comparison purposes, we will need approximatelv two hundred drivers per UDA class (100 UDA drivers and 100 non-UDA drivers).

We are interested in the motivations for committing UDA's of Arivers of all types of vehicles. However, for practical reasons, some types of vehicles will be excluded from the study. Those vehicles not included are:

- vehicles that because of their size or shape cannot pull into and out of the survey area safely (e.g., large trucks, heavv equipment vehicles);

- emergency vehicles (e.g., ambulances, police cars); and 
- vehicles for hire (e.g., taxis, limousines, buses).

While the above groups are important to highway safety, their inchsion is outside the scope of this study. These groups represent specific select driver groups. The emphasis in the current effort is on the general driving population-and the identification of general-deterrence countermeasures directed toward this general driving population. Inclusion of members of these select groups would obviously necessitate decreasing the number of the general driving population to be interviewer. Any such reduction would certainly limit the validity of the inferences to be mare about the general driving population. This issue has been discussed bv both survev and test researchers (for example, Trattner and O'Leary 1980; Warwick and Lininger 1975). It has been stated: "Analvsts sometimes forget that the standard error of an estimate for one of these subgroups depenis on the absolute size of the sample for that subgroup. The more the subgroups to be analyzed, and the smaller the groups, the larger the sample needed to have sufficient cases to keep the sampling error within tolerable limits" (Warwick and Lininger 1975, p. 94). Sampling only members of the general driving population (and not select groups) will provide for more adequate and valid results.

No driver will be interviewed at roadside more than once. Because we will survey more than once on the same roads (with commuter traffic), a driver may be stopped more than once for the survev. Should that happen, the driver will be thanked for stopping again and not reinterviewed.

\section{(ii) Design and Procedures}

The roadside survey technique will be the primary survev methor. Roadside surveys have been used extensively in the past to collect information about driver behavior. Past studies using roadside survevs fall into two categories-epidemiologic studies to determine the traffic crash risk created by alcohol-and drug-impaired drivers and origin-destination surveys used for state transportation planning. This latter study--the origin-destination surveys-are concerned with identifying the movement of persons and goods on state and federal roads to determine the most 
efficient allocation of state transportation funds. DiRenzo (1976) reported that seventeen states had conducted origin-destination survevs, and at least seven states were planning future studies. Procedures for conducting roadside surveys of drinking and driving have evolved over a period of more than forty years since Holcomb (1938) conducted the first roadside survey in Evanston, Mlinois. Since then more than 100 drinking-driving roadside surveys have been conducted. One of the most recognized of these was the Grand Rapids Study reported by Borkenstein et al. (1964) in which 7,590 drivers were stopped and requested to submit to a breath test; driver interviews were limited to questions regarding demographic information, trip information, and drinking practices. A national roadside survey of drinking drivers was conducted by HSRI in 1973 (Wolfe 1974). A total of 3,698 drivers across the nation were stopped and asked to give a breath test and answer questions related to driver demographics, trip characteristics, drinking practices, and drivers' opinions and knowledge about alcohol-driving laws. The most recent roadside survey identified in the literature is a 1979 survey of drinking drivers conducted in Ontario, Canada (Ontario Interministerial Committee on Drinking-Driving 1980). The most recently reported roadside surveys in the United States were conducted in 1976. Clark (1976) investigated davtime driving and drinking patterns; information on drivers' background as well as drinking characteristics were obtained. The second 1976 studv involved the measurement of drugs other than alcohol and collected urine, blood, and saliva specimens in addition to breath. Driver demographic and health information as well as drug use were addressed in the driver interviews (Blackburn and Woodhouse 1977).

Standard procedures developed for roadside survev research (Carr et al. 1974; Perrine 1971) will be followed in the proposed study. These include, for example: the presence of a police officer for traffic control; minimal contact between drivers and the police officer; and the use of a van or recreational vehicle as the interview vehicle. (Procedures are describer more specifically later in this section.) Drivers will be asked about their reasons for committing (or refraining from committing) the specific UDA 
at the time and location of the roadside survey stop. Other information, including background and general driver information, will either be collected at the roadside survey location or arrangements will be mare for a followup telephone call convenient to the driver.

Selection of UDAs. The UDAs to be studied will be selected from the following list:

- speed too fast over the limit;

- speed too fast for conditions;

- speed too slow;

- following behavior;

- turning left in front of traffic;

- pulling in front; and

- running a stop sign or traffic signal.

Final selection will be made with the concurrence of the CTM based upon the involvement of the UDAs in traffic crashes.

Site Selection. A variety of roadway environments located in southeast Michigan will be represented in the survey. These sites will be determined, to an extent, by the nature of the UDA. For example, some UDAs or families of UDAs are characteristic of particular road types: illegal turns are less likely on limited-access roads than in urban areas; the speed UDA is different on interstates than in urban or residential areas. A second criterion is that it be feasible to stop drivers for a roadside survey on that road. Segments of interstates located near roadside rest stops meet both criteria for the "speeding" UDA; urban boulevards are more suitable for the "running a stop sign or signal" UDA. The sites will also be selected to be representative of the general highway environment (e.g., typical driver and vehicle mixes, traffic volume, roadwav environments, etc.).

Local traffic enforcement agencies will be contacter to obtain additional information regarding traffic volume, accident frequency, and roadway characteristics for potential survey sites. Pretests were conducted 
to ascertain the likelihood of such cooperation. HSRI experience in that pilot test activity indicates that such cooperation is readily available. (The pretests are described in item III of this section.) Project staff will also investigate survey sites to determine the feasibility of stopping drivers at the selected locations. Factors considered in the site selection process include characteristics of the survey site itself, the observers' site, and general characteristics of the survev location. The following characteristics of the survey site will be considered in the selection process:

- Paved/nonpaved - the presence of pavement or firm gravel at the survey site is considered important, particularly since survey activity will take place in the spring when unpaved areas are likely to be muddy.

- Entrance/exit configuration - it is considered ideal for a survey site to have a separate entrance and exit to minimize the hazards and inconvenience of pulling into and out of the site bv survey participants. Locations with only one entrance/exit will be considered if the site is large enough to handle incoming and outgoing traffic safely.

- Size of survey site - a site should be large enough to accommodate the survey vehicle and a participant's vehicle without interrupting the normal activities of the area.

- Nonsurvey traffic - a site with a low amount of nonsurvev traffic during the survey hours is consideren ideal because the potential of the survey to disrupt the normal activities at the site would be minimized.

- Police action - all sites should have an appropriate area for the police officer who flags the drivers over to the survey site. This area should be large enough to accommorate the police officer and his patrol vehicle and should be located at the entrance to the survey site.

The following characteristics of the observers' site will be considered in the selection process:

- Distance from survey site - in the pilot test activitv, it was determined that the observer site should be located about twotenths to one-half mile from the survev site. This distance 
provides the observer time to radio to the police officer in time for the proper car to be flagged over and in most instances allows the observer to visually verify that the proper car has been stopped.

- Visibility to traffic - observer sites that are inconspicuous to traffic are considered ideal. For example, observer sites located in parking lots off the roadway are considered preferable to road shoulder sites.

- Other factors associated with the location of the observer site that could affect speed measurement will be considered. For example, if there is a stop sign or traffic light a short distance before the observer site, the location would not be considered because the vehicle's actual traveling speed on that road would probably not be reached by the time the speed measurement was made.

There are several general characteristics of the survey location that will be considered:

- Traffic volume - a minimum traffic volume der iav will be considered in determining the likelihood of obtaining an adequate nainber of driver interviews at each survev location.

- Posted speed limit - this will be especially important for the speed-related UDAs.

- Presence of intersecting roads - any survey location with intersecting roads between the observer site and the survev site will not be considered for the speed-related UDAs because of the possibility of having the identified vehicle turn before reaching the survey site.

No more than fourteen survey locations will be necessary to study the specified UDAs. All will be located in Washtenaw County, Michigan. Final selection of the survey sites will be made on the arivisement of local law enforcement agencies.

Schedule of Survey Times. Survev times will be selected based on the likelihood of observing the UDA in question. Primary consideration will be given to times when traffic flow past the survev site is high enough to assure that a sufficient number of UDA drivers can be identifien and stopped in a reasonable period of time. 
Sites wili be covered on all days of the week and during dav and evening hours. As it is anticipated that weather conditions will vary, survey staff will be instructed to record relevant environmental information.

Equipment. Traffic measuring equipment will be identified as necessary for the study of each UDA. For example, road tubes with time switches can be used for the speeding UDA; an alternative is to use raciar to determine speeds. Other UDAs can be determined bv standard timedistance measures and by observation. Time-distance measures are often made by using a stopwatch to determine how long a vehicle takes to travel a given distance. The speeding, following, pulling, in front, and tuming in front UDAs all can be measured using a time-distance measure. Final selection of equipment will be based upon the feasibility of its use, cost, and availability.

Two vehicles will be used for the roadside activity: an interview vehicle and an observer vehicle. The driver interviews will be conducted inside a motor home. This type oi vehicle was used in the pilot test and has been recommended by other highway safety researchers for roadside survey activity (Carr et al. 1974; Perrine 1971). It is more comfortable (e.g., warmer, cooler) than outside, and allows the interviewer and driver to sit facing each other. This latter practice is recommented bv survev researchers in general (Bradburn and Sudman 1979). Moreover, preliminarv review of the pilot test data indicates that the quality of information is substantially better from interviews conducted in a van versus those conducted at carside. Drivers elaborated more on their answers to questions when the interview took place in the van than when it took place at carside. Vehicles are available for rental from private vendors. Liability insurance cover all aspects of survey activity.

A vehicle will be used for an observer who will be located upstream from the survey site. This vehicle will be a passenger sedan.

Walkie-talkies will be used for communication between the observer and the interviewers. This method of communication was used successfully in 
the pilot test activity. A citizens band radio will also be monitored during the roadside activity. These broadcasts will provine additional information regarding the effects of the presence of the survey team on traffic behavior.

Interview Materials. Through the review of the literature and a series of pretests using speeding too fast above the limit as a model, a questionnaire was developed to identify drivers' reasons for committing or refraining from committing UDAs. Questions are adaptable to other UDAs. For example, the question: "What was your speed just before vou were stopped for the survey?" would be modified to: "How much distance was there between you and the nearest oncoming car when you made your turn at the intersection?" for studying drivers' judgments in making turns in front of oncoming traffic. Drivers will be aided in making these judgments with a diagram of the roadway. Questions not related to specific UDAs will remein constant regarfless of the UDA querier.

The questionnaire consists of items ardressing'general driver characteristics; many of these questions are demographic, such as age, or highest level completed in school. Other items relate to driving experience, such as number of vears driving or number of traffic tickets for any particular UDA-related violation. Finally, there are items that pertain to the driving behavior at the time of the traffic stop. These include questions about the origin and destination of the trip and frequency of driving on the survey road. These questions are designed to give the study a set of driver characteristics to compare to specific driving behavior.

The major portion of the questionnaire contains items specific to the UDAs. - These questions are designed to identify the iriver's reasons for committing or refraining from committing the UDA at the time of the traffic stop. There are also a series of questions designed to get trivers thinking about their driving behavior with respect to a particutar UDA. Drivers will be asked to answer these questions not onlv in terms of their behavior at the time thev were stopped, but in terms of their iriving at 
other times on that road. Such probes are necessary for some drivers to aid them in verbalizing about their changes in driving behavior.

Figure 1 depicts the types of items containen in the questionnaire. The questions move from the most general at the base of the pyramid to the most specific at the apex.

A letter signed by the head of the local law enforcement agencv and the local prosecutor will be given to each driver stopped for the survev. This letter will explain that the driver will not be subject to anv traffic enforcement activities arising out of the behavior that lead to the survev stop. Drivers will also be given a brief explanation of the sturty in a letter from the project director. In addition, a letter will be available to drivers to verify the survey stop.

A complete set of interview materials is contained in Attachment 1. A question-by-question justification can be found in Attachment 2.

Survey Personnel. The personnel necessary for the survey activity include: two interviewers, ore observer, and one police officer.

The interviewer team will consist of one male and one female interviewer. All survey interviewers will be experienced in interviewing. They will be thoroughly briefed on the nature of the project and given training in roadside surveying procedures.

The observer's primary task will be to look for drivers committing the UDA in question. The observer will also make a brief vehicle descriotion of each vehicle to be stopped (e.g., color, make, morel). These descriptions will be compared later with the vehicle descriptions on the interviewer cover sheet to check that the correct vehicle was stopped.

A police officer will be present at the survev site to flag down the selected drivers and guide them to the interviewer. Past roadside survev experience has shown the necessity of police assistance in this activity for both safety and legal reasons. The risk of an accident to the subject or: other drivers is minimized by the presence of a trained traffic control : officer to stop the vehicle and regulate other vehicles in the traffic flow. Moreover, the authority to stop vehicles moving on a public highwav, in 
almost all circumstances, is vested only in law enforcement officers. Therefore, the use of police officers to stop moving vehicles for a roarsite survey is not only preferable from a safety standpoint, but necessary from a legal standpoint. Drivers will not be subject to enforcement of traffic violations based on the reasons they were stopped for the survey. The cooperation of local law enforcement and prosecution agencies not to cite and prosecute for such offenses was obtained in the pretest and will again be sought. Such agencies have agreed that the benefits of the research outweigh the need to enforce minor traffic offenses.

The officer's contact with the drivers will be minimal. The officer will flag down the designated vehicle, explain that the driver was stopped for a roadside survey, and direct the driver to the interviewer for further explanation. There are no indications in the literature such a stop is a problem. Roadside surveys using police have been reported since 1938 with literally hundreds of thousands of drivers participating. Use of police is a standard part of the roadside research protocol. Moreover, a recent public opinion study conducted bv Mathematica Policv Research for the U.S. Department of Transportation established that respondents preferred to have a police officer present when roadside surveys were conducted. Traffic officers from the local sheriff's department were used successfully in the pilot test activity. Drivers understood the presence of the police and did not express any hostility at being so stopped. We will again have the cooperation of local law enforcement agencies regarding the law enforcement manpower to be present during the survey hours.

No impaired drivers were identified during the pilot test activitv. Furthermore, it is unlikely that survey activity will be conducted during high-risk drinking-driving hours (for example, late night, early morning weekend hours). If an impaired driver is identified, the survey team will use police communications to call a taxi or a friend of the driver. If the driver refuses this offer, the survev team will notify the police officer at the survey site, who then may take whatever action is necessary to ensure that the impaired oriver does not resume driving. In no case will an obviously impaired driver be allowed to drive away from the survev site. 
Publicity. Prior to conducting the survey, locel newspapers will be contacted about a feature story on the study to be run before the roadside activity. The story will include a picture of the survev team. This approach gives the studv and the survey team recognizability and promotes greater driver cooperation (Perrine 1971; Wolfe 1974). News articles were run in local newspapers prior to the pilot test activitv; several drivers acknowledged these articles upon being stopped.

Traffic Observation. Observations will be made of both traffic volume and the UDA of interest for the roadside survev activity. During the survey activity, the observer will be in a vehicle parked along the roat upstream from the survey site. The observers will be notified (via walkietalkie) from the survey site when the interviewers are ready for the next driver interview. Observations will include both UDA-committing and nonUDA-committing vehicles. The observer will note descriptions of the identified vehicles. These descriptions will be recorded only by the number of the vehicle to be stopped for interview (i.e., Vehicle 1, Vehicle 2, Vehicle 3 , etc.). The descriptions will be matched up with the interview number (i.e., Interview 1, Interview 2, Interview 3, etc.) after the dav's survey activity is completed. The observer will also have responsibility for monitoring CB communications on Channel 19; these communications wilı provide additional information regarding the effects of the survev on traffic flow.

The measurement of the UDAs was discussed previously in this section under the heading Equipment.

Roadside Survey Procedure. The general strategy for the study is to randomly survey drivers regarding their reasons for committing a particular unsafe driving action on a selected roadway. The HSRI survev team will be parked in a van at the designated survey site; police officers will park their vehicle at the entrance to the survey site. When the interviewers are ready to interview the next driver, they will ask the police officer to 
radio the observer to look for the next appropriate vehicle; interviewers will specify whether a UDA committing or a non-UDA committing triver is to be stopped (as required by the studv design). The observer will radio a brief description of the appropriate vehicle (e.g., blue Chevrolet) to the police officer. The police officer will flag down the designated vehicle, explain that the driver was stopped for a survev, and direct the triver to the interviewers for further explanation. If the officer is unable to stop the vehicle, the observer will be notified to begin looking for another vehicle traveling in the same manner. These procedures were tested and found to be successful during the pilot test activity.

After the driver has pulled over, the interviewer will greet the driver, briefly explain the purpose of the survey, and invite the driver to participate. The survey team will be thoroughly briefed on and follow strictly all Department of Health and Human Services (DHHS, formerlv Department of Health, Education, and Welfare) human subjects regulations !45 C.F.R. Secs. 46.101-46.401 (1979)1. Care will be taken bv all interviewers to make sure that the driver understands that participation is completely voluntary. A statement of informed consent will be read to the driver before the interview begins. (See Appendix A.) The driver will be given an opportunity to ask any questions about participating. Also, if drivers are asked for their name and telephone number for followup telephone contacts (described below), they will first be informed that further participation is completely voluntary. Drivers may refuse to participate at any point in the survey process and will be explicitly so told. Also, drivers will be informed that they may refuse to answer any specific question considered to be objectionable.

Follow-up Interviews. A number of follow-up interviews will be necessary to assess the reliability and validity of the information obtained at roadside. For this reason, drivers will be asked if they are willing to be reinterviewed at another time. Such interviews will be conducted by telephone. Drivers who indicate they are willing to do so will be asked to sign a consent form on which they will write their name and phone 
number. The number of the interview will be noted on this sheet. This will allow investigators to compare answers when necessarv in evaluating the interview information. The only time the actual interviews and the drivers' names will be paired is at the time of the follow-up interview. Subsequently, the sheets with the drivers' names will be destroved.

No more than 500 drivers will be contacted in the follow-up interviews. This will occur approximately one month following the initial interview. The same survey questions will be asked again at that time. These interviews are not anticipated to exceed fifteen minutes.

\section{(iii) Pretests}

A series of four pretest surveys were conducted in September 1980. Only the "speeding over the limit" UDA was studied. The objectives of the pretest surveys were:

- to determine if survey activity affected traffic volumes and speeds;

- to determine if drivers could be safely stopped and would cooperate with a roadside survey;

- to determine if drivers who agreed to be interviewed could verbalize their reasons for committing (or refraining from committing) an unsafe driving action;

- to determine the usability of information given by drivers for their driving behavior; and

- to develop a questionnaire that could elicit responses from drivers as to why they committed (or refrained from committing) UDAs.

The roadside survey procedures described above were followed. Speeders and nonspeeders were stopped in each of the pretests. Speeders were asked questions about why they were exceeding the speed limit. Nonspeeders were asked questions about why they were not exceeding the speed limit. OMB clearance was not necessary because no more than eight drivers in each category were stopped in each pretest. Because a basic objective of the pretest was to develop the questionnaire, changes were 
made in the questions asked of drivers in each pretest. Questions that were not useful were discarded and new questions were adred based on information obtained from the previous pretest.

The results of the pretests indicated the following:

- Although vehicular speeds appeared to be affected to some degree by the presence of the traffic observer and the survey equipment, drivers who exceeded the speed limit were still able to be identified and stopped for participation in the survey.

- Drivers were able, for the most part, to explain with sufficient specificity why they were driving as they were.

- The reasons that drivers gave for committing UDAs were, in many instances, amenable to reasonable countermeasures aimed at preventing future UDAs. It must be emphasized that many of the countermeasures proposed as a result of driver responses have not been implemented before and are only proposals, not actual countermeasure programs.

- A questionnaire was developed to elicit responses from drivers about their reasons for committing. (or refraining from committing) UDAs.

- The strategy of using a roadside survev to interview drivers about reasons for committing (or refraining from committing) UDAs was found to be feasible and useful.

\section{(iv) Bxpected Response Rates}

An objective of the pretests was to determine if drivers stopper in a davtime roadside survey were willing to participate. The pretests were scheduled for early morning and late afternoon. It was anticipated that these times would be among the most difficult to obtain subject cooperation due to commuter traffic.

Response rates at roadside during the pretests ranged from $71 \%$ to $81 \%$. Most refusals were from drivers who were late for an appointment.

The strategy for dealing with nonresponse is to ask drivers if they would be willing to be interviewed by telephone at a later time. Drivers so willing were asked to leave their name and telephone number with the 
interviewer. This alternative provides the driver a frame of reference within which to recall the behavior of interest.

The above approach was used in the pretests. Seventy-seven percent of those drivers who were not interviewed at roadside were willing to be interviewed at a later time. Thus, the overall percent of irivers who expressed willingness to be interviewed during the pretests was $94.9 \%$

\section{(v) Survey Design Review}

The development and review of the survev design has heen the responsibility of several members of the project staff. Kent B. Joscelvn, research scientist/attorney and head, Policy Analysis Division of The University of Michigan Highwry Safety Research Institute (HSRI) is proiect director and co-principal investigator. Mr. Joscelvn is an established socio-legal researcher with significant experience in the field of highwav safety. He has been directing research examining the operations of the legal system and countermeasure implementation since 1967 under NHTSA sponsorship. These efforts have included extensive field survevs of the traffic law system, the development of models for prediction and explanation of law system activity, the conduct of seminars for modification of system attitudes and functioning, and the examination of legal constraints on countermeasure development.

Ralph K. Jones, staff consultant to HSRI, is a senior analyst with extensive experience in the field of highwav safety. Prior to working with HSRI, he served as associate director of the Indiana Universitv Institute for Research in Public Safety. He was closely involved as an analyst in the major traffic crash investigation studies and served as co-principal investigator of studies of the influence of enforcement actions on traffic now behavior and computerized allocation of police traffic services. Each of these projects required a detailed understanding and analysis of unsafe driving actions, traffic flow behavior, and mechanisms for altering traffic now behavior. Mr. Jones serves as co-principal investigator of the two major HSRI studies of UDAs and technical advisor on a third NHTSA studv being conducted by PRC Public Management Services. 
John R. Treat, research scientist/attorney, shares responsibilities as a co-principal investigator. Mr. Treat is widelv recognized in the area of driver behavior research, having served as project director for the "Trilevel Study of the Causes of Traffic Accidents" and numerous related projects. Prior to working at HSRI, he was director of the Indiana University Institute for Research in Public Safetv, where he was also a research scientist and tenured associate professor. At HSRI he currentlv is coordinator of an NHTSA-sponsored study to analyze UDAs and, in a broader context, serves as program manager for this and other projects of the Policy Analysis Division, which involve driver problems and behavior.

Mary Beth Marks, assistant research scientist, is a psychologist concerned with human-oriented highway safety research. Her focus of study has been on individual choices in transportation settings. Dr. Marks brings to the project a strong capability in experimental and quasiexperimental design essential for the work of this project.

John W. McNair, staff consultant, is an attorney whose research interests lie in the area of socio-legal sustems. His emphasis has been on the interaction of legal factors in the conduct of epidemiological research. Mr. McNair has served as the field studies coordinator for several NHTSAsponsored contracts including "Legal Constraints on Highway Safetv Countermeasures" and "Incidence of Drugs Among Fatally Iniured Divers."

In addition, project staff have consulted with Phvllis A. Gimmotv, a statistician on the HSRI staff.

The data will be collected by the Policy Analysis Division of The University of Michigan Highway Safety Research Institute (HSRI) for the National Highway. Traffic Safety Administration. Mir-America Research Institute (MARI) serves as a subcontractor to HSRI. The contractor is responsible for the data collection activity subject to NHTSA approval. The subcontractor supports the contractor in this area.

\section{(vi) Confidentiality}

The contractor recognizes that the work to be done is regulated by the Federal Privacy Act and professional staff are well aware of the privacy 
rights of research participants. In addition to the Federal Privacy Act, staff are bound by the ethical codes of their individual professions such as the Ethical Standards in Psychological Research of the American Psychological Association. Care will be taken to insure that all staff (professional and nonprcfessional) involved in the survev project are fully briefed on the protection of human rights throughout the studv.

Before collecting personal data from individuals, they must be informed what data are being sought, why it is being collected, and how it will be used. The interviewers will describe the purpose of the studv to the drivers at the initial contact at carside. Drivers will be advised that they may leave at once or at any time during the interview and that thev are under no obligation to participate. They will also be told that they will not be cited for any traffic violations that led to their being stopped for the survey.

The initial part of the driver contact will be anonvmous. Thus, written consent will not be obtained at this point in the interview. The explanation by the interviewer and the subject's response will be openlv tape recorded with the subject's permission.

We will conduct a limited set of follow-up interviews with drivers. At the close of the interview drivers will be asked to participate in a further interview by telephone. An informed consent form will be signed by drivers who agree to participate and will contain the identitv of the subject.

Confidentiality of responses will be strictly maintained at all times. A Michigan Statute has recently been enacted that provides researcher-subject privilege for highway safety research projects. Action will be taken to qualify this project under that statute so that the data are legallv protected.

The customary and usual physical safeguards will be instituted to protect the integrity of the data against inadvertent disclosure. This will include: appropriate instructions to research staff, segregation of identifiers, maintenance of a chain of custorty of data, phvsical securitv for files, and reporting of findings in a manner that precludes the 
identification of any individual subject.

Agreements will be made with all police agencies participating in the roadside survey that drivers will not be ticketed or prosecuted for driving behavior that was the reason they were stopped for the survev. Local prosecutors and district attorneys will also be contacted for their concurrence in the agreement. In past roadside studies such agencies have agreed that the benefits of the research outweigh the need to enforce minor traffic offenses. Police and prosecutors will continue to retain the authority to enforce major criminal offenses. Past studies have shown that police agencies have been unwilling to agree that no arrests will be made. For example, a roadside stop may result in the identification of a subject who is wanted for a felony. Police would retum the authoritv to take action in cases such as these. Such arrangements were successful in the pretest activity.

\section{(vii) Remuneration}

No form of remuneration will be used in the survev.

\section{(viii) Tabulation and Publication Plans}

The final report will be submitted to NHTSA by September 30, 1981 . Once the report has been reviewed and approver, dissemination of the study's results through publication in an appropriate journal or presentatior. to a professional meeting will be considered. No Dublication plans have been made at this time.

The driver survey data will be analyzed to identify the motivations (reasons) for engaging in specific UDAs. Comparisons of motivations will! be made for the specified UDA groups as well as for the UDA/non-UDA drivers: In addition, relations between the driver motivations and various demographic variables (age, sex, etc.) will be analyzed.

An analytic scheme for reviewing the motivation results will be developed in which the major categories of motivations are identified by UDA characteristics and by driver characteristics. Countermeasure approaches for dealing with these clesses of motivations will be described. 
3. TIME SCHEDULE FOR INFORMATION COLLECTION AND PUBLICATION

Table 1 shows the project milestones and their expected completion date. The project began on September 27, 1979.

TABLE 1

PROJECT MILESTONES

$\begin{array}{ll}\text { Activity } & \text { Date } \\ \text { Start of Data Collection } & 05 / 15 / 81 \\ \text { End of Data Collection } & 08 / 15 / 81 \\ \text { Submission of Final Report } & 09 / 30 / 81\end{array}$




\section{CONSULTATIONS OUTSIDE THE AGENCY}

\section{(i) Consultations}

The development of the driver interview questions was discussed with Donald C. Pelz, research scientist at The Universitv of Michigan Institute for Social Research (ISR) and Professor of Psychology. Dr. Pelz is a former director of the Center for Research on Utilization of Scientific Knowledge (CRUSK) at ISR. His research experience has focuser not only on the conduct of basic and applied research on leadership, motivation, and causal analysis, but also on the translation of research findings into practical relevant applications. He is collaborating with staff of The University of Michigan School of Nursing on a project to assist nursing departments to develop an innovation process whereby findings from nursing research can be translated into improvements in hospital nursing. He has collaborated with staff of The University of Michigan Biological Station in promoting the use of information on inland lakes and their residents in watershed management decisions. In his book on social factors related to performance of scientists and engineers, several chapters end with a dialogue between the authors and a hypothetical research director to translate the findings into management practices. Following his research on emotional factors in the high crash rates of young male drivers, the author designed and field-tested countermeasures for young drivers in several high schools.

No major problems arose in the consultations with Dr. Pelz.

In addition, the study's design and procecures were submitted for review to the ISR Human Subjects Review Committee. This committee consists of scientists within ISR as well as members of the local public. The ISR committee was selected because of its Darticular expertise in the collection of survey data. The ISR committee reviewed and approved the study's design and procedures. 


\section{(ii) Public Contact}

Public input to the study was received through the ISR Human Subiects Review Committee. As noted above, a local community representative is named to the ISR committee to participate in the review process. The study's design and procedures did meet with the approval of the ISR committee.

In addition, the Washtenaw County Sheriff and Prosecutor were consulted about the study. Both elected officials have approved of its procedures. Evidence of their support is found in the letter signed by the sheriff and the prosecutor to be given to drivers (see Appendix A).

Finally, the public has been informed of the studv through local newspapers. Articles about the pretest activity were run prior to its initiation. No public comment was received.

(iii) Information from Local Governments

This study will not collect information from State or local governments.

\section{(iv) Use of Standards}

The study does not involve the use of techniques that necessitate coordination with the Office of Federal Statistical Policy and Standards. 


\section{BSTIMATB OF RESPONDENT BORDBN}

\section{(i) Respondent Number and Frequencp}

No more than 2000 drivers will be surveyed. Respondent will be asked to participate. in a follow-up interview. No more than 500 drivers will be recontacted. The pretest experience indicates that the interviews will average 10 minutes in length. It is anticipated that no more than 15 minutes will be needed to complete any interview. Reporting times are also applicable to the follow-up interviews.

\section{(ii) Variance of Burden}

The reporting burden is not expected to vary. 


\section{SENSITIVB QUESTIONS}

The instrument does not contain sensitive questions. 


\section{BSTIMATION OF COST TO FEDERAL GOVERNMENT}

\section{(i) Project Cost}

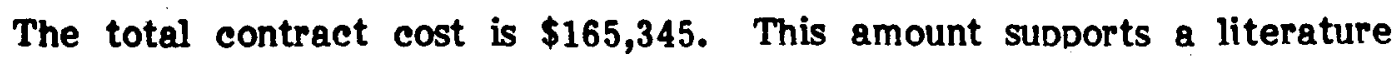
review; a feasibility study; development of the questionnaire; the Ariver survey; data analysis; and completion of a final report.

\section{(ii) Data Collection Costs}

The total in (i) above includes all costs of the project activity including: data collection; instrument and collection design development; tests; printing forms; editing; coding; tabulating; analysis; and oublication of results. Mailing list compilation and maintenance as well as mailing or enumeration tasks are not called for in the study design. In addition, the above amount includes overhead costs.

The work will be performed by The University of Michigan Highwav Safety Research Institute (HSRI) under contract to the Department of Transportation, National Highway Traffic Safety Administration (DOT-HS-902276). Mid-America Research Institute will support HSRI as a subcontractor.

(iii) Design Costs

See explanation in (ii) above. 


\section{BIBLIOGRA PHY}

Borkenstein, R.F.; Crowther, R.F.; Shumate, R.P.; Ziel, W.B.; and Zylman, R. 1964. The role of the drinking driver in traffic accidents. Bloomington: Indiana University, Department of Police Administration.

Bradburn, N.M., and Sudman, S. 1979. Improving interview methods and questionnaire design. San Francisco, California: Jossey-Bass Publishers.

Cannell, C.F., and Kahn, R.L. 1968. Interviewing. In The Handbook of Social Psychology, Vol. II, eds. G. Lindsey and E. Aronson, Pp. 526-595, Reading, Massachusetts: Addison-Weslev Publishing Companv.

Carr, B.; Borkenstein, R.F.; Perrine, M.W.; VanBerkom, L.C.; and Voas, R.B. 1974. International conference on research methodologv for roadside surveys of drinking-driving alcohol countermeasures workshop. Final report. National Highway Traffic Safety Administration report no. DOT-HS-801-220.

Holcomb, R.L. 1938. Alcohol in relation to traffic accident. Journal of the American Medical Association 1ll:1076-1085.

Motorists Information, Inc. 1978. Michigan safety belt project report: Program summary. Michigan.

Perrine, M.W. 1971. Methodological considerations in conducting and evaluating roadside research surveys. National Highwav Traffic Safetv Administration report no. DOT-HS-800-471.

Perrine, M.W.; Waller, J.A.; and Harris, L.S. 1971. Alcohol and highwav safety: Behevioral and medical aspects. National Highway Traffic Safetv

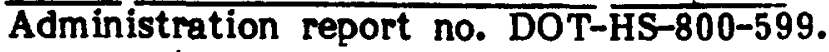

Stroh, C. 1973. Roadside surveys of drinking-driving behavior. In Alcohol and road safety series, vol. IV. Ottawa: Department of Transport.

Treat, J.R.; Thompson, D.S.; Jones, R.K.; Joscelvn, K.B. 1980. National analysis of unsafe driving actions: Interim report on UDA selection and definition. Preliminary draft. National Highway Traffic Safety Administration contract no. DOT-HS-8-02023.

Wolfe; A.C. 1974. 1973 U.S. national roaiside breathtesting survey: Procedures and results. National Highway Traffic Safety Administration report no. DOT-HS-801-241. 


\section{ATTACHMENT 1 \\ INTERVIEW MATERIALS}

The following interview materials are contained in Attachment 1:

Introduction;

Informed Consent Procedures;

Sheriff and Prosecuter Letter;

Questionnaire;

Follow-up Consent Form;

Thank you Statement;

"Excuse" Letter; and

Project Director Letter. 


\section{INTERVIEW INTRODUCTION}

Hello, I'm - This is - We're from The

University of Michigan Highway Safety Research Institute. We've stopped you to ask you to take part in a highway safetv study. It's not a traffic stop; you're not going to receive a ticket

We would like you to answer some questions for us about how you drive. We're trying to learn more about driving and your point of view. What we're interested in are your opinions about driving.

Will you help us out by answering some questions?

If driver agrees to interview, explain that we have an interview van where the interview will be more comfortable. If driver does not want to go to interview, offer to do interview at carside.

If driver refuses to participate, interviewer should note the reasch for refusal. If driver does not offer a reason, interviewer should thank the driver and politely ask the reason for the refusal. For examole: "Thank you for stopping and would you just tell us the reason for not wanting to participate? (pause) It would help in future study planning."

Also, if driver refuses to participate, interviewer should ask: "Would you be willing to be contacted by telephone at a later date to answer some questions about your driving here today?" If yes; take driver name and phone number, and continue: "We mav be contacting some additional drivers within the next couple of weeks."

Thank driver for stopping. 


\section{INFORMED CONSENT PROCEDURES}

Before we begin the interview, we are required to get your consent. If it's all right with you, we'd like to tape record this so that we will have a record of your agreement to participate.

Wait for driver response. If driver does not object to tape recorder, turn it on and read the informed consent statement.

If driver does not want to be tape recorded, ask to sign bottom of informed consent statement.

Read Informed Consent Statement

If tape recorded:

Do you understand what Tve just read?

Pause for response.

Will you participate?

Pause for response.

Now we're ready for the interview. If you don't object, mav we keep the tape recorder on?

Adhere to driver's response.

If not tape recorded:

Will you sign the bottom of this informed consent statement?

Hand statement to driver for signing.

Now we're ready for the interview. Would you mind if this was tape recorded?

Adhere to driver's response. 


\section{INFORMED CONSENT STATEMENT}

Your participation in this survey is completely voluntary.

Give Sheriff's letter to driver.

Also, the Washtenaw County Sheriff and Prosecutor have agreen that you will not be ticketed for any traffic violations that may have been the reason you were stopped for this survey.

Any information you give us will be used to help make ariving safer for you and others.

Also, if you participate, you are free to quit at any point. You may also refuse to answer any question you find objectionable. All we ask is that you do answer the questions as accurately and honestly as possible. It is not a test; there are no right or wrong answers. We are really interested in your point of view and driving.

I understand the above and agree to be interviewed for this studv.

Signature 


\section{DRIVER QUESTIONNAIRE}

1. Have you heard about this study before being stopped just now?

2. If yes to Question \#l1 Where did you hear about it?

3. How many days did you drive last week?

4. How many times did you drive on this part of in either direction in the last month?

5. a. For speed UDAs only Can you tell me what vour speed was about back before you were stopped? $\mathrm{mph}$.

b. For turning, following, and pulling in front UDAs

Show driver scale of roadway Can vou tell me the distance between you and (the vehicle you were following; the oncoming vehicle before vou turned) on this picture of the road? inches note distance by inches on scale

c. For running sign; signal UDA only

Can you tell me how far back the last stop sign or traffic light you passed was? by number of intersections back intersections

Questions 6-9 are for speed, following, pulling in front, turning left UDAs. Omit for running sign, signal UDA only.

6. Is this (speed, distance) different than the last time you (drive on this road, made that turn)?

7. Why were you driving differently today?

8. Do you think you would ever (drive, turn) on this road at ( $\mathrm{mph}$; distance)? show on scale. 
Continue (adding; reducing) (mph; distance) until driver answers "No." Exclude passing or emergency responses. Record only the (speed; distance) at which driver answers "No."

(mph; distance)

9. How come you wouldn't drive like that on this road?

10. Would you say drivers who (go about the limit; keep a reasonable distance; heed all traffic signs) on this road do so because:

1. they don't want a ticket

2. they don't want an accident

3. it's the law

4. its comfortable

11. For speed UDA only Can you tell me the speed limit on this section of the road? What is it? mph.

12. Where were you going just now when stopped?

13. Where did you start out from?

14. How does being late or in a hurrv affect your driving?

15. How does your driving change depending upon who else is in the car with you?

16. How do distractions, like a radio/tape deck or people talking affect your driving?

17. How does your mood or what's on vour mind affect your driving? 
18. How does the size of the vehicle affect your rriving?

19. How does driving a vehicle that doesn't belong to you affect vour driving?

20. Are there any other reasons for changing your driving?

21. How many years have you been driving? years

22. How many years have you been driving this car? years

23. What is the model year of this car?

24. Is this your car? If no Whose is it?

25. Have you ever received a traffic ticket for (speeding; following too close; disregarding a stop sign or signal; or unsafe tuming)? If yes How many in last five years?

26. What is your job or occupation?

27. In what year were you born?

28. Where do you live?

29. What is your marital status?

30. What is the highest grade you have completed in school?

31. What is your household income? 
32. How many thousands of miles do you drive a year? 
Case No.

\section{FOLLOW-UP CONSENT FORM}

For research purposes, we will need to talk to a number of drivers one more time. Only a few questions will be asked. They will be like the questions you answered today. Your additional help will be very much appreciated. 'If you are willing to answer a few questions for us again, please write your name, address, and phone number below.

You are not required to leave your name with us. If you do, you are free to refuse to participate in further interviews when we call later. Again, you are free to quit at any point, and vou may refuse to answer any questions you find objectionable.

Thank you for your cooperation.

Name:

Telephone: 


\section{"Thank You"}

Thank you very much for talking with us today. Your answers will be helpful in making highways safer for all drivers. Hand driver thank-you letter. Here is a letter explaining a little more about the study and thanking you for your participation. Also, if you are going to be late for work or an appointment, we can give you a letter explaining where you were this morning. Wait for driver response.

Once again, thank you very much. 
ATTACHMENT 2

ITEM-BY-ITEM JUSTIFICATION

Attachment 2 contains the item-by-item justification of the driver interview questions. The complete set of questions can be found in the interview materiads in Attachment 1.

1. Have you heard about this study before being stopped just now?

This item addresses general driver information.

Past roadside survey research has shown that drivers are more likely to participate in a study if they have heard of it before being stopped. It is important to determine if publicity is reaching its intended targets by asking drivers if they have heard of the studv.

2. Where did you hear about it?

This item addressed general driver information.

It is important to determine how the respondent learned about the study. In so doing, we can: (1) verifv that the driver actuallv saw the articles; (2) assess "word-of mouth" reporting; and (3) determine the most effective channels (formal and informal) for reaching the driving public.

3. How many days did you drive last week?

This item addresses general driving information.

Driver exposure is an important variable to be considered in a driver's decision to commit or refrain from committing a UDA. This question seeks to determine familiarity with the driving task as well as exposure to highway safety risks. 
4. How many times did you drive on in the last month?

This item addresses general driving information.

Like Question 3, this question is a measure of driver exposure. It is important to determine whether the behavior of drivers who are familiar with the road is different from behavior of drivers who are not.

5a. Can you tell me what your speed was?

5b. Can you tell me the distance you were following or the distance before your turn?

5c. Can you tell me how far back the last stop sign or traffic light vou passed was?

This item addresses UDA time-specific aspects of driving.

Driver's knowledge of their actions at the time they were observed is important. This question is designed to assess driver's awareness of their actual driving patterns. For speed UDAs, the triver will be asked to remember speed at a specific and recent point on the road. For followin;; turning, and pulling in front behavior, drivers will be asked the distance between their vehicle and another specifier car. For running a stop sign or traffic signal, drivers will be asked for the last location they remember seeing a sign or signal. The estimates that drivers give will later be compared to objective measurements made by the observer.

6. Is this different than the last time you drove on this road?

This item addresses UDA time-specific aspects of driving.

It is important to determine the conditions, if any, under which drivers' behavior varies for the purposes of the study. This question tries to identify any unique sets of stimuli that motivate drivers' behavior. This question determines whether the driver's behavior at the time it was observed was different for that day. 
7. Why were you driving differently today?

This item addresses UDA time-specific aspects of driving.

This question is a follow-on to Duestion 6. Its purpose is to identify specific reasons for particular driving behavior.

The development of specific countermeasures will be influenced by the specific reasons that drivers cite for changing their driving behavior.

8. Do you think you would ever drive on this road?

This item addresses a specific UDA behavior.

The purpose of this question is to elicit from drivers the conditions under which they operate a vehicle with respect to a particular UDA.

9. Why wouldn't you drive like that on this road?

This item addresses the UDA in a specific fashion.

This question is a follow-on to Question 8. In addition to determining the linits of specific driving actions for drivers, it is also important to determine why drivers choose to stav within those limits. An understanding of these reasons can be valuable in the development of countermeasures to keep drivers within certain limits.

10. Would you say drivers who on this road do so because? This item addresses the UDA in a more general fashion. This question is a further attempt to determine the reasons that control a driver's behavior with respect to specific UDAs. It will be read as a multiple-choice item. The reasons drivers give about others' driving will be compared to the reasons given when drivers explain their own behavior. Furthermore, testing specialists have also noted that individuals will often project their own feelings on to questions about others more quickly than questions which address the individual directly. 
11. Can you tell me the speed limit on this road? Do you think that is too high, too low, or what?

This is a UDA-specific item.

This question will be asked only when speed UDAs are studied. The laws for other UDAs are not specific enough to allow for an equivalent type of response. For example, there is no specific following distance required by state traffic laws; instead "a reasonable and prudent distance" is required.

The purpose of the question is to determine whether drivers are knowledgeable about the speed limits where thev do drive. Thus, if drivers who are observed to be exceeding the speed limit are unaware of the limit, countermeasures should focus on providing information about speed limits to drivers (e.g., more speed-limit signs).

The second part of the question is designed as a venting mechanism for the driver and to keep the first question from appearing to be a test of the driver's knowledge. It will not be an analytic variable.

12. Whire were you going when stopped?

This item addresses general driving information.

Question 12 relates to the purpose of the driver's trip. A number of studies have indicated that trip destination and origin mav be correlated with accidents and traffic violations. This information has potential value in the development of countermeasures aimed at the specific UDAs if certain destinations can be identified with the occurrence of those UDAs.

13. Where did you start out from?

This item addresses general driving information.

Question 13 is similar to Question 12. For the reasons stated above, it is important to determine if the origin of the trib is relater to the commission of a UDA. 
Questions 14-20.

Questions 14 through 20 are designed as probes to determine how a specific condition or set of stimuli affect a driver's behavior. Each question is asked in relation to the specific UDA being studied. These probes will only be asked of drivers who have not responded to the UDAspecific questions with specific reasons for their driving behavior on the day of the survey. The purpose is to try to get drivers to think further about their driving.

Late. Question 14 seeks to determine the effect that being late or in a hurry has on driving behavior. - Both past research, and the pretest for this study indicate that this is an important determinant of driver behavior relative to speeding.

Others in the car. Question 15 is asked to determine the effect that passengers have on the driver's behavior. Responses in the pilot test indicate that the relationship of the passenger to the driver has an effect on the way the driver operates a vehicle.

Distractions. Question 16 tries to determine how distractions in the vehicle affect a driver's behavior with respect to a specific UDA. There is little past research to suggest how such distractions may affect driving.

Mood. Past research has indicated that driver mood mav have an effect on accident involvement. Question 17 tries to assess the potential effect of mood or driver preoccupation on specific driving behavior. Examples of the moods or feelings described here are: angrv, haopv, nervous, preoccupied, sad, tired, relaxed, upset, daydreaming, the influence of alcohol, and sick or ill. Note that this question is onlv asked if the respondent has indicated no difference in Question 6.

Vehicle size. Pretest experience suggests that the size of the vehicle may influence the way a driver operates a vehicle with respect to specific UDAs. Question 18 will attempt to assess how vehicle size can make a difference in oriving behavior.

Vehicle ownership. Like Question 18 above, this item was suggested by the pllot test experience. Drivers indicated that driving vehicles other than their own may affect driving behavior. Question 19 will ask how 
those vehicles make a difference and what the difference is.

Other reasons. Question 20 has two purposes. First, it solicits other reasons that drivers may give for changing their behavior with respect to a specific UDA. Second, it acts as a venting mechanism for drivers. There are a number of obvious effects on driver behavior that we have not chosen to query because they do not appear amenable to countermeasure development. For example, weather conditions, while they have a clear effect on driver speeds, do not suggest feasible driver-oriented countermeasures. This question allows drivers to vent their feelings ahout such effects.

\section{Questions 21-32. Driver Characteristics and Demographics.}

The number of years (Question 21) a driver has been driving is an important measure of driving experience. This question will collect the information necessary to determine how driving experience affects a driver's decision to commit or refrain from committing a UDA.

The length of time a driver has been driving a particular vehicle - (Question 22) is a measure of familiarity with that vehicle. This question will collect the information necessary to determine if driver familiarity with a particular vehicle has an effect on drivers' decisions to commit or refrain from committing UDAs.

The age of a car (Question 23) may be related to a driver's willingness to commit (or refrain from committing) a UDA. This question will collect information necessary to determine if the age of the vehicle has an effect on a driver's decision to commit a UDA.

Question 24 again addresses vehicle ownership. It serves several purposes. One, the question serves as an internal check with Question 19. If the driver responds that the vehicle belongs to someone else, then observed behavior can be compared to the response given to Question 19. Also, for those drivers who are not asked Question 14-20, this question enables the researchers to further assess how vehicle ownership may affect driving.

Research suggests that past traffic violations for a specifie UDA 
(Question 25) are an indicator of a driver's likelihood of committing that UDA in the future. This question will collect the information necessary to determine how drivers with a history of committing a specific UDA differ from other drivers.

Question 26 will collect informetion concerning a standard demographic variable-cecupation. The occupations of all respondents will be comparer with respect to their driving behavior. These comparisons mav suggest target groups for specific countermeasures.

Like Question 26, Question 27 collects information about a standard demographic variable, age. The results, when compared with driving behaviors may suggest target groups for specific countermeasures.

The information collected about resideney (Question 28) will be used to investigate the influence of location on driving. This information has potential importance by suggesting target locations for countermeasure development.

Research has indicated that marital status may affect driving behaviors. For example, some' studies have found that recentlv divoreed persons have a higher rate of accident involvement. The information collected in Question 29 will be used to determine how marital status affects specific driving behavior. Once again, this information mav suggest potential countermeasure target groups.

The information collected about education (question 30 ) will be user to investigate its effect, if any, on driving behavior. Also, information about educational level will be matched with driver's reasons for UDA behavior to suggest countermeasures directer at specific educational levels of drivers or different groups of irivers.

The information collected in Question 31, income, will be used to assess if and how income level is correlated driver behavior. This information will be used in considering potential countermeasures.

Question 32 is a further measure of driver exposure. The information will be used to determine if the number of miles driven per year varies with respect to a specific UDA. This information may be used to make judgments about driver familiarity as well as to suggest countermeasure 
target groups for specific types of driver behaviors. 
APPENDIX C

REVIEW OF THE LITERATURE 


\subsection{INTRODUCTION}

This appendix is a review of the literature relevant to drivers' motivations for committing unsafe driving actions (UDAs) and to collecting data to determine such motivations. The review was prepared for the National Highway Traffic Safety Administration (NHTSA) under contract number DOT-HS-9-02276, entitled "Identification of Motivations for Unsafe Driving Actions and Potential Countermeasures."

\subsection{Objectives}

The objective of the larger studv supported by this review was to develop and test instruments for use in the field in determining the reasons why drivers commit UDAs. The review was conducter to assist in identifying specific information needs and in selecting methods for collecting such information. Specific objectives were to identifv:

- motivations for UDAs and other risk-taking behavior studied in the literature

- methods for determining in the field when a UDA has been committed

- methods for collecting data on Ariver motivations

The material in this appendix was developed to support the analvsis and design of field data-collection methods for determining UDA motivations. The resulting designs and design-evaluations are described in the main body of this report.

\subsection{Background and Scope}

The data collection approach selected for this study involves questioning drivers who have just committed a UDA to determine why they drove unsafely. This approach is called a "roadside survev" by highwav safetv researchers. This approach was selected over other interview aporoaches 
mainly because the short time lapse between the UDA and interview maximizes the chances that the actual motivating factor(s) will be recalled by the driver. Thus, a major data-collection design problem for this project was determining what questions should be asked of drivers selected from the traffic stream. A collateral problem was to determine how such drivers should be selected and what procedures should be used in "processing" drivers who have been selected.

This review deals with literature that addresses these two problems. Studies of driver behavior and risk taking were revised to identify the variables that should be pursued in developing a questionnaire to assess driver motivations. Methodology and measurement literature were reviewed to identify optimal techniques for collecting reliable and valid data. The literature examined included that pertaining to roadside observation and survey techniques that have been used bv highway safety researchers and practitioners. Methods of observation and measures of motivation user in the behavioral sciences were also reviewed.

\subsection{Organization of This Appendix}

This review is presented in five major sections. Section 2.0 discusses the literature relevant to developing questionnaire content, i.e., literature on driver behavior and risk taking. Literature related to the design and administration of questionnaires for measuring driver motivations for committing specific UDAs is reviewed in Section 3.0. Section 4.0 deals with the literature on methods and procedures for using the questionnaire in the field to collect data on UDA motivations. Section 5.0 summarizes the major conclusions of the literature review. Section 6.0 is a bibliography of the documents reviewed. 


\subsection{DRIVER BEHAVIOR AND RISE TARING}

This section presents a review of selected literature on driver behavior and risk taking. The literature treated falls into three general categories:

- personality characteristics of drivers

- driver attitudes

- situational factors

Such literature is useful in providing insight into the content of questionnaires for measuring driver motivations for committing UDAs. Literature in each of these categories is discussed below.

\subsection{Personality Characteristics}

Researchers in the area of highway safety have tried to distinguish the dangerous from the safe driver on the basis of personality characteristics or traits. A wide range of characteristics has been studied. Generally, such research suggests that unsafe driving is related to more negative personality traits. For example, higher scores on both social and personal maladjustment measures have been reported for high-accident drivers (Mayer and Treat 1977; Treat et al. 1979b). Tillman (1948) found that sixty-six percent of accident repeaters had a record of antisocial behavior compared with nine percent of the low-accident drivers; the personality structure of the high-accident drivers in Tillman's sample indicated impulsive, immature living habits compared to mature, stable patterns displayed by the low accident drivers. Similarly, Haekkinen (1958) reported safe drivers to be stable and calm; accident-prone drivers generally presented an opposite picture. Shoham et al. (1976) suggested a relationship between anxiety and risk taking. They administered questionnaires to 99 army drivers between the ages of 18 and 20 . Their results indicated that anxious drivers tend to be greater risk takers and consequently may cause more accidents.

Several personality questionnaires were administered to 875 drivers by 
Fergenson and Johnson (1968). These investigators also obtained the driving violation and accident history of each driver. They found the following characteristics to be more frequently associated with the problem drivers in their sample than with other drivers: suspicious, mistrusting, doubtful, opinionated, deliberate in actions, unconcerned about other people, and poor team members. The problem drivers also scored higher on anxiety, a characteristic that Fergenson and Johnson hypothesized to be disruptive of driving performance. High violation drivers were "cocky" about their driving skills and slightly older than the high accident drivers.

A similar study was done by Beamish and Malfetti (1962). These investigators administered two personality inventories to male drivers between the ages of 16 and 19 . Traffic violators were found to be in conflict with others and to perceive themselves as imposed upon. These drivers were rebellious and selfish. They expressed feelings of personal unworthiness and showed a lack of self-confidence. Traffic violators scored lower on emotional stability and objectivity as well as on conformity and mood. In contrast to Fergenson and Johnson, Beamish and Malfetti reported that traffic violators do not give proper thought to their actions.

In their study of personality factors in driving, Signori and Bowman (1974) delineated a number of characteristics found among accident driver groups. These drivers were found to have poor control of their hostility and to possess a low tolerance for tension. Many were suicidal or depressed. Such drivers were reported to be either extremely self-centered or excessively concerned with others. Very often their only consideration was the immediate future. In addition, Signori and Bowman found members of the accident groups to be aggressive, irresponsible, immature, fatalistic, and materialistic.

Hostility and aggression have also been associated with the unsafe driver by a number of other investigators: Kole and Henderson (1966), L'Hoste (1978), Pelz (1968), and Pelz and Schuman (1971). In their review of the driver literature, Naatanen and Summala (1976) concluded that aggressiveness is especially influential in traffic behavior and accidents.

Zemp and Associates (1980) reported on the results of twelve in-depth. 
psychological interviews conducted with drivers who speed. These interviews indicated "a commonality of underlying emotional motivations behind speeding behavior" (1980:2). The investigators proposed a model of the speeding cycle. The stages of this cycle are as follows:

\begin{abstract}
Bmotional Conflict. Emotions which, in the case of speeding, are in the form of internal conflicts about morality, uncertainty, and fear (power, status, recognition, self-esteem, and sexuality).
\end{abstract}

Tension Builds. They drive fast to release the tension (by confronting, challenging, surviving, overcoming, and erasing the conflict/uncertainty/fear).

After Speeding. The tension has been released, conflict is gone for now, and they feel exhilarated and fulfilled but exhausted.

Wear Out. As time passes, the fulfillment wears out, new conflicts arise, and the cycle starts again. (1980:18)

In latioratory studies of driving, Quenault and Fairhead (1972) found differences among driver groups in extroversion, with safe drivers scoring the lowest on this particular trait. A greater number of violations and accidents among extroverts was similarly reported by Loo (1978). Loo later noted that "both greater extroversion and greater field dependence are associated with poor performance on both driving-related tasks and driver records" (1979:125).

Some research has looked at differences in cognitive ability among drivers. Pergenson (1971) reported that drivers who have a high accident record process information at a significantly lower rate than other drivers. Similar results were reported by Mayer and Treat (1977). Intelligence per se did not prove to be a valid indicator of accident rate in a study of Finnish bus and train drivers (Haekkinnen 1958).

The descriptions of the safe driver read opposite those of the unsafe driver. MeGuire (1956) administered a battery of personality tests to a group of drivers in the U.S. Army. The accident- and violation-free driver was found to be more mature, conservative, and intellectual in interests and tastes than the unsafe driver. The safe drivers also expressed higher 
levels of aspiration.

Other researchers have looked at driver's self-image as it relates to safe driving. Market Opinion Research (1977) reports that a driver's selfimage is strongly linked to the driver's seat belt use. A self-image of good driving judgment and good driving habits is accompanied by an increase in the driver's use of seat belts.

Similar results were reported by Marzoni (1971) in a study on seat belt use. This investigator concluded that drivers who always wear seat belts are not fatalistic, not concerned with putting up a good front, not claustrophobic, and not exponents of the "common wisdom." These drivers were found to be methodical and accepting of technological innovations.

Andriessen (1971) used a theoretical model of the motivational determinants of risk-taking behavior to investigate performance on $a$ number of laboratory measures of risk taking. The model was developed by Atkinson (1957) to explain how the motive to achieve and the motive to avoid failure influence behavior in any situation where performance is evaluated against some standard of excellence. According to this model, people low in achievement motivation occasionally are more inclined to take risks than persons high in the need to achieve. Andriessen found the opposite: a positive correlation between high need for achievement and risky behavior. However, skill and perceptual variables were found to explain a greater part of the variance than were the motivational variables. Similarly, Rim (1963) reported a positive relationship between achievement motivation and risk taking in a study of Israeii students. Subjects scoring high on achievement motivation tended to take more risks in decisions than did the low-scoring subjects. Berkowitz (1969) hypothesizes with regard to the discrepancies between these studies and the model: "But whether they are too daring or not, the low achievement-oriented group might well be unrealistic at times; they may be either more extravagant or more cautious than the circumstances warrant" (1969:81).

Klein (eited in Naatanen and Summala 1976) has proposed that risk taking is a national characteristic of Americans: "Americans actually do not desire safe surroundings and . . many of them even actively look for 
risks in highway traffic and leisure pursuits." Klein argues that Americans have been taught the pioneer values of aggression, competition, individualism, and independence from their early days.

Not all investigators agree that negligent drivers are a homogeneous group with respect to personal characteristics (Case and Stewart 1957; Deutsch et al. 1981). Shaw (1965) also admits that it may be difficult to categorize these drivers, but the difficulty stems from the personal characteristics associated with involvement in accidents. Shaw points out that such characteristics can be as diametrically opposed as "aggressive dominance" and "neurotic inadequacy." MeGuire (1976) offers the conclusion that, in general, the accident-prone driver is less mature, less responsible, has a lower aspiration level, expresses poor attitudes toward the law and driving, and is not as well-adjusted as the safe driver.

\subsection{Driver Attitudes}

Studies of driver attitudes are not uncommon in the area of highway safety. The premise underlying such studies is that individual attitudes infuence individual behavior, and that the relationship between the two is consistent. A delineation of drivers' attitudes and thẹir relationship to subsequent behavior can provide information necessary for identifying potential driving problems.

Knapper and Cropley (1978) assessed drivers' attitudes in two areas: sources of hazard on the road and the image of the dangerous or bad driver. Their respondents identified other people as one of the major sources of road hazards. Aspects of people's driving behavior which were seen as dangerous are directly relevant to risky driving, such as carelessness or impatience. Many of the "dangerous" traits mentioned referred to qualities of an interpersonal nature such as discourtesy. Bad drivers are described in terms of personal characteristics. One set of characteristics involved traits related to driving behavior, such as "hesitant" or "inexperienced"; a second set referred to more general characteristics, such as "arrogant" or "selfish."

Drivers' attitudes have been reported to vary according to drivers' experience, age, and gender. A number of attitudinal differences among 
drivers were reported by Joscelyn and Jones (1972) in a study of drivers' attitudes toward the Traffic Law System in Fairfax County, Virginia. Two hundred drivers were randomly selected for the study from a general Fairfax County population; 100 drivers (the traffic violator group) were selected from traffic court records. Interviews were conducted on a household basis. Traffic violators were more likely to be under 20 years of age, have less than five years of driving experience, and have a history of traffic violations. Significant differences in attitudes between the two driver groups were also found. Violators did not view traffic laws as being up to date with traffic conditions and did not think that obeying traffic laws would improve driving safety. This group favored driver judgment on the road over strict observation of traffic laws as well as flexible enforcement of stop signs and traffic lights more than did the general population. More traffic violators also expressed the viewpoint that police were biased in traffic enforcement, being more likely to direct efforts toward the young driver, the sports car driver, or the motorcyclist. Respondents in the violator group indicated that they would drive more carefully in the presence of police; unmarked or hidden patrol cars were viewed as unfair. Finally, traffic violators were more likely than the general population to view penalties for traffic offenses as too high; they did indicate that if fines were refunded as rewards for good ariving, they would avoid violations until they received back their money.

Soliday (1975) found that persons having no accidents or violations in the five-year period immediately preceding the study rated a variety of driving situations as more hazardous than those drivers who had had at least one accident during that time. Stewart (1958) reported on the results of some early studies of driver attitudes, for example, a study of attitudes of accident-free drivers and accident repeaters by the ENO Foundation. This study concluded that attitudes about certain aspects of driving are significantly poorer among the accident repeaters. In a 1939 ; study. of Connecticut drivers, very low correlations were found between driving attitudes (as messured by the Iowa State Multi-Attitude Scale) and accident records. Stewart notes, however, that the real extent of accidents among the individuals in the study group was uncertain. 
Attitudinal differences between female and male respondents were also reported by Joscelyn and Jones (1972). Women generally expressed more conservative views than men with regard to traffic laws and traffic operation. They were more likely than the men in the survey to favor gtricter enforcement of traffic laws, to think they would be caught for a traffic violation, and to see a higher crash risk in the violation of traffic laws. The latter two views were more characteristic of the women in the general population than in the traffic violation population.

Goldstein and Mosel (1958) report a negative correlation between attitudes toward pollce and traffic violations in women; more favorable attitudes toward police, for example, were associated with fewer violations and accidents. Women also expressed a greater regard for speed, rules, and regulations. Driving experience was significantly correlated with miles driven, better driving attitudes being associated with greater experience. These investigators also found attitudes toward traffic rules and regulations generally to be positively related to age.

Soliday's (1975) results also support the notion of age and gender differences in driver attitudes. This investigator found that women rated various driving situations as more hazardous than did the men in the study. A similar relationship held for age with older drivers rating situations as more hazardous than younger drivers.

Pelz (1968) and Pelz and Schuman (1971) examined the motivational factors in crashes and violations in young drivers. They emphasized male drivers under the age of 25 since analyses of traffic accident data indicate that the fatality rates for these young men are twice those for men in their forties. These investigators sampled cross-sections of drivers to see what factors might account for dangerous driving in these youth. Their data indicated that the young males who were likely to have accidents and violations were more involved with cars than those who were not and that dangerous drivers, compared with safe, were more likely to spend time in cars for fun, to work on their cars, and to race cars.

Other investigators have tried to identify drivers' opinions with regard to more specific behaviors such as speeding. Lawshe (1940) mailed questionnaires to drivers whose speeds had been previously recorded on an 
open highway. A significant relationship was found between the maximum safe speed for ideal conditions shown in the individual replies and actual driving speeds. In general, those drivers who belleved that higher speeds were safe had been driving faster than others.

More recently, a number of studies have been undertaken to identify drivers' reasons for complying or not complying with the $55 \mathrm{mph}$ National Maximum Speed Limit. For example, a nationwide telephone survey was conducted by Teknekron (1979a; 1979b). Responses indicated that drivers believed safety was the major benefit of a $55 \mathrm{mph}$ speed limit and that stricter enforcement would be beneficial. Stewart and Hatle (1979) mailed questionnaires to 1,000 drivers in South Dakota. The reasons drivers gave for speeding included: in a hurry or bored; doubts about enforcement; no improvement in gas mileage; everyone does it; and no danger.

Drivers' attitudes about their own driving have also been studied, particularly as they relate to attempts to change drivers' behavior. It has been found that drivers generally tend to characterize themselves as better than average drivers. This topic has been discussed in Naatanen and Summala (1976). These researchers note: "Another factor eliminating the increase of the subjective risk of the road user while receiving information about crashes is the common belief that in their possession of superlative driving ability" (1976:69). They cite a study done by Barlow in which ninety percent of the drivers interviewed (and $100 \%$ of the traffic law violators) rated themselves as better-than-average drivers. In the Joscelyn and Jones study (1972), respondents agreed that most drivers violate traffic laws frequently or all the time; the respondents themselves, however, stated that they violate these laws not often or rarely. Seydel (1972) reports similar findings in a study of 662 drivers in Germany. Results from a self-assessment technique indicated that drivers feel superior, or at least equal, to other drivers. Naatanen and Summala note: "The fact that most drivers obviously regard themselves as good drivers and feel that accidents happen only to others might also explain the generally minimal success of fear-arousing exhortations in the improvement of road safety" (1976:70).

In contrast to the above studies, Case and Stewart (1957) argue that 
negligent drivers are not homogeneous with respect to attitudes expressed toward the law, the police, or themselves. The sample for their study consisted of 300 drivers who all met the Callornia criteria for "negligent drivers." These investigators found no consistent relationship between favorable or unfavorable attitudes and violation history.

\subsection{Situational Factors}

Evidence suggests that there is more variability within one driver's behavior than there is among drivers. LeFevre (1954) observed speeds on a rural roadway near Albany, New York, to determine driving habits. Results indicated that the variation of speeds for the same driver on different days was greater than among different drivers. Fhaner and Hane (1973) suggest that seat belt use is to some extent tied to situational variables; differences in usage levels between highway and city driving is one example of this.

The importance of temporary states to driving have long been recognized in the area of highway safety. DeSilva in 1942 identified several such temporary states or "indispositions" including: intoxication, fatigue, inattention, irritation, feelings of inferiority, nervousness, emotional shock, and ill health. More recently, Jones (1978) has hypothesized that the performance of a driver is unstable across time. Possible sources of this variability include: "driving experience, route familiarity, car familiarity, fatigue, stress, time pressure, activation level, motivation, and health" (1978:6).

The influence of many of the above factors on drivers' performance is supported by the findings of Treat et al. (1979a) in the tri-level study of accident causes. Human factors were cited as a probable cause in approximately 93 of the accidents investigated by the in-depth investigation teams. The major direct human causes identified were: improper lookout, excessive speed, inattention, improper evasive action, and internal distractions. In addition, "human conditions and states" were found to be related to accident involvement. Conditions and states were defined by these investigators as: nfactors which adversely affect the ability of a driver as an information processor and vehicle controller. These factors 
were viewed as reasons for reasons..." (19798:44). The ten most frequently identified conditions or states were: alcohol impairment, other drug impairment, fatigue, driver inexperience, in a hurry, emotional upset, vehicle unfamiliarity, pressure from other drivers, road/area unfamiliarity, and reduced vision.

In this section, situational factors will be discussed in terms of (1) distractions to the driver, and (2) the physical condition of the driver. Distractions to the driver may be both external and internal (such as preoccupation). In reviewing accident statistics, Shinar (1978) suggests that as many as forty-five percent of accidents could possibly be prevented if all of the involved drivers were attentive to the critical events immediately preceding the accident. Shinar notes:

These lapses in attention are manifested in failure to observe stop signs and signals because of internal (inside the car) and external (outside the car) distractions, as well as preoccupation with non-driver thoughts. Even perceptually conspicuous information is often unattended to. (1978:72)

Inattention was the human factor most mentioned as being responsible for traffic accidents in a survey conducted by L'Hoste (1978). It was ranked a high third in the tri-level study of traffic accidents (Treat et al. 1979a). The most frequent subcategory of inattention cited was "inattention with respect to traffic stopped or slowing ahead" (p.42). Other subcategories identified included inattention with respect to position of the car on the road, road features, road signs or signals, and cross-flowing traffic.

Fluctuations in attention level appear to vary with: the external involvement, situational demands, and the driver's internal state of motivation or arousal (Shinar 1978). Clayton and Mackey (1972) interviewed 625 accident-involved drivers. These investigators found that fallure-to-look errors usually resulted from a preoccupation with other things; such errors seemed to increase on unfamiliar roads.

Desilva (1942) reported the following forms of inattention occurring in a classification of the faults of motorists in accidents in one state: attempting to avold bees or other insects; eating while driving; flirting with pedestrians on the sidewalk; lighting cigarettes; one-arm driving; playing with chlldren or dogs in the car; preoccupation or daydreaming; 
reaching for a hat that is blown off; reading billboards and newspapers; sleeping; talking with occupants; tuning in or listening to the radio; and watching construction, fires, scenery, etc.

Internal distraction ranked as the fifth leading cause of accidents in the tri-level study done by Treat et al. (1979a). Conversation with a passenger was the predominant type of distraction cited. Other causal distractions identified were events in the car (e.g., dropped cigarettes) and adjusting radios or tape players.

Distraction was also found to be a major factor in traffic crashes by Greenshields (1959). He surveyed 3,090 drivers involved in rural accidents in Michigan. Of the 990 who responded, twenty percent indicated that they had been distracted at the time of the accident. For some of the respondents (about 1 out of 15), the distractions involved events immediately preceding the accident such as looking for a road, children fussing, or talking. However, for others (approximately 1 out of 10), these distractions or preoccupations involved stress in their personal life. Examples of the life situation distractions that were cited are worry over exams, marriage, divorce, and illness. Similarly, Selzer and Vinokur (1974) obtained a significant correlation between psychological stress and accidents in their search for the high-risk driver. Among the life stresses identified in their sample were illness, marital problems, job-related problems, worries over school, and financial problems.

Pelz (1968) and Pelz and Schuman (1971) identified a number of emotional factors affecting young drivers. These investigators found that traffic crashes and violations were often preceded by arguments, fights, or broken engagements. In addition, the new responsibilities and changes in life situations (e.g., marriages, new jobs) that must be met by this age group (i.e., 18 to 25 years of age) were also found to have a detrimental effect on driving behavior.

Driver stress has been discussed as a possible causal factor in accidents in a number of other studies (see McGuire 1976, for example). The categories of in a hurry and emotional upset were ranked fifth and sixth, respectively, among the human conditions and states implicated as an accident cause in the tri-level study (Treat et al. 1979a). Naatanen and 
Summala (1976) report a study in which twenty percent of the drivers involved in fatal accidents had been upset about some unpleasantness curing the six hours preceding the accident. In the majority of the cases, the male ariver had had a serious quarrel with a female, usually a wife, girlfriend, or barmaid. There were also instances of fights with other men.

There is also evidence to suggest that drivers involved in divorce proceedings have worse than average driving records. McMurray (1970) studied the driving records of 410 persons who were in the process of getting a divorce. Driving records for one year after the divorce action was initiated were worse than average; the greatest number of violations occurred within three months of filing for divorce. The most common violations by divorce-involved drivers were: speeding, failure to stop, and equipment violations. Similar findings have been reported by Signori and Bowman (1974).

Physical conditions have also been found to affect a driver's performance. These conditions include alcohol and other drug impairment, fatigue, and illness. Probably the condition most frequently related to severe accidents is alcohol intoxication (U.S. Department of Transportation 1968). In their review of the problem of alcohol and highway crashes in the United States, Jones and Joscelyn (1978) point out:

Some $40-55 \%$ of all driver fatalities in the studies had blood alcohol concentrations high enough to be considered, legally, too intoxicated to drive, in most states (i.e., BAC $.10 \% \mathrm{w} / \mathrm{v}$ ). An even higher percentage (55-65\%) of drivers who were killed in single-vehicle crashes had BACs of at least $.10 \% \mathrm{w} / \mathrm{v}$. Smaller but still significant fractions of drivers involved in injury crashes (9-13\%) and property damage crashes (5\%) were illegally intoxicated. (1978:33)

These authors also note that the risk of being involved in a traffic crash increases as alcohol concentration in the blood increases.

The relative probability of a crash starts to rise sharply as a BAC of $.08 \% \mathrm{w} / \mathrm{v}$ is approached. At a BAC of $.10 \% \mathrm{w} / \mathrm{v}$. the probability of a serious injury crash or a fatal crash is some 6 to 12 times as high as it is with no alcohol. At a BAC of $.15 \% \mathrm{w} / \mathrm{v}$, the relative probability of such a crash could be as high as 15 to 20 . (1978:33) 
In an analysis of the effect of alcohol on driver performance, Shinar (1978) found that the likelihood of a critical nonperformance (usually falling asleep) was increased by a factor of five.

A comprehensive review and analysis of the relationship between drugs (other than alcohol alone) and highway safety were conducted by Joscelyn et al. (1979). The authors summarize their review: "The reported studies have thus far shown that drugs do appear in accident-involved drivers, that drugs are used just before driving, and that many drug users have poorer than average driving records" (p.73). Impairment due to drugs other than alcohol was raniked second among the human conditions implicated in accidents in the tri-level study (Treat et al. 1979a).

L'Hoste (1978) reported that fatigue was a frequently mentioned response in a survey about traffic accident causes. It was ranked third among the human conditions related to causes of accidents by Treat et al. (1979a).

\subsection{Summary}

Literature related to driver behavior and risk taking was reviewed to identify possible motivations for UDAs. The literature strongly suggests that unsafe driving is related to negative personality traits and to maladjustment of drivers. Accident-involved drivers and drivers who violate traffic laws tend to be more hostile and aggressive than "safer" drivers. Other personality traits that have been found to be negatively correlated with safe driving include impulsiveness and immature habits, irresponsibility, rebelliousness, selfishness or excessive concern for others, lack of self-confidence, anxiety and tenseness, and a fatalistic outlook. Some studies suggest that extroverts tend to drive more unsafely than others. Other studies have found that risk takers in general tend to process information more slowly than others, but no relationship has been found between risk taking and general intelligence. Risk takers have been found to have less motivation for achievement than others.

Persons who drive unsafely (accident-involved drivers and traffic law violators) tend to have poorer attitudes toward traffic safety and traffic law enforcement than other drivers. Several studies have found that 
women have more positive traffic-safety attitudes than men. The literature also suggests that the more unsafe drivers believe that they are better drivers than do other drivers. Few studies have examined the effect of attitudes on specific UDAs. Some attitudinal studies of reasons for violating the 55 miles per hour National Maximum Speed Limit have been conducted. Respondents indicated a variety of reasons for violating the law, including being in a hurry, boredom, a belief that they would not be stopped by police, no improvement in gas mileage, everyone does it, and no danger in driving faster than the limit.

situational factors contributing to UDAs have been examined in several studies. The studies suggest that the pattern of unsafe driving is highly variable for a given driver and that this variation is greater than that found across drivers. A number of human conditions or states have been found to be associated with unsafe driving. These include the use of alcohol and drugs, fatigue, inexperience, lack of familiarity with the vehicle and the road area, pressure from other drivers, and reduced vision. Driver distractions, both external and internal, have also been found to be related to unsafe driving resulting in traffic crashes. Distractions or conditions caused by stress or emotional upsets have been identified as causes of traffic crashes in some studies.

All in all, the literature on risk taking provides useful insights for developing questionnaires for determining driver motivations for UDAs. In-depth studies of driver motivations should elicit information about drivers' personality and attitudes. Information on situational factors should be sought in any study attempting to identify more direct motivations for UDAs. Information on drivers' physical conditions or states and on distractions to drivers is particularly critical to determining UDA motivations. 


\subsection{MBASURBMBNT OP DRIVBR MOTIVATIONS}

The preceding section discussed literature relevant to the content of questionnaires for eliciting information from drivers on their motivations for committing UDAs. This section reviews literature dealing with the design and administering of questionnaires for obtaining such information.

The review of studies measuring characteristics of risk-taking drivers, however, reads frequently like a text book in personality measurement. Included among the measuring instruments are: the Allport-Vernon Study of Values; Eysenck's Neuroticism and Extraversion Scales; the GuilfordZimmerman Temperament Inventory; the Minnesota Counseling Inventory; the Minnesota Multiphasic Personality Inventory; the PEN Inventory; the Rorschach Ink Blot Test; the Semantic Differential; sentence completion tests; the Sixteen. Personality Factor Questionnaire; Social Relations Test; and the Thematic Apperception Test (see, for example, Atkinson 1957; Beamish and Malfetti 1962; Conger et al. 1959; Fergenson and Johnson 1968; Loo 1978; Parry 1968; Quenault and Fairhead 1972; Shaw 1965). Within the social sciences, measurements of motivation reads much the same; that is, measures of individual personality traits of characteristics (see Chun, Cobb, and French 1975 for a listing of such measures). These instruments are not designed to measure a reason for a specific behavior at a specific point in time. They are more often used to describe or explain behavioral differences among individuals across time.

Examples of measures of motivation in more specific areas were also reviewed. These included measures related to consumer buying behavior (e.g., Belk 1974; Bonfield 1974; Sheth 1967); sports motivations (e.g., Butt 1979); and Job motivation (e.g., Patchen 1965; Ronen and Kraut 1980). Such measures were found to be very specific to the behavior of concern; the applicability of their content to driver risk taking is limited. Therefore, the review of measurement literature in this section focuses on identifying strategies most likely to yield complete and accurate 
information on drivers' reasons for committing specific UDAs.

\subsection{Obtaining Complete Information on UDA Motivations}

Openness refers to the form of a question and the response that it requires. Open questions allow respondents to reply in their own words; closed questions (or forced-choice questions) ask respondents to select from a list of alternatives that best describe their situation. The following questions from Cannell and Kahn (1968:565) illustrate the contrast between the two question forms:

(open) What happens in your work group when things go wrong?

(closed) When things go wrong in your work group, do the people blame each other or don't they?

(open) How do people in this union feel about attending meetings?

(closed) Do most people in this local feel they should attend meetings, or do some, or don't any feel they should?

(open) How would you say you and your family are getting along financially now compared to a year ago?

(closed) Would you say you and your family are better off or worse off financially than you were a year ago?

There is general agreement in the literature that open-ended questions should be used when little is known a priori about the range of responses that subjects will give. Such a strategy is more likely to yield more complete information (Cannell and Kahn 1968; Lansing and Morgan 1971; Scott 1968; Warwick and Lininger 1975).

Cannell and Kahn (1968) have identified five considerations for the use of open questions versus closed questions: interview objectives, respondent information level, structure of respondent opinions, respondent motivation to communicate, and initial interviewer knowledge of the preceding respondent characteristics.

The open question is considered appropriate when the interview objectives are broad; that is, the research objective is not only to identify respondent attitudes or attributes but also to learn about information level, the structure and basis of respondent opinions, respondents' frame of reference, or intensity of feelings. Closed questions are considered more 
appropriate when the objeatives are limited to the classification of respondents on a clearly understood dimension.

If the respondents' level of information is unknown to the interviewer or is likely to be variable, the open question is the preferred strategy. Cannell and Kahn (1968) point out that the ill-informed respondent may prefer the closed question since it demands less of the respondent. However, the use of structured items under such conditions may produce answers where none really exist (Warwick and Lininger 1975). The interviewer therefore is unable to distinguish between knowledgeable answers and those chosen blindly in such circumstances. With the open question, the interviewer is better able to ascertain uncertainty or lack of information on the part of the respondent. These researchers note that it is possible to determine information level with a series of closed questions but that this may be embarrassing to respondents who "must reveal their ignorance by a string of negative answers" (1975:566).

The structure of respondent opinions or experience is also important in choosing between the open and closed question. The closed form is appropriate where respondents are likely to have thought about the topic ahead of tine and have formulated their opinions. In cases where respondents' thoughts are less structured, the respondent must be assisted in recalling, ordering, and evaluating the experience. The open question, with permissible probing, provides for this opportunity. The use of the closed question in such circumstances runs the risk that respondents will quickly choose alternatives quite different from the conclusion that would be reached if they went through "the process of recall, organization, and evaluation ${ }^{n}$ of their own experience (Cannell and Kahn 1968:566-67).

There is some suggestion in the literature that the use of open questions encourages respondents to communicate. Warwick and Lininger note that open responses are "helpful in allowing the respondent to warm up at the beginning of an interview" (1975:134). Cannell and Kahn (1968) suggest that the closed question is probably less threatening and less demanding of respondents, but it is also restrictive. These authors note: "An interview in which the respondent is never invited or allowed to express himself in his words had best demand little motivation, for it is 
likely to generate little" (1968:567).

Finally, the researcher's advance knowledge of respondent characteristics should be taken into account in deciding between open and closed questions. The use of closed questions requires substantial information about respondents. If the researcher knows relatively little about the range or terms of the responses likely to be given, the open question is preferable.

Because little is known a priori about the range of reasons that drivers will give regarding the specific UDAs under consideration, the open-ended question appears to be the preferred approach for obtaining more complete driver information.

\subsection{Obtaining Accurate Information on UDA Behavior}

A second issue in the design of any interview instrument or situation is the accuracy of the information obtained. Self-report measures such as those called for in this study are subject to distortion by a number of influences. One. such influence discussed extensively in the behavioral measurement literature is social desirability. This occurs "when respondents distort their answers to conform to the prevailing norms and values in their own community or the larger society" (Warwick and Lininger 1975:202). Certain characteristics of self-report measures are especially susceptible to distortion in the responses. These have been noted by Cook and Selltiz.

The purpose of the instrument is obvious to the respondent; the implications of his answers are obvious to him; he can consciously control his responses. Thus a person who wishes to give a certain picture of himself whether in order to impress the tester favorably, to preserve his own self-image or for some other reason can rather easily do so. (1964:40)

As a consequence of social desirability, respondents may be reluctant to admit to behaviors considered immoral or illegal. These authors discuss a number of techniques that have been devised to make the purpose of a self-report instrument less apparent, to make it easier to give answers that

- may be undesirable, and to make it harder to give false answers that may be considered desirable. These approaches include: 
- assurances of anonymity

- statements emphasizing the importance of honest answers in order to contribute to some desirable outcome

- building up rapport between the questioner and respondent

- inclusion of items irrelevant to the behavior in which the investigator is interested

- inclusion of items to which an unfavorable reply is likely to be considered acceptable

- use of forced-choice items

3.2.1 Obtaining Driver Information on UDA Behavior. One consideration in developing an instrument to assess drivers' reasons for committing specific unsafe driving actions is the ability of drivers to verbalize those reasons. Motivational theorists have not always been in agreement about the basic nature of this particular behavioral construct. While some have conceptualized motivation in terms of conscious volition, others have emphasized unconscious wants, needs, and drives (Berkowitz 1969). A number of complex and irrational factors are involved in why people behave the way they do, including individual, social, cultural, and circumstantial influences (Morton-Williams 1961). The use of indirect questioning is one means of assessing those driver motivations that are not able to be verbalized. Directness and indirectness deal with the relationship between the question and the concept the researcher is measuring. Cannell and Kahn (1968) have provided the following example to illustrate: when a respondent is shown an ambiguous picture and asked to tell a story about its meaning so that the story can be subsequently used to infer the level of the respondent's need for achievement, the question is considered to be indirect; a direct question would ask respondents how achievement-oriented they consider themselves to be.

Several indirect approaches have been identified by Cannell and Kahn (1968). The first of these is the use of the third person; that is, questions may be phrased with reference to an anonymous third person. The assumption underlying this approach is that respondents will place their 
own attitudes, beliefs, or feelings onto that third person. Bradburn and Sudman (1979) report some increase in responses to threatening questions when respondents are asked about their friends' behavior.

A second approach to indirect questions is the use of manifest and latent content. Respondents are asked to respond directly to meaningful questions about themselves. The interpretation of the responses, however, is indirect and is based upon the assumptions underlying the test questions. The personality inventories mentioned previously make use of manifest and latent content.

The use of ambiguous stimuli is a third indirect approach. Such techniques require an individual to describe or interpret a relatively unstructured stimulus situation (e.g., an ink blot, pictures of people in various settings). The rationale underlying such techniques is that "an individual's responses to an 'unstructured' stimulus are influenced by his needs, motives, fears, expectations and concerns" (Nunnally 1972). However, these tests require clinical training for administration and evaluation of results and are very time consuming. Such measures are primarlly used to assess personality attributes.

of the approaches identified above, the one most appropriate to a driver survey on UDAs is the use of the third person. The third person is readily adopted in the formulation of interview questions and does not require exceptional time in its administration and evaluation. Moreover, even if the more clinical tests (that is, the use of latent content or ambiguous stimuli) were readily adaptable to this study it is unlikely reasonable countermeasures could be identified from the results of the test.

\subsection{Summary}

Measurement of drivers' reasons for committing specific UDAs requires interview instruments that can provide complete and accurate information. The literature points to a strategy employing questionnaires with open questions, techniques that minimize the respondent's tendency to provide socially desirable responses, and third-person formulations of questions.

Open questions are preferred because little is known beforehand about 
the range of responses or about respondents' prior level of knowledge of the concepts under study. Open questions appear better for our purposes because they will help "warm up" the relationship between the interviewer and the respondent.

A respondent's tendency to provide socially desirable responses rather than true responses can be minimized through several approaches. These include assurances of anonymity, statements stressing the importance of honest answers, building up rapport between the interviewer and the respondent, having some items that are irrelevant to the UDA behavior being studied, having some items to which an unfavorable response will be considered desirable, and using some forced-choice items.

Finally, the literature indicates that third-party formulations of questions will help drivers verbalize motivations that they might not understand or be able to put into words. This technique allows the respondent to profect his or her attitudes, beliefs, and feelings to an anonymous third person. Such an approach tends to increase the amount and depth of responses to certain types of questions, for example, questions that might be viewed as threatening. 


\subsection{DATA COLLECTION MBTHODS AND PROCBDURBS}

The roadside survey approach was selected for use in this project to collect data on driver motivations for committing unsafe triving actions (UDAs). This approach requires that vehicles in the traffic stream be observed to identify those drivers who are committing a UDA, and that the drivers be removed from the traffic stream for an interview at a roadside location near the location of UDA. Literature on the nature and use of this approach are reviewed in this section. Characteristics of relevant observational methods are discussed in Section 4.1. The roadside survey as a research method is discussed in Section 4.2.

\subsection{Methods of Observation}

The use of observations in highway safety research as well as in behavioral science research is well established. Highway safety observations have been made of such diverse behaviors as seat belt or child restraint use, pedestrian behavior, and behavior with respect to UDAs such as speeding or turning. The term "observational method" is user to refer to looking at events in their natural surroundings. Simple observation involves (1) defining the behavior to be observed; (2) selecting the setting for the observation; and (3) developing the strategy for observation. The obtrusiveness of the observational method is frequentlv a concern to researchiers. Obtrusiveness refers to the extent to which people mav be aware that they are being observed.

One problem in describing the methods of observation used in highwav safety research is that many researchers treat the observation method summarily. For example, several highwav safety sturies report onlv that "observations were made" (Berger and Robertson 1976; Ellinger 1976; Geddis 1979; Mamlouk 1976). Varying levels of description are, however, reported in a number of other studies. These include observations of moving traffic (or temporarily stopped traffic such as stop light 
observations) as well as observations of parked cars. Since UDAs are committed in moving traffic, the following section reviews observations of only moving or temporarily stopped traffic. Observations from behavioral science research are considered as well.

4.1.1 Types of Behavior Observed. Observational studies mav real with almost any public, visible, extemal event (Weick 1968). Behaviors commonly studied through systematic observation include: nonverbal behavior, such as facial expressions, exchanged glances, and body movement; spatial behavior; extralinguistic behavior, such as vocal and temporal dimensions and continuity; and linguistic behavior. Crosbv, Bromley, and Saxe (1980) recently reviewed unobtrusive studies of racism conducted in the last decade; these efforts fall into three categories: helping behavior studies, in which the measure of racism is differential helping behavior; aggression studies, in which the measure of racism is differential degrees of direct and indirect aggression in situations in which aggression is socially permissible; and nonverbal behavior studies, in which differences in nonverbal behaviors (e.g., tone of voice) constitute the maior measure of racism.

A broad range of driving behaviors has been the focus of highwav safety observation as well. There have been a number of studies in which occupant restraint use has been observed (for example, Johnston and Cameron 1979; Opinion Research Corporation 1980; Stowell and Brvant 1978; Williams and Robertson 1979). In other studies, the use of motorcycle helmets has been observed (Ellinger 1976; Lummis and Tucker 1979; Struckman-Johnson and Ellingstad 1979). Observations of turning behavior, speeding, and stop sign/light behavior have been observed in studies of unsafe driving actions (for example: Karan et al. 1976; Mamlouk 1976; Millar and Generowicz 1979). Other observational studies of driving behavior include: driver response to freewav quide signs (Hanscomb and Berger 1976); passenger loading (Henderson 1975); and drtver-pedestrian interactions (for examole, Dueker 1978; Jennings et al. 1977; Ven der Molen 1976).

Consumer behavior has often been the focus of observational studies. 
The observation of a store's traffic Datterns is one example. This methor is commonly used to study the effect of store layout on sales and is conducted most often in supermarkets. Tvpically, observers plot the paths of a sample of customers on a small replica of the store lavout. The paths are summed to obtain the density of customes: traffic in different parts of the store. These numbers can then be converted into passingbuying ratios: the number of customers who pass and buy from maior product groups. Considerable variation exists among shoppers in overall store coverage. Generally, a positive relationship exists between locations passed and purchases; that is, the greater the number of locations passer, the greater the number of purchases. The findings of these studies serve as the basis for retailing strategies. A limitation of such studies is that they cannot measure purchase intentions (Engel, Kollat, and Blackwell 1973).

4.1.2 Settings for Observations. Almost any naturalistic setting can be used for observational studies. The minimum requirements for setting are: (1) the behavior of interest must occur in that setting, and (2) there should be lew impediments to clear observation in the setting.

Observations of driver behavior may occur at any point along the roadway (e.g., intersections, freeway exits). The choice depends greatly upon the behavior being observed. Visibility is a kev concern for observational studies of driver behavior. Many studies stress the need to perform the observations furing daylight hours (Duncan et al. 1977; Hochberg et al. 1977; Opinion Research Corporation 1980; Williams and Robertsion 1979), although one study of seat belt use did report making observations at night (Johnston and Cameron 1979). Still other studies have reported making observations only in dry weather when visibilitv is clear (for example, Duncan et al. 1977; Elman and Killebrew 1978; Mathews 1978).

Researchers will often modify a situation to evoke or amplifv a response when the event of interest occurs relatively infrequently. Manv behaviors might not be easily obtained in naturalistic settings because "the responses are of low frequency, require special precipitating conditions, or 
would be prohibitive to observe in terms of available resources" (Kaztin 1979:716). Situations are thus contrived to evoke the behavioral responses of interest. An additional consideration in setting selection is therefore frequently added, the amenability of the setting to modification (Weick 1968). Stimuli are varied by the investigator in an inconspicuous way in order to evoke or amplify a relatively infrequent response. The classic study by LaPiere (1934) on verbal attitudes and overt behavior illustrates the contrived approach to observation. LaPiere visited 250 hotels and restaurants across the United States with a Chinese couple; service was refused only once. Questionnaires were also sent to those same establishment asking if thev would welcome Chinese customers; approximately ninety-two percent answered no.

Webb et al. (1966) have noted that driving behavior provides a setting In which to embed a measure of persuasion. These researchers sugeester that the content of traffic signs could be varied systematicallv (for example, high fear appeal versus low fear appeal); the driver's behavior after passing the sign could then be observed by radar or helicopter.

4.1.3 Strategies for Observation. Strategies for observation include both unassisted human observation and instrumented observation and measurement. Observational methods in the social sciences have for the most part been used to study forms of social interaction; observation strategies reflect this focus. Simple observation, i.e., unassisted human observation, is the primary strategy used by behavioral scientists in makine observations. Often the observer will use a checklist svstem to record the behaviors of interest. These checklist strategies include sign analvses and fleld formats. According to such strategies, observers classify behaviors with specific behavioral codes (Kazdin 1979). In sign analyses, a number of specific acts or incidents that may occur during a period of observation are listed beforehand; the record shows the behaviors that occurred and their frequency during a period of observation (Mefley and Mitzel 1963). Field formats are used to ensure that the observer attends to various aspects of an event; subcategories of an event are delineated, and a system of notations is developed to aid the observer. Traditionallv, 
observers have also used tape recordings to make detailed narratives of their observations. More recently, motion picture films and videotapes have begun to be used to assist in making observations (Weick 1968).

Jones (1980) describes three observation strategies used in pedestrian research: simple observation using only humans as observers; human observation assisted by instrumentation; and observation by instrumentation. These methods apply to other areas of transportation research as well. Simple observation is most commonly reported in the highwav safetv literature as well as in the social sciences (e.g., Elman and Killebrew. 1978; Johnston and Cameron 1979; Stowell and Bryant 1978; Williams and Robertson 1979). Simple observations have been described as the preferred method because on-the-spot coding of behavior by highly trained observers is feasible in all situations. It is cost effective as well (Jones 1980).

Strategies for simple observations depend to a great extent on what is being observed. Observations of seat belt usage, child restraint usage, and stop-sign or stop-light behavior are most of ten made at intersections or freeway exits. Several studies report that in order to observe seat belt or child restraint usage, it is necessary to make the observation at a boint where the vehicle being observed is either stopped or moving at a speed less than $15 \mathrm{mph}$ (Johnston and Cameron 1979; Williams and Robertson 1979). The positioning of the observer at the intersection is also important (e.g., Deutsch et al. 1981). To observe for seat belt or child restraint usage, previous studies have demonstrated that the best spot for the observer to stand is on the side opposite the driver as the stoo sign or light is approached. This gives the observer an unobstructed view of the driver's lap (Stowell and Bryant 1978; Williams and Robertson 1979). For stop-sign behavior, several observer locations háve been suggested. In a study of drivers' behavior in the presence of changing traffic signals, Konecni et al. (1976) placed the observer at the pedestrian traffic light control button. When a car reached a given distance before the light, the observer pressed the traffic light button. At this position the observer har a clear view of the driver's behavior as the intersection was being approached and the traffic light changed. In a stutv of drivers' behavior at stop signs, Feest (1968) placed the observer in a vehicle fust before the 
stop sign on the side of the street opposite from the traffic being observed.

Observations of speed, turning behavior, and other moving UDAs have been made along the roadway. The position of the observer varies according to the characteristics of the observation site and the behavior being observed. For speed observation, the observer has usuallv been placed on the road shoulder of the lane of traffic being observer (for example: Karan et al. 1976; Mathews 1978). This is because radar is often used to measure speeds; measurement requires a small angle between the traffic and the radar unit in order to determine speeds accurately. When measuring traffic speeds on an expressway, Mathews (1978) parked the observer vehicle on a bridge crossing the expressway and pointed a . radar unit down on the moving traffic. A cosine correction was used to compensate for the angle of the radar beam.

For observations of turning behavior, placing the observer in a nearby parking lot with an unobstructed view of the turn has been suggested (Jackson and Gray 1976). In a study of UDAs, Lohman et al. (1976) placed observers along the side of the road or in parking lots, depending on the characteristics of the observation site. These investigators also differentiate between the "point method" of observation described above and the "trip method" where a vehicle is identified, followed, and observed for a period of time. The "trib method" is used less frequently than is the "point method."

In a review of traffic conflict studies, Glauz and Migletz (1979) described the observation procedures used by traffic conflict researchers. The General Motors (GM) procedure calls for two observers located 1.00 to 300 feet from the intersection of interest, to observe vehicle movements for ten hours on a Tuesday, Wednesday, or Thursday. Procedures used bv United States agencies were found to be basically the same as the GM procedure, but with some modifications to suit their needs. One, two, or three observers are used to observe conflicts, traffic volume, or special activities. Observers are located at a site that permits a good view of traffic movements at that location. This is typically 200 to 300 feet upstream of the location of interest and along the right edge of the 
traveled roadway. Times of observation vary from state to state. Manv types of recording techniques are used, including manual and automated counting, photographs, time-lapse photography, and videotapes. All of the studies with on-site observers reviewed by Glauz and Migletz used some form of manual counting.

Two highway safety studies reported a moving observer as their primary observation method. In a study of shoulder-restraint use on interstate highways, Hochberg et al. (1977) reported that an observer was stationed in an elevated van. Observers recorded shoulder-restraint use as traffic passed the van. In a study of passenger loading conducted by NHTSA, staff kept records of the number of passengers in automobiles they encountered on specific segments of their routes to and from work (Henderson 1975).

Because the observation methor relies on judgments, the issue of observer reliability is often raised. The most common reliabilitv measure in observational studies is observer agreement. According to this strategv, the fudgments of two persons observing the same event are obtained and compared. Weick notes, "unless this is achieved there is no assurance that any distinct phenomenon is being preserved in the record" (1968:404). Instrumentation (such as videotaping) has been used as an aid in observing. Although this practice has served primarily to preserve a record of the behavior of interest, the permanence of such records allows for greater checks on the reliability of observer fudgments. This use of instrumentation has been concerned with reducing the errors associated with the human observer as a measuring instrument; such errors may include, for example, selective perception or the lack of capacity to note all the elements in a complex behavior pattern (Webb et al. 1966). Observation by instrumentation has also been used to minimize the influence or obtrusiveness of the observer. (This latter point is discussed in the following section.)

Human observers have also been assisted by instrumentation in highway safety studies. Millar and Generowicz (1979), for example, used observers at intersections as well as a mechanical surveillance device in a sturtv of stop-light behavior. The device contained a photorecorder that was 
automatically activated when a vehicle went over a wire 1000 installed a short distance before the intersection. All vehicles crossing the loop after the beginning of the red signal were photographed. In a study of the effect of bridge shoulder width on traffic flow, Roberts (1976) used both observers and tapeswitches. The tapeswitches were used to measure speeds and lane position; the observers recorded characteristics of the drivers.

Instrumentation alone has also been used to make and record observations in highway safety research, although to a much lesser extent than simple observation. For some UDAs the use of instrumentation is necessary to assure the accuracy of measurement. The most commonly used instrumentation appears to be videotape. For example, Bottom and Ashworth (1978) reported a study in which a segment of one roan was. videotaped on seventy-nine separate occasions. The tape was later analyzed for drivers' gap acceptance behavior. In a study of pedestrian accidents, Jennings et al. (1977) videotaped the behavior of adult pedestrians at intersections. There was no detailed description of where the cameraman was positioned, however.

Closed circuit television was used to observe pedestrian crossings at urban intersections in a study reported by Dueker (1978). A series of three cameras was used. Two cameras had wide angle lenses that photographed the entire intersection and were attached to utility Doles. A third camera was located in an observation van and was adjusted to focus on specific pedestrians. No detailed description of the position of the observation van was given.

Automated counters were user in five of the studies on traffic conflicts reviewed by Glauz and Migletz (1979). The tvpes of automated devices used included tapeswitches, loop detectors, and radar. Time-lapse photography was used in seven of these studies. Videotape was used in eight. Glauz and Migletz conclude that, in general, "the use of the various technical recording devices was preferred in the research projects, and manual observation was normally used in operational applications" (1979:7).

Joscelyn et al. (1971) reported using a computer sensor svstem to observe the effect of law enforcement on traffic flow behavior. The 
system consisted of a series of magnetic-induction loods connected to telephone wires that carried signals to a central computer. The data included vehicle velocity, length, direction, lane of travel, and headway.

The utility of instrumentation versus simple observations in highway safety studies has been discussed by several researchers. Forde and Birse (1977) report that measuring instruments are more effective in heavy traffic because they record everything and, unlike a human observer, are not subject to missing information. They point out, however, that a human observer may be more effective in light traffic flow because he or she has greater flexibility than does a camera. In their study of pedestrian behavior, Beyer and Robertson (1976) found hardware techniques too costly. It was their opinion that manual tallies made by observers were the most cost effective method.

4.1.4 Obtrusiveness of Observation. The influence of the observer in any observational setting must be determined. Webb et al. (1966) have noted the patently visible observer can produce changes in hehavior that diminish the validity of comparisons both across populations and across time in the same population. It is also possible that this observer effect on behavior erodes over time. The real issues, as Weick (1968) points out, are how extensive the impact is, which settings and processes are most vulnerable to its effects, and whether interference can be detecter. Investigators have identified several settings in which observers do interfere with natural processes. Inactivity in some situations makes the observer stand out. In some settings, persons often turn to the observer for help; this frequently happens when the interaction between two persons resolving an issue is under study. Finally, interference is a problem when - persons have reason to suspect the motives of observers (Weick 1968).

Many of the studies reported in the highway safety literature do not address the issue of obtrusiveness in the observation procedure. Other studies recognize the need for unobtrusiveness but have not retailed their methods for making the observers unobtrusive (for example, Gadallah 1976; Hanson and Berger. 1976; Hauber 1976).... There are a number of studies, however, that explicitly recognize the need for observations to be 
unobtrusive and to avoid the possible impact of the observation procerture on the behavior being studied. The difficulty of developing unobtrusive techniques for human observations was recognized by Johnston and Cameron (1979) in their study of seat belt use. They includer in their site selection criteria observation sites that oermitted the observer to be as unobtrusive as possible. Unfortunatelv, thev did not detail the characteristics of their sites that made their observers unobtrusive.

A number of strategies for dealing with observer interference have been proposed. The most basic of these is concealment: the observer is not seen, the setting is not changed, and the subject of the observation is not aware that observation is taking place. Thus, observer effects "are not an issue" (Webb et al. 1966:138). Concealed observation, however, has frequently raised ethical questions. Barker and Wright (1955), for example, have argued that concealment is fustified only if the behavior is public and open to scrutiny by all.

Alternatives have been suggested in response to the ethical arguments against concealment. These include partial concealment and nonconcealment. In partial concealment, the observer does not hide the observations but only who or what is being observed. Partial concealment represents an attempt to address the ethical arguments against concealment and, at the same time, minimize the effects of observation on the behavior and population of concern. With nonconcealment, the observer indicates the purpose of observation in advance to the subjects and then tries to remain inconspicuous while recording (Weick 1968). Nonconcealment most directly addresses the ethical issue underlying concealment. However, it is much more likely that this strategy will influence the behavior under observation. Webb et al. state:

No matter how well integrated an observer becomes, we feel he is still an element with potential to bias the production of the critical data substantially. The bias mav be a selective one to jeopardize internal validity, or, perhaps more plausibly, It may cripple the ability of the social scientist to generalize his findings very far beyond his sample." (1966:113)

Only a few highway safety studies detail the procedures used to make observations unobtrusive. Most make use of concealment or 
nonconcealment strategies. Jackson and Grav (1976), in their studv of turning behavior, placed observers inside a vehicle on a used car lot to prevent drivers from noticing them. In two studies of vehicle speeds, the authors recommended that, was radar is used to measure speeds, the radar be placed in an older type of vehicle that did not resemble a police car (Beaubien 1976; Karan et al. 1976). The latter study also noted that the most unobtrusive location to mount the radar was on the right rear window facing the traffic approaching from the rear.

In studies of stop-sign or signal behavior, Feest (1968) recommended that observers be stationed in a car parked by the side of the road and avoid making eye contact with the driver. Konecni (1976) demonstrated that the most unobtrusive place to put an observer was at the street corner appearing as if ready to cross the street.

An additional means to control observer interference is the use of instrument-assisted observations. Equipment can be used to supplant the observer, thereby minimizing the influence of observer oresence. Examples of such instrumentation include the use of hidden microphones or hidden cameras.

The obtrusiveness of instrumentation has also been recognized in highway safety as well. Dueker (1978) reported that the installation of closed circuit television cameras on utility poles made pedestrians less likely to notice the cameras. Similarly, Joscelyn et al. (1971) reported a computer sensor system (with loops installed in the roadway) to be completely unobtrusive in their study of the effect of law enforcement on traffic now.

Not all hardware has proven to be unobtrusive. Millar and Generowicz (1979) reported that their mechanical surveillance device for observing stop signal behavior did have an effect on traffic stops; they attributed this impact to the device's bulkiness.

When such instrumentation is fixed at a single point, the investigator becomes dependent upon the character of the population passing by that point and the content appropriate to it. As Webb et al. note: "The waiting game can give accurate and complete measurement of a limited population and limited content ..." (1966:169). The authors further point 
out that the decision to use this approach should be based on both theoretical and practical considerations: "Are the limitations likely to be selective enough to inhibit the generalizability of the findings? Can the investigator absorb the time and money costs of developing material with a low saturation of pertinent data for his comparisons?" (1966:169). One remedy to this problem is to vary the time and the location of the data collection activity.

Archival records and physical trace measures have been identified as two data sources not subject to observer interference (Wehb et al. 1965; Weick 1968). Archival records refer to the "ongoing, continuing recoris of a society" (Webb et al. 1966:63). Examples of such records include: the federal census; birth, marriage, and death records; membership lists; political records; sales records; and industrial records. Kazdin (1979) reports that a number of social and community extensions of behavioral programs have frequently used archival records to evaluate performance. Examples include programs designed to curb energy consumption in the home, for which records from oil, gas, or electrical meters have been obtained; conservation of automobile fuel has been evaluated unobtrusivelv by recording mileage from the odometers of automobiles. Phvsical trace measures refer to the physical incidence "surviving from past behavior" (Webb et al. 1966:35). Such evidence includes the selective wear on material (e.g., wear on library books as a measure of popularitv) or the deposit of some material (e.g., fingerprints on a displav case as a measure of attention).

\subsection{Roadside Surveys}

The roadside survey is a well-organized research strategv in the area of highway safety. It is the preferred method for the present sturiv of driver motivations. This section reviews the use of the roadside survev in past transportation research. It discusses the role of police officers in roadside surveys as well. 


\subsubsection{Use of Roadside Surveys in Transportation Research. Past}

studies using roadside surveys fall primarilv into three categoriesepidemiologic studies to determine the traffic crash risk created by alcohol- and drug-impaired drivers, origin-destination survevs for use in state transportation planning, and more general driver behavior studies. Each category is discussed in this section.

Procedures for conducting roadside surveys of alcohol and drug use have evolved over a period of more than 40 years since Holcomb (1938) conducted the first roadside survey in Evanston, Ilinois. Since then more than 100 drinking-driving roadside surveys have been conducted. One of the most well recognized is the Grand Rapids study reported bv Borkenstein et al. (1964), in which 7,590 drivers were stopped and requested to submit to an interview and a breath test. A national roadside survey of drinking drivers was conducted bv The Universitv of Michigan Highway Safety Reșearch Institute in 1973 (Wolfe 1974). A total of 3,698 drivers across the nation was stooped and asked to give a breath test and answer a brief questionnaire. In 1974 a similar study was conducted in Canada (Smith et al. 1976). In Vermont, Perrine et al. (1971) reported conducting a roadside survev in which $1,1.84$ drivers were stopded and asked to submit to an interview and a breath test. A roadside survev in Huntsville, Alabama, conducted bv Farris et al. (1977) requester 804 drivers to submit to an interview and a breath test. At least 27 of the 35 federally funded Alcohol Safety Action Programs (ASAP) conducted over 100 roadside surveys of more than 100,000 drivers as part of each ASAP's program evaluation of its effectiveness in reducing alcohol-related traffic crashes (U.S. Department of Transportation 1979).

All of the above studies involved the measurement of alcohol in the driving population. Two recent roadside surveys involved the measurement of drugs other than alcohol and collected urine, blood, and saliva specimens in addition to breath tests (Blackburn and Woodhouse 1977; Glauz and Blackburn 1975).

Origin-destination surveys conducted by state transportation Dlanning agencies at roadside have been reported at least since 1965 (Holmes 1965). A typical origin-destination-type survey is described by Voorhees and 
Associates (1971). The purpose of the study was to determine the volume and characteristics of travel between 19 pairs of cities in the Northeast Corridor of the United States. Approximately 100,000 drivers on maior routes in the area were stopped and interviewed in late 1969. Other origin-destination roadside surveys include a study prepared for the federal Rallroad Administration by Wilbur Smith and associates (1973) and stateline cordon surveys conducted by numerous states including California, Kentucky, New York, and Oklahoma. Descriptions of the state survevs have been complled by DiRenzo (1976).

Several studies have used the roadside survey to assess drivers' attitudes and driving knowledge. Seydel (1972) surveyed drivers in Germany about their personal adherence to speed limits and attitudes toward speen enforcement. Solomon (1964) conducted a roadside survev to obtain information on such driver characteristics as sex, age, militarv status, and residence. Information about the vehicle was also collected. Drivers' speeds were measured with concealed measuring devices. At a distance beyond the observation point, drivers were stopped and interviewed. No information about drivers' reasons or motivations for their driving speeds was obtained.

An investigation of the occurrence of aggression among drivers was conducted by Parry (1968) in England. A roadside survey was one of three methods of data collection used by this investigator. Drivers were presented with questionnaires at the stop and asked to return them by mail at a later time. Knowledge and attitudes about general driving situations were obtained; specific reasons or motivations for unsafe driving actions were not addressed.

One roadside survey of particular interest was done by Hanscom and Berger (1976). These investigators studied driver responses to freeway guide signs. An observer was stationed at the location of the quide sign to look for the targeted vehicle behaviors. These behaviors were land changes, gore weaves, stopping, backing, driving slowlv, following closelv, and exhibiting brake lights. The observer radioed a descriotion of the subject vehicle to the survey crew farther down the roar. State police officers waved the appropriate vehicle over and directed the driver to the 
survey crew. A questionnaire was administered if the driver consenter. The authors reported identifying 455 vehicles; 376 were stopped safelv, while 340 agreed to the interview. The focus of this study was on responses to guide signs and the reasons for that response. Reasons for driving actions were not investigated.

4.2.2 Roadside Survey Procedures. Procedures for conducting roadside surveys of drivers have been delineated bv a number of highwav safety researchers. Perrine (1971), for example, provides a systematic description of the procedures to be used in roadside survey research. This section follows Perrinels outline for the most part and supplements it where appropriate, with recommendations from other researchers. Detailed attention is given to both the planning and the conducting of the survey.

The planning phase of a roadside survey is essential to its smooth operation. Stroh (1973) recommends that sufficient time be set aside to ensure the support of all relevant agencies. The use of police in roadside surveys is well-recognized by highway safety researchers. The primarv function of the police in the roadside survey is one of traffic control. Wolfe (1974) points out that survey team members do not have the experience to stop safely the vehicles randomly selected out of the traffic now. Almost all studies recognize that it is the responsibility of the police officer to see that drivers are stopped safely and are guided safelv back into the traffic now (e.g., Carr et al. 1974; Perrine 1971; Wolfe 1974).

Moreover, as Wolfe (1974) notes, civilians simply do not have the authority to stop vehicles moving on a public highway. This authoritv, in almost all circumstances, is vested only in law enforcement officers. Therefore, the use of police officers to stop moving vehicles for a roadside survey is not only safer, but also legally necessary.

In almost all of the roadside surveys that report a description of the procedures used to conduct the survey, police are used to direct traffic at the sirvey site. Police were used in all the alcohol and drug surveys previously noted, with the exception of the San Diego study reported by Farris et al. (1977). In San Diego, police were not allowed by the city to 
participate, so traditional roadside survey procedures were changed. Because the researchers had no authority to stoo moving vehicles, the research team had to set up its operations at the traffic signal closest to the desired survey location. Researchers approached the drivers while they were stopped at the traffic signal.

At least seventeen of the ASAP jurisdictions that reported roadside surveys included descriptions of the procedures used to conduct the roadside survey. All reported the use of police for traffic control. It is highly likely that police were used in the other furisfictions because all ASAP roedside surveys were to be conducted under guidelines developed bv Perrine (1971) for the National Highwav Traffic Safetv Administration. These guidelines stressed the importance of the use of police in traffic control.

Most of the origin-destination roadside surveys do not rebort survev procedures in detail. The Northeast Corridor Survev discussed in DiRenzo (1976) does specify procedures. These include the use of one to three traffic police for traffic control. Other origin-destination studies do not contain detailed procedures but simply report that "standard roadside "survey procedures were used."

Since participation in a roadside survev is completelv voluntarv, researchers have been extremely concerned that drivers not be intimidated by the presence of police in roadside surveys. The Organisation for Bconomic Co-Operation and Development, in advocating the use of police in roadside surveys, has stressed that the role of the police officer be as small as possible: "In the case of voluntary surveys (as will be conducter by most countries) the police contact with the driver should be minimal. The survey should be introduced and explained to the driver by the trained survey personnel, and not by the police officers" (1978:131). All of the roadside arveys that reported detailed procedures have followed this recommendation. In many instances the police officer savs nothing to the driver. The officer simply hays the car down and waves the driver over to the survey site. If the driver asks the officer any questions, the officer instructs the driver to ask the questions at the survev site. Some surveys have reported that the officer is instructed to explain brieflv to 
the driver that he or she has been stopped for a roadside survev, but if any further explanation is necessary, it is done by survey personnel (for example, Wolfe 1974).

Another reason for having a police officer present during a roadside survey is to assist the researchers in dealing with drivers who are obviously too impaired to continue driving. When such a Ariver is encountered by a member of the research staff, the staff member asks the driver to be driven home in a taxi or a staff car driven by a staff member. In the event that the impaired driver refuses this request, the staff member informs the police officer who can take whatever action deemed necessary. Such action could include having the police officer drive the impaired driver home or placing the impaired driver under arrest for refusing to obey the lawful instructions of a police officer. At no point does the staff member. attempt to restrain the driver or restrict his movements. Such a procedure protects the stopped driver and other drivers from possible injury and property damage, and protects the project from allegations of liability for allowing a known impaired driver to continue driving.

\subsection{Summary}

This project requires that drivers in the traffic stream be observed to determine which of them are committing UDAs and that a sample of the observed drivers be selected for interviews in a roadside setting. Unobtrusive observation is preferred so that driving behavior is not altered by the presence of the observer or the observing device.

Observations can be made by an unassisted human, a human with instruments for detection and measurement, or instruments alone. The literature indicates that the unassisted human is most commonly used in highway safety research. Humans are used at traffic control points or along the roadway to observe a variety of behaviors, from occupantrestraint use and pedestrian behavior to driving maneuvers. A checklist system employing behavioral codes is often used to record the behaviors of interest. Observer reliability is a major consideration in unassisted-human 
approach. Reliability is determined either by having two or more Dersons observed the same event or bv using instruments to check the human observations.

Human observers assisted by instruments are commonly used in highwav safety studies. Automated observation devices not requiring a human operator have been used in a number of highway safety applications, including studies of traffic conflicts. In general, the automated devices have been found to be better suited than human observers for use in heavy traffic and for providing reliable quantitative data.

The issue of obtrusiveness of the observation procedure has not been explicitly addressed in most highway safety studies. Obtrusiveness affects the valldity of the observations across time and populations.

The roadside survey approach has been widely used for more than $\mathbf{4 0}$ years in highway safety research to collect data from drivers whose behavior has identified them. as research subjects. Topic areas studien through this method include alcohol-impaired drivers, Ariver attituries, drfver characteristics, driver knowledge, and responses to advisorv signs.

Careful planning has been found to be essential to the successful roadside sirvey, particularly, allowing time to get the support of reliant public and private agencies (e.g., law enforcement and prosecutorial agencies). Use of police officers to provide traffic control is another critical element of the roadside survey, although a few roadside survevs have succeeded in having researchers approach motorists stopped at traffic lights for interviews. 


\subsection{CONCLUSIONS}

This literature review discusses documents related to designing and conducting surveys to determine driver motivations for committing unsafe driving actions. Literature from the behavioral sciences as well as literature on highway safety was examined in the review. The review found no documentation of past studies to determine motivations for driving behavior, unsafe or otherwise. The need for such a study was thus confirmed.

Three categories of literature were covered in the review:

- literature on driver behavior and risk taking

- literature on measurement of motivations of the tvpe expected to be found in studying driver behavior

- literature on data collection methods and procedures

The literature on driver behavior and risk taking was examined to help identify subject-matter areas to be explored in a study of driver motivations. The literature studied fell into three major categories: personality characteristics, attitudes, and situational factors. It was found that information in all three categories should be sought in an in-depth study of driver motivations. More limited studies should at least elicit information on driver attitudes about traffic safety and on situational factors that might affect driving behavior. Attitudes about traffic safetv and traffic law enforcement appear especiallv relevant to this sturv. Situational factors of particular interest include those related to certain human conditions or states that have been found to be associated with unsafe driving, for example, use of alcohol and irugs, fatigue, inexperience, and pressure from other drivers. The literature indicates that information on driver distractions and conditions caused by stress or emotional upset is also important to the study of driver motivations.

The literature on measurement of driver motivations was reviewed to identify factors important to designing and administering questionnaires for obtaining complete and accurate information on driver motivations for. 
UDAs. The literature suggests that open questions would be better for the purposes of this project because of the lack of a prior knowletge about the knowledge or range of responses of subjects, and because oden questions often enable the interviewer to establish better rapport with the subject. The importance of measures to increase the likelihood of obtaining honest rather than socially desirable answers (e.g., statements of anonymity) is stressed in the literature. The need to help some drivers verbalize their true feelings about their motivations is also identified in the literature. Third-party formulations of questions are recommended by some researchers for enhancing verbalization of the less understood motivations of drivers.

Literature dealing with data collection procedures and methods was studied to help determine how best to observe for and identify orivers who are committing UDAs, and how to remove drivers from the traffic stream and to conduct roadside interviews to determine their motivations. The literature indicates that the best observation strategy for this tvpe of driving behavior is the use of human observers complemented bv appropriate measuring instruments (e.g., radar for speeding UDAs). Care should be taken to rake both the observers and the instrumentation as unobtrusive as possible so as not to affect oriver behaivior. Concealment or disguise of the observers and measuring instruments is the preferred method for making unobtrusive measurements.

The literature review confirmed our belief that the roadside survey is a viable approach to collecting UDA data from drivers. None of the literature reviewed identified any significant problems in applying this approach to this project. Careful planning and coordination with local agencies (particularly law enforement agencies) are essential ingredients for a successful roadside survey.

In sum, the literature review provided useful information for designing questionnaires and procedures for determining driver motivations for UDAs. A detailed description of designs tested in this project and the results of those tests are contained in the main body of this final report. 


\subsection{BIBLIOGRAPHY}

Andriessen, J.H. 1971. Motivational determinants of risk-taking behavior. Paper presented to the International Symposium of Psvchological Aspects of Driver Behavior, 2-6 August 1971, Noordwijkerhout, The Netherlands.

Atkinson, J.W. 1957. Motivational determinants of risk taking behavior. Psychological Review 64(6):359-372.

Atkinson, J.W. 1964. An introduction to motivation. Princeton, New Jersey: D. VanNostrand Company, Inc.

Barker, R.G. and Wright, H.F. 1955. Midwest and its children. Evanston, Illinois: Row, Peterson.

Beamish, J.J. and Malfetti, J.L. 1962. A psychological comparison of violator and nonviolator automobile drivers in the 16-19 year age group. Traffic Safety Research Review 6:12-15.

Belk, R.W. 1974. An exploratory assessment of situational effects on buyer behavior. Journal of Marketing Research 11:156-163.

Berger, W.G. and Robertson, H.D. 1976. Measures of pedestrian behavior at intersections. Transportation Research Record 615:54-59.

Berkowitz, L. 1969. Social motivation. In The Handbook of Social Psychology, vol. III, eds. G. Lindzev and E. Aronson, pD. 50-135. Reading, Massachusetts: Addison-Wesley Publishing Company.

Beaubien, R.F. 1976. Stop signs for speed control? Traffic Engineering 46(11): 26-28.

Blackburn, R.R. and Woodhouse, E.J. 1977. A comparison of drug use in driver fatalities and similarly exposed drivers. National Highway Traffic Safety Administration report no. DOT-HS-802-488.

Bonfield; B.H. 1974. Attitude, social influence, personal norm, and intention interactions as related to brand purchase behavior. Journal of Marketing Research 11:379-389.

Borkenstein, R.F.; Crowther, R.F.; Shumate, R.P.; Ziel, W.B.; and Zylman, R. 1964. The role of the drinking driver in traffic accidents. Bloomington: Indiana University Department of Police Administration.

Bottom, C.G. and Ashworth, R. 1978. Factors affecting the variability of driver gap-acceptance behavior. Ergonomics 21(9):721-34.

Bracburn, N.M. and Sudman, S. 1979. Improving interview methods and questionnaire design. San Francisco, California: Jossev-Bass Publishers.

Butt, D.S. 1979. Short scales for the measurement of sport motivations. 
International Journal of Sport Psychology 10:203-216.

Cannell, C.F. and Kahn, R.L. 1968. Interviewing. In The Handbook of Social Psychology, vol II, eds. G. Lindzev and E. Aronson, pp. 526-595. Reading, Massachusetts: Addison-Wesley Publishing Company.

Carr, B.; Borkenstein, R.F.; Perrine, M.W.; VanBerkom, L.C.; anf Voas, R.B. 1974. International conference on research methodologv for roanside surveys of drinking-driving alcohol countermeasures workshop. Pinal report. National Highway Traffic Safety Administration report no. DOT-HS-801-220.

Case, H.W. and Stewart, R.G. 1957. Some personal and social attitudes of habitual traffic violators. Journal of Applied Psychology 41:46-50.

Clayton, H.B.= and Mackey, G.M. 1972. Aetiology of traffic accidents. Health Bulletin 31:277-280.

Chun, K.T.; Cobb, S.; and French, J.R.P., Jr. 1975. Measures of paychological assessment: A suide to 3,000 original sources and their applications. Ann Arbor, Michigan: The University of Michigan Institute for Social Research.

Conger, J.J.; Gaskill, H.S.; Glad, D.D.; Hassel, L.; Rainey, R.V.; and Sawrey, W.L. 1959. Psychological and psychophysiological factors in motor vehicle accidents. Journal of the American Medical Association $169: 1581-1587$.

Cook, S.W. and Selltiz, C. 1964. A multiple-indicative approach to attitude measurement. Psychological Bulletin 62:36-55.

Crosby, P.; Bromley, S.; and Saxe, L. 1980. Recent unobtrusive studies of black and white prejudice: A literature review. Psvchological Bulletin 87 :546-563.

DiRenzo, J.R. 1976. Travel survey procedures for statewide transportation planning. Washington, D.C.: Peat, Marwick, Mitchell; and Company.

DeSilva, H.R. 1942. Why we have automobile accidents. New York: John Wiley and Sons, Inc.

Detroit Pree Press. Speeding excuses are real winners. June 12, 1979.

Deutsch, D.; Sameth, S.; and Akinyemi, J. 1981. Seat belt usage and risk-taking behavior at two major intersections. American Association for Automotive Medicine Quarterly Journal 3(1):23-25.

Dueker, R.L. 1978. Urban crossing problems. Final report. National Highway Traffic Safety Administration report no. DOT-HS-805-127.

Duncan, N.C.; Sumner, S.L.; and Shrewsburg, J.S. 1977. Measurements of 
the speeds of cars on motorways in 1976. Crowthorne, England: Transport and Road Research Laboratory.

Ellinger, M. 1976. Illinois motorcycle helmet use survev-Summarv of findings. Springfield: nllinois State Department of Transportation, Division or Traffic Safety.

Elman, D. and Killebrew, T.J. 1978. Incentives and seat belts: Changing a resistent behavior through extrinsic motivation. Journal of Applied Social Psychology 8(1):72-83.

Engel, J.F.; Kollat, D.T.; Blackwell, R.D. 1973. Consumer behavior. Hinsdale, minois: Dryden Press.

Farris, R.; Malone, T.B.; and Kirkpatrick, M. 1977. A comparison of alcohol involvement in exposed and injured drivers. National Highway Traflic Safety Administration report no. DOT-HS-802-555.

Feest, J. 1968. Compliance with legal regulations: Observation of stop sign behavior. Law and Society Review 2(3):447-461.

Fergenson, P.E. 1971. The relationship between information processing and driving accidents and violation records. Human Factors 13:173-176.

Fergenson, P.E. and Johnson, J.M. 1968. The problem driver: Personality and demographic variables. Stevens Institute of Technologv Davirison Laboratory report 1317. Sponsored by the U.S. Department of Health, Education, and Fielfare Public Health Service research grant no. 5 R01 U1. 0031-01/02.

Fhaner, G. and Hane, M. 1973. Seat belts: Factors influencing their use. A literature survey. Accident Analysis and Prevention 5:27-43.

Porde, M.C. and Birse, R.M. 1977. The use of time lapse cinematographv for the moving car observer method. Traffic Engineering and Control $18(3): 103-05$.

Gadallah, A.A. 1976. Driver response to voluntarv and mandatory speed limits. Traffic Engineering 46(3):32-35.

Geddis, D.C. 1979. Children in cars-Results of an observational studv in New Zealand. New Zealand Medical Journal 90(649):468-71.

Glauz, W.D. 1975. Wichita-Sedgwick County Alcohol Safety Action Project roadside survey number 4. National Highway Traftic Safety Administration report no. DOT-HS-802-949.

Glauz, W.D. and Migletz, D.J. 1979. Traffic conflicts-A literature review. Paper prepared for NCHRP Project 17-3 and reprinted for distribution at the Twelfth Annual Transportation Research Board Workshop on Human Factors in Transportation, 12 January 1979, Washington, D.C. 
Goldstein, L.G. and Mosel, J.N. 1958. A factor study of drivers' attitudes with further study on driver aggression. Highway Research Board Bulletin No. 172. Washington, D.C.: Highway Research Board.

Greenshields, B.D. 1959. Attitudes, emotions, accidents. Traffic Quarterly 13:221-235.

Haekkinen, S. 1958. Traffic accidents and driver characteristics. Helsinki, Finland: Institute of Technology.

Hanscom, F.R. and Berger, W.G. 1976. Vehicle behavior at one interchange related to driver guide sign responses. National Cooperative Highway Research Project report no. 3-21.

Hauber, A.R. 1976. Agression in traffic situations. Report of an empirical research. In The Voice of the Pedestrian. VI. The Hague: International Federation of Pedestrians pp. 129-137.

Henderson, R.L. 1975. Effect of passenger loading on triver's visibility from automobiles. National Highway Traflic Safety Administration report no. DOT-HS-801-743.

Hochberg, Y.; Stutts, J.C.; and Reinfurt, D.W. 1977. Observed shoulder belt usage of drivers in North Carolina: A follow-up. Final report. National Highway Traffic Safety Administration report no. DOT-HS-803-040.

Holcomb, R.L. 1938. Alcohol in relation to traffic accidents. Journal of the American Medical Assciciation 111:1076-85.

Holmes, E.H. 1965. Mississippi valley origin-destination study: Summary report. Circular memorandum to regional and division engineers of the Bureau of Public Roads.

Jackson, T.T. and Gray, M. 1976. Field study of risk taking behavior of automobile drivers. Perceptual and Motor Skills 43(2):471-74.

Jennings, R.D.; Burki, M.A.; and Onstine, B.W. 1977. Behavioral observations and the pedestrian accident. Journal of Safety Research $9(1): 26-33$.

Johnston, I.R. and Cameron, M.H. 1979. The use of television publicity to modify seat belt wearing behavior. Melbourne: Australia Commonwealth Department of Transport, Office of Road Safetv, and Victoria: Cameron, M.H. and Associates.

Jones, M.H. 1978. The reliability of driver performance-Test reliabilitv or driver stability. Paper presented to the Annual Meeting of the Transportation Research Board, 15-19 Januarv 1979, Washington, D.C.

Jones, M.H. 1980. Measuring pedestrian behavior. Transportation Research Board 743:1-4. 
Jones, R.K. and Joscelyn, K.B. 1978. Alcohol and highwav safety 1978: A review of the state of knowledge. Technical and summary volumes. National Traffic Safety Administration report nos. DOT-HS-803-714 and 803-764.

Joscelyn, K.B.; Bryan, T.H.; and Goldenbaum, D.M. 1971. A study of the effects of law enforcement on traffic flow behavior. Final report. National Highway Traffic Safety Administration report no. DOT-HS-800-505.

Joscelyn, K.B. and Jones R.K. 1972. A sustems analysis of the traffic law system. Reference volume II. Final report. National Highway Traffic Safety Administration report no. FH-11-7270-72-3.

Joscelyn, K.B.; Jones, R.K.; Maickel, R.P.; and Donelson, A.C. 1979. Drugs and driving: Information needs and research requirements. Final report. National Highway Traffic Safety Administration report no. DOTHS-804-774.

Karan, M.A.; Haas, R.; and Kher, R. 1976. Effects of pavement roughness on vehicle speeds. Transportation Research Record 602:122-27.

Kazdin, A.E. 1979. Unobtrusive measures in behavioral assessment. Journal of Applied Behavioral Analysis 12:713-724.

Knapper, C.K. and Cropley, A.J. 1978. Towards a social psvehology of the traffic environment. In Environmental Assessment of Socioeconomic Systems. eds. D.F. Burkhardt and W.J. Ittelson. Plenum Publishing Corporation.

Kole, T. and Henderson, H.L. 1966. Cartoon reaction scale with special reference to driving behavior. Journal of Applied Psychology 50:311-316.

Koneeni, V.J.; Ebbesen, E.B.; and Konecni, D.K. 1976. Decision processes and risk taking in traffic: Driver response to the onset of yellow light. Journal of Applied Psychology 61(3):359-67.

Lansing, J.B. and Morgan, J.N. 1971. Economic survev methods. Ann Arbor, Michigan: The University of Michigan Institute for Socia] Research.

LaPiere, R.T. 1934. Attitudes vs. actions. Social Forces 13:230-237.

Lawshe, C.H. 1940. Studies in automobile speed on the highwav. III. Some driver opinions and their relationship to speed on the open highway. Journal of Applied Psychology 24:318-324.

LeFevre, B.A. 1954. Speed habits observed on a rural highway. In Proceedings of the Highway Research Board xxxiii, pp. 409-428.

LHoste, J. 1978. A fifteen country study of some factors influencing the number and severity of road accidents. Drivers Attitudes and Opinions, Part 2. 92401. Courbevoie, France: International Drivers' Behavior Research Association. 
Lohman, L.S.; Lessett, E.C.; Stewart, J.R.; and Campbell, B.J. 1976. Identification of unsafe driving actions and related countermeasures. Final report. National Highway Traffic Safety Administration report no. DOTHS-803-064.

Loo, R. 1978. Individual differences and the perception of traffic signs. Human Factors 20:65-74.

Loo, R. 1979. Role of primary personality factors in the perception of traffic signs and driver violations and accidents. Accident Analysis and Prevention 11:125-127.

Lummis, M.L., and Tucker, G.J. 1979. Impact of the repeal of the Kansas mandatory motorcycle helmet law. Final report. National Highwav Traffic Safety Administration report no. DOT-HS-804-018.

Lynn, C.W. 1976. Trends in trinking-driving at night. A comparison of the first five roadside surveys of the Fairfax Alcohol Safety Action Project. Final report. National Highway Traffic Safety Administration report no. DOT-HS-802-803.

Mamlouk, M.S. 1976. Right turn on red: Utilization and impact. Final report. Lafayette: Purdue and Indiana State Highwav Commission, Joint Highway Research Project report no. JHRP-76-17.

Market Opinion Research. 1977. An analysis of the factors affecting seat belt use. Prepared for General Motors Corporation.

Marzoni, P. 1971. Motivations factors in the use of restraint systems. National Highway Traffic Safety Administration report no. DOT-HS-800-585.

Mathews, M.L. 1978. A field study of the effects of drivers adaptation to automobile velocity. Human Factors 20(6):709-16.

Mayer, R.E. and Treat, J.R. 1977. Psychological, social, and cognitive characteristics of high-risk drivers: A pilot study. Accident Analysis and Prevention 9:1-8.

McGuire, F.L. 1956. Psychological comparison of automobile drivers: Accident- and violation-free versus accident- violation-occurring drivers. U.S. Armed Forces Medical Journal 7:1741-1748.

McGuire, F.L. 1976. Personality factors in highway accidents. Human Factors 18:433-442.

McMurray, L. 1970. Emotional stress and driving performance: The effect of divorce. Behavioral Research in Highway Safetv 1:100-114.

Medley, D.M. and Mitzel, H.E. 1963. Measuring elassroom behavior hv systematic observation. In Handbook of Research on Teaching, ed. N.L. Gage, pp. 247-328. Chicago: Rand MeNally 
Millar, L. and Generowicz, B. 1979. A study to assess the effectiveness of varying levels and types of enforcement on driver behavior at urban signalised intersections. South Bend: Western Australia Institute of Technology.

Morton-Williams, J. 1961. Motivation research as applied to the problems of road safety. International Road Safety Traffic Review 9(2):31-35.

Naatanen, R. and Summala, H. 1976. Road-user behavior and traffic accidents. Amsterdam: North-Holland Publishing Company.

Nunnally, J.C. 1972. Educational measurement and evaluation. New York: MeGraw-Hill Book Company.

Opinion Research Corporation. 1980. Highlights of four research studies. I: Safety belt usage among drivers. II: Use of child restraint devices, passenger safety belts, and seat position data. III: Motorcvcle helmet usage. IV: Automatic safety belt systems. Princeton, New Jersev: Opinion Research Corporation report no. ORC 51495.

Organisation for Economic Co-Operation and Development. 1978. New research on the role of alcohol and drugs in road accidents. Paris, France.

Parry, M.H. 1968. Aggression on the road. London: Tavistock Publications, Ltd.

Patchen, M. 1965. Some questionnaire measures of emplovee motivation and morale: A report on their reliability and validity. Ann Arbor, Michigan: The University of Michigan Survev Research Center of the Institute for Social Research.

Pelz, D.C. 1968a. Driver motivations and attitudes. In Driver Behavior: Cause and Effect. Proceedings of the Second Annual Traffic Safety Research Symposium of the Automobile Insurance Industry, ed. J. O'Dav, pp. 101-122. Washington, D.C.: Insurance Institute for Highwav Safetv.

Pelz, D.C. 1968b. Driver motivations and attitudes. Paper oresented at Second Annual Auto Insurance Industrv Traffic Safetv Research Symposium, 19-21 March 1968, Northbrook, nlinois.

Pelz, D.C. and Schuman, S.H. 1971. Motivational factors in crashes and violations of young drivers. Paper presented to the American Public Health Association Meetings, 13 October 1971, Minneapolis, Minnesota.

Perrine, M.W. 1971. Methodological considerations in conducting and evaluating roadside research surveys. National Highway Traffic Safety Administration report no. DOT-HS-800-471.

Perrine, M.W.; Waller, J.A.; and Harris, L.S. 1971. Alcohol and highway safety: Behavioral and medical aspects. National Highway Traffic Satety Administration report no. DOT-HS-800-599. 
Quenalt, S.W. and Pairhead, R.D. 1972. Driver behavior and results of some psychological tests. Paper presented to the International Symposium of Psychological Aspects of Driver Behavior, 2-6 August 1971, Noordwijkerhout, The Netherlands.

Rim, Y. 1963. Risk-taking and need for achievement. Acta Psychologica $21: 108-115$.

Roberts, R.R. 1976. The effect of bridge shoulder wiath on traffic operational characteristics. Columbla: South Carolina University, Traffic and Transportation Center.

Ronen, S. and Kraut, A.I. 1980. An experimental examination of work motivation taxonomies. Human Relations 33:505-516.

Scott, W.A. 1968. Attitude measurement. In The Handbook of Social Psychology, Vol. II, eds. G. Lindzey and E. Aronson, Pp. 204-273. Rearing Massachusetts: Addison-Wesley Publishing Company.

Selzer, M.L. and Vinokur, A. 1974. Detecting the high risk driver: The development of a risk questionnaire. National Highway Traffic Safety Administration final report no. DOT-HS-801-099.

Seydel, V. 1972. Self-assessment of the Ariver and his attitude toward speed limits. In Kuratorium fur Verkehrssicherhert, Sept. 1972, Dp. 60-68, Kleine fach buchreihe Band 11, arbeiten aus dem Verkehrspsvchologichen Institut $\mathrm{V}$. Wien.

Shaw, L. 1965. The practical use of projective personality tests as accident predictors. Traffic Safety Research Review 9:34-72.

Sheth, J.N. 1967. A review of buyer behavior. Management Science 13:B718-B756.

Shinar, D. 1978. Psychology on the road: The human factor in traffic safety. New York: John Wiley \& Sons.

Shoham, S.G.; Geva, N.; Markowski, R.; and Kaplinskv, N. 1976. Internalisation of norms, risk-perception and anxiety as related to driver offences. British Journal of Criminology 16:142-155.

Signori, B.I. and Bowman, R.G. 1974. On the study of personality factors in research or driving behavior. Perceptual and Motor Skills 38:1067-1076.

Smith, G.A.; Wolynetz, M.S.; and Wiggins, T.R.I. 1976. Drinking drivers in Canada. A national roadside survey of the blood alcohol concentrations in nighttime Canadian drivers. Ottawa: Transport Canada, Road and Motor Vehicle Safety Branch.

Smith, W. and Associates. 1973. A study of the potential for improved rail advanced vehicle service: Highway analysis. 
Soliday, S.M. 1979. Relationship between age and hazard Derception in automobile drivers. Perceptual and Motor Skills 39:335-338.

Solomon, D. 1964. Accidents on main rural highwelvs relater to speed, triver, and vehicle. Washington, D.C.: Bureau of Public Roads.

Stewart, J.R. and Hatle, H. 1979. Highway safety survey. Universitv of South Dakota Department of Social Behavior.

Stewart, R.G. 1958. Can psychologists measure Ariving attitudes? Educational and Psychological Measurement 18:63-73.

Stowell, C. and Bryant, J. 1978. Safety belt usage: Survev of the traffic population. Final report. National Highway Traffic Safetv Administration report no. DOT-HS-803-354.

Stroh, C. 1973. Roadside surveys of drinking-driving behavior. Alcohol and road safety series. Volume IV. Ottawa, Canada: Department of Transport.

Struckman-Johnson, C. and Ellingstad, V.S. 1979. Impact of motorcycle helmet law repeal in South Dakota. Final report. National Highway Traflic Safety Administration report no. DOT-HS-803-996.

Teknekron Research, Inc. 1979a. 1979 survey of public perceptions on highway safety. National Highway Traffic Safety Administration report no. DOT-HS-805-165.

Teknekron Research, Inc. 1979b. Compendium of survey items and results of safety countermeasures. McClean, Virginia: Teknekron Research, Inc. report no. TK 76-1045R. Sponsored by the National Highway Traffic Safety Administration.

Tillman, W.A. 1948. The psychiatric and social approach to the detection of accident-prone drivers, Masters thesis. Canada: University of Western Ontario.

Treat, J.R.; Tumbas, N.S.; McDonald, S.T.; Shinar, D.; Hume, R.D.; Maver, R.E.; Stansifer, R.L.; and Castellan, J.J. 1979a. Tri-level study of the causes of traffic accidents: Final report. Volume I: Causal factor tabulations and assessments. National Highwav Traffic Satetv Administration report no. DOT-HS-805-085.

Treat, J.R.; Tumbas, N.S.; McDonald, S.T.; Shinar, D.; Hume, R.D.; Maver, R.E.; Stansifer, R.L.; and Castellan, J.J. 1979b. Tri-level studv of the causes of traffic accidents: Final report. Volume II: Special analvses. National Highway Traffic Safety Administration report no. DOT-HS-805-086.

U.S. Department of Transportation. 1968. Alcohol and highway safety. Washington, D.C.: U.S. Government Printing Office. 
U.S. Department of Transportation. 1979. Summarv of national alcohol safety action programs: Report to the U.S. Congress. National Highwav Trallic Safety Administration report no. DOT-HS-804-032.

Van der Molen, H.H. 1976. Observational studies of children's road crossing behavior: A review of the literature. In Proceedings of the International Conference on Pedestrian Safety. Volume 2, ed. A.S. Hakkert, pp. 77-98. Technion, Haila, Israel: Michlol-Publishing House.

Vorhees, A.M. and Associates, Inc. 1971. The northwest corridor intercity travel survey.

Warwick, D.P. and Lininger, C.A. 1975. The sample survev: Theorv and practice. New York: MeGraw-Hill Ine.

Webb, E.J.; Campbell, D.T.; Schwartz, R.D.; and Sechrest, L. 1966. Unobtrusive measures: Nonreactive research in the social sciences. Chicago: Rand McNally Publishing Co.

Weick, K.E. 1968. Systematic observational methods. In The Handbook of Social Psychology, volume II, eds. G. Lindzev and E. Aronson. Reading, Massachusetts: Addison-Wesley Publishing Co.

Williams, A.F. and Robertson, L.S. 1979. Observed daytime seat belt use in Vancouver before and after the British Columbia belt use law. Canadian Journal of Public Health 70(5):329-32.

Wolfe, A.C. 1974. 1973 U.S. national roadside breathtesting survev: Procedures and results. National Highway Traflic Salety Administration report no. DOT-HS-801-2-241.

Zemp, W.M. and Associates. 1980. $55 \mathrm{mph}$ interstate communications project: Target audience segmentation study, Task 2. National Highway Traffic Safety Administration contract no. DOT-HS-9-02290. 